Marine Biological Laboratory Library Woods Hole, Massachusetts

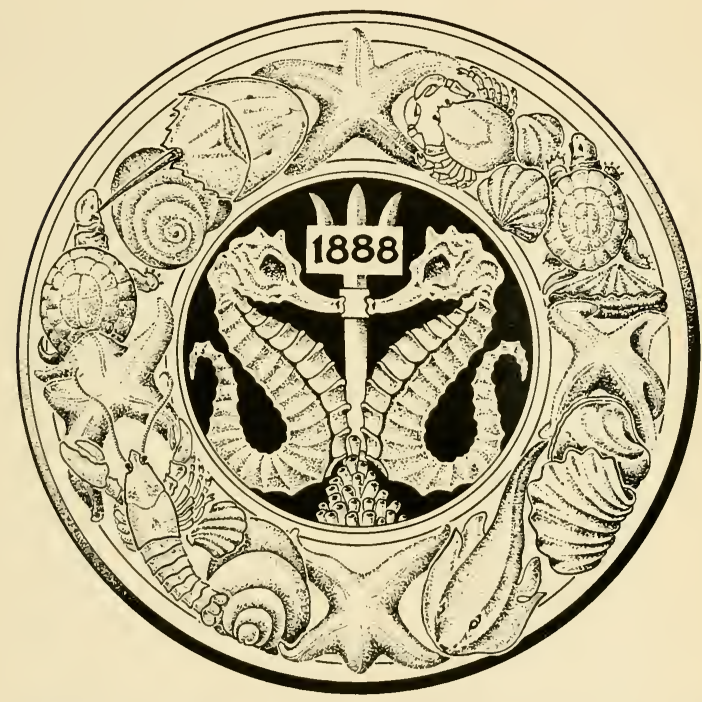

Gift of F. R. Lillie estate - 1977 



TEXT-BOOKS OF ANIMAL BIOLOGY

Edited by Julian S. Huxley, M.A.

Professor of Zoology, King's College, London

COMPARATIVE PHYSIOLOGY 


\section{TEXT-BOOKS OF ANIMAL BIOLOGY}

Edited by Professor Julian S. HuXley Other volumes in preparation.

ANIMAL ECOLOGY. By C. S. EltoN. VERTEBRATE MORPHOLOGY. BY

G. R. DE BEER.

EXPERIMENTAL ZOOLOGY. BY JULIAN S. HUXLEY.

ANIMAL MORPHOLOGY, WITH ESPE-

CIAL REFERENCE TO THE INVERTEBRATA. By W. Garstang. 


\title{
COMPARATIVE PHYSIOLOGY
}

\author{
BY \\ LANCELOT T. HOGBEN \\ M.A.(Cantab.), D.Sc.(Lond.)
}

Assistant Professor in ZoOLOGY, McGill Univeraity

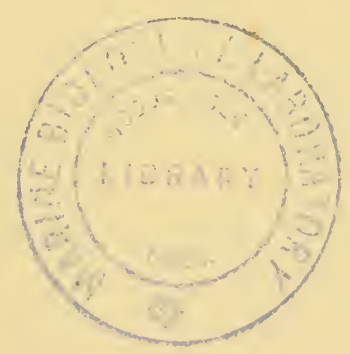

LONDON

SIDGWICK \& JACKSON, LTD. 1926 
PRINTED IN GREAT BRITAIN BY WILLIAM CLONES AND SONS, LIMITED LONDON AND BECCLES. 
E. A. S. S. 



\section{AUTHOR'S PREFACE}

THERE is, so far as I know, no work in English which aims at giving an account of the physiology of the lower organisms. Few of those who are aware of the existence of Winterstein's monumental work are likely to find the time to obtain from its encyclopædic pages a bird's-eye view of the ground already traversed and the fields that lie ripe for the research worker armed with sufficient familiarity with animal life and understanding of physiological methods of inquiry. Winterstein's Vergleichende Physiologie meets the needs of the research worker who is in search not of problems to tackle so much as detailed information of previous inquiries on similar lines to those with which he is concerned. There seems nothing to supply any encouragement to those who are not sufficiently advanced in their studies to distinguish between lines of inquiry that are practicable as well as profitable, to realise as yet what materials are available for the solution of the problem in which interest has already been quickened, or to have gained much insight into the methods at our disposal for extending our knowledge of the physiology of the lower organisms.

I am well aware that to attempt to supply this need within the limits of space at my disposal would be a sufficiently embarrassing task for an author reassured with a far more exalted sense of his own equipment for the task than I can boast. If I have succeeded in stimulating twenty-one years of age (or thereabouts) to dip into an immense and at present scattered literature and find some fruitful fields of inquiry and sources from which more precise information can be obtained, I shall have accomplished precisely what I set out to do.

These chapters represent the materials of a course of lectures delivered first in the Zoology Department and later in 
the Department of Physiology in Edinburgh University to medical students having completed a course of elementary physiology and to science students taking an honours course in zoology. I have in mind the same mixed audience as readers : the advanced student in zoology who knows very little physiology, and the student who, having passed through a course in physiology designed to equip him for the pursuit of the medical profession, may wish to acquire information about branches of the subject that have at present no such remunerative value. In doing this one has the feeling of falling between two stools. The physiological critic will object to dealing with topics which practitioners do not regard as the business of the physiologist; while zoologists will protest against omission of reference to experimental work which seems to them to be as important as much that has been treated as physiological in the pages which follow.

Since the objective of physiological inquiry is the quantitative study of the relation between processes characteristic of living organisms and properties of inanimate matter, in attempting to treat the subject with reference to a coherent theme one of two courses is open : to illustrate the known properties of non-living matter by reference to their operation in the processes of living organisms, or to consider what are the characteristic properties of animate systems and inquire how far it is possible to interpret each in terms of known physico-chemical laws.

Against the former course, it is sufficient to point out : first, that this method of treatment has been adopted as successfully and comprehensively as possible in the existing state of knowledge in such works as those of Bayliss and of Hoeber ; secondly, that if carried out consistently it necessitates the elimination of all reference to some of the most characteristic properties which distinguish living systems. Generally speaking, those who restrict the scope of physiology to phenomena for which ready-made physico-chemical explanations are at hand, make an exception for the treatment of reflex action. By some obscure convention this grace is rarely extended to the phenomena of reproduction. I shall make no apology for 
regarding the building-up of a new animate system as a proper field for physiological inquiry.

On the other hand, I do not regard the terms "experimental" and "quantitative" in the sense employed above as co-extensive. For this reason no reference is made in the last chapter to the large body of work on implantation of organs and regeneration, much of which is of great importance, but like the too familiar descriptions of tracts in the mammalian spinal cord, not susceptible as yet to treatment in relation to the fruits of inquiries based on the use of physiological methods as ordinarily understood.

Generally speaking, I have borne in mind the fact that Winterstein's Handbuch makes the literature of comparative physiology accessible to those who care to consult it up to I9I2. I have therefore aimed at familiarising the reader with what has been done during the last ten or fifteen years. Where references cannot be obtained by consulting monographs, the particulars of the journals in which they are found are given. The completeness of Winterstein's bibliography makes any attempt to give further assistance to the student a work of supererogation.

In the selection of materials, one is naturally expressing one's individual judgment; and it is hoped that the reader will appreciate that the author puts forward no claim to be authoritative or encyclopædic. The material selected has been chosen to help the student of zoology to appreciate what is being achieved by the application of physiological methods to the study of the lower animals, and to widen the horizon of the student of physiology who has not been brought into touch with the diversity of problems which are suggested by a consideration of function in a wider range of animals than those with which he has been accustomed to deal in the course of his medical studies.

My thanks are due to Dr. A. D. Macdonald and Mr. A. D. Hobson, who read the MS., and to Professor Julian Huxley for valuable suggestions.

LANCELOT T. HOGBEN. 



\section{CONTENTS}

\section{CHAPTERS I-III}

Response-the Manifestations of Vital Activity

PAGE

I. Muscular Contraction . . • • . • • I

II. Ciliary Activity, Amœboid Motion and Colour Response . 23

III. Secretion . . . . . . . • . 47

\section{CHAPTERS IV-VI}

Metabolism-The Sources of Vital Energy

IV. Respiration . . . . . . . • . 64

V. Nutrition . . . . . . . . . 85

VI. The Circulation of Body Fluids . . . . , Ior

\section{CHAPTERS VII-IX}

CO-ORDiNATION-THE INTEgRation of Vital ACTivities

VII. Endocrine Co-ordination . . . • . . II8

VIII. The Mechanism of Nervous Conduction and Excitation . 134

XI. The Analysis of Behaviour in Animals . . . . I5 I

\section{CHAPTERS X-XII}

REPRODUCTION-THE BUILDING UP OF A NEW Animate Unit

X. The Fertilisation of the Egg • . . . . $\quad$ I69

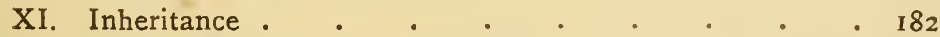

XII. The Physiology of Development . . . . . 200 



\section{LIST OF ILLUSTRATIONS}

FIG.

1. Diagram illustrating liberation of potential energy in muscular contraction

2. Scheme to illustrate modern work on muscular contraction .

3. Time relations of the electrical variation in the isometric response to two successive stimuli $\quad$ • . . $\quad$ I3

4. Mechanical heat and electro-cardiogram of heart of Homarus 14

5. Effect of excess of calcium on the perfused heart of Homarus

6. Effect of removal of magnesium on the perfused heart of Pecten

7. Effect of removal of calcium on the perfused heart of Pecten 18

8. Diagram of ciliary motion . . . . . . 24

9. Relation of hydrogen ion concentration to ciliary movement .

IO. Relation of oxygen consumption and mechanical activity of cilia to temperature . $\quad . \quad$. $\quad$ •

II. Relation of hydrogen ion concentration to the velocity of amœboid movement • • • • • • 32

12. Effect of temperature on velocity of amœboid movement - 35

I3. Melanophores of Fundulus . $\quad$ • $\quad$ • $\quad$ • $\quad 38$

14. Melanophores of Fundulus : effects of adrenaline. • • 39

I5. Results of variation of $\mathrm{CO}_{2}$ tension of inspired air of insect $\quad 68$

16. Dissociation curves of mammalian blood . • • • 72

17. Dissociation curves of Arenicola blood . • • • 74

18. Dissociation icurves of Hæmocyanin in Crustacean Blood . 76

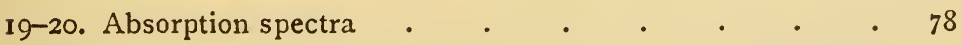

2I. Relation of amount of $\mathrm{CO}_{2}$ taken up by mammalian blood to $\mathrm{CO}_{2}$ pressure . $. \quad . \quad . \quad$. . 
FIG.

PAGE

22. Relation of amount of $\mathrm{CO}_{2}$ taken up by crustacean and cephalopod blood to $\mathrm{CO}_{2}$ pressure . . . $\quad$. 82

23. Ciliary currents on Lamellibranch gill . • • . 90

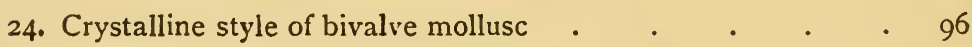

25. Innervation of heart of Palinurus . . . . . 107

26. Heart and nerves of Limulus . . . . . . 108

27. Inhibition of heart-beat of Limulus by electric stimulation of brain . . . . . . . . 108

28. Heart of Cephalopod . . . . . . . III

29. Circulatory system of Ascidian . . . . . . 115

30. Action of adrenaline on heart of Pecten . . . . I2I

31. Action of adrenaline on crop of Aplysia . . . . 122

32, 33. Function of pituitary gland in coloration of frogs

To face page 130

34. Excitability to second stimulus in sciatic gastrocnemius of frog . . . . . . . . . 136

35. Diagram of Adrian's experiment . . . . . 144

36. Diagram illustrating electrical conditions in excited and resting neurone. $. \quad . \quad . \quad . \quad$. 146

37. Excitability by single or double stimuli of abductor nerve of

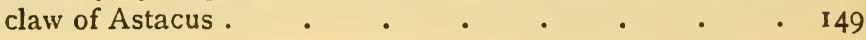

38. Diagram of simple reflex arc • • • • • $\quad$ - I55

39. Diagram of pedal ganglion of Razor-shell • • • $\quad$ - 157

40. Effect of unequal illumination on insect . . . . 160

4I. Genetic segregation . . . . . . . 185

42. Sex-linked inheritance in Drosophila . . . . 190

43. Crossing in the gypsy-moth Lymantria . . . 192

44. Oxygen consumption of chick embryos . . . . 206 


\title{
COMPARATIVE PHYSIOLOGY
}

\section{CHAPTER I}

\author{
MUSCULAR CONTRACTION
}

Physiological science is concerned with describing those properties which distinguish living beings from inorganic objects, and relating the processes specially characteristic of the former to the more familiar and accessible phenomena of which we have exact knowledge in the realm of inanimate matter. It is not legitimate to be dogmatic regarding the extent to which similar principles will be found to hold good both in biological and physical science. But the onus of proof lies on those who discourage the attempt to further this end. There have always been those who wish to set limits upon the extent to which the mechanistic approach to vital phenomena can continue to yield profitable results. On the very eve of Wöhler's synthesis of urea, Henry wrote with reference to the artificial production of organic compounds, "It is not probable that we shall ever attain the power of imitating nature in these operations. For in the functions of a living plant a directing principle appears to be concerned, peculiar to animated bodies, and superior to and differing from the cause which has been termed chemical affinity." It may be said, however, that the validity of a mechanistic outlook stands quite apart from the possibility of manufacturing animate systems, just as truly as the justifiability of interpreting the movements of the heavenly bodies in terms of the dynamical relations of immediate experience is independent of the likelihood that we shall ever succeed in bringing into existence a new satellite for Jupiter. 
For our present purpose we shall wherever possible seek to relate the properties of living matter to those of inanimate nature; where this cannot be done in the present state of knowledge, we must proceed with the task of recording our observations, as in the physical sciences, in quantitative terms.

In so doing we shall consider first the characteristic activities which living organisms display; second, the sources of energy which lie behind these activities ; third, the way in which the activities of an organism are co-ordinated with the changing conditions of the external world; and finally, the means by which a new animate unit is brought into being.

Organisms respond to their surroundings by movements of various kinds-muscular, ciliary, amceboid; by the elaboration of material secretions; by the production of light, electrical discharge; and by changes in bodily colour. Structures which carry out these responses in Metazoa are collectively referred to as effector organs. The first type of effector which will be dealt with is muscle. Muscular activity is a ubiquitous phenomenon in metazoan organisms; and therefore cannot be excluded from the present survey of the physiology of the lower animals, although our knowledge of muscular mechanism is largely derived from the study of vertebrate animals.

Of no form of response in organisms is our knowledge more extensive than in the case of muscular contraction. The greater part of this knowledge is based upon the study of amphibian skeletal muscle. Before considering the quantitative treatment of the energy changes associated with excitation in muscle, a brief sketch must be given of those elementary phenomena which can be demonstrated when an excited muscle is allowed to lift a weighted lever whose movement is recorded on the surface of a revolving drum. By this method (isotonic contraction) we can arrive at some preliminary insight into the sequence of events in the contraction cycle.

When a muscle is excited by a single electrical stimulus the curve recorded in this way shows three distinct phases: (i) a period of latency intervening between the applicacion of the stimulus and the beginning of response; (ii) a period in which 
the mechanical response rises to a maximum; and (iii) a period in which the mechanical response falls off, i.e. the muscle relaxes. If a sufficient interval elapses between the completion of relaxation and the application of a second stimulus, the contraction curve traced out by the response to the latter will be identical with the first. If, however, we record the response to a succession of stimuli of equal strength sent in successively at equal intervals very soon after relaxation is complete, the period of relaxation becomes progressively more prolonged, and the height to which the lever rises at each contraction gradually falls off. Thus we must add to the above a fourth phase, the recovery period, during which the muscle is restored to its original condition. When a second stimulus is applied to a muscle before it has completed the process of relaxation, the contraction due to the second starts from the level at which the previous one happens to be when the new one comes into operation; if the process is repeated a summation results so that the height of the combined contraction is greater than that of a single twitch. But each stimulus produces less increase than its predecessor, a limit being soon attained when further succession of stimuli only permits a maximal level to be maintained. This maximum depends partly on the frequency with which the stimuli are sent in, i.e. how far the contraction due to one stimulus has progressed before that due to the next starts. Prolonged contractions of this kind correspond to the deliberate and sustained movements of everyday life, and are described by the term tetanus.

In seeking for light on the way in which the muscular mechanism works it will be best to consider separately the energy changes which occur when a muscle is excited. There are, in addition to the mechanical response itself (which can only occur if the muscle is permitted to shorten), chemical, thermal, and electrical phenomena which appear whenever the muscle is excited with an adequate stimulus. Since we are ultimately concerned to explain the origin of the mechanical response, it is of the utmost importance to have in the first place some means of treating the mechanical energy of contraction with quantitative accuracy. Though this might at 
first sight appear a simple issue, it is really a very complex one, and it is only within recent years that the work of A. V. Hill has placed the question on a satisfactory basis.

(a) Mechanical Response in Muscle.-In attempting to grasp the significance of the chemical and thermal aspects of contraction, it is necessary to measure the potential mechanical energy of contraction. The inevitable limitations of laboratory equipment tend to give the beginner a distorted idea of the significance to be attached to records of work done by a muscle in lifting a lever. Since the tension of the muscle is not the same at every stage in the contraction, there are two obvious difficulties in the interpretation of observations on isotonic contractions: either the muscle is too heavily weighted and cannot contract fully, or it is insufficiently weighted at the beginning and cannot exert its maximal energy. A more subtle difficulty lies in the fact that the muscle is an elastic body. When a resting muscle is stretched by virtue of a load it possesses potential energy like that of an extended spring; thus it does not follow that the work it may be made to perform when its tension is increased during excitation is entirely the result of the energy so liberated. An analogy given by A. V. Hill will make this clear. Imagine a balance with two scalepans equally balanced when empty. Suppose that a weight of one kilo is placed in one pan, the other being held in its original position by a spring. The spring is now exerting a tension of one kilo. If a small weight-say, Io grams-is placed on the empty scale-pan it will sink, let us say, I cm., and the other pan will be raised a corresponding height, thereby doing work proportional to the product of the weight and the distance through which it is raised. Clearly the ro-gram weight has not contributed more than one-hundredth of this energy; the remainder is derived from the potential energy of the spring. In just the same way, the energy which we get out of a weighted muscle is not simply the amount of energy liberated by the contractile mechanism sensu stricto.

The way in which we may calculate the maximal amount of work which the muscle is capable of doing in virtue of the energy freed in contraction will present no difficulty to the 
student who is familiar with the expression for maximum work done by a gas in changing its volume. The condition for maximal work done by a gas in expanding from $v$ to $v^{\prime}$ is first, that the internal pressure $\mathrm{P}$ should be opposed at each stage by an external pressure $\mathrm{P} \longrightarrow d p$ differing from it by an infinitesimal amount. Then, if the process be carried out so slowly that the gas is not allowed to gather momentum and dissipate part of its energy as heat

$$
\mathrm{W}=\int_{v}^{v^{\prime}} \mathrm{P} \cdot d v
$$

In order to realise the total amount of potential energy liberated in contraction, one must imagine that the tension of the muscle does work at every stage against a load differing by an indefinitely small amount from the tension it exerts. Since the energy released at each infinitesimal step is the product of the force into the distance, the total energy is the sum of a series of products $\mathrm{T} d l$; expressed analytically :

$$
\mathrm{W}=\int_{\mathrm{C}}^{\mathrm{E}} \mathrm{T} \cdot d l
$$

( $\mathrm{E}$ being the extended length and $\mathrm{C}$ contracted length of the muscle.)

In this form it is not possible to evaluate $\mathrm{W}$ directly, since we do not know what function $\mathrm{T}$ is of $\mathrm{L}$. But the integral formula at once suggests that the potential energy of the contractile mechanism is represented by the area of a curve expressing the relation of tension to length in the unstretched muscle. We have therefore to construct a tension-length indicator diagram for the muscular machine analogous to the familiar pressure-volume indicator of the heat engine.

The accompanying diagram (Fig. I) will explain to the reader unfamiliar with the notation of the calculus the way in which $\mathrm{W}$ is calculated. $\mathrm{OC}$ is the contracted, $\mathrm{OE}$ the extended, length of an unstretched muscle. $\mathrm{T}_{1}$ is the initial tension of the muscle, $T_{2}, T_{3}, T_{4}$, etc., the tensions exerted when the muscle has been allowed to shorten by equal steps $\Delta l$. The average tension between $T_{1}$ and $T_{2}, T_{2}$ and $T_{3}$, etc., are represented by $t_{1}, t_{2}, t_{3}$, etc. In contracting through the first step $\Delta l$ the work done (force $\times$ distance) is $t_{1} \Delta l$, in 
contracting through the second step the work done is $t_{2} \Delta l$. The total work is the sum of a series of products represented by the rectangular areas which are together equivalent to the area $\mathrm{T}_{\mathrm{I}} \mathrm{EC}$.

If $T_{x} C$ is curvilinear, the area enclosed by the curve may be made as near as we like to the sum of these rectangles by making $\Delta l$ sufficiently small.

To construct such a tension-length curve the muscle is excited isometrically, i.e. an arrangement is used by which the tension is recorded by a spring lever without appreciable

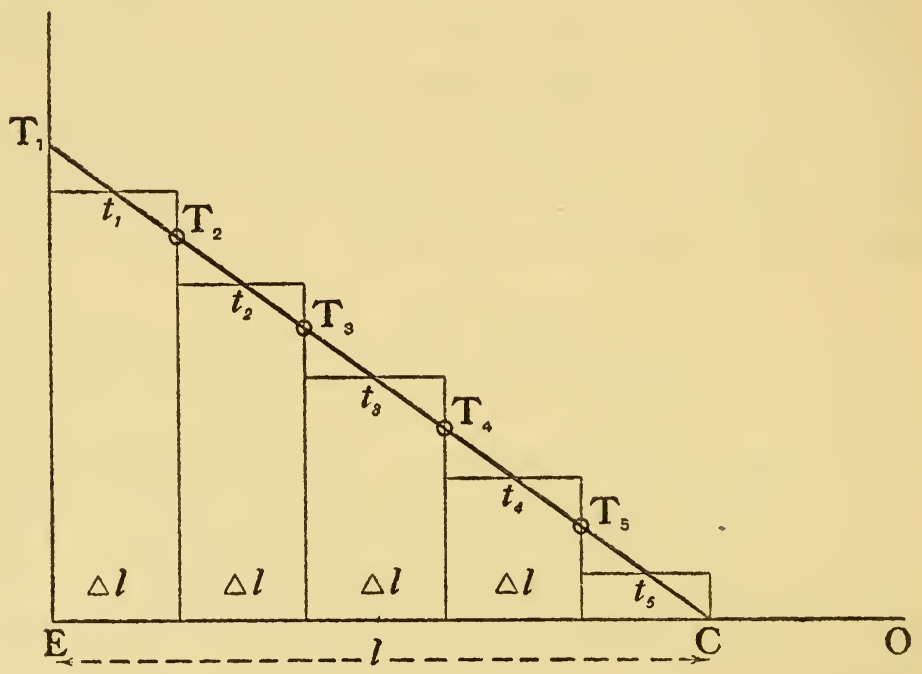

FIG. I.

movement of the muscle itself. In general the records so obtained resemble those of isotonic twitches. The procedure adopted is as follows. The muscle is held rigidly by a clamp which can be screwed up and down a graduated scale. At the beginning of the experiment the clamp and muscle are screwed down until the cord attaching the other extremity of the latter to the tension lever is just tight, but not sufficiently so to stretch the muscle appreciably. A stimulus is now given, and the tension recorded. The screw of the clamp is now turned so as to raise it I $\mathrm{mm}$., thereby slackening the cord. 
The tension developed when the muscle is stimulated is then recorded. This represents the force the muscle exerts when it has contracted through I $\mathrm{mm}$. In a similar way the tension is observed in stages of $\mathrm{I} \mathrm{mm}$. till the muscle is so slack that it exerts no tension on the lever, i.e. till the clamp has been raised through a distance corresponding to that through which the muscle contracts in a single twitch.

The experiment is only valuable as a means of arriving at a simple expression for $\Sigma \mathrm{T} d l$. in terms of easily determined quantities. Now the potential energy of an elastic body stretched to a length $x$ from the unextended condition $c x$ is $\frac{1}{2} \mathrm{~T} x(\mathrm{I}-c x)$, and we might therefore anticipate that the energy of contraction would be of the general form $\mathrm{K} . \mathrm{Tl}$, where $\mathrm{K}$ is a constant, $\mathrm{T}$ the initial tension and $l$ the normal length. According to Hill's determinations the area of the tensionlength curve satisfies the relation $\mathrm{K}=\mathrm{I} / 6$ approximately.

Thus the potential energy liberated in a single twitch is $\mathrm{Tl} / 6$. In practice all this energy is not realised, because while it has been found possible to devise an apparatus by which the force opposed to the muscle is balanced against the actual tension throughout the act of contraction, we cannot carry out the process so slowly as to avoid degradation of energy through internal friction (i.e. protoplasmic viscosity). For an understanding of the mechanics of muscle we are only concerned with the theoretical value of $\mathrm{W}$, i.e. $\mathrm{T} l / 6$.

(b) Chemical Phenomena in Contraction of Muscle.-The essential facts as regards skeletal muscle are two: first, that the muscle can contract and relax in the total absence of oxygen, though the presence of oxygen delays the onset of fatigue; secondly, that lactic acid is produced in the process of contraction, rapidly disappearing in the presence of oxygen, but accumulating if oxygen is excluded. The elucidation of this aspect of the contractile processes is due in the first place to the work of Fletcher and Hopkins. The conclusions which can be drawn from their observations are that the production of lactic acid without utilisation of oxygen is the salient event associated with the tension which results in muscular contraction; that the accumulation of lactic acid underlies the 
phenomenon of fatigue, in which the muscle is unable to recover its original reactivity between successive stimulation; and that the oxidative removal of lactic acid is an essential feature of the recovery process by which the state previous to excitation is restored. More recently Meyerhoff has shown that the appearance of lactic acid in muscle is correlated with the disappearance of a corresponding amount of glycogen, a hexose diphosphate being an intermediate compound in the transformation. The appearance of the lactate ion in the contraction process must not be taken to imply that there is any observable increase in hydrogen ion concentration in a single twitch or short tetanus; Ritchie finds that there is not. The presence of free lactic acid must ordinarily be instantaneous, as one would expect in a buffered system such as that which exists in tissues. Since the mechanical relaxation of muscle occurs as well in the absence of oxygen, this part of the recovery may be assumed to correspond with the immediate neutralisation of the lactic acid set free at excitation. Further light can be obtained on this question by considering heat production in muscular contraction.

(c) Heat Production in Muscle.-That the temperature of a muscle rises during contraction is easily demonstrated by stimulating living and dead muscle in contact with the metallic junctions of a thermopyle placed in circuit with a sensitive galvanometer. The extension of our knowledge of the heat production of muscle in recent years is chiefly due to the work of A. V. Hill. Two questions are of pre-eminent interest as throwing light on the mechanism of muscular contraction, namely, the relation of the heat produced to the chemical events of the contraction cycle, and the relation of heat-production to the potential energy for mechanical work set free at excitation.

Hill has formulated the first of these two issues in the following way: Is the heat-production of muscle given out in some process by which the tension of muscle is increased, or in the recovery process by which the mechanism is restored to its original condition? A satisfactory answer to this question is obtained by studying the time-relations of heat 
production and comparing the effects of stimulation upon heatproduction in conditions promoting or impeding the recovery process.

According to Hill's data three definite conclusions can be drawn. Firstly, when a muscle is excited directly or indirectly in oxygen by either a single shock or a short tetanus, the liberation of heat continues for some time after the mechanical response is over. Secondly, the amount of heat so liberated after mechanical response is over is, in oxygen, at least as great as that evolved in the contraction and relaxation itself. But

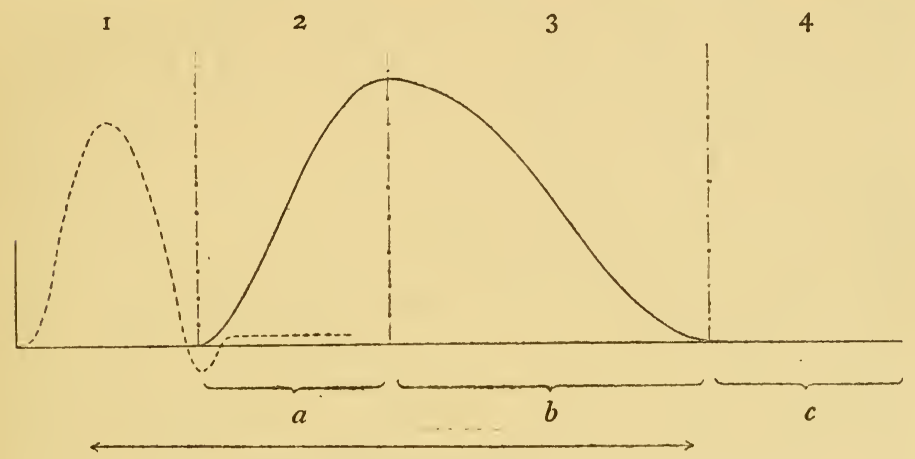

Heat production in $\mathrm{N}_{2}$

Heat production in $\mathrm{O}_{2}$

FIG. 2.- Scheme to illustrate modern work on muscular contraction.

I. Latent period-concentration of ions at surface of excitation (electrical change). 2. Development of tension-associated with disappearance of glycogen and appearance of lactic acid. 3. Relaxation-lactic acid neutralised by buffer action of muscle proteins. 4. Recovery-lactate ions in part oxidised: some glycogen reappears. (a) Heat of formation of lactic acid from glycogen. (b) Heat of dissociation of muscle proteins. (c) Heat of combustion of part of lactic acid.

thirdly, when the muscle is stimulated in nitrogen, there is hardly any heat-production after contraction is over, though the normal quantity is evolved when oxygen is again admitted. It seems therefore justifiable to infer that oxygen is used up, and "delayed" heat liberated, in that part of the recovery process which occurs after relaxation is complete. As we have already seen, this part of the recovery process is dependent on the presence of oxygen and cannot occur in pure nitrogen. 
Thus part of the heat generated in muscular contraction arises in the process which results in tension, part in the process by which the substance liberated at excitation is reinstated or removed.

When the muscle is stimulated isometrically no work is done. All the energy must disappear as heat. By subtracting the heat-production of isometric contraction in nitrogen from the heat-production of isometric contraction in oxygen, that of the oxidative recovery process is obtained. The heatproduction in pure nitrogen represents, on the hypothesis advanced above, at least two processes : the liberation of lactic acid and its subsequent neutralisation during relaxation. The formation of one gram of lactic acid from glycogen in vitro is accompanied by the liberation of 190 calories. The appearance of one gram of lactic acid in muscle is associated with the evolution of total energy equivalent to nearly 400 cals. The heat of neutralisation by bicarbonates or phosphates is far too small to account for the excess. Meyerhof suggests that the remainder may be due to the heat of dissociation of the muscle proteins. This has recently received some experimental confirmation from the work of Hartree and Hill, who have shown that to keep the hydrogen ion concentration inside the muscle within reasonable limits, we must assume the existence of some buffer in it more effective than a bicarbonate or phosphate solution. As in the case of blood, this is presumably brought about by alkali proteinates capable of forming neutral salts and undissociated protein.

The heat-production of oxidative recovery, on the other hand, only accounts for a small fraction of the lactic acid which disappears. Hartree and Hill estimated that in oxygen the delayed heat-production is one and a half times the initial heat-production, which represents about 400 cals., as stated, per I grm. lactic acid. The combustion of I grm. of lactic acid is accompanied by an evolution of $366 \mathrm{r}$ calories in vitro. Since now, according to Meyerhof, the disappearance of lactic acid is associated with increase in glycogen in the muscle, it is suggested that the lactic acid disappears partly by oxidation, the energy so liberated appearing in part as heat and being 
utilised in part for the resynthesis of the remaining lactic acid. About one-fifth of the lactic acid removed appears to be oxidised. The sequence of phenomena is represented diagrammatically in Fig. 2.

(d) The Nature of the Mechanism.-In considering the heat-production of muscle in relation to the chemical events of the contraction cycle, the muscle has been assumed to respond under conditions in which no mechanical work is done, so that all the energy set free at excitation is measured in heat units. It has been shown, however, that we can determine how much of this energy is available for the performance of mechanical work in appropriate circumstances. The potential energy available for the performance of mechanical work in a single twitch is $\mathrm{T} l / 6$. When the value of $\mathrm{H}$ for initial heatproduction (heat-production without recovery) in isometric contraction is reduced to the same units, the ratio $\mathrm{Tl} / 6 \mathrm{H}$ expresses the absolute mechanical efficiency of muscle; and its value is found to approximate to unity (as high as $0^{\circ} 9 \mathrm{I}$ in a series of A. V. Hill's experiments) in a suitable muscle such as the frog's sartorius. This implies that the whole of the energy liberated at excitation is free energy, i.e. capable, unlike heat, of being transformed entirely into mechanical work.

Heat, as implied in the Second Law of Thermodynamics, cannot be transferred into mechanical work without waste. No heat engine can be more efficient than a reversible engine working between the same temperature-limits, i.e. with a maximal efficiency of $\mathrm{T}-\mathrm{T}^{\prime} / \mathrm{T}$ on the gas thermometer scale. Thus, in order that a frog's sartorius may have an efficiency of 0.25 (which is actually realisable), it would be necessary, on the assumption that the energy was derived from the heat produced, for the muscle to be raised to a temperature above the boiling-point of water. The muscular machine is not therefore a heat engine; and the fact that all the energy set free at excitation is available for doing mechanical work signifies that the exciting substance must be liberated at the seat of tension; if it were not so, a large part of the energy liberated would be irreversibly degraded into heat.

It is not difficult to construct a mechanical model to show 
how the application of acid to a colloidal system may give rise to a considerable quantity of mechanical energy. Thin strands of catgut immersed in acid undergo quick and extensive shortening; the process is completely reversible when the acid is removed, and can be repeated indefinitely. Shortening in the length of a muscle-fibre could occur without a change in volume by increased curvature of the surface; as regards the muscle as a whole, this as a matter of fact is what does happen. Now Hartridge and Peters have shown that increase of hydrogen ion concentration increases the surface tension at an oil-water interface, and Neuerschloss finds that analogous phenomena occur with lecithin sols. There is very good reason, based on the penetration of dyes into living cells, to bear out the conclusion that lipoid substances accumulate at the cell surfaces and interfaces. Hill has shown that, provided that the muscle is allowed to shorten before maximum tension has been developed, the heat-production of a muscle which is released after stimulation so as to shorten (without lifting a weight) is less than in a rigidly isometric twitch ; this is so if the muscle shortens while the processes which give rise to tension are still at work, but if the muscle is liberated after maximum tension has been attained there is no diminution of heatproduction. Were the heat-production uniformly distributed through the substance of the muscle one can see no reason why this should occur, since the muscle does not change its volume. But if the heat production is located at definite interfaces, it must tend to become smaller if the area of these interfaces is reduced, as it presumably must be, when the muscle shortens.

(e) Electrical Phenomena in Muscle.-When the cut end of a muscle is connected with one lead of a delicate galvanometer and the uninjured surface with the other, there is found to be a difference of potential between the two surfaces, the cut end being negative to the uninjured surface of the muscle. When the latter is stimulated, there is a diminution of this potential. This diminution or "negative variation" is referred to as current of action, and flows in the opposite direction to the normal or demarcation current which is from the cut to the uninjured surface of the resting muscle. It is not a specific 
attribute of the muscular mechanism, but is a phenomenon shared by other excitable tissues. It has been the subject of extensive research partly because of its practical application to the diagnosis of heart disease (electrocardiography), partly because it provides a very delicate means of detecting the existence of an excitatory process, where mechanical appliances fail, and to some extent because it has been customary in the past to seek for an explanation of colloidal behaviour, and therefore the processes which occur in the living organism, in

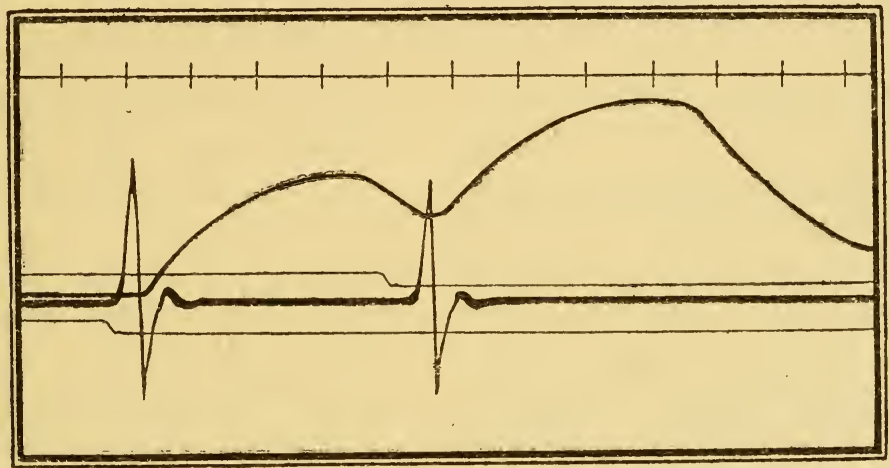

FIG. 3.-Time relations of the electrical variation in the isometric response to two successive stimuli (after Fulton).

Responses of the intact gastrocnemius of a decerebrate frog at $16.5^{\circ}$. Time indicated above, $0.02 \mathrm{sec}$. The horizontal shadows from above downwards are: the signal denoting the moment of the second stimulus (make); the myograph; the string of the galvanometer; signal for the first stimulus (break); line of zero tension, $29 \mathrm{~mm}$. movement of the myograph vertically being equal to $500 \mathrm{gms}$. tension. String tension $5 \mathrm{~mm}$. per m.v., the magnification being 285 . Stimuli delivered to the cut nerve, the cathode being at a point $1^{\circ} 9 \mathrm{~cm}$. from the entry of the nerve into the muscle; stimuli just-maximal induction shocks. Initial tension $90 \mathrm{gms}$. Frequency of the myograph 460 per sec.

terms of electrical phenomena rather than the stoichiometrical relations which form the subject-matter of traditional chemistry.

There is little doubt that the demarcation current arises from the distribution of electrolytes in the muscle system ; its relation to temperature, according to the work of Bernstein, follows the thermodynamical relation which applies to the 
concentration cell. The action-current occurs in denervated (Adrian) as well as normal muscle. It travels as a wave along the length of the muscle like the mechanical response itself. Any excited region becomes momentarily electronegative to an unexcited part. The existence of this potential indicates a redistribution of ions within the system in which the potential difference is developed. One explanation, offered by Mines, is that the sudden concentration of hydrogen ions at the sensitive surfaces of the fibres sets up there a condition which may be likened to that of a concentration battery. There are, however, two very cogent objections of a general nature to this

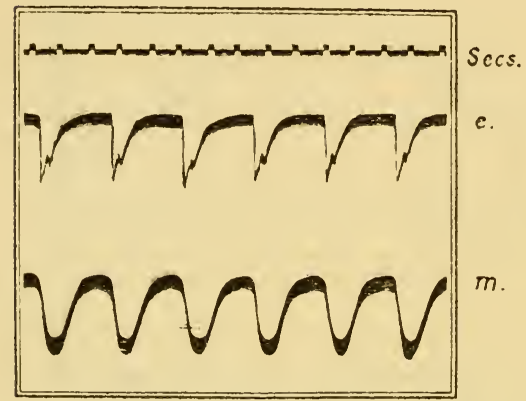

Fig. 4.-Mechanical beat ( $m$ ) and electro-cardiagram $(e)$ of heart of Homarus.

proposal. One is that the electrical change in striped muscle (see Fig. 3) is practically complete before the mechanical response begins; the negative variation occurs in the latent period and begins contemporaneously with the application of the stimulus. It is thus probable that the electrical phenomenon is associated with events antecedent to those with which Hill's hypothesis is concerned, since Hill has shown that the production of acid continues up to the point at which maximum tension is developed. This conclusion is strengthened by the close similarity (Chapter VIII) between the electrical accompaniments and physical conditions which are associated with the initiation of the excited state in nerve and muscle. Therefore the electrical response may be considered more conveniently in relation to excitation in the more restricted sense (Chapter VIII). It is of interest in connection with Mines' hypothesis, however, to note that the phase of negative variation is often succeeded by a second phase which is developed at the beginning of the mechanical response. Possibly the origin of the electrical phenomena is itself complex. It is difficult to believe that a concentration 
of hydrogen ions, such as Hill's hypothesis demands, produces no measurable bio-electric effect.

$(f)$ The Phenomenon of Tonus.-An aspect of muscular contraction which is still very obscure is exemplified in a rather striking manner by certain contractile mechanisms of invertebrates. In the living animal a skeletal muscle is not normally relaxed completely, as in the isolated nerve-muscle preparation. The partial contraction of skeletal muscle in situ is maintained by the C.N.S. The opposite is the case with smooth muscle which when isolated from the body remains in a state of tonus, and in the intact animal is subject almost universally to control by nerves whose action is inhibitory. Smooth muscle is capable of maintaining this state of tonus for very long periods without any appreciable sign of fatigue. Thus Parnas (I9ro) found that the adductor of the mollusc Dioxinia can keep its shell closed for twenty or thirty days at a stretch against a tension per sq. $\mathrm{cm}$. of muscle attachment of about two and a half million dynes-a tension exerted in virtue of the elastic cushion which causes the shell valves to fly apart when the muscle is relaxed. This can be brought about, in the freshwater mussel Anodon at least, by stimulating the inhibitory nerves from the pallial ganglion; section of the nerve supply of the adductors does not lead to relaxation. In Pecten a rather curious phenomenon results from the co-operation of two separate constituents of the adductor muscle, one composed of striated fibres and the other of smooth muscle fibres. When scallops (Pecten) are taken out of the water they usually give one or two flaps of the shell-valves and then close tightly; if a solid object is interposed between the valves they close on it like a vice. But if the foreign body is then made to slide out of position, the valves remain set fast at the same degree of closure. Uexkull (IgI2) has shown that on cutting away the smooth muscle, the remainder can be excited to contraction by nervous stimulation; but the contraction of the striated fibres of the adductor persists only so long as stimulation lasts. The motor portion (striated fibres) of the adductor serves to bring the valves together rapidly, while the more slowly reacting " catch muscle " (smooth fibres) keeps the valves closed 
by its sustained tonus. A double neuromuscular mechanism probably of the same type exists in the adductor of Astacus, Homarus, Carcinus and other decapod crustacea (Lapicque, Keith Lucas). The economy of such an arrangement, which combines the rapidity of action of striped muscle with the low energy output of the tonus mechanism, is evident. Tonus is not associated with increased metabolism, and cannot therefore be of the same nature as a low-grade tetanus.

The tonus of a catch muscle may be looked upon as a natural form of isometric response. We are probably dealing here not with a change in the intensity factor but with the capacity factor of the surface energy of the cell. It is possible to think of a mechanism of isometric response by which a mechanical stress sets up in some part of the protoplasmic system a change in phase relations of the colloidal constituents such as to oppose it by a virtual tension co-extensive with the maintenance of the external force. The coagulation of liquid silk in stretching is possibly analogous.

(g) Relation of the Muscle Cell to Electrolytes.-Certain phenomena, notably those associated with the maintenance of tone which has just been discussed, raise difficulty in the way of any attempt to extend to plain muscle the conclusions respecting the contractile mechanism in striped muscle. This is also the case in considering the rôle of the hydrogen and calcium ions respectively in the contractile process. The effect of adding acid to a saline medium in which a preparation of striped muscle is immersed is to produce contraction; on the other hand, it is found both for the cardiac muscle of the vertebrate heart (frog, dogfish, skate), and the unstriped muscle of the molluscan heart (Pecten) (Mines, 1913), as well as for various forms of mammalian plain muscle which have been recently studied with great care by Lovatt Evans (1923), that increased hydrogen ion concentration produces arrest, at first reversibly and beyond a certain point irreversibly, in the relaxed condition. The action of calcium on striped muscle has been carefully studied by Overton (1904) and Mines (I9I2); in a medium containing sodium ions but no calcium the muscle displays rhythmical spontaneous twitching; the addition of a 
small trace of calcium suffices to prevent these spontaneous movements and bring about stoppage in the relaxed condition. Similarly, removal of calcium brings about systolic stoppage of the crustacean heart (Hogben). Mines also showed that addition of $\mathrm{Ca}$ diminishes excitability of muscle towards electrical currents of long duration. On the other hand, the effect of increased calcium is to diminish relaxation in the plain muscle of the crop of the fowl (Fienga) and the pharynx of Aplysia (Hogben), while complete absence of calcium produces diastolic arrest of the heart in Pecten (Mines), Raia, Scyllium

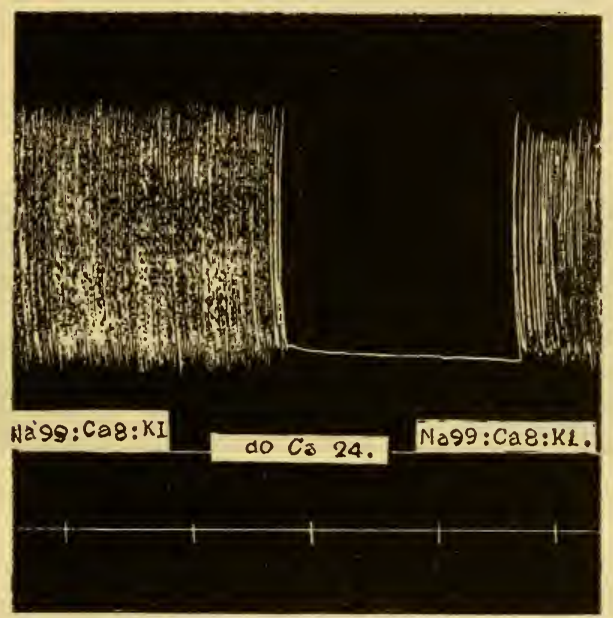

FIG. 5. -Effect of excess of calcium on the perfused heart of the lobster, Homarus (Hogben).

and Rana (Mines) ; on the other hand, Lovatt Evans describes diastolic arrest in the heart of Helix by excess of calcium.

So far we have little information with respect to the specific rôle of anions, though certain of these have very characteristic effects, as illustrated in the universal action of cyanides in depressing oxidative processes. The fact that proteins appear to behave as amphoteric electrolytes and are found in the cell in general on the alkaline side of their isoelectric point, thus existing as metallic proteinates, is a valid reason for attaching special significance to the relation of kations to biological 
processes. On the basis of a prolonged series of experiments on the cardiac and striped muscle of the frog, the heart muscle of Pecten and several species of elasmobranch fishes, Mines has attempted the classification of kations under three headings, combining, nomadic, and polarising ions. Mines postulated (I) that the normal activity of the muscular apparatus depends on the maintenance of a certain degree of permeability at some cell-surface ; (2) that the permeability of the cell-membrane depends partly on the chemical composition determined by the combination (inter alia) of $\mathrm{Ca}$ (and $\mathrm{Sr}$ under experimental conditions) with some constituent of the cell ; and partly on the electrical potential between the two sides of the membrane itself. This latter is supposed to be modified by $(a)$ the ability of certain ions ( $\mathrm{Na}$ and $\mathrm{K}$ ), the nomadic ions, to pass through

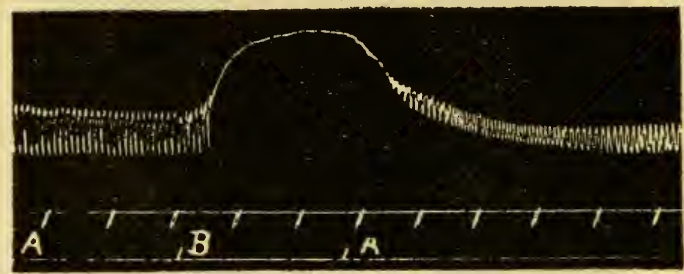

Fig. 6. -Effect of removal of magnesium (B-A) on the perfused heart of Pecten (Mines, Fourn. Physiol. 43, 1912).

it selectively; and $(b)$ the adsorption of certain other ions, e.g. $\mathrm{Mg}, \mathrm{La} .$. and $\mathrm{Ce} .$. to the surface itself, thereby reducing or reversing its normal charge. The hydrogen ion is regarded as acting sometimes in one way, sometimes in the other.

On the whole the indications of recent work are distinctly favourable to the rôle which Mines postulates for calcium. The effects of the other polyvalent ions are more obscure, since $\mathrm{Mg}$.., Ce..., La ..., etc., agree with $\mathrm{Ca}$ in depressing the striped muscle of the vertebrate, and that of the crustacean heart; while their action is opposite to that of $\mathrm{Ca}$ in a large number of instances in the case of cardiac and plain muscle. Thus in Pecten, removal of $\mathrm{Mg}$, which is apparently essential to the heart-beat, produces systolic arrest, while removal of 
Ca produces diastolic stoppage of the heart. In his conception of the action of the "polarising" ions Mines was unduly influenced by the work of Schulze and of Linder and Picton on precipitation of arsenious sulphide sols. The relation of valency to coagulation phenomena in hydrophile sols of sulphur (Odén), lecithin (Neuerschloss); and gelatin (Loeb) differs very considerably from that described by the SchulzeLinder and Picton law, and gives evidence of antagonism between divalent and monovalent ions which is suggestive in relation to certain vital phenomena described below. Loeb's work makes it very doubtful if the action of hydrion and trivalent ions on membrane potential depend on the same mechanism, and the degree of reversibility of the effects of one or the other on the vertebrate heart reinforce this conclusion. As regards

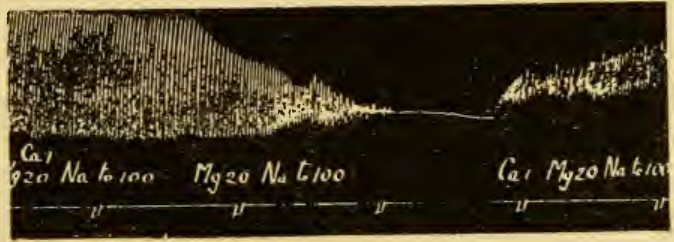

FIG. 7. Effect of removal of calcium on the perfused heart of Pecten (Mines, loc. cit.).

the " nomadic" ions, Mines' hypothesis gives no explanation of the opposed action of $\mathrm{Na}$ and $\mathrm{K}$ in certain cases and their relative potency in others ; moreover, the extent to which these ions are actually capable of penetrating the muscle cell is an open question.

The combining nature of the $\mathrm{Ca}$ ion, on the other hand; finds considerable confirmation in the work of Clark (1912) on the frog's heart, and is reinforced by very diverse lines of inquiry into cell physiology which will be described in connexion with ciliary activity. Clark showed that increase in the $\mathrm{Ca} / \mathrm{Na}+\mathrm{K}$ ratio revives the amplitude of the frog's heart when it has become diminished by prolonged perfusion, this loss being associated with the removal of a substance of lipoid nature. $\mathrm{He}$ suggests that $\mathrm{Ca}$ which precipitates lecithin, a normal constituent of the cell membrane, maintains the normal semi- 
permeability of the muscle cell by its action on the colloidal lipoid constituents of the surface layer. The work of Clowes affords a crude model of how this effect might be produced. In an oil-water emulsion addition of $\mathrm{Ca}$ salts produces a reversal of phase so that the water becomes the internal and the oil the continuous phase, i.e. so that the system as a whole becomes impenetrable to water soluble substances. For a more realistic conception the work of Neuerschloss on lecithin sols should be consulted. If $\mathrm{Ca}$ determines the condition of the lipoid constituents of the cell surfaces, the assumption that $\mathrm{Na}$ and $\mathrm{K}$ are nomadic ions in Mines' sense provides for a ready explanation of the widespread antagonism of $\mathrm{Ca}$ to $\mathrm{Na}$ as illustrated by the work of Mines on striped muscle and that of Clark on the vertebrate heart. Such antagonism might be regarded simply as the opposition to the penetration of $\mathrm{Na}$ ions set up by surface action of calcium.

An example drawn from the field of invertebrate physiology is afforded by the work of Lillie (1909) on the larvæ of Arenicola. The larvæ of this polychæte in isotonic solutions of the chlorides of $\mathrm{Na}$., $\mathrm{K}$., $\mathrm{Li}$., and $\mathrm{NH}_{4}$ undergo contraction to about half their normal length in a few seconds, and simultaneously the yellow pigment enclosed in the cells of the organism diffuses out into the medium, showing that the normal semipermeability of the cells has been suspended. Solutions of the chlorides of $\mathrm{Mg}$. . and $\mathrm{Ca}$. . do not have this action either as regards the contracture or discharge of colouring matter ; and addition of a small quantity of $\mathrm{Ca}$. . ions to a solution of isotonic sodium chloride prevents the contracture and pigment extrusion produced in a pure solution of the latter. On the other hand lipoid-solvent anæsthetics such as chloroform produce contracture and discharge even in pure magnesium chloride. This antagonism is by no means confined to muscular phenomena. Thus Loeb (1912) showed that if eggs of the Atlantic minnow (Fundulus) are placed in hypertonic sea-water they remain alive for days, floating on the surface in an apparently impermeable condition. If for sea-water hypertonic $\mathrm{NaCl}$ is substituted, they sink to the bottom, undergo shrinkage and rapidly perish. The addition of a small quantity 
of calcium to the sodium chloride solution prevents the untoward effects of the latter alone and maintains the normal impermeability of the egg-membrane. The work of Osterhout on the electrical conductivity of plant tissues affords interesting parallels.

Clowes has in fact constructed a model in which the interstices of a partition of filter-paper fixed by rubber rings in a U-tube are filled with an emulsion consisting of oil and a saline medium containing sodium, potassium, and calcium chlorides in roughly the same proportions as they occur in living tissues. The conductivity of the artificial membrane varies in the presence of electrolytes in the medium in a manner closely analogous with the conductivity of protoplasmic surfaces in plant cells, as in Osterhout's experiments. In pure $\mathrm{NaCl}$ conductivity increases ; in pure $\mathrm{CaCl}_{2}$ it decreases, owing presumably to reversible changes of phase in the interstices of the filter paper.

Some light is thrown on the relation of electrolytes to the contraction of muscle by a study of the concomitant electrical phenomena. Thus in vertebrate heart-muscle the absence of calcium does not prevent electrical changes after mechanical response has ceased. To have a clear appreciation of the relation of muscle to electrolytes it is essential to recognise not only that muscle is the seat of a state of tension which in appropriate circumstances results in mechanical work being done, but that it is also the seat of a propagated disturbance leading up to the events which condition this state of tension. The foregoing treatment of the contractile mechanism has been focussed on the events which succeed the explosive breakdown of some substance intermediate between glycogen and lactic acid ; but, as we have seen, the electrical phenomena must be referred to phenomena independent of the nature of the contraction process itself. The disturbance which travels along the muscle initiating the breakdown of glycogen has so many points in common with excitation and conduction in nerve that there is excellent justification for extending to the action-current of muscle an interpretation analogous to that suggested for the corresponding phenomenon of nerve discussed 
in a later chapter. Excitation in nerve depends on surface phenomena which are characteristically sensitive to changes in the ionic composition of the external medium; it is highly probable therefore that the effect of any given ion may be independently related to the initial and final stages in the contraction cycle; and we should therefore be wrong in drawing from the different behaviour of striped and plain muscle to electrolytes the conclusion that the contractile mechanism is fundamentally different. This is clearly the case with the calcium ion. Diastolic arrest of the heart of the frog (Daly and Clark) in the absence of $\mathrm{Ca}$ ions is not due to any failure of the excitatory mechanism : the electrical response continues. On the other hand, diastolic arrest of the heart of the lobster (Hogben) by excess of calcium ions is associated with cessation of the electrical change, and is probably due to the depressant action of calcium on the excitatory process.

\section{FURTHER READING}

Hill (1913). The Absolute Mechanical Efficiency of Muscle. Journ. Physiol. 46.

- (1914). The Heat Production in Prolonged Contraction. Ibid. 47.

- (1922). The Mechanism of Muscular Contraction. Physiol. Reviews, 2.

Hartree And Hill (1923). The Anærobic Processes involved in Muscular Activity. Journ. Physiol. 58.

Hogben (1925). Studies on the Comparative Physiology of Contractile Tissues I. Quart. Journ. Exp. Physiol. I5 (for bibliography).

Evans and Underhill (1923). Studies on the Physiology of Plain Muscle. Journ. Physiol. $5^{8}$.

Mines (I912). On the Relations to Electrolytes of the Hearts of different Species of Animals. Journ. Physiol. 45.

- (1914). On Functional Analysis by the Action of Electrolytes. Ibid. 47. 


\section{CHAPTER II}

\section{CILIARY ACTIVITY, AMEBOID MOTION AND COLOUR RESPONSE}

In the previous chapter we have considered a form of response which has several advantages for experimental treatment. The activity of skeletal muscle is not spontaneous, it can be made accessible at will. Further, muscular tissue can be obtained in sufficient bulk to facilitate very considerably the measurement of the energy changes which accompany its activity. On the other hand; all that we know of the muscular mechanism is of a statistical nature. In the case of ciliary, amœboid; and chromatophore movements, however, it is possible to make direct observations on individual cellular units. To these forms of response, which are more conveniently studied in the lower organisms, we shall now turn, taking first of all ciliary activity. Of this, our knowledge has been lately advanced by the extensive investigations of Gray (1922-1924), which will form the basis of the present treatment.

Ciliary Motion.-For a clear appreciation of the issues raised by a consideration of the mechanism of ciliary motion, a few remarks must be introduced concerning the contractile rhythm of the ciliated cell. Favourable material for observations of this kind are afforded by the gills of the common mussel Mytilus. The face and sides of each filament are respectively lined with frontal and lateral ciliated cells, whose movement maintains an efficient stream of water and mucus (see Chapter V) easily detected by the naked eye if a little carmine is added to the medium. Microscopic observation shows that the maintenance of these currents in a definite direction is due to the characteristic manner in which the cilium moves. The movement of a single cilium is divisible into two phases, a very rapid forward or effective stroke, and a slower backward 
or recovery stroke. The form of the beat suggests that it is during the rapid effective stroke that the cilium performs work on the surrounding medium. At the conclusion of the forward movement, it can be seen that the cilium, which at the beginning of the effective stroke is a more or less rigid rod moving forward on a pivot at its base, becomes limp; a stress is set up which starts at its base and is transmitted thence to its free end. For the purpose of forming a working hypothesis, it may be assumed, as suggested by Gray, " that the energy which is expended by the cilium is stored as tension energy." We are entitled to

$\leftarrow$ Forward or Effective Beat

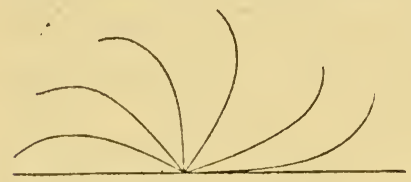

$\rightarrow$ Backward or Recovery Beat

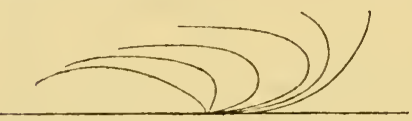

FIG. 8.-Diagram of ciliary motion (after Gray). surmise that this energy has its origin in some chemical compound either in the cilium itself or in the cell to which it is attached. The problem to be faced is the elucidation of the sequence of events by which chemical energy is converted into kinetic energy; or-as implied above-the chemical processes by which the state of tension in the cilium is relieved.

We shall here accept Gray's hypothesis as a basis for discussion. The results of the foregoing survey of muscular contraction have led us to conclude that the physical changes which result in contraction are associated with the production of lactic acid from carbohydrate without intake of oxygen, and that oxygen is employed in the recovery process to restore the mechanism to its original condition. Though ciliated epithelium is structurally very different from muscle, there are two sets of considerations which suggest the possibility that a similar sequence of chemical phenomena might be found to underlie the changes of physical state, which in both cases result in liberating contractile energy. One is that lactic acid is an obligatory intermediary in the breakdown of carbohydrates in all animal tissues. The other is that the physical properties of proteins, being probably dependent on conditions 
defined by the Donnan membrane equilibrium, are intimately affected by the acidity of the medium with which they are in contact.

Gray has outlined an hypothesis according to which the chemical events of the contraction cycle in muscle and ciliated cell are closely analogous. It may be considered under three headings: (a) the possible production of an acid substance during the contractile process; $(b)$ the relation of oxygen consumption to the events of activity and recovery; $(c)$ the nature of the substances used up in the transformation of chemical into kinetic energy by the cell.

The production of acid may be taken first. The only method at present available for obtaining any evidence on this question is derived from studying the relation of ciliary activity to the ionic constituents of its surroundings. Ciliary motion of Mytilus gill-filaments can be preserved for many hours in a Van 't Hoff solution containing chlorides of $\mathrm{Na}, \mathrm{K}, \mathrm{Ca}$; and $\mathrm{Mg}$ in the same proportions as sea-water at a $\mathrm{pH}$. about 7.8 . On addition of acid the cilia on the gill of Mytilus cease to move when the hydrogen ion concentration of the solution reaches a limiting value on the acid side of neutrality. What is especially interesting is the way in which this stoppage is brought about; the cilia come to rest in an acid solution by a gradual slowing of the rate, without reduction in the amplitude of the beat, till finally movement is arrested at the end of the effective stroke, i.e. in the relaxed condition. This fact, while suggesting that the acid does not exert its effect by damaging the contractile fibrils of the cilium itself-since the amplitude is not directly affected-at first sight points to the conclusion that the effect is a surface one, concerned only with the rate at which the excitation state is generated.

That the action is not a surface one, however, Gray has proved by several lines of experimentation. The first depends upon the fact that the weak organic lipoid-soluble acids penetrate the lipoid membrane of the cell more readily than do strong acids. Similarly, weak bases like ammonium hydrate are more penetrative than strong bases like sodium hydroxide. If the cessation of ciliary motion in acid medium were a surface 
effect the $\mathrm{pH}$. limits with both types of acid would be expected to be the same. A number of experiments were carried out by Gray to determine the critical concentration of hydrogen ions in the external medium which would produce arrest in one minute. The results are given below.

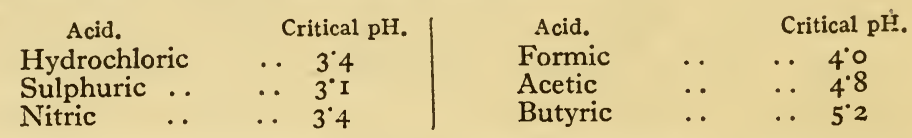

It will be noticed that the mineral acids are of practically uniform efficiency ; while the fatty acids form a series of which the higher members are more efficient, all being more efficient than the mineral acids. This result strongly suggests that the acid enters the cell, since the effect is related not to the absolute hydrogen ion concentration of the medium but the penetrative power of the acid employed. The value of those observations are, moreover, reinforced by considering the phenomenon of recovery of pieces of gills exposed to acid for the same length of time, when transferred to sea-water made alkaline with weak and strong alkalis. The time (in minutes) for recovery in such an experiment is given in the following protocol:-

$\begin{array}{lcccc} & & \begin{array}{c}\text { Sea-water, } \\ \mathrm{pH} .7^{*} 8 .\end{array} & \begin{array}{c}\text { Sea-water }+\mathrm{NaOH}, \\ \mathrm{pH} .8{ }_{4} .\end{array} & \begin{array}{c}\text { Sea-water }+\mathrm{NH}_{4} \mathrm{OH} \text {, } \\ \mathrm{pH} .84_{4}\end{array} \\ \text { Movement begins } & \ldots & \text { I2 } & 7 & \text { I } \\ \text { Full recovery .. } & \ldots & 25 & 19 & 3\end{array}$

The experiment may be varied by determining the time for recovery on transference to sea-water raised to a known alkalinity by addition of $\mathrm{NaOH}$ and $\mathrm{NH}_{4} \mathrm{OH}$, respectively, as given below.

\begin{tabular}{|c|c|c|}
\hline pH. & $\begin{array}{c}\mathrm{NH}_{4} \mathrm{OH} \\
\text { min. }\end{array}$ & $\mathrm{NaOH}$. \\
\hline 9.5 & $\frac{1}{2}$ & 5 \\
\hline $9^{\circ} 2$ & $\frac{1}{2}$ & 7 \\
\hline $\begin{array}{l}9 \circ 0 \\
8.7\end{array}$ & $\frac{1}{2}$ & $8_{8-10}^{8}$ \\
\hline $\begin{array}{l}8.7 \\
8.5\end{array}$ & I & $\begin{array}{r}8-10 \\
10-12\end{array}$ \\
\hline $\begin{array}{l}8.5 \\
8.4\end{array}$ & $\begin{array}{l}3 \\
5\end{array}$ & $\begin{array}{l}12-12 \\
12-15\end{array}$ \\
\hline
\end{tabular}

To sum up in Gray's own words, " The weak acids which enter the cell are more efficient inhibitors of ciliary movement than the strong acids which do not enter readily, and conversely the weak alkalis are much more efficient restoratives than the strong alkalis." 
Circumstantial evidence also pointing to the conclusion that the acid enters the cells is gained from a study of the effects of removal of calcium. Lillie (1900) originally showed that the toxic effect of pure sodium salts on ciliary movement, as on muscular contraction and on irritability in nerve, is prevented by the presence of the alkaline earth metals. In the case of the ciliated cell either magnesium or calcium will serve in adequate proportions to maintain the normal semipermeability of the cell membrane, but magnesium must be present to ensure recovery (according to Gray) after exposure to a solution

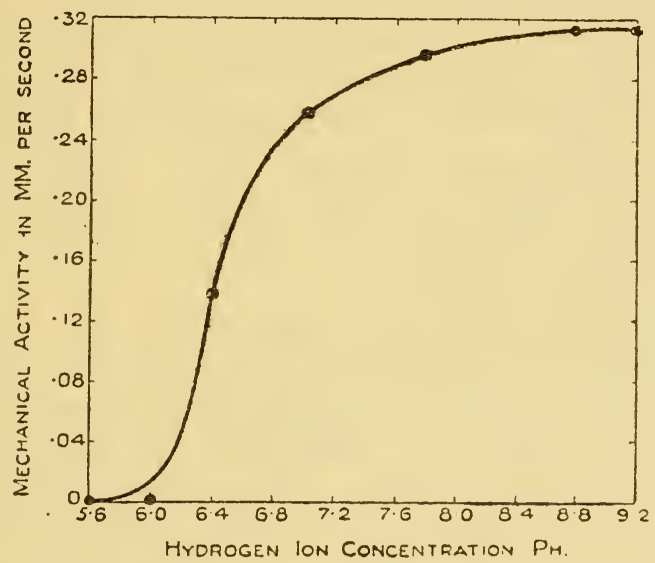

FIG. 9.- Relation of hydrogen ion concentration to ciliary movement (after Gray).

containing no divalent ions. On the other hand, if calcium is replaced by an equivalent amount of magnesium, cessation of ciliary movement is brought about unless the $\mathrm{pH}$. is kept well above absolute neutrality.

In other words, the cell is more susceptible to the action of hydrogen ions if the calcium ions, which confer upon the membrane its normal semipermeability, are removed. More direct evidence that the acid enters the cell is obtained by intra vitam staining with an indicator, such as neutral red. Before drawing conclusions from these data one other fact may be mentioned. At the critical point the cilia are brought 
to rest at the end of the forward stroke. If the hydrogen ion concentration is increased suddenly to a much lower $\mathrm{pH}$. than that which suffices to bring about cessation of movement, the cilia come to rest not at the end of the forward stroke but in the contracted condition, i.e. at the end of the recovery stroke. We see then that the cilia are brought to rest in the relaxed condition at a certain degree of acidity depending on the penetration of the cell by the acid ; but if a greater quantity of acid is present, they are brought to rest in the contracted condition. This Gray interprets as due to the fact that the cell itself is more permeable to acid than the cilium. In hypertonic solutions arrest is brought about by a reduction not of the rate, as with stoppage in acid medium, but of the amplitude of the beat ; and the fact that the amplitude is affected by an increase in the osmotic pressure of the external medium suggests that withdrawal of water from the cell interferes not with the periodic liberation of energy but with some part of the contractile mechanism.

To bring all these phenomena within the scope of a single hypothesis Gray has suggested that the cilium flies forward owing to imbibition resulting from periodic liberation of acid. This is not essentially very different from a suggestion put forward many years earlier by Schafer. But direct proof of the production of acid in ciliary movement is lacking.

Turning now to the second aspect of the problem, that is, the relation of oxygen to the contractile mechanism, there is now satisfactory evidence of a close analogy between the ciliary and muscular tissues. The mechanical activity of cilia can be treated quantitatively by timing across a standard distance of gill filament or other ciliated epithelium the movement of a minute circular plate of platinum. The oxygen consumption of ciliated epithelium can be conveniently measured by the Barcroft manometer. When the rate of oxygen consumption and mechanical activity are plotted for various temperatures and reduced to the same scale of ordinates, the curves correspond closely (Fig. 10), showing that the rate at which oxygen is consumed is normally a function of the mechanical 
activity of the cell. But the same is true of a rhythmically contractile muscle such as that of the heart.

Engelmann maintained many years ago that the ciliated epithelium of the frog's œsophagus remains active for as long as two hours in an atmosphere of hydrogen, but regarded this

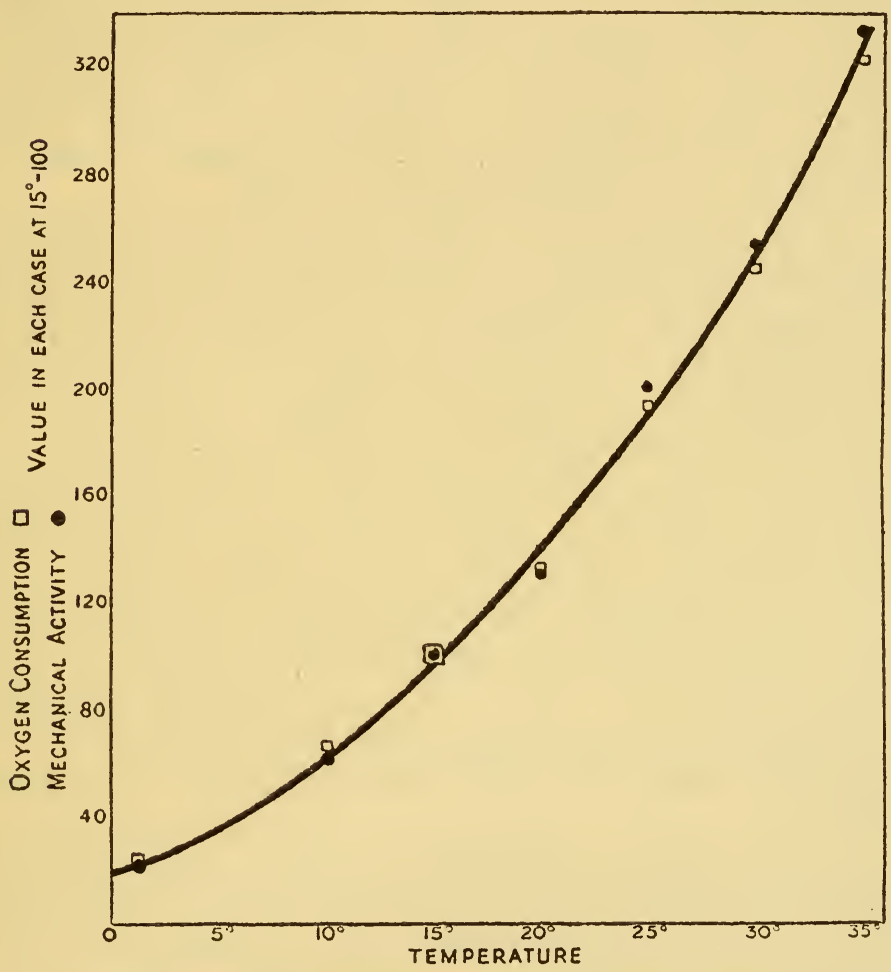

FIG. I0.-The relation of oxygen consumption and mechanical activity of cilia to temperature (after Gray).

as evidence that the cell stored oxygen in some intramolecular form. By spectroscopic examination of water in which hæmoglobin was dissolved, Gray has proved conclusively that in the gills of Mytilus ciliary movement continues long after all oxygen has been removed from the medium. When ultimately brought to rest by this means recovery is very slow, 
though intra vitram staining with methylene blue shows that the diffusion of oxygen back into the depleted tissues is rapid. The conclusion seems justified that while the ciliary mechanism is ultimately dependent on the presence of oxygen, oxygen is not a necessary factor in the contractile process, but only for the maintenance of the requisite conditions for prolonged activity. In other words; oxygen would seem to be concerned with the recovery process, as in muscle. When movement is abolished by deprivation of calcium or increased osmotic pressure of the medium, the amount of oxygen consumed is not affected for a considerable period of time.

By means of Barcroft's manometer it is also possible to obtain light on the nature of the substance on which a supply of chemical energy available for transformation into mechanical energy depends. If the ultimate fate of the substance is to be oxidised, the "respiratory quotient" or ratio of $\mathrm{CO}_{2}$ evolved to $\mathrm{O}_{2}$ consumed must be unity for carbohydrates, and about $0^{\circ} 7$ in the case of fats and proteins. Gray finds that the respiratory quotient for ciliary activity is about 0.8 , which implies that the substance used in ciliary activity is not exclusively or mainly of carbohydrate nature, a conclusion which agrees with the failure of micro-chemical methods to detect glycogen in the cells. Since fats are not stored by the ciliated epithelial cell, it would appear that the substance on whose energy the contractile mechanism depends is of a protein nature.

To sum up, the mechanism of ciliary activity may be analysed on the basis of Gray's experiments into three components; a reaction by which free energy is liberated from some chemical reserve, sensitive to monovalent ions (especially the hydrogen ion), a mechanism by which this free energy is transformed into mechanical energy, presence of calcium and a. certain osmotic pressure in the external medium being essential to its efficient working; and, finally, an oxidative recovery process which is necessary only for sustained activity.

Amoboid Movement.-Amœboid movement is the characteristic means of progression in certain Protista (Rhizopoda, Mycetozoa, etc.) and the wandering cells present in many 
Metazoa. Reference to the behaviour of leucocytes, phagocytes, etc., will be found in works on bacteriology and medical aspects of physiology. Attention will here be confined to the phenomena of amøboid movement, as they can be studied in free-living forms. For quantitative treatment of amœboid activity the only accessible criterion of the energy of movement is the rate at which the animal progresses. This has been studied in relation to changes in external conditions in a recent series of investigations by Pantin (1923-1925). Marine amœbæ were used in these experiments. Two species (referred to as type A and B) were used, both being of the "limax" form which progresses by protrusion of a single anterior pseudopodium, thus tending, in the absence of external interference, to move in a straight line. If the conditions of the medium were kept constant, Pantin found that the velocity of an individual amœba was constant to within 5 per cent. for periods of as long as twenty-four hours, and if the conditions are changed without irreversibly damaging the organism, the original velocity is regained when the initial state of affairs is restored. This velocity is readily observed by timing with a stop-watch the period which is required for an amoba to traverse a given number of divisions of the micrometer scale of the microscope ocular.

By this method Pantin has described the relation of amœboid activity to osmotic pressure, temperature, and hydrogen ion concentration of the external medium. The amœbæ studied were, like many other contractile mechanisms, very insensitive to $\mathrm{OH}$ ions. On the other hand, amœboid activity is reduced with mineral acids to zero immediately on the acid side of neutrality, to be precise at a $\mathrm{pH}$. of 6.8. As long as the hydrogen ion concentration is kept at a level above $\mathrm{pH} .4^{\circ} \circ$ the stoppage is reversible, movement recommencing when the organisms are transferred to an alkaline medium. But below this $\mathrm{pH}$. limit cytolysis occurs. The velocity of progression increases continuously up to $\mathrm{pH} .9^{\circ} 6$; and the velocity curves for hydrochloric, sulphuric, butyric, lactic, and acetic acids closely agree (Fig. II).

It has already been suggested that production of acid in the 
cilium, as in muscle, is an essential part of the contractile mechanism. The same appears to be the case with amœboid
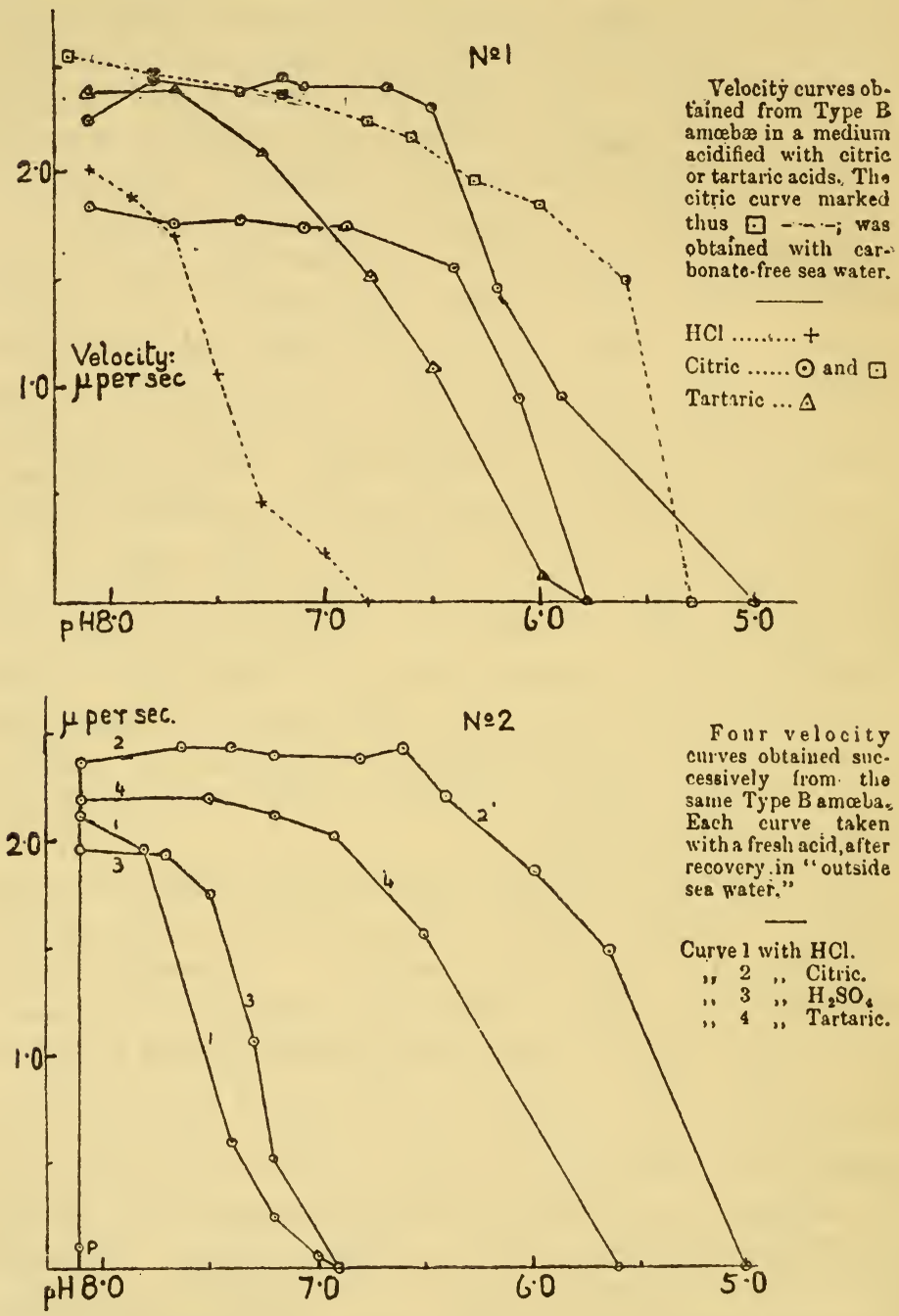

FIG. I I.-Relation of hydrogen ion concentration to the velocity of Amœboid movement (after Pantin).

movement. Bethe, Harvey, and others have used dyes which stain the living cells and are themselves indicators of hydrogen 
ion concentration, to determine the penetration of cells by acids and alkalis. Pantin has applied the same method of attack to test whether there is an increase of hydrogen ion concentration within the cell during pseudopodium formation. The dye successfully employed for this purpose was neutral red, which has its turning point in the neighbourhood of absolute neutrality (becoming red on the acid side), is nontoxic, readily absorbed by protoplasm, and has a negligible protein error. The colorometric determination of protoplasmic $\mathrm{pH}$. is facilitated by focussing an image of the standard indicators on the observation slide by aid of the achromatic condenser.

By this method Pantin found that the hydrogen ion concentration of the normal endoplasm and ectoplasm respectively corresponded to a $\mathrm{pH}$. of about $7^{\circ} 6$ and $7^{\circ} 2$ (in the resting amoba the difference between ectoplasm and endoplasm tended to be rather less than during active progression), but the formation of a pseudopodium is preceded by a local intensification of the red tint, indicating increased hydrogen ion concentration; while retraction of the pseudopodium is accompanied by a local reduction of hydrogen ion concentration.

Such considerations have led the above-named author to suggest an hypothesis of the mechanism of amœboid action on rather different lines from those advocated by previous workers. These for the most part have sought to interpret pseudopodium formation as the consequence of a local lowering of surface tension in a system which is for the purpose regarded as a fluid drop in an immiscible medium. There are in the surface phenomena exhibited by simple fluid systems remarkable analogies to the behaviour of the amœba. Bayliss quotes from Rhumbler a picturesque phenomenon which occurs when particles of glass fibre coated with shellac are brought into contact with a globule of chloroform suspended in water. The chloroform drop first envelops the particle, then, after sufficient time has elapsed to permit of the shellac being dissolved away, rejects the glass remainder, thus resembling an amœba swallowing a diatom and defæcating the insoluble 
materials of the cell-wall. The disadvantage of surface tension theories is that the results of microdissection studies reveal the gelated character of the ectoplasmic membrane. In the "limax" form the body of the organism is to be regarded, according to Pantin, as a contracting tube of ectoplasmic gel closed at its hind end. Endoplasm is continuously streaming from a point of liquefaction on the inner side of the ectoplasm at the tail end, while the fluid ectoplasm at the anterior extremity is continuously adding to the contracting tube by becoming gelated round the sides of the advancing pseudopodium. The outer layer of the amœba is apparently a lipoid-protein system in the gel state, undergoing liquefaction, as Pantin's observations indicate, in consequence of a local increase of hydrogen ion concentration. Pantin argues that it is natural to regard the swelling and liquefaction of the advancing tip of the pseudopodium as a process of imbibition. By surface coagulation the tube is always adding to itself in front, and always contracting by synerezis (withdrawal of water) as the hydrogen ion concentration falls in the region furthest behind.

The variation of amœboid activity with temperature is seen in Fig. 12. The optimum temperature for the amœbæ which Pantin studied is remarkably low-about $20^{\circ} \mathrm{C}$. The effects of changes in temperature below $15^{\circ} \mathrm{C}$. are completely reversible. But when raised from a lower temperature to one near the optimum or one above it, the previous rate is not regained when the amœba is brought back to a lower temperature. One of the factors upon which amœboid activity depends is therefore some substance or structural arrangement of substances-probably an enzyme-which is progressively destroyed near or above the optimum temperature. If the temperature is raised from, say, $10^{\circ}$ to $\mathrm{T}^{\circ}$ (above the optimum) and then rapidly lowered to $10^{\circ}$, the resulting velocity has a precisely similar relation to the initial velocity at $10^{\circ}$, as has the observed velocity at $\mathrm{T}^{\circ}$ to the velocity that would have been observed at $\mathrm{T}^{\circ}$ if no destruction had taken place, since the amount of destruction is identical in both cases. In this way the observed temperature curve can be extrapolated 
(Fig. I2). Analogous phenomena are seen in the heart of the crab Maia. The low temperature at which irreversible changes in the physical state of protoplasm are produced in many marine organisms is well worth studying in its ecological bearing on problems of distribution.

The relation of electrolytes to the amœba has recently been studied with microdissection technique by Chambers and Reznikoff (1925). Their results present a remarkably close

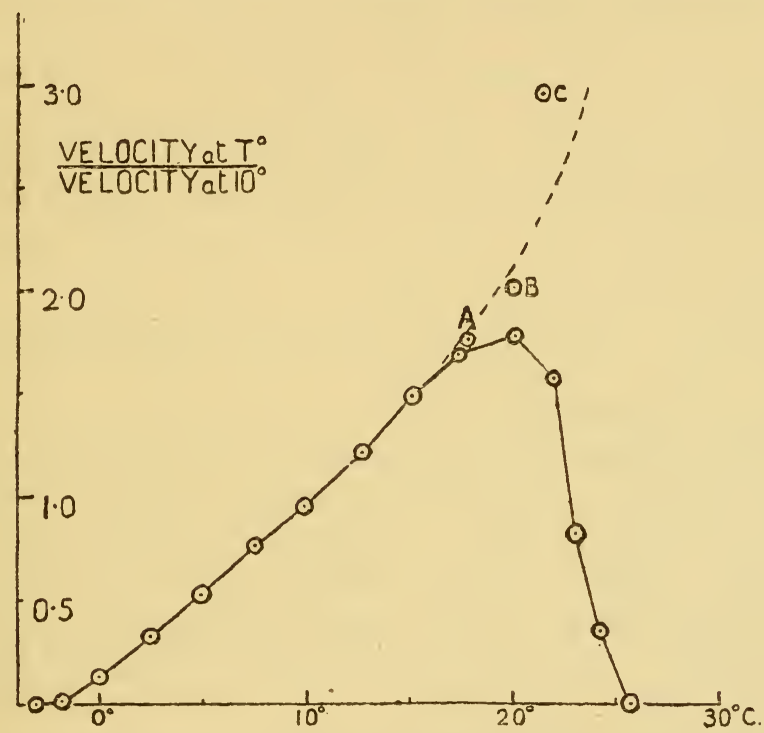

FIG. I2.-Effect of temperature on velocity of Amœboid movement (Pantin).

analogy to the phenomena described by Clowes in oil-water systems. When solutions of $\mathrm{NaCl}$ and $\mathrm{KCl}$ are injected into the living amoba a liquefaction of protoplasm takes place in the neighbourhood of the injected area. When the chlorides of calcium or magnesium are injected there is, however, an immediate solidification of the adjacent protoplasm, the affected portion being pinched off when calcium chloride is used. In suitable proportions mixtures of sodium and calcium chlorides have neither of these effects $(\mathrm{rCa}: 52 \mathrm{Na})$. There 
is complete antagonism between the sodium and calcium ions. This is also true of potassium and calcium, but the critical ratio is not the same.

When amœbæ are torn in water by Chamber's technique the surface is rapidly repaired after outflow of some of the cell contents. Slight tearing in $\mathrm{NaCl}$ or $\mathrm{KCl}$ prevents any repair in solutions of $\frac{\mathrm{M}}{\mathrm{I} 3}$ concentration. With weaker solutions repair takes place with increasing ease in $\mathrm{NaCl}$ as the dilution is increased. In solutions of $>\frac{\mathrm{M}}{6.5} \mathrm{CaCl}_{2}$ or $>\frac{\mathrm{M}}{5^{2}} \mathrm{MgCl}_{2}$ repair does not occur; the surface sets into a solid mass. The antagonism between the monovalent and divalent ions is seen again in this process : in a solution of $\mathrm{NaCl} \frac{\mathrm{M}}{13} \cdot \mathrm{CaCl}_{2} \frac{\mathrm{M}}{52}$ or of $\mathrm{KCl} \frac{\mathrm{M}}{\mathrm{I} 3} \cdot \mathrm{CaCl}_{2} \frac{\mathrm{M}}{208}-\frac{\mathrm{M}}{4 \mathrm{I} 6}$ repair of a torn surface takes place in the normal manner.

Pantin (1925) has also investigated the relation of electrolytes to the velocity of amœboid movement, and has obtained somewhat analogous results. The marine amœba is destroyed in isotonic solutions of the chlorides of the four principal kations present in sea water (i.e. sodium, magnesium, potassium, and calcium). For actual movement to take place calcium must be present. The addition of a minute trace of calcium to a solution of sodium or potassium alone permits movement to continue for a short time. Movement can be prolonged indefinitely by increasing to a certain optimum value the proportion of calcium to sodium in a solution containing these two kations alone. In this relationship calcium can be replaced by strontium, but not by any other kation. In a mixture of sodium and calcium, sodium may be replaced by any alkali metal; but it is found that the optimum ratio of calcium to monovalent ion with respect to the velocity of amœboid movement differs for different alkali metals, increasing with the atomic weight of the latter. In the presence of a trace of calcium the addition of magnesium to a certain optimum 
ratio antagonises the effect of pure solutions of the monovalent ions on the velocity of amœboid movement, the optimum ratio differing again with the monovalent ion used. Nevertheless, amœboid movement, which, as stated, ceases in pure solutions of either calcium or magnesium, can be prolonged in mixtures of the two, this antagonism being evidently of a different nature from the antagonism of either to monovalent ions.

The Pigmentary Effector System.-Colour response in coldblooded vertebrates and crustacea has been regarded by some investigators as a form of amœboid activity. The power to respond to environmental influences in changes in bodily colour is also met with in molluscs where the pigmentary organs are muscular structures. In vertebrates and crustacea colour response is brought about by the dispersion or aggregation of pigment granules in special cells or groups of cells, which may be described as pigmentary effectors to distinguish them from the chromatophores of molluscs. The pigmentary effectors of vertebrates (reptiles, amphibia, and fishes) are unicellular organs charged with pigment granules. Only one type has been subjected to careful experimental investigationthe melanophores or black pigment cells. According to some authors the concentration of pigment granules in the "contracted" condition is associated with the active withdrawal of the cell processes, which are supposed to lie in preformed lymph spaces. The majority of recent observers, with the notable exception of Graham Kerr, however, do not regard the process as analogous to amœboid movement, but consider that the pigment granules stream to and fro within fixed cell processes.

The co-ordination of vertebrate pigmentary response with environmental agencies will be considered in a later chapter (Chapter VII). Here we are concerned chiefly with the properties of the pigmentary effector as an isolated organ. If the contracile mechanism is one of dispersion and aggregation of granules, it is possible that the visible responses of pigmentary effectors are more directly related to known properties of colloid systems than those of any of the mechanisms so far discussed. Up to the present there has been little quantitative 
work on the responses of pigmentary effectors. To Spaeth (I914-I9I8), however, we owe the elaboration of an ingenious method by which such observations may be made. Spaeth fixes scales of the Atlantic minnow Fundulus in a glass container, through which water circulates, on the mechanical stage of a microscope. By connecting the adjusting screw of the latter to a lever writing upon a smoked surface, the migration of the pigment granules is recorded as the observer adjusts the screw so that the distal extremity of the pigment mass is in alignment with a particular scale mark on the micrometer (Fig. 13). Melanophores of Fundulus do not react to visible light, but they respond to electrical and chemical stimulation. Single make shocks do

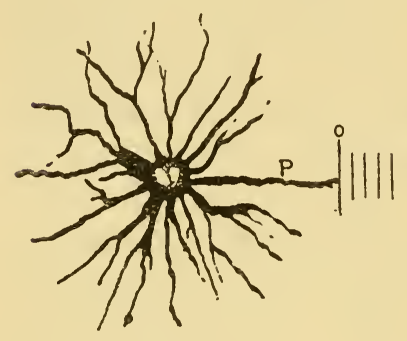

ค

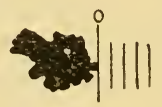

B

FIG. 13.-Melanophores of Fundulus (Spaeth). (A) expanded; (B) contracted. about 5 secs. before contraction begins. Single make shocks successively applied produce a summated effect if the intervening period is not more than $2-3$ secs.

According to Spaeth, neutral electrolytes exert a specific physiological action upon fish melanophores. Sodium chloride (normal saline) promotes melanophore expansion; while potassium salts and salts of the alkaline earths bring about immediate contraction. Distilled water always produces this latter response. By combining these salts in such proportions that their characteristic effects are balanced, Spaeth produces a medium in which, after a preliminary contraction, the melanophores display partial expansion, so that, when a pharmacological reagent is dissolved in such a balanced solution, the 
specific action of the added substance in either direction can be conveniently observed. He recommends the following formula for Fundulus : 6 vols. $\mathrm{N} / \mathrm{ro} \mathrm{NaCl}$, I vol. $\mathrm{N} / \mathrm{I} \circ \mathrm{KCl}$, 0.35 vol. $\mathrm{N} /$ ro $\mathrm{CaCl}_{2}$.

The most remarkable result which emerges in this connection from Spaeth's experiments is the effect of barium salts, which, as is well known, exercise a very characteristic excitatory action upon true contractile tissues. After treatment of scales for ten minutes in $\mathrm{N} / \mathrm{I}$ o $\mathrm{BaCl}_{2}$ no sign of recovery may appear for as much as half an hour, during which the melanophores remain completely contracted. After this period of quiescence, the melanophores in the periphery of the scale abruptly expand

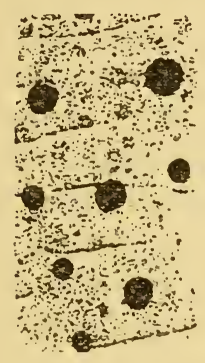

$a$

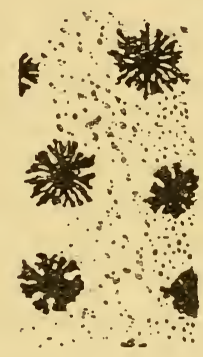

$b$

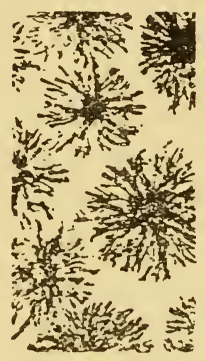

c

Fig. 14.-Melanophores of Fundulus (Spaeth).

Effect of adrenaline $(a)$ on the partially contracted pigmentary effectors $(b)$; effect of adrenaline after previous immersion in ergotoxine $(c)$.

and contract almost at once. After a brief interval a second expansion wave appears at the periphery, and melanophores lying nearer the centre begin to behave in a similar manner. This time, however, the peripheral melanophores expand more completely. Eventually after about an hour the wave of rhythmic expansion and contraction extends to the centre of the scale so as to include all the melanophores, which pulsate between the extremes of contraction and complete expansion. This pulsation may continue for several hours.

The Crustacean chromatophore consists essentially of a centre, branches radiating therefrom in a luxuriantly ramifying system. In the adult forms of most Crustacea which have been 
thoroughly investigated, the chromatophores are highly complex structures of a multicellular or cœnocytic character. However, the structure of the Crustacean chromatophore differs very widely in the different groups and in different regions of the same individual. A necessary prerequisite to quantitative treatment in this case is a clear recognition of the normal behaviour of the pigmentary effector organs. The phenomena of colour response in Crustacea may be illustrated by reference to the Schizopod Macromysis and the Decapod Hippolyte, as described by Gamble and Keeble (1900-1906).

In Macromysis the chromatophores are localised in definite regions lying for the most part in a deep situation where their action is rendered visible by the translucent nature of the integument. The majority of the chromatophores contain a large amount of dark brown pigment and a smaller quantity of a substance which by reflected light has a white or yellow hue, but appears greyish by transmitted light. On a sandy shore the animal appears transparent and colourless or greyish in tint; amid dark surroundings and in deeper water, its colour deepens and a pattern becomes manifest in the form of paired arborisations of yellowish-white upon a brown background corresponding to the chromatophore centres. In the transparent, colourless, or greyish form the brown and yellow pigment is withdrawn into the central body of the chromatophores; in the dark condition the brown and yellow pigments diffuse along separate paths throughout the interlacing tracery of branches; the yellow pigment does not mix with the brown, and it responds to stimuli at a different rate.

In Hippolyte we have to draw a distinction between two modes of colour response occurring normally in nature. By day the adult prawns are of a reddish-brown or bright green hue according to the tint of the seaweeds to which they are attached. Whatever the diurnal colour of Hippolyte may be, however, it changes at or soon after nightfall to a beautifully transparent blue or greenish-blue. The depth of the nocturnal blue corresponds to the intensity of the diurnal colour ; that is to say, dark brown prawns become deep blue and light ones become pale blue. The nocturnal tint ordinarily persists till 
daybreak, when the green and brown varieties represent interchangeable states. Green Hippolytes placed on brown weeds may conserve the green colour for about a week before assuming the brown condition. The extent and rapidity of the change varies very much from one individual to another. There are three chromatophore pigments involved: red, yellow, and blue. In addition to the more deep-seated elements in the nerve cord, viscera, and principal muscles, the epidermis is itself in Decapod Crustacea richly charged with chromatophores. These consist of groups of as many as eight pearshaped cells with tubular branches, each containing pigment of one colour, yellow or red. Blue pigment is present in the tracts along which the red pigment flows, but is also found in branched cells lying among the pear-shaped cells which contain the yellow or red pigments. The reddish-brown tones are associated with the extension of the red pigment into the tubular processes of the chromatophores. In the green condition the yellow pigment extends throughout the branches of the cells in which it occurs, but the red pigment is retracted, its place being occupied by the blue substance. Finally, the nocturnal blue colour is produced, when both yellow and red pigments are withdrawn from the branches, but the blue substance diffuses along them.

The bulk of recorded observations on Crustacean chromatophores are concerned with the more immediate problem of analysing what forces incident to the animal's environment promote colour response, and the channels through which the different stimuli gain access. Both Crustacean and Piscine chromatophores, however, offer admirable material for studying the physical chemistry of the cell.

Whereas in Fishes and Amphibia, though possibly not in Reptiles, light and dark backgrounds appear to act merely by modifying the intensity of illumination, in the case of Crustacea it would seem from Gamble and Keeble's researches that something besides intensity is involved. To detail the chief colour phases induced by various light conditions in Macromysis and Hippolyte, it will be necessary to call attention to a difference between the two genera. Freshly-caught Mysids 
and some shrimps, e.g. Palæmon, generally have their pigments moderately expanded; and this represents the condition of the chromatophores of the same animals when kept in the light in glass containers. In Hippolyte, on the other hand, the yellow and red pigments are always fully expanded in the day and fully contracted at night. In darkness the yellow, red, and brown pigments of both Hippolyte and Macromysis become completely retracted into their chromatophore centres, which then appear as minute dots so widely separated that they do not interfere with the translucency of the body as a whole; the time required to produce the contraction ranges from a few minutes to an hour or two, varying considerably with the time of day and the condition of the animal.

Paradoxically enough, the same result is brought about by exposing Crustaceans to a pure white reflecting background, such as a porcelain surface. When subjected to such treatment there occurs a condition essentially the same as the nocturnal state accompanied in Hippolyte by diffusion of the blue pigment already referred to, and conditioned in both Macromysis and Hippolyte by the complete retraction of the other pigments into the chromatophore centres. This response is exceedingly rapid, being accomplished in about a minute or even less. The effect of a dull black, light-absorbing background is no less surprising. In Hippolyte itself it cannot be demonstrated because the red and yellow pigments are, as stated, always expanded fully in daylight; but in Macromysis and Palæmon, where expansion on a neutral background is incomplete, the normal accompaniment of transferring individuals to dark-bottomed vessels is to induce a condition of more extreme outward migration of the chromatophore pigments from the chromatophore centres into the branching processes, so that the animal assumes in the case of Macromysis nigra a black aspect and in the case of Palæmon serratus a speckled brown coloration. These colour phases persist so long as the light conditions remain unchanged. At nightfall the pigments which have expanded in the "dark background phase," are withdrawn; but the expanded phase is again resumed on the morrow. The white background contracted 
phase and the black background expanded phase are produced no matter whether the light intensity is high or low, variable or constant.

The chromatophores of isolated strips of the integument of the shrimp react to bright light by expansion. This suggests that there is a direct response of the chromatophores in Crustacea. After amputation of the eyes in Macromysis or Palæmon the chromatophore pigments, instead of assuming the contracted phase, expand when the animal is placed on a light-reflecting bottom; in fact, in the case of Palæmon, a deep chocolate colour even darker than the normal expanded condition associated in the intact animal with a black background is produced. But the contracted phase characteristic of the nocturnal state occurs at night in Hippolyte even after the eyes have been removed. These data permit the inference that the nocturnal-diurnal rhythm depends on the direct reactivity of the chromatophores to the intensity of illumination, and the white and black background responses are determined by events conditioned by photic stimulation of the organs of vision.

The supposition that the eye exerts its influence upon colour response in virtue of the intensity of illumination alone is adequate to explain the peculiar reversal of response in seeing and blinded salamander larvæ as described by Babak and Laurens. But it offers no explanation of the fact that a bright white background which scatters light produces in the intact shrimp a response similar to darkness, while a dull black background which reduces the intensity of illumination acts in the direction of intensifying the diurnal state. Some other factor besides intensity of illumination is involved, and the transcending importance of this factor is clearly seen in experiments which are described as follows in Keeble and Gamble's own words :-

"To show how, compared with this influence of background, that of light intensity is of small importance, we mention the following experiment which we have often performed with Hippolyte and Macromysis. We take with us on a collecting expedition four jars, two of glass wrapped round with black 
cloth and two of porcelain. For one of the former and two of the latter we provide covers of white or black paper pierced with several pin-holes. As the animals are caught they are distributed between the four jars. When brought into the laboratory and examined, the animals in "open " porcelain and in "pin-hole" porcelain are found to be in the fully contracted phase. Now the light intensity in the open jars is far higher than that to which the animals are subjected before capture, and the intensity in the pin-hole jars is probably far lower. Any effect which a raised or lowered light intensity might produce is swamped by the background effect. The latter is of such a nature that an absorbing (black) background induces expansion, and a scattering (white) background produces complete contraction, and these effects are produced in the faintest (pin-hole) light."

Apart from the intensity of illumination, an essential difference between the condition of a shrimp exposed to black (absorbing) or white (scattering) background is to be sought in the direction of the incident rays impinging upon the eyes, which as we have seen are the receptor organs involved in the background response. When placed against a mirror background which reflects incident light mainly in one direction, the animals display a state of partial expansion and not the complete contraction characteristic of exposure to a white surface which scatters light rays in all directions. It would appear, then, to quote the same authors once again, that "it is, in some way or other, the ratio direct/scattered light which determines " the background reaction. This interpretation implies a dorsiventral differentiation of the photoreceptive elements of the eye. But whatever be the nature of this dorsiventrality, it does not reside in any permanent structural arrangement of the retinal elements, for illumination of the animal from below against a white surface calls forth the characteristic transparency of the contracted phase.

Keeble and Gamble have, in addition to the foregoing analysis of the more rapid responses to light, darkness, and light or dull backgrounds, attempted to analyse the factors involved in the production of the different colour forms of 
Hippolyte. Hippolyte, as we have seen, displays a remarkably close resemblance of bodily colour to the hue of the seaweeds on which it resides. While this similarity is striking, there are in reality two sharply defined categories of colour forms, greens on the one hand, and reds or browns on the other. The green state corresponds to an "expansion" of the yellow pigment, the red being withdrawn into the cell bodies whose branches are suffused with the blue "nocturnal" substance; and the brown or red colour forms display "extension" of the red pigment into the cell branches; we should be tempted to presume that sympathetic coloration depends on the wavelength of the light reflected respectively by green or brown weeds ; this interpretation is not, however, compatible with the results of experiments in which the effect of light of different wave-lengths has been put to the test.

In carrying out experiments on the effect of monochromatic light of different qualities, it is evident from what has already been stated that the direction of the incident rays must be taken into account by controlling each experiment by comparison of the response evoked both by absorbing and dispersing backgrounds. Monochromatic lights, whether red, yellow, green, or blue, acting on a black background, produce pigment expansion, the yellow pigment reacting more readily than the red. Monochromatic lights, whether red, yellow, green, or blue, acting on a white background, induce, like white light, the transparent condition. Thus the quality of the light does not seem to be the effective factor which evokes "sympathetic" coloration in Hippolyte. It would, therefore, seem that the slowly effected transition from one colour to another, when individuals are transferred from green to red weeds or vice vers $\hat{a}$, is in all probability a reaction to the different intensities and not to the predominant wave-lengths of the light reflected from the differently coloured surfaces of the green, red, or brown weeds. It should be added, however, that the diurnalnocturnal rhythm of colour change is in part an automatic process whose periodicity is independent of external stimuli once there is an appreciable tendency to contract by night or expand by day, when the animals are kept in continuous light 
or darkness. It is to be hoped that in the near future the physicochemical properties of chromatophores will be the subject of investigations analogous to those on ciliary and amœboid activity described at the beginning of this chapter.

\section{FURTHER READING}

Gray (1922-3). The Mechanism of Ciliary Movement, I-IV. Proc. Roy. Soc. B. 93-95.

Pantin (1924). On the Physiology of Amœboid Movement, II. Brit. Journ. Exp. Biol. I.

Chambers and Reznikoff. Proc. Soc. Exp. Biol. Med. 22, 1925.

Spaeth (1916). Responses of Single Melanophores to Electrical Stimulation. Am. Journ. Physiol. 41.

KafBle AND Gamble (1904-6). The Colour Physiology of the Higher Crustacea. Phil. Trans. Roy. Soc. 


\section{CHAPTER III}

\section{SECRETION}

THE last form of response which we shall consider is secretion. The phenomena of secretion have been studied far more from the standpoint of their relation to other functions than with a view to throwing light on the mechanism by which the gland cell elaborates and discharges its specific products of its activity. In vertebrates secretion has been studied especially in relation to the digestive processes (which will be discussed in a later chapter), to the elimination of waste products (renal secretion), heat regulation (sweat glands), and reproduction (the mammary apparatus, oviducal secretions, etc.). Slime-secreting skin glands have also received some attention. But the study of other animal groups opens up an immense variety of secretory mechanisms, some of which are doubtless of considerable bionomic interest as a means of defence or attack. Our knowledge of a few of these will be briefly indicated by reference to such phenomena as bioluminescence, gas secretion, silk formation, etc. Others such as the secretion of ink in cephalopods, of calcareous matter forming the tubes of sedentary animals or the exoskeletons of mobile forms, etc., can only be mentioned in passing. The importance of mucous glands in relation to digestion will be touched on under that heading. There is a vast field for biochemical research awaiting inquiry in connexion with the comparative physiology of secretion.

Renal Secretion.--Concerning the mechanism of secretory activity, perhaps the study of the vertebrate kidney has yielded more valuable information than any other secretory organ. The characteristic differentiation of each glandular element of the vertebrate kidney into a capsular portion and "renal 
tubule " has focussed an immense amount of research on the attempt to define the rôle of these two structures in the process by which non-volatile waste products are eliminated from the body. Since the secretion includes practically all the crystalloidal constituents of the blood plasma, though these are neither individually nor collectively present in the same concentration as that in which they occur in the blood, it is attractive to explore the possibility that the whole process is composed of two distinct phases, one consisting of the separation of a fluid identical in crystalloidal constitution with the blood-a deproteinised plasma filtrate formed by exudation from the capillary walls of the glomerulus, and a subsequent process involving the specific activity of the glandular epithelium of the tubule and resulting in the differential concentration of each of the crystalloidal constituents, either by secretion or by reabsorption or both.

Some colour is lent to this interpretation by a line of experimentation which is possible owing to the peculiar vascular arrangements which exist in the amphibian kidney, where the glomerular blood supply is derived from the aorta (via the renal arteries), while the renal portal veins only supply the tubules. It is thus possible in the frog, to cut off the glomerular blood supply while leaving intact that of the tubules, or to perfuse separately the vessels of the capsules and renal tubules.

When the glomerular blood-supply is cut off the secretion of urine stops. It is still possible, by injection of a solution of urea, to induce a flow of acid urine containing chlorides, sulphates, and urea, but the quantity is small compared with the diuresis produced by the same method in the intact kidney. Perfusion of the arterial (glomerular) supply of the kidney with Ringers' solution at normal aortic pressure $(20-24 \mathrm{~cm}$. in the frog) induces a copious flow of urine (of somewhat more dilute concentration than the perfusion fluid). Perfusion of the renal portal system at normal venous pressure does not result in production of urine.

Further support for the belief that the initial stage in the process of renal secretion is the separation of a deproteinised 
plasma filtrate is derived by studying the physical conditions under which urine is produced. If the capsular membrane is impermeable to the colloidal constituents of the blood, work must be done (I) against the osmotic pressure of the proteins, etc., in removing a filtrate of identical crystalloidal composition ; (2) in driving the filtrate along the narrow lumen of the tubules at the observed rate of flow. From the first consideration it follows that no secretion of urine can take place when the bloodpressure falls to a value below the osmotic pressure of the serum proteins. As a matter of fact, secretion of urine has long been known to cease in the mammal when the arterial bloodpressure falls below about $35 \mathrm{~mm}$. of mercury. Starling (1899) was the first to recognise the theoretical significance of this fact, and on comparing the osmotic pressure of a crystalloidal filtrate separated from blood by a gelatine filter with the osmotic pressure of the original serum, showed that the osmotic pressure of the blood colloids is actually about $30 \mathrm{~mm}$. of mercury. Conversely, urinary secretion can be prevented by increasing the pressure in the ureter so that the difference between the pressure of the arterial blood and that of the fluid in the capsule is of the same order as the osmotic pressure of the serum proteins. Later it was shown by Barcroft and Straub (I9II) that a great increase of urinary secretion follows replacement of normal blood by a suspension of red corpuscles in Ringers' solution without any rise in arterial pressure or increase in oxygen consumption by the kidney.

However, the possibility that the first stage of renal activity is a process of simple filtration deriving its energy from the heart beat, does not throw any light on the essentially secretory function of the kidney, namely, that of modifying the composition of the filtrate in such a way that the concentration of each of the crystalloidal constituents is finally different from its concentration in the plasma. To effect this, work must be done by the epithelial portion of the tubule. Barcroft and Brodie found in experiments on the gaseous metabolism of the active kidney that the respiratory quotient (ratio of $\mathrm{CO}_{2}$ given off to oxygen absorbed) is practically unity ; i.e. that the activity 
of the kidneys involves oxidation of carbohydrate material, as in the case of striped muscle.

It has been seen in a previous chapter that activity of muscle and cilia depends on an anærobic reaction, oxidative processes being associated only with the recovery process. That this is true of secretory response is not easily demonstrated in an organ which secretes more or less continuously like the kidney. But in the case of salivary secretion, which can be controlled for the exigencies of experiment by means of its nervous connexions, Barcroft and Piper (I9I2) were able to demonstrate that the maximal rate of oxygen consumption occurred appreciably later than maximal rate of flow from the gland; and that the increased oxygen consumption accompanying secretory activity in the salivary gland of the mammal outlasts by a considerable interval the cessation of active secretion. This clearly points to the probability that in the mechanism of secretion as in that of muscular and ciliary activity oxidative reactions are especially characteristic of the recovery phase.

For a detailed discussion of the evidence concerning the way in which the adjustment of concentration of each of the constituents of the urine is carried out in the renal tubules, the reader should consult Cushny's monograph on the secretion of urine. Two rival hypotheses have been advocated. According to one the renal tubules selectively absorb from the filtrate; according to the other they differentially remove from the blood appropriate quantities of the urinary constituents. It is certain that dyes are excreted by the cells of the renal tubules, and innumerable researches of this kind have been prosecuted in connexion with the segmental excretory organs and malpighian tubes of Arthropods and the nephridia of worms. But it is difficult to see what light they throw on the normal elimination of salts and nitrogenous waste from the body fluids. The fluid of the excretory glands of molluscs is particularly rich in uric acid and other purine bodies. A filtration mechanism in these animals is, however, excluded by the very low blood-pressures which are found in all Invertebrates except Cephalopods. It is possible that reabsorption and 
secretion in the ordinary sense each play a part in the activity of the renal tubules of the Vertebrate, and evidence relating to one constituent of the urine is not necessarily valid as regards another.

Nitrogenous Excretion (after v. der Heyde, J. Biol. Chem. 46).

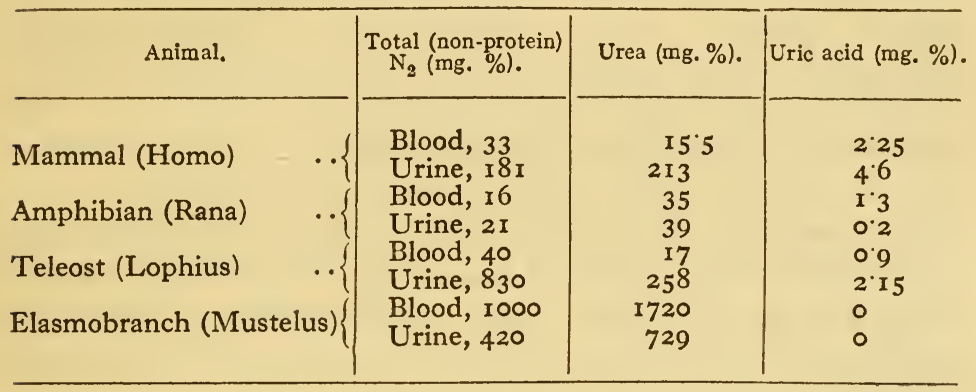

Looking at the alternative of secretion and reabsorption from the standpoint of comparative physiology, it seems likely that a thorough comparison of the state of affairs in fishes with that which exists in land vertebrates would well repay investigation. For in fishes the blood from the heart encounters the resistance of the gill capillaries before reaching the kidneys by way of the dorsal aorta ; the pressure of blood in the dorsal aorta is therefore extremely low even as compared with that of the frog. Exact data are unfortunately lacking, but it seems unlikely that there is ever a blood-pressure in the renal vessels of the fish sufficient to overcome the osmotic pressure of the blood colloids. If this is really the case, filtration clearly plays no part in the renal function of fishes ; and the hypothesis of reabsorption cannot be applied to them. The amount of urine secreted is, according to Denis, about I c.c. per kilo body weight per hour in the elasmobranch; and destruction of the cord, which would presumably lower the blood-pressure, does not reduce the output. At the same time, the distribution of nitrogenous (non-protein) materials in blood and urine is not very different in Teleosts from the condition found in land vertebrates (see table). In Elasmobranchs an anomalous feature is the large amount of urea present in the blood and 
tissues. According to Baglioni (1903) and Mines (1912), addition of urea to the saline medium is essential to the maintenance of activity in the artificially-perfused heart of Elasmobranchs.

Bioluminescence.-Of all forms of secretion which are of interest from a bionomic standpoint none have received so much attention as the phenomena of light-production. Bioluminescence is widely distributed throughout the animal kingdom, and is also found among bacteria and fungi. It is met with in many Protozoa (e.g. Noctiluca); in representatives of all groups of Cœlenterates, several Polyzoa (e.g. Membranipora) ; Polychætes (e.g. Chætopterus) ; Ophiuroids, Urochorda, many crustacea (e.g. Cypridina), Myriapods and Insects (e.g. Lampyris), many Cephalopods, a few other molluscs (e.g. Pholas), and, among Vertebrates, in some genera of fishes.

The actual intensity of illumination produced by animals is hardly ever such as to bear the scrutiny of the light-adapted eye. In some forms the oxidative process involved proceeds more or less continuously, independently of stimulation, as in bacteria and a few fish. More generally it is an intermittent form of activity, luminescence occurring only in response to stimulation. In some cases, e.g. among Ctenophores, light has an inhibiting influence. Previous exposure to illumination is not essential to photogenic response in animals. The most interesting physical aspect of the phenomenon is that the light emitted is cold. Within the limits of experimental error a hundred per cent. of the radiant energy emitted is light. Thus, though feeble in quantity, light-production in animals is prodigiously more efficient than any ordinary artificial source of illumination.

The organs concerned with light-production may be divided into two categories, according as the production of luminous material is extra-cellular or intracellular. In the former category, exemplified by Pholas, Chætopterus, Cypridina, and Myriapods, are included those cases in which a slimy secretion containing the phosphorescent substance is produced by unicellular glands. These may be either scattered diffusely 
over the whole surface of the body (as in Chætopterus); restricted to various regions-narrow bands on the siphon and mantle and a pair of triangular regions near the retractor muscle in Pholas ; or more definitely localised, as in Cypridina, which possesses on the upper lip above the mouth, a luminous gland, made up of spindle-shaped cells each opening by a separate pore with a kind of valve.

Intracellular light-production is characteristic of the more specialised types. In this category are the complex photogenic organs of insects, some crustacea, cephalopods and fishes. In the fireflies the photogenic organ develops from the fatbody and consists of a mass of granular luminescent cells abundantly supplied with nerve fibres and tracheæ, and enveloped above by a layer of supposedly reflecting cells which probably scatter incident light on account of the crystals of xanthin, urates, or other purine derivatives contained in them. In some of the shrimps (Sergestes), Cephalopods (Sepia), and fishes (Stomias) the photogenic organs are still more elaborate and diffusely scattered over the body. In these forms the photogenic organ possesses not only a reflector behind the photogenic cells, but in addition a cuticular lens, and in one genus of fishes it is even endowed with an iris diaphragm by which flash effects are produced. In general, photogenic organs are richly innervated, and there is no special phyletic or bionomic significance to be attached to the particular structural arrangement. Both intracellular and extracellular types occur within the crustacea.

For the production of light by the organism it has long been known that oxygen and moisture are essential. Robert Boyle (I665) showed that rotten wood infested with luminous fungi ceases to glow if placed in a vacuum; and Spallanzani lifted the subject out of the domain of vitalism by showing that the luminous material of medusæ, if dried, would emit light when water was added. Pyrosoma, Pholas, Phyllirhœ, fireflies, Pyrophorus, copepods, ostracods, pennatulids can all be desiccated without destruction of the luminescent material. Desiccated ostracods and copepods will luminesce in the presence of moisture after being kept for several years. Though 
total absence of oxygen brings about cessation of luminescence in the moistened material, a very low tension of oxygen $(3 \mathrm{~mm}$. in the case of Cypridina) suffices to maintain the emission of light. Measurements of the electrical conductivity of luminescent solutions prepared in this way by E. N. Harvey show no progressive increase in $\mathrm{H}$-ion concentration indicative of $\mathrm{CO}_{2}$ production.

Bioluminescence, like the secretion of digestive fluids, affords an instance of the production of the substances known as enzymes for specific ends. And a few words may here be inserted with reference to the conception of an enzyme. According to their velocities, molecular reactions may be divided into two categories, those involved in the familiar methods of volumetric analysis, where the combination of reacting substances is practically instantaneous-e.g. precipitation of barium salts in the presence of $\mathrm{SO}_{4}$ ions or the union of hydrochloric acid gas with ammonia-and a large class of organic reactions, such as the saponification of esters or inversion of cane sugar, for which an appreciable interval must be allowed to elapse if a condition of equilibrium is to be attained. Reactions in the living body are for the most part of the latter type. It is a familiar fact that many reactions which ordinarily proceed at an immeasurably slow rate take place with great rapidity in the presence of substances known as catalysts, which though influencing the velocity of the reaction do not enter into the composition of the end-products or in general shift the point of equilibrium for a given set of conditions. The facility with which the organism is able to disintegrate highly stable compounds is due to the agency of a special type of catalysts known as enzymes, characterised especially by their extreme instability (which is illustrated by the fact that practically all enzymes are rapidly destroyed at temperatures well below the boiling-point of water), and by the extremely minute quantities in which they act. Thus the preparation known as rennet, of which the active constituent represents a very small fraction of the total bulk, is able to clot 400,000 times its own weight of the milk protein caseinogen.

Of the general catalytic properties of enzymes, the most 
important for an understanding of chemical equilibrium in the organism is the complete reversibility of their action, first shown by Croft Hill (1898). The same is true of inorganic catalysts ; thus in the preparation of ethyl acetate, to take an illustration from the historic researches of Berthelot and Péan de Saint Gilles, if molar equivalents of acid and alcohol are mixed, equilibrium is reached when two-thirds of the acid and alcohol are converted into ester, and precisely the same equilibrium point is reached when a molar solution of ethyl acetate is subjected to hydrolysis. It is usual to regard both reactions as contemporaneous and equilibrium as the equalisation of their respective velocities. The catalyst, in this case usually a mineral acid, acts by accelerating both reactions; the actual point of equilibrium is unchanged and the total energy of the system unaffected. This is also the case with enzyme catalysis. Thus maltase accelerates both reactions symbolised by maltose $\rightleftarrows d$-glucose. As with inorganic catalysts (e.g. finely divided platinum) an enzyme is often reclaimable at the end of a reaction; this is well illustrated in the case to be discussed immediately. Another aspect of enzyme reaction illustrated by the phenomenon of bioluminescence is specificity. Any enzyme is able to catalyse only a restricted range of reactions, usually all of a well-defined type. The recognition of separate enzymes in a tissue-extract depends on the possibility of differential destruction of one or other of the catalytic activities of the extract. When different tissueextracts have different optima of temperature or hydrogenion concentration, etc., for catalysing precisely the same reaction, there is good reason to believe that their enzymes are distinct chemical entities.

The term "enzyme" was introduced by Kühne (1878) to obviate the confusion resulting from the use of the older term "ferment," a term originally used to include the activities of micro-organisms like yeast. Pasteur's researches led to a distinction being drawn between the fermenting action of gastric juice (" unorganised ferment") and that of microorganisms ("organised ferments"). This confusion was finally dissipated when Buchner (1903) extracted from crushed 
yeast cells an "unorganised" ferment, zymase, capable of effecting the same transformation previously identified with the intact organisms.

The foundations of modern knowledge of bioluminescence were laid by Dubois in the eighties. Dubois' studies elicited the following facts; (i) when a preparation of the photogenic organ of Pyrophorus is dipped in hot water, light-production is irreversibly stopped; (ii) when the fresh organ is ground up the mass only glows for a short time; (iii) if a hot-water extract of the gland is added to a cold-water extract in which all luminescence has ceased the production of light begins again. This was also found to be the case in Pholas. Dubois therefore advanced the hypothesis that the hot-water extract contains a heat-stable substance, luceferin, which is oxidised in the presence of an enzyme, luciferase, present in the coldwater extract. The latter can only go on glowing as long as any luciferin remains unoxidised. Boiling the mixed extract brings about cessation of light-production. Luciferin can be obtained from Pholas by heating the viscous luminous secretion to $70^{\circ} \mathrm{C}$. or extracting for some hours in 90 per cent. alchohol.

Similar phenomena have been studied by Newton Harvey in luminous bacteria, fireflies and other forms, especially in the ostracod, Cypridina. The process involved has its parallel in other biochemical reactions which can be carried out in vitro. The glucoside, esculin, in horse-chestnut bark is oxidised in presence of hæmoglobin and hydrogen peroxide with production of light, and luminescence is also characteristic of the oxidation of pyrogallol by the peroxidase of potato or turnip juice. The oxidation product of luciferin can be reconverted into its precursor by inorganic reducing agents. We must recognise, therefore, three entities: (a) luciferin, an oxidisable substance, heat-stable and dialysable; $(b)$ luciferase, non-dialysable, destroyed by temperatures above $60^{\circ}$ and by tryptic digestion, an enzyme, probably of proteinlike constitution; $(c)$ oxyluciferin formed from $(a)$ in presence of $(b)$ with emission of light. As stated, oxyluciferin can be reconverted by reducing agents into luciferin. 
Conversely the luciferin of Pholas can be oxidised with emission of light by various inorganic oxidising agents, e.g. hydrogen peroxide, potassium permanganate. This is not true of the luciferin of Cypridina, which differs in other respects from that of Pholas, being in particular more heat-stable. Whether the luciferases of different animals are identical is not wholly certain; in Cypridina the presence of luciferase is confined to the photogenic organ. Apparently luciferase-or luciferases, if there are several of such substances-belongs to the category of enzymes known as oxidases which catalyse other oxidative processes in the body.

To sum up, photogenic response in at least three groups of luminous animals, beetles, molluscs, and crustacea, involves the interaction of two readily separable components which have entirely different chemical properties. Probably, however the "luciferins" and "luciferases" of different animals are not identical. Thus the luciferin of Cypridina differs from that of Pholas in that it cannot be oxidised with lightproduction by $\mathrm{H}_{2} \mathrm{O}_{2}$ and $\mathrm{KMnO}_{4}$. The luciferase of Cypridina differs from that of Pholas in being less readily destroyed by lipoid solvents. When the luciferin of Cypridina is oxidised, no dissolution of the molecule takes place, since the product can be readily reconverted into its precursor by such reducing agents as $\mathrm{H}_{2} \mathrm{~S}$ or nascent hydrogen. The luciferases are destroyed by proteoclastic enzymes, and are to be regarded as oxidases either themselves of protein constitution or adsorbed to proteins in solution.

Electric Organs.-Under the heading of secretion reference may conveniently be made to the electrical organs which are present in several genera of fishes, since in one genus at least (Malapterurus) the electric organ is a modified gland, though in other cases the cellular elements have been derived from muscle fibres. These phenomena serve to draw attention to a property which gland cells share in common with other excitable tissues, namely an electrical response accompanying excitation. The existence of an electrical charge accompanying excitation is well illustrated by the experiments of Anrep and Harris on pancreatic secretion induced by secretin, and 
therefore independent of any concomitant nervous disturbance. In the electrical organ, the P.D. which accompanies muscular or glandular activity has been elaborated into a weapon of defence or aggression. The E.M.F. of each cellular element in a gland or muscle is of very small dimensions. In a frog's sartorious, where the parallel arrangement of the elements eliminates any summation of potentials, the currents of action or injury are rarely greater than 0.05 volt. But it has been shown that by arranging several frog's muscles in series with the cut surface of one opposed to the uninjured surface of the other, a summation of the potential difference due to injury can be obtained up to a volt or more.

Electric organs have been studied in three genera of fishes -a Mediterranean ray, Torpedo, Malapterurus, a catfish of North African rivers, and Gymnotus, the electric eel of the tropical zone of S. America and Africa. They consist essentially of disc-like cellular elements richly supplied with nerve-endings on one surface and arranged in columns in a manner reminiscent of Volta's pile. In Torpedo there is an electrical organ on either side of the head, consisting of horizontal rows of discs which represent functionally modified muscle fibres. In Malapterurus the electrical organ is developed from unicellular glands situated beneath the skin in the middle region of the body. In Gymnotus it is located in the tail. The columns are arranged transversely in Torpedo and longitudinally in the other two genera. The shock delivered by the electric organ of Torpedo is equivalent to that obtained from about thirty Daniell cells. Bernstein and Tschermack, who studied the variation of the P.D. with cooling and heating, found it to be (within physiological limits) directly proportional to the absolute temperature, as would be expected from Nernst's formula for the E.M.F. of a concentration cell.

Secretion of Poisons.-Secretion of poisonous substances which are undoubtedly means of attack or defence is met with throughout the animal kingdom; and their study raises a number of points of general biological interest, notably the questions of anaphylaxis and immunity. Many poisonous 
substances of colloidal nature produced by animal tissues when introduced into the body in sublethal doses call forth a condition of reduced susceptibility as compared with their effect after an initial dose. This condition is known as immunity. While this mode of reaction to toxic substances is in some cases of undoubted utility to the organism, it must be borne in mind that the phenomena of immunity are by no means exclusively of an "adaptive" significance. Thus the blood of the crayfish when injected into the mouse renders the latter immune against the venom of scorpions, though the crayfish itself is more susceptible to scorpion venom than the mouse. Frog serum injected into the body cavity of the crab specifically protects the latter against the poisonous secretion of the pedicellariæ of certain Echinoderms. The mechanism of immunity is exceedingly complex; in addition to immunity to poisons produced by secreting glands of larger animals or by micro-organisms the blood of some animals produces specific lysins which directly destroy micro-organisms, and substances, opsonins, which favour phagocytic activity.

The poisons produced by the nematocysts of Colenterates illustrate a phenomenon which may be described as the reverse of immunity and is referred to as anaphylaxis. If extract of the tentacles of a sea anemone are injected into a dog intense vascular congestion in the viscera resulting in death follows after a few hours. When a sublethal dose is given, it is found that the administration of a very much smaller quantity of the poison after a certain minimum period of about ten days has much more severe consequences. This supersensitiveness, according to Richet, involves the co-operation of two factors. From extracts of sea anemone tentacles two toxic substances can be obtained, one congestin when injected first increases the sensitivity of the dog to a subsequent dose of the other known as thalassin. If the order is reversed thalassin acts as an antitoxin, diminishing the sensitivity to the poisonous action of congestin. Neither the phenomena of increased sensitivity or anaphylaxis nor of decreased sensitivity or immunity to specific poisons are, as the important work of Dale, Gunn, and others has shown, due simply to the production of 
substances analogous to or antagonistic to the effects of the poison in the blood itself. The supersensitivity in the one case and increased resistance in the other in part reside in the cells of the organ affected. Thus Dale (I9I2) has shown that the isolated virgin interus of the guinea pig from an animal treated with horse serum as the anaphylactic reagent shows specific supersensitiveness to the reagent. Again, Gunn and Heathcote (I92I) have shown the greater resistance of the cat as compared with the rabbit to cobra venom is shown by isolated organs of the two species. The minimal lethal dose per kilo of cobra venom for the cat is twenty times that for the rabbit. Both the isolated heart and gut muscle of the cat can withstand much higher doses of cobra venom than corresponding preparations from the rabbit. Of the venoms of Arthropods the most important are those of the spiders, scorpions, and hymenoptera. Nearly all spiders possess poison glands connected with the mouth parts, the poison being instantly fatal to the small animals on which they prey. The toxin is destroyed by heat, and like the venom of viperine snakes displays both coagulant and hæmolytic properties with reference to vertebrate blood. Scorpion venom more closely resembles the venom of the Colubrine snakes (vide infra). The poison glands of bees contain at least three toxic substances, one of which possesses hæmolytic properties and acts on the nerve centres, but like viperine venom produces marked local effects. A particularly interesting case from the pharmacological standpoint is the presence of a substance allied to tyramine (parahydroxyphenylethylamine) in the salivary secretion of the cephalopod (Henze). By means of it the cuttlefish paralyses its decapod prey. Tyramine is closely related to tyrosine, as is the latter to the melanic secretion of the ink sac in cephalopods. It is one of a class of compounds allied to " adrenaline," the hormone of the mammalian suprarenal glands, prepared synthetically by Barger and Dale. Adrenaline itself has been isolated by Abel and Macht in association with an alkaloid bufagin having an action akin to digitalis in the poisonous parotid and skin glands of the toad, Bufo agua.

The venoms of snakes may be divided into two groups. 
That of the colubrine forms (including the cobras) has, like the salivary secretion of the leech (hirudin) and mosquito, anticoagulant action on the blood, and produces death chiefly by asphyxiation through paralysis of the respiratory centre. Cobra venom is also hæmolytic, i.e. it disintegrates the red blood corpuscles. The venom of the viperine snakes (including rattlesnakes) is also hæmolytic, and differs from cobra venom in the more marked local inflammatory reaction and the presence of a substance which promotes coagulation of the blood ; its effect on the nerve centres is less marked. Alkaloids are present in snake venoms, but their toxicity is slight. The poisonous action is due to constituents of a simple proteinlike structure. Mammals may be artificially immunised by injection of sublethal doses in increasing quantities. The serum of animals so treated may be used as anti-toxin. It is interesting to note that the blood of snakes (which are immune to snake venoms), and that of animals like the hedgehog, which prey on snakes and also possess a high degree of natural immunity, is toxic to animals which are relatively susceptible to the poisonous effects of snake-bite.

The phenomena of poison secretion are illustrated in all large groups of the animal kingdom, and a more extensive discussion would take us beyond the scope of the present volume.

Secretion of Acids.-An aspect of the comparative physiology of secretion which opens up a fascinating field for experimental investigation that may throw light on the bionomics of some boring animals is the production of strong acids by the digestive glands of certain animals. More than half a century ago Troschel noticed that the gasteropod, Dolium galea, squirts from its mouth a liquid of strongly acidic reaction capable of producing effervescence on coming into contact with the limestone of the soil. This fluid is the secretion of the salivary glands and contains as much as 4 per cent. free sulphuric acid and about $0^{\circ} 5$ per cent. hydrochloric acid. Schulz (1905) has also studied the phenomenon of acid secretion in an opisthobranch, Pleurobranchia meckelii. This animal not only ejects an acidic fluid from its pharynx but produces with its 
skin glands a very acid slime. Little is known of the mechanism by which such a very high concentration of acid can be attained in the cells which secrete it. We are still in the dark as to the mechanism of acid secretion in the stomach of the mammal. It may be presumed that the source of sulphuric acid must be the sulphur of either proteins or sulphates of the food. The bionomic significance of acid secretion in the lower organisms has been interpreted as a means of softening the calcareous skeletons of animal prey or as a protective device. Neither interpretation is proved; but the subject would well repay investigation.

The Secretion of Gas. - Among those fishes (Ganoids and Teleosts) in which a gas bladder is present a peculiar form of secretion is often met with. The bladder (homologous with the lungs of air-breathing Vertebrates) is in some cases a true respiratory organ. In those teleosts which dwell in deep water and habitually move over a considerable range of depths, it subserves the function of facilitating movements from one level to another by altering the specific gravity of the fish. It was shown over a century ago that in those teleosts which have a closed duct (physoclistous condition) the bladder contains oxygen only. The oxygen content of the bladder changes during inflation and deflation. Though the tension of oxygen in sea-water is about a fifth of one atmosphere and in the capillaries of the bladder considerably less, the tension in the gas bladder may rise to about a hundred atmospheres. Secretion and absorption of oxygen (in the physoclistous forms) provide an auxiliary mechanism to promote sinking and rising in the water. Deflation in physoclistous fishes is apparently effected by means of the oval, a thin-walled area on the dorsal wall of the bladder overlying the cardinal sinuses and enclosed by a sphincter. That oxygen is reabsorbed into the blood by diffusion through the oval is indicated by the fact that during active gas-secretion the sphincter is completely closed so that the thin-walled area is invisible, while it opens widely when the bladder is completely inflated.

It is fairly certain that the inflation is brought about by the 
activity of the gas gland. The form of the gland varies in different fishes. Typically it is a local proliferation of the lining epithelium of the bladder, elsewhere composed of squamous cells. The cells of the glandular region are columnar where in contact with the endothelial lining of a peculiar arrangement of blood-vessels called the rete mirabile. This consists of a closely packed bunch of fine capillaries; its essential feature is the juxtaposition and intermingling of capillaries carrying blood in both directions. It has been shown by Bohr that the gas gland, like the salivary gland of the mammal, is under nervous control ; and Dreser states that oxygen secretion can be induced by the action of pilocarpine which provokes activity of salivary and skin glands. In appearance the gas gland is a bright red diffuse mass typically situated on the ventral wall of the bladder. Little is known of its intimate mechanism. Artificial activation of the gland can be achieved by attaching a weight to the fish. A load of about five per cent. of the body weight is convenient for the purpose. In experiments upon the Pollack, Woodland found that when the weight is first attached, the fish sinks immediately to the bottom of the tank. Soon it begins to swim upwards by active movements. After about twelve hours or rather less it regains, owing presumably to the activity of the gas gland, its normal quiescence completely. It is able to float easily near the surface without the aid of caudal movements. Exposure of the viscera at this stage reveals the bladder in a distended condition. If instead the weight is removed and the fish allowed to resume its former state, it floats at first to the surface; and has to swim downwards vigorously in order to keep away from the surface.

\section{Further READING}

Swale Vincent. An Introduction to the Study of Secretion. Arnold. Bernsteln. Elektrobiologie. Vieweg.

Cushny. The Secretion of Urine. Longmans, Green.

Newton Harvey. The Nature of Animal Light. Lippincott.

Calmette. Venoms. Bale \& Danielsson. 


\section{CHAPTER IV}

\section{RESPIRATION}

From the knowledge which we have gained concerning the nature of response in animals we have learned that the utilisation of oxygen is an essential feature of the processes by which effector mechanisms are restored to their original condition after a state of induced activity. The intake of oxygen by the organism will be our first consideration in dealing with the sources of vital energy, since the necessity of oxygen for the maintenance of animal life is a universal phenomenon.

Under the heading of respiration it is customary to include not only the intake of oxygen, but the removal of carbon dioxide which is associated with it. Except where we have to deal with tissues like ciliated epithelium in immediate contact with the external world, the intake of oxygen involves: (i) the absorption of oxygen by the tissues from the body fluids; (ii) the absorption of oxygen by the body fluids from the external medium. It will be convenient (though less logical) to treat the latter before passing on to the special arrangements for the transport of oxygen to the tissues by the body fluids, and $\mathrm{CO}_{2}$ from the tissues to the external medium.

(a) Localised Respiration.-In many animals the absorption of oxygen takes place to some extent over the entire surface of the body. Though this is not true of mammals, birds, and probably reptiles, it is certainly the case with most coldblooded vertebrates. Thus Paul Bert showed that the axolotl larva of the Mexican salamander survives after removal of both 
the lungs and gills with but little diminution of total respiratory activity. The following data from Krogh's (1904) experiments show that the skin is a very important factor in the respiration of the frog, especially when it is pointed out that the total surface of the skin is only about one and a half times the internal surface of the lungs.

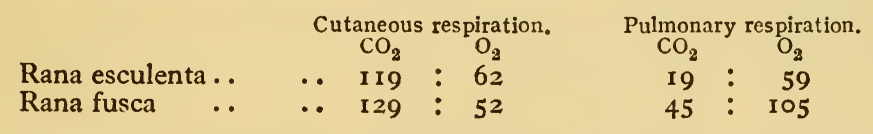

Where a respiratory pigment is present it is sometimes possible to recognise its respiratory function by the colour of the blood which enters and leaves an organ. This is true of course of the lungs and gills of vertebrates, from which the blood issuing is a brighter red owing to the formation of oxyhæmoglobin to be discussed below. Analogous evidence points to the conclusion that the gills of the cephalopodwhose arterial blood is of a more bluish complexion than that in the veins - are to be regarded as structures specialised for the intake of oxygen from the surrounding medium. This is confirmed by direct measurements of Winterstein (1908) on the oxygen and carbon dioxide content of arterial and venous blood in Octopus vulgaris.

\section{Arterial and Venous Blood in Living Octopus}

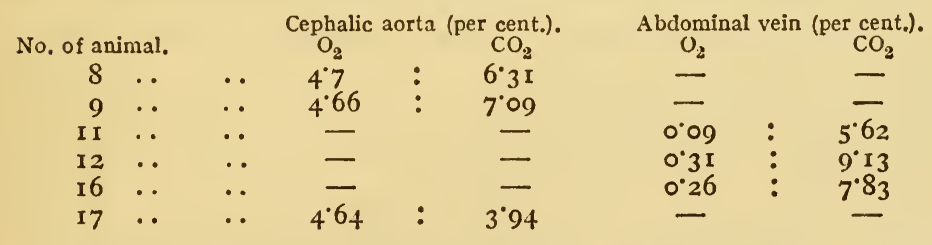

It is highly probable, but not proven, that the gills of Crustacea are to be regarded in the same light. But it is not wise to assume that all structures labelled gills by systematists are special arrangements to facilitate respiration. This is well illustrated by experiments of Fox (I920) on Chironomus. This author employed an ingenious method to investigate the localisation of respiratory exchange in minute organisms, by 
making use of the fact that the flagellate Bodo migrates to a region having a certain optimum oxygen tension. Fox found that when pupæ of Simulium, which respire by means of filamentous appendages at the junction of head and thorax, are placed in a suspension of Bodo, the micro-organisms collect at first round the filaments in a dense congregation, and then migrate outwards in a crescentic configuration, as the oxygen concentration falls through absorption to a lower level than the optimum. When Chironomus larvæ are similarly placed in a suspension of Bodo, the flagellates show no special concentration with reference to the so-called anal gills ; furthermore, as this species possesses hæmoglobin, it was possible to obtain independent confirmation by spectroscopic observation for the conclusion that these structures have no special respiratory function. It will be seen later that the so-called gills of lamellibranchs are to be regarded primarily as apparatus for entrapping food-particles. Bounhiol (1902) brought forward evidence that respiratory exchange in some Annelids falls from 25 to 75 per cent. after removal of the gills; and Winterstein's (1909) observations on the effect of occluding the anus in Holuthurians seem to indicate that either the " respiratory" tree or the alimentary canal is responsible for about fifty per cent. of the respiratory exchange which occurs in these forms.

Of localised respiratory organs among Invertebrates the most fascinating arrangement is the tracheal system of Arthropods. Though the tracheal system of insects was fully described by Malpighi in 1669 , it is only comparatively recently that the respiratory significance of the tracheal apparatus has been put to conclusive experimental test, initially by the work of Krogh (1915). Krogh demonstrated the respiratory function of the tracheæ by two methods of attack. The first consisted in analysing the gaseous contents of the trachex of the limbs in grasshoppers which had remained for some time in a quiescent condition, as compared with the carbon dioxide and oxygen in the tracheæ of individuals which had been chased to exhaustion to increase their respiration. For this purpose the hindmost legs were squeezed out under glycerine 
for gas analysis by Krogh's micro-method. The following table indicates the results obtained in percentages :--

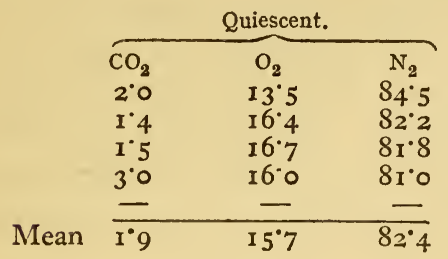

\begin{tabular}{|c|c|c|}
\hline & & \\
\hline $\mathrm{CO}_{2}$ & $\begin{array}{r}\mathrm{O}_{2} \\
3 \cdot 0\end{array}$ & $\begin{array}{c}\mathrm{N}_{2} \\
80^{\circ}\end{array}$ \\
\hline 37 & 73 & $89^{\circ} 0$ \\
\hline$I^{\circ} 5$ & $5^{\circ} 8$ & $922^{\circ 7}$ \\
\hline $\begin{array}{l}2 \cdot 3 \\
6.0\end{array}$ & $\begin{array}{l}4.5 \\
6.4\end{array}$ & $\begin{array}{l}93^{\circ}= \\
87^{\circ}\end{array}$ \\
\hline $4^{\circ 2}$ & 5.4 & $90^{\circ}$ \\
\hline
\end{tabular}

In a second series of experiments the animals were placed in a mixture of pure $\mathrm{O}_{2}$ and $\mathrm{CO}_{2}$ till no nitrogen remained in the trachea. The requisite time previously determined by trial was found to be about ro minutes. Analysis showed that about one minute after being allowed to breathe ordinary air the normal nitrogen content of the tracheæ is restored. Even after one second there is 2.5 per cent. of nitrogen in the trachex, while half a minute suffices to bring the percentage of nitrogen up to $62^{\circ} 5$. From the first set of data it is clear that oxygen disappears and carbon dioxide increases in the tracheal tubes during enforced respiratory activity. From the second it is clear that gaseous diffusion takes place within the tracheal system with a surprising rapidity, when one considers the internal friction encountered by the gases in passing along the lumen of tubes of such minute dimensions. If the rhythmical movements of the abdomen which have been supposed to facilitate the renewal of air in the tracheæ are truly acts of inspiration and expiration, it seems, from the rate at which these succeed one another, that the air within the tracheal system is renewed to the extent of about twenty per cent. at each movement.

An admirably thorough investigation of tracheal respiration in insects has recently been carried out by Buddenbrock and Rohr (1923). The species employed in their researches was Dixipus morosus, the familiar stick insect, whose barrellike configuration renders it specially suitable for some forms of manipulation. Using Krogh's microrespiration methods, they first demonstrated the fact that closure of the orifices (stigmata) of the tracheal system reduces respiratory exchange 
to about a quarter of its normal dimensions. The remaining twenty-five per cent. might be effected through the mouth or anus, or by the skin. Buddenbrock and Rohr investigated this point and found that occlusion of the mouth and anus does not reduce the total exchange of gas. The alimentary tract does not therefore contribute materially to the respiratory process. The oxygen content of the tissues was found by Buddenbrock to be in equilibrium with a partial pressure of about $76 \mathrm{~mm}$. of

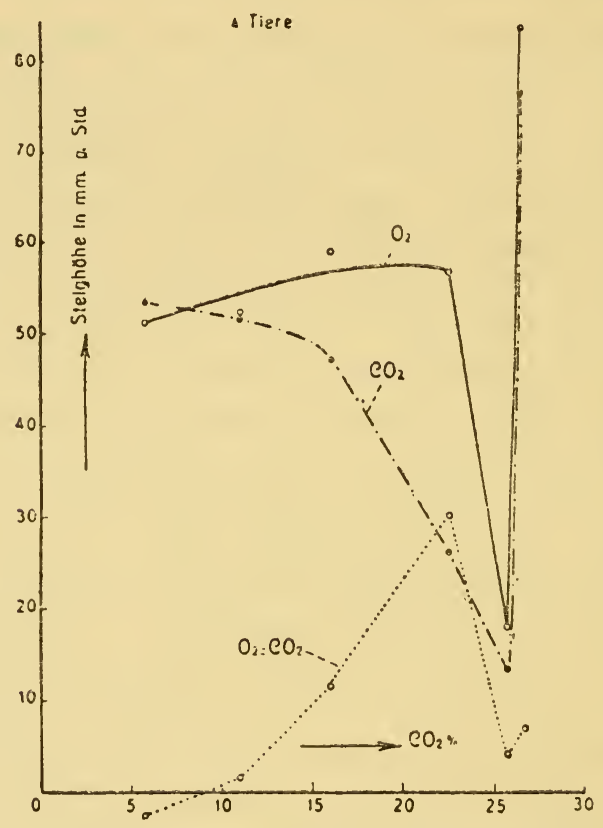

FIG. 15.-(After Buddenbrock and Rohr.)

mercury. It might be surmised, therefore, that no effects would accompany reduction of the oxygen content of the air so long as there remained at least ten per cent. This proved to be the case. Below this point physical diffusion does not compensate for the rate at which oxygen can be used up, and the respiratory exchange falls.

Very remarkable results accompany variation of the $\mathrm{CO}_{2}$ tension of the inspired air (Fig. 15). The intake of oxygen 
diminishes as the carbon dioxide is increased, down to a miminum (at about 25 per cent. $\mathrm{CO}_{2}$ ). With further increase of $\mathrm{CO}_{2}$, it then suddenly increases till it actually exceeds the oxgyen consumption in $\mathrm{CO}_{2}$-free air. Finally, after attaining a maximum, the intake of oxygen rapidly falls to zero under carbon dioxide narcosis. This surprising phenomenon sheds a new light on the significance of the abdominal contractions extensively studied by Babak (I912) and regarded by him as respiratory movements. Babak had shown that phenomena analogous to Cheyne-Stokes breathing and asphyxia could be induced by varying the contents of the inspired medium; but crucial evidence that such disturbances of the normal rhythm of abdominal movements had any compensatory value was lacking. In Dixippus, however, when the normally spasmodic contractions of the rump and abdomen became rhythmical in lack of oxygen or excess of carbon dioxide, the increased rapidity of the movements corresponds with an increase in oxygen consumption, and it is difficult to escape the conclusion that they actively facilitate the renewal of air in the tracheal system. There is, moreover, a correlation between the opening and closure of the stigmata and the respiratory movements. In Dixipus, according to the observations of Buddenbrock and Rohr, the thoracic stigmata open with each expiratory movement and close with relaxation of the abdominal muscle, thus, seemingly, promoting the passage of a current of air from behind forwards.

Lee (1924), working on several other genera of Orthoptera, has recently observed in their respiratory movements a definite sequence of valvular motions of the thoracic and abdominal spiracles (stigmata). According to Lee's account the external valves or lips of the thoracic and first two pairs of abdominal orifices of grasshoppers open when the abdomen enlarges and close when it contracts. The orifices of the last six pairs of abdominal spiracles are open during expiration and closed when the abdomen enlarges. Hence if the abdomen of a normal grasshopper is submerged while the head and thorax are kept above the level of the water, minute bubbles escape from the posterior abdominal spiracles; when the whole 
animal is put under water no bubbles escape and asphyxia results.

Thus in insects there has been evolved-and in passing we may note that analogous structures have appeared independently in at least two other groups of Arthropods (isopoda and arachnida) - a system by which oxygen is brought direct to the tissues by a ramifying system of minute tubules which penetrate even to the individual cells of the lining epithelium of the gut. The evolution of this remarkable arrangement is correlated with a very degenerate condition of the vascular system. The efficiency of the tracheal system, which as we have seen accounts for the greater part of the respiratory exchange of these animals, must be extremely high when it is remembered that insects in muscular activity surpass all other invertebrates and many vertebrates also. It is interesting, however, to note that a limit is set to the efficiency of this device by the size of the organism, since the internal surface of the tracheal system cannot increase proportionately to the bodyweight.

Respiratory Pigments. - The body fluids of many animals are known to contain substances whose affinity for oxygen enables them to take up far more of this gas than is contained by serum or sea-water in physical solution. The most familiar example of a respiratory pigment is provided by the substance, hæmoglobin, present in the erythrocytes of all craniata and in the serum of some invertebrates, especially annelida.

As is well known, hæmoglobin on taking up oxygen assumes a different colour ; reduced hæmoglobin is of a purple tint, whereas oxy-hæmoglobin is bright scarlet. The difference is correlated with characteristic absorption spectra. Oxyhæmoglobin has two absorption bands in the green ; reduced hæmoglobin has one which overlaps the space included by the outer edges of the oxy-hæmoglobin bands. Hæmoglobin also combines very readily with carbon monoxide to form carboxyhæmoglobin, a much more stable compound than the oxygen derivative. This also has two bands in the green; it is not of such a bright red colour. Oxy-hæmoglobin can be reduced to hæmoglobin by exposure to a vacuum or neutral gas and 
by various reducing agents. With potassium ferricyanide it yields up all its oxygen, but the hæmoglobin is speedily reoxidised by the reagent to form a brown isomer methæmoglobin with a conspicuous absorption band in the red. Hæmoglnbin is a compound of a protein and a nitrogenous pigment called hæmochromogen. The nature of the protein differs in different animals. Hæmatin, which is the oxidised form of hæmochromogen, is known to contain four pyrol rings and one atom of iron in its molecule. The constant relation between the iron-content and the oxygen-capacity of a solution of hæmoglobin, established by Peters, shows that the formation of oxy-hæmoglobin is an essentially chemical union. Hæmatin is separated from its conjugate globulin by dilute alkalis and acids. The brown solutions formed in the two cases have slightly different absorption spectra. On reduction of the alkaline derivative with ammonium sulphide the red pigment hæmochromogen is found. Hæmatoporphyrin is the purple substance formed by splitting off the iron from the molecule with strong acids, and is isomeric with the bile pigment bilirubin.

Hæmoglobin and oxy-hæmoglobin respectively take up or give up oxygen according to the partial pressure of the gas in the medium with which they are in contact. In the case of man roo c.c. of blood take up about 18.5 c.c. of oxygen when fully saturated. Human blood is fully saturated at a partial pressure of $100 \mathrm{~mm}$., which is less than the partial pressure of oxygen in the atmosphere. The curve relating oxygen tension to oxygen content (or percentage saturation) in a hæmoglobin solution is a rectangular hyperbola. Complete saturation of the blood occurs at the same partial pressure, but the initial part of the curve is steeper in a pure hæmoglobin solution, so that at low tensions its oxygen-content is higher than in blood at the same partial pressure of oxygen. Among factors which influence the form of the oxy-hæmoglobin dissociation curve are those which affect the physical chemistry of proteins generally-neutral salts, hydrogen-ion concentration, and temperature. Increased hydrogen-ion concentration facilitates the dissociation of oxygen at low tensions-i.e. flattens 
the initial part of the curve; and differences in salt-content and $\mathrm{pH}$. play a part in determining differences in the form of the dissociation curve from the blood of different species. The effect of acid is of physiological importance, since it implies (see Fig. 16) that the readiness of the blood to give up oxygen is greater under the conditions-presence of $\mathrm{CO}_{2}$-normally associated with oxygen want. Rise in temperature also increases the dissociation of oxy-hæmoglobin at low tensions. Thus the warm blood of the mammal or bird is better suited as a carrier of oxygen to the tissues than a pure solution of

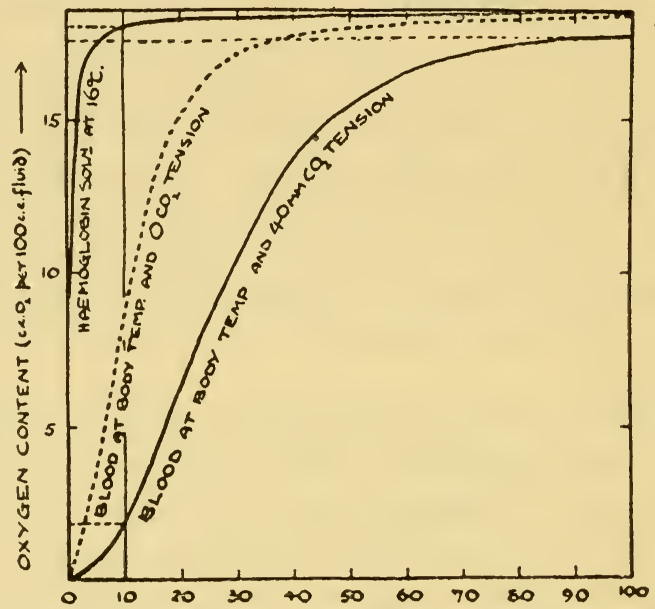

FIG. 16.-Dissociation curves of mammalian blood (after Parsons).

hæmoglobin at atmospheric temperature in the absence of salts. Seeing that the hæmoglobins of different species are not identical, it is of interest to inquire into the extent to which the properties of different hæmoglobins can be correlated with the conditions in which a given species pursues its existence. Investigations with this end in view have been carried out by Krogh and Leitch (1919) on fishes, and by Barcroft and Barcroft (1924) on the polychæte, Arenicola.

Krogh and Leitch compared the oxygen dissociation curves of the blood of several species of fishes between $10^{\circ}-20^{\circ} \mathrm{C}$. in the presence and absence of $\mathrm{CO}_{2}$ to make the data as complete 
as necessary for the purpose. In the absence of carbon dioxide the blood of such fresh-water genera as the eel, pike, and carp is half saturated at a partial oxygen pressure of $2-3 \mathrm{~mm}$. ( $15^{\circ} \mathrm{C}$.). In the marine species, represented by the cod and plaice, and also in the trout, $5^{\circ}$ per cent. saturation at $15^{\circ} \mathrm{C}$. requires an oxygen-tension of considerably greater dimensions, viz. I $8 \mathrm{~mm}$. with the cod, and about II $\mathrm{mm}$. with the plaice or trout. In both cases the presence of $\mathrm{CO}_{2}$ greatly diminished the oxygen affinity of the blood at low tensions. In fresh water the oxygen content is very variable and may sink to extremely low values. The low loading tension of the blood in the freshwater fishes is thus appropriate to their medium, and accounts for the low oxygen pressure to which Leuciscus (the minnow) can, according to Winterstein's data, be subjected without harm. In sea-water the dissolved oxygen is practically always present in abundance at all depths. 'The water of the sea is practically saturated with oxygen; it therefore has an oxygen tension above the $70 \mathrm{~mm}$. which represents the tension below which (at $15^{\circ} \mathrm{C}$.) a cod suffers from oxygen-want. In association with this is the fact that sea-water fishes are very sensitive to oxygen-want. The oxygen dissociation curve explains the sensitiveness which makes sea-water aquaria more difficult to maintain than fresh-water. The trout, which, as we have seen, has a higher oxygen loading tension than such typical fresh-water fish as the pike and carp, will only live in wellaerated water, and is easily killed when the water is not renewed or is insufficiently aerated.

Barcroft and Barcroft investigated not only the entire range of the dissociation curve for hæmoglobin in Arenicola, but compared its chemical and physical properties with that of human hæmoglobin. As regards the first, which are graphically set out in Fig. I7, it is to be noted that the blood of Arenicola has at low tensions a very much higher affinity for oxygen than mammalian blood. The oxygen loading tension is of the same order as that described by Krogh and Leitch in fresh-water fish. Complete saturation is obtained at an oxygen tension of $10 \mathrm{~mm}$. There are, apart from this, two characteristic differences between the hæmoglobins of Arenicola and 
man. The former has a much lower affinity for carbon monoxide than the latter. At the point of 50 per cent. satura-

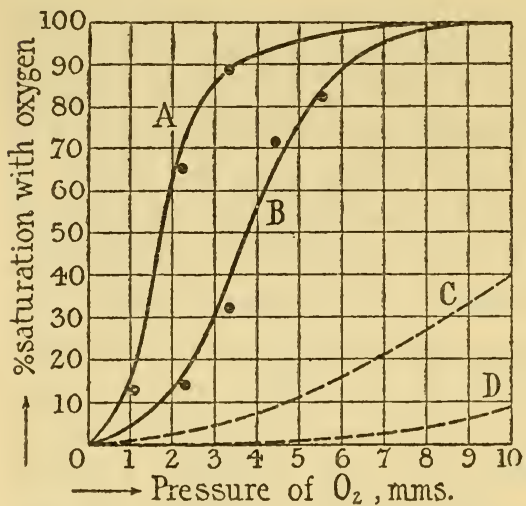

$-\mathrm{A}=p \mathrm{H} .7^{\circ} 3 ; \mathrm{B}=p \mathrm{H} .6{ }^{\circ} 9 ;$ Temp. $20^{\circ} \mathrm{C}$. $\mathrm{C}$ and $\mathrm{D}$ human blood, $\mathrm{C}=20^{\circ} \mathrm{C} . ; \mathrm{D}=$ $37^{\circ} \mathrm{C}$; $p \mathrm{H} .=7^{\circ} 45$.

Fig. 17.-Dissociation curves of arenicolan blood (Barcroft and Barcroft). tion under exposure to a mixture of oxygen and carbon monoxide, the partial pressures of $\mathrm{CO}$ and $\mathrm{O}_{2}$ were not $250: \mathrm{I}$ as in the case of man, or $140: I$ as in the mouse, but more nearly $40: \mathrm{I}$. Again, as regards the blood spectra, it was found that the $\alpha$ oxy-hæmoglobin band is I8 Angstrom units nearer the violet end, and the $\alpha$ carboxy-hæmoglobin band is I I Angstrom units nearer the violet end than are those of human blood. Further, Vlés has shown that the methæmoglobin of Arenicola has not the typical bands in the spectrum of mammalian hæmoglobin. There is a quantitative relation (Barcroft) between the affinities of the different hæmoglobins for carbon monoxide and oxygen, on the one hand, and the position of the bands in their absorption spectra on the other. The logarithm of the reciprocal of the pressure at which the pigment is half saturated with each is a linear function of the situation of the $a$-band. The further the band is situated towards the violet end, the greater in each case is the affinity for the gas. From measurement of the blood-volume and oxygenconsumption of Arenicola, it appears that Arenicola blood can store just about enough oxygen to last when, sealed up in its burrow at low tide, it has temporarily no access to water.

We may now turn to the consideration of the respiratory pigment of molluscs and crustacea. Hæmocyanin is a term given to a family of substances which in the presence of oxygen display a bluish hue, are like the hæmoglobins of pro- 
tein nature, and contain in organic combination a metal which, however, is not iron but copper.

There is no doubt that the hæmocyanin of molluscs and crustacea is a reversibly oxidisable pigment. Octopus blood saturated with air was found by Winterstein (1908) to take up 4-5 per cent. of oxygen. The oxygen capacity of the blood of Palinurus was decidedly less-about $\mathrm{I}^{\circ} 5$ per cent., a difference possibly correlated with the lower hæmocyanin content of the blood in Crustacea. The blood of the Arachnid, Limulus, like Crustacean blood contains a bluish pigment which is a colloidal compound of copper, to which the term hæmocyanin has also been extended. Alsberg and Clark (I9I0-1914) have, however, stated that the oxygen capacity of the blood of Limulus or of a I0-per-cent. solution of Limulus "hæmocyanin" is not significantly greater than that of seawater. Their observations have further shown that the composition of Limulus hæmocyanin is not the same as that of the hæmocyanin of Octopus as determined by Henze (1904).

\begin{tabular}{|c|c|c|c|c|c|c|}
\hline \multirow{2}{*}{$\begin{array}{l}\text { Carbon } \\
\text { Hydrogen }\end{array}$} & \multirow{2}{*}{ 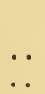 } & \multirow{2}{*}{$\begin{array}{l}\cdots \\
\cdots\end{array}$} & \multicolumn{2}{|c|}{$\begin{array}{l}\text { Octopus (Henze). } \\
53^{.66} \text { per cent. }\end{array}$} & \multicolumn{2}{|c|}{$\begin{array}{c}\text { Limulus (Alsberg and Clark) } \\
48^{\circ} 94 \text { per cent. }\end{array}$} \\
\hline & & & 733 & ", & $7^{\circ} 10$ & , \\
\hline Nitrogen & . & $\ldots$ & 16.09 & ," & $16^{\circ} 18$ & ," \\
\hline Sulphur & .. & . & 0.86 & , & $I \cdot I 6$ & , \\
\hline Copper & .. & . & 0.38 & , & 0.28 & , \\
\hline Oxygen & . & . & $2 I^{\circ} 68$ & ", & $25^{\circ} 94$ & ," \\
\hline
\end{tabular}

Notable additions have recently been made to our knowledge of hæmocyanin as a respiratory pigment through the researches of Dhéré (1916-1921), and of Quagliariello (1910I923), who have obtained hæmocyanin from a number of species in crystalline form. Hæmocyanin of cephalopods can be prepared by precipitation with concentrated $\left(\mathrm{NH}_{4}\right)_{2} \mathrm{SO}_{4}$, that of the snail and rock-lobster by crystallisation of the supernatant serum dialysate in ice. Oxy-hæmocyanin so prepared in crystalline form is a protein, completely precipitated by dialysis, coagulated by heat and alcohol, behaving as an amphoteric electrolyte with a minimal solubility at its isoelectric point ( $\mathrm{pH} .4{ }_{7} 7$ in the case of Octopus). The oxyhæmocyanin of cephalopods crystallises in needles of a greenish- 
blue tinge. Reduced hæmocyanin does not show any absorption bands. The spectrum of oxyhæmocyanin from molluscs and arthropods shows one band in the yellow and the beginning of another in the blue in virtue of the copper-pynol complex in the hæmocyanin molecule. The position of the yellow band in molluscs is about $\lambda_{579 \mu \mu}$, and in crustacea about $\lambda_{5} 63 \mu \mu$.

As regards the properties of hæmocyanin as a respiratory pigment, Dhéré finds that oxy-hæmocyanin of both crustacea

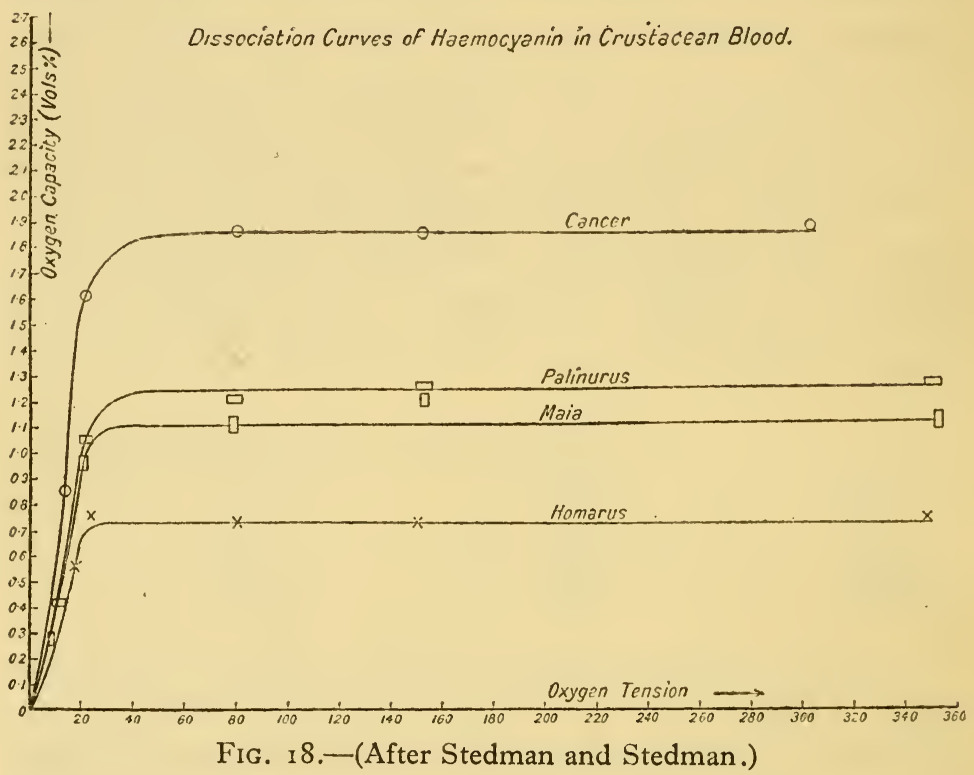

and molluscs undergoes dissociation by lowering of the oxygen tension, exposure to an inert gas or heating. There is no combination between carbon monoxide and hæmocyanin, which however (snail, lobster) form a green compound with $\mathrm{N}_{2} \mathrm{O}_{2}$. The physiological rôle of hæmocyanin in the respiratory processes of crustacea and molluscs is not completely established; but is strongly suggested by comparison of the hæmocyanin content (as measured by the amount of copper present) with the oxygen capacity of the blood in different 
species. The following table from Dhérés data shows how close the correspondence is :

\begin{tabular}{|c|c|c|c|c|c|}
\hline $\begin{array}{l}\text { Animal. } \\
\text { Octopus }\end{array}$ & & & $\begin{array}{l}\text { Temperature, } \\
18^{\circ}\end{array}$ & $\begin{array}{c}\text { Oxygen c.c. } \\
\text { per 100 c.c. blood. } \\
4^{\circ} 05\end{array}$ & $\begin{array}{l}\text { Copper mg. } \\
\text { per 1oo c.c. blood. } \\
25^{\circ} 6\end{array}$ \\
\hline Helix & . & $\cdots$ & $17^{\circ}-19^{\circ}$ & $1 \cdot 82$ & 90 \\
\hline Homarus & . & . & $18.5^{\circ}$ & $3^{\circ} \mathrm{I}$ & $10^{\circ} 5$ \\
\hline Cancer & . & . & $18^{\circ}$ & $I^{\circ} 6$ & $5^{\circ} 5$ \\
\hline Astacus & . & . & $22^{\circ}$ & 24 & 8.0 \\
\hline
\end{tabular}

From the recent work of Fox (1924) it would appear that the green pigment, chlorocruorin, of certain polychætes is like hæmoglobin and hæmocyanin a substance which may facilitate the carriage of oxygen to the tissues or its temporary storage in the body. Chlorocruorin occurs in the Chlorhæmidæ and the Sabelliformia. The blood of these worms is green by transmitted and red by reflected light. It was first observed by Milne Edwards (I838); and its spectrum was later studied by Ray Lankester (1867-1870). Oxy-chlorocruorin has two absorption bands, the limits of which were given as $618-593 \mu \mu$ and $576-554 \mu \mu$. By reduction with ammonium sulphide a derivative was obtained which had only one band situated between 625 and $596 \mu \mu$. As this reduced form reassumed the oxy-chlorocruorin spectrum on shaking with air, Lankester concluded that it was respiratory in function.

The fact that chlorocruorin is reduced by reducing agents and reoxidised in air is, however, insufficient reason for believing that reduction can take place in the body of the worm. It has now been shown by Fox that oxy-chlorocruorin is reduced in a vacuum, that is to say, it both takes up and gives up oxygen according to the oxygen tension of the surroundings. Furthermore, its reduction by living tissues can be demonstrated by spectroscopic observation of the blood of Spirographis in contact with a piece of living muscle under a sealed coverslip. On removing the cover-slip the oxy-chlorocruorin bands reappear. Assuming that the gas liberated by potassium ferricyanide is oxygen, the oxygen capacity of the blood of Spirographis was found by Fox to be about 6.17 per cent. or 10.3 times the quantity dissolved in sea-water. This is distinctly higher than the figure for the blood of Cephalopods 
and about twice or three times the oxygen capacity of the blood

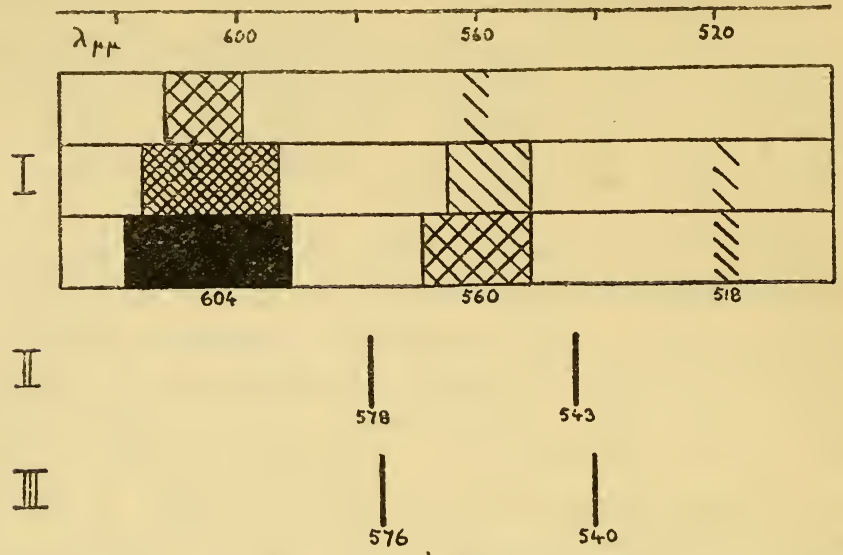

FIG. 19.-Absorption spectra. I: oxychlorocruorin in three concentrations ; II and III give the spectrophotometric axes of the bands of the hæmoglobin of the horse (II) and Arenicola (III) (after Fox).
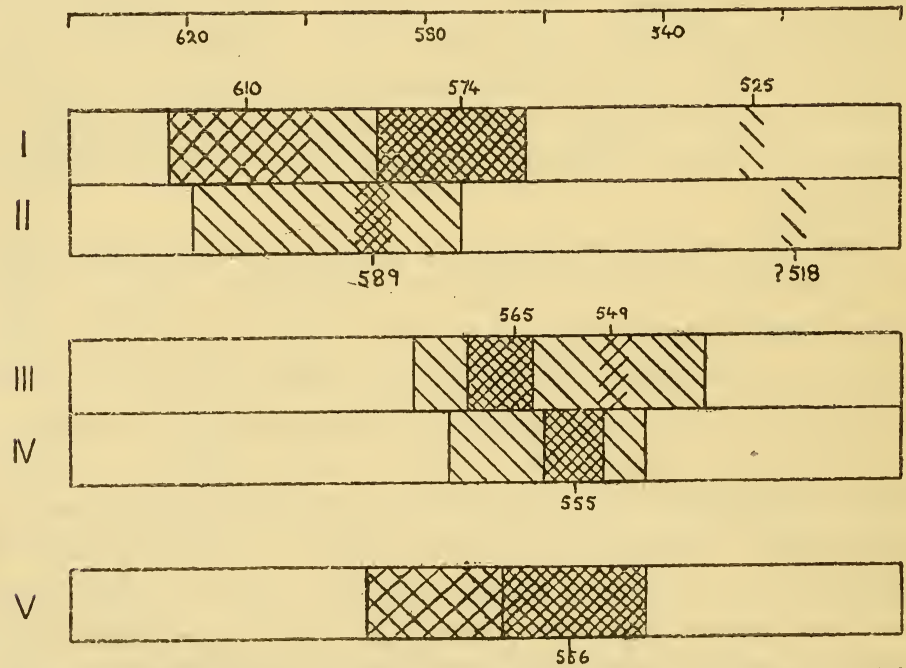

FIG. 20.-Absorption spectra. I : chlorocruorin reduced by $\mathrm{Na}_{2} \mathrm{CO}+$ $\mathrm{Na}_{2} \mathrm{~S}_{2} \mathrm{O}_{4}$; II chlorocruorin reduced by $\mathrm{Am}_{2} \mathrm{~S}$; III arenicolan hæmoglobin reduced by $\mathrm{Na}_{2} \mathrm{CO}_{3}+\mathrm{Na}_{2} \mathrm{~S}_{2} \mathrm{O}_{4}$; IV arenicolan hæmoglobin reduced by $\mathrm{Am}_{2} \mathrm{~S}$; V mammalian hrmoglobin (after Fox).

in crustacea and other molluscs. It is almost equal to the 
oxygen capacity of Arenicolan blood. Bounhiol (1902) found that the polychætes with hæmoglobin have a more active gas exchange than those without hæmoglobin. It cannot be stated as yet with confidence that chlorocruorin performs an essential rôle in the life of the worm; for the blood circulation is poorly developed and there appears no danger of oxygen deficiency in the water in the life of Spirographis under normal conditions. It is interesting to note that the earthworm will survive perfectly well after all its hæmoglobin has been converted into carboxy-hæmoglobin so that the blood pigment can no longer function as a vehicle for the transport or a means for storing oxygen. Chlorocruorin in many respects resembles the hæmoglobins. It forms a compound with carbon monoxide. The oxidised form is reduced by potassium ferricyanide. It acts as a peroxidase. It is possible to prepare a parallel series of derivatives of chlorocruorin analogous to met-hæmoglobin, hæmatoporphyrin, hæmochromogen, etc.

Finally, mention must be made of a pigment allied to hæmoglobin in the liver of the crayfish and the gut of all pulmonates except Planorbis, a genus in which hæmoglobin itself occurs in the blood. Helicorubin, as this pigment is called, has been investigated by Anson and Mursky (1925), who find that it combines loosely with oxygen, its affinity for the latter being increased, not as in the case of hæmoglobin decreased, by the acidity of the medium. These authors have put forward a rather different view of the biochemical and phyletic relationship of the hæmoglobins from that hitherto accepted and indicated earlier in this chapter. They regard hæmochromogen and its oxidised form hæmatin as themselves conjugated proteins of which hæmoglobin and oxyhæmoglobin are respectively polymers. To the iron-pyrrol part of the molecule Anson and Mirsky apply the term ham. Hæmochromogen is a compound of hæm and a nitrogenous substance, protein or otherwise. The hæms of different hæmoglobins and of helicorubin are identical; the specificity of the hæmoglobins depends on the nature of the conjugate globin or the degree of polymerisation of the hæmochromogen. The separation of hæm from its conjugate protein (or other 
nitrogenous compound) takes place in acid medium. At present the physiological significance of helicorubin is obscure.

The Transport of Carbon Dioxide.-We have seen that in the recovery phase of muscle the intake of oxygen is accompanied by an evolution of carbon dioxide. The removal of carbon dioxide is generally considered under the heading of respiration, though it cannot be assumed without direct evidence that the intake of oxygen and the excretion of $\mathrm{CO}_{2}$ always takes place in the same organs.

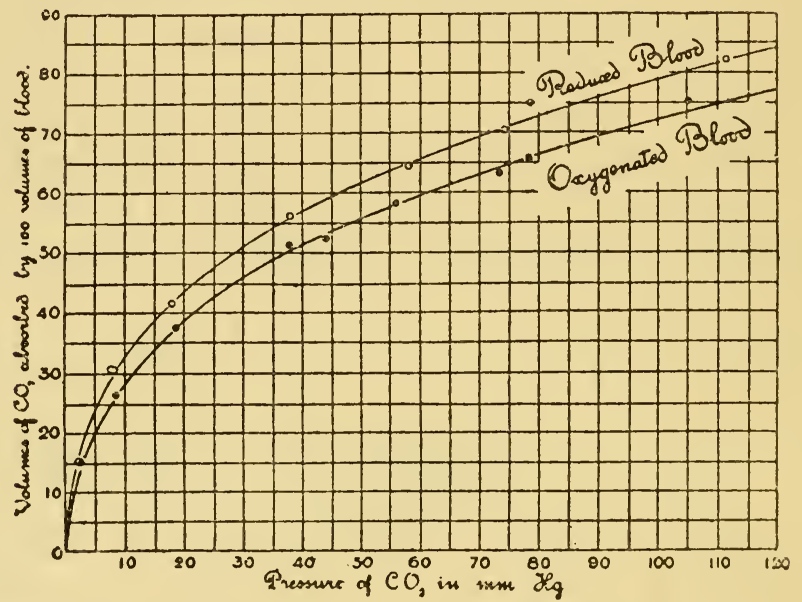

FIG. 2I.-Curves relating the amount of $\mathrm{CO}_{2}$ taken up by a given volume of blood to $\mathrm{CO}_{2}$ pressure, showing that oxygenated blood takes up less $\mathrm{CO}_{2}$, and that therefore oxygenation has made the blood more acid (after J. S. Haldane).

If the carriage of carbon dioxide in the blood of the mammal is studied by analogous methods to those employed for plotting the dissociation curve for hæmoglobin-i.e. exposure of the blood to different tensions of carbon dioxide and estimation of the carbon dioxide absorbed,-it is found that the amount of carbon dioxide which can be taken up by the blood is considerably greater than that which would be dissolved by physical solution even at comparatively high tensions. At a partial pressure of $40 \mathrm{~mm}$., which corresponds to the lowest tension of $\mathrm{CO}_{2}$ with which the arterial blood of the mammal 
is in equilibrium, 100 c.c. of blood contain over 50 c.c. of carbon dioxide. This combined carbon dioxide exists in the blood in the form of sodium bicarbonate. It has been shown by Parsons that the alkali comes from the dissociation of hæmoglobin, which exists in the blood on the alkaline side of its isoelectric point as a sodium salt. Hæmoglobin is a weaker acid than its oxygen derivative, and oxygenation therefore favours the displacement of $\mathrm{CO}_{2}$ in the competition between the weak carbonic acid and the protein anion for a fixed amount of base (Fig. 2I).

The conditions of carbon dioxide in the blood of marine invertebrates have been recently studied by Collip (I920) and by Parsons and Parsons (1923). The state of affairs existing in these animals is different in some respects from that which is found in the mammal. Collip's investigations, on representatives of molluscs, arthropods, annelids, and cœlenterates, indicate that in general the amount of carbon dioxide taken up at pressures greater than the low tension of $\mathrm{CO}_{2}$ in ordinary atmospheric air are only such as would be accounted for by physical solution. Practically all the available alkali is combined to form bicarbonate at a carbon dioxide tension far below that found even in the arterial blood of the mammal, where the alkali reserve is not used up until comparatively high tensions are attained. This peculiarity is of interest, firstly, in relation to the part played by hæmoglobin as an alkaline salt in the blood of the mammal ; secondly, in relation to the rate of metabolism which such an arrangement permits; and thirdly, as affecting the reaction of the blood which in the normal life of the mammal is kept constant within fairly narrow limits by the buffer action of the dissociated protein.

These points have been investigated in several genera by Parsons and Parsons (1923), from whose observations emerges a very significant difference between the conditions of carbon dioxide transport in the blood of comparatively active free-living forms such as the crustacean genera Maia and Palinurus or the cephalopod Octopus, and sluggish or sedentary forms such as the mollusc Aplysia and the tunicate Phallusia. In Aplysia and Phallusia the uptake of $\mathrm{CO}_{2}$ is 
practically a linear function of the partial pressure for all values of the latter, and the carbon dioxide capacity of the blood is not greater than that of sea-water. In the case of the tunicate that of the whole blood is rather less; but the capacity of the plasma is somewhat higher than that of the whole blood, and the difference is probably correlated with the distinctly acid reaction of the corpuscles which, according to Henze, may contain as much as 3 per cent. free sulphuric acid. In marked contrast with the carbon dioxide capacity of these comparatively inactive forms are the curves derived

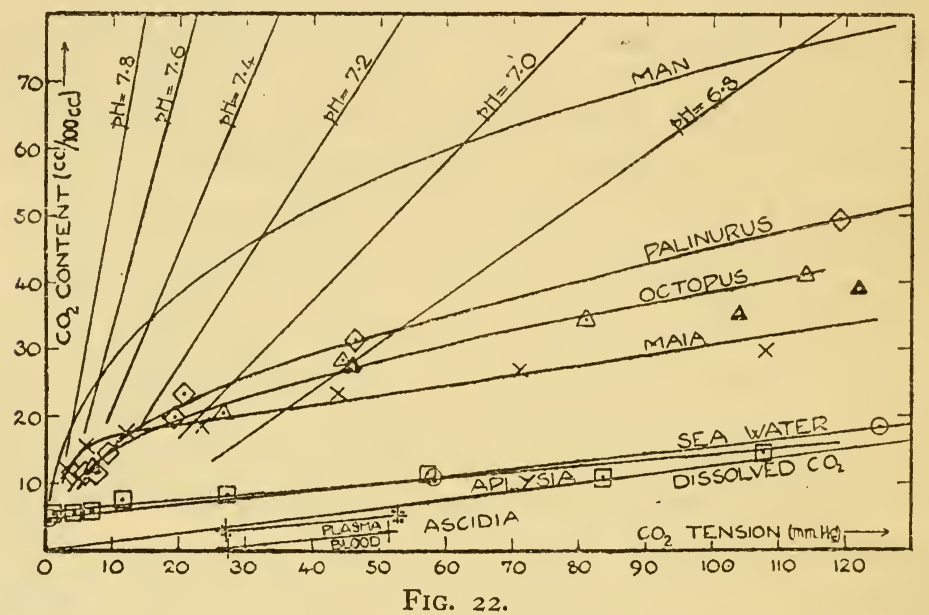

from the blood of the crustacean and cephalopod (Fig. 22). Here the uptake of $\mathrm{CO}_{2}$ by the blood increases steeply up to a tension of about $15 \mathrm{~mm}$. Hg; and within this limit the reaction remains well on the alkaline side of neutrality. The steep portion of the curve is much less protracted than in the mammal ; but according to Parsons and Parsons there is never more than about 3-10 c.c. of $\mathrm{CO}_{2}$ per Ioo c.c. of blood in these animals as against 50 c.c. in roo c.c. of mammalian arterial blood. The more stable reaction and greater carbon dioxide capacity of the blood in the crustacean and cephalopod as contrasted with the condition in Aplysia is that the blood of the former is rich in hæmocyanin and other proteins. The 
body fluid of Aplysia (Bottazzi) contains less than o.or per cent. of protein nitrogen. The isoelectric point of hæmocyanin is well below absolute neutrality, being according to Quagliariello about $\mathrm{pH} .47$, so that in the slightly alkaline blood of the invertebrates which possess it, it should be dissociated as an anion; and Quagliariello finds, as might be expected on the assumption that proteins are amphoteric electrolytes, that the acid-neutralising power of invertebrate blood is roughly proportional to its protein content. Thus it would appear that the proteins of the blood of invertebrates, as in the mammal, exist normally as sodium salts capable of giving up their kation for the carriage of carbon dioxide away from the tissues as sodium bicarbonate, and that the steep initial portion of the carbon dioxide dissociation curve exhibited by those forms which possess hæmocyanin is due to the competition of $\mathrm{CO}_{2}$ and protein anions for the alkali kations of the blood.

\section{FURTHER READING}

Books.

BARCROFT's Respiratory Function of the Blood.

KroGh's Respiratory Exchange of Animals and Man.

HALDANE's Organism and Environment.

Haldane's Respiration.

On Respiration in Cephalopods.

Polimanti (1912). Beitrage zur physiologie von Sepia II. Arch.f. anat. u. Physiol. p. 53 (1909).

Winterstein. Zur kenntnis der Blutgase wirbellose Seetiere. Biochem. Zeitschr. I9.

Annelids.

Bounhiol (1902). Recherches sur la respiration des annelides. Ann. de sci. nat. 16.

\section{Insects.}

Buddenbrock AND RoHr (I922). Die Atmung von Dixipus morosus. Zeit. Allg. Physiol. 20.

KRoGh (1913-20). On the Composition of the Air in the Trachea System. Skand. Arch. Physiol. 29.

Studien ueber Tracheen Respiration II-III. Pflugers Arch. 179.

LEE (1924). On the Mechanism of Respiration in Certain Orthoptera. Journ. Exp. Zool. 4I. 


\section{Fishes.}

BAglioni (1909). Der Atmungsmechanismus der Fische. Zcit. Allg. Physiol. 7.

Winterstein (1908). Bcitrage zur Kenntnis der Fischatmung Pflugers Archiv. 125.

\section{Pigments.}

AlsberG AND Clark (1910-14). Hæmocyanin of Limulus. J. Biol. Chem. 8. Solubility of Oxygen in the Serum of Limulus. Ibid. 19. Barcroft and Barcroft (r924). The Blood Pigment of Arenicola. Proc. Roy. Soc. B. 96.

DHËRÉ (I916-2I). Recherche sur l'hæmocyanine I-VIII. Journ. de Physio. et Pathol. Gen. r6-20.

Fox (1924). On Chlorocruorin I. Proc. Camb. Phil. Soc.

KROGH AND LeITCH (1919). The Respiratory Function of the Blood in Fishes. Journ. Physiol. 52.

Quagliariello (I920). Ricerchi etc. sulla emocianina. I-III. Arch. Sci. Biol. (1922) Pubbl. St. Zool. Napoli.

Stedian and Stedman (1925). Biochem. Journ. 19.

Carbon Dioxide.

Parsons AND Parsons (1923). Transport of Carbon Dioxide in the Blood of Some Marine Invertebrates. Journ. Gen. Physiol. 6. 


\section{CHAPTER V}

\section{NUTRITION}

WHEN a muscle contracts glycogen disappears. Only part of this glycogen is reinstated in the recovery phase of muscular contraction, and probably an analogous phenomenon occurs, as already indicated, in the case of ciliary and glandular activity. It is necessary, therefore, that the supply of materials in the effector organ should be replenished. In the case of growing organisms, it is necessary also that a supply of the materials concerned with the manufacture and growth of cells shall be maintained. In this chapter we shall deal with the means by which a supply of necessary material is ensured.

It is more than a century since Lavoisier and Laplace showed that the bodily heat of warm-blooded animals is a form of slow combustion, and that the amount of oxygen used up and of carbon dioxide liberated has a definite and ascertainable relationship to the heat that is generated. By applying the balance and the thermometer to the phenomena of life, Lavoisier founded the modern science of nutrition. By the middle of the following century Liebig had shown that the three categories of organic compounds known as proteins, carbohydrates and fats are the substances whose decomposition and oxidation form the basis of those chemical changes which occur under the influence of living cells and are collectively referred to under the term "metabolism." A signal advance was made by the researches of Voit and others in the 'sixties, when it was shown that muscular activity does not increase protein metabolism (estimated by the nitrogenous content of the urine); that the complete combustion of a given weight of each class of compounds is associated with the 
intake of a definite amount of oxygen; and that the ratio of carbon dioxide evolved to oxygen used up is different for carbohydrates, fats, and proteins respectively. This ratio is known as the respiratory quotient. It is, as would be expected, unity in the case of carbohydrates, and less than unity for fats $\left(0^{\circ} 7 \mathrm{I}\right)$ and proteins $\left(0^{\circ} 78\right)$. The investigations of Liebig coincided with the formal statement of the conservation of energy by Mayer on the basis of Joule's determination of the mechanical equivalent of heat. The general applicability of the first law of thermodynamics to living organisms was universally accepted as the basis of physiological research by the end of the nineteenth century.

For the greater part of this period, however, the impossibility of oxidising animal foodstuffs at such temperatures as are consistent with organic existence as we know it, or of stimulating the digestive reactions in vitro without recourse to reagents which would be fatal to the organism, presented an inflexible barrier to the probability that the mechanism of living organisms conforms to the known laws of energetics. To-day the position has changed in two ways. The study of those more complex chemico-physical systems which are for convenience described as "colloids," and the rôle of surface tension, osmotic pressure, and electrolytic dissociation in modifying their properties, opens up a new horizon of possibilities, while the extension of the principle of catalysis to enzymes, and its clarification by Ostwald and others, has thrown a flood of light on the chemical equilibrium of the organism.

Sources of Animal Food.-Fats, proteins, and carbohydrates are the principal constituents of a healthy diet. There is a certain amount of evidence that fats and carbohydrates are convertible into one another, and that carbohydrates can be manufactured from the deaminised products of protein metabolism. Protein as such is not necessary; but it seems that it can only be replaced by its hydrolysis products, the amino-acids. In this connection some interesting bionomic problems arise.

It was found by Loeb (1915) that the banana fly (Droso- 
phila) can complete its larval stage in a solution of cane sugar and salts adsorbed in filter paper. The larvæ grows quickly, and on addition of ammonium tartrate, glucose, and citric acid, successive generations can be reared. Here at first sight appears to be an organism that can flourish in a medium deficient in nitrogen compounds of the degree of complexity hitherto thought to be required by animals invariably. This, however, is not the case.

The nitrogen supply of Drosophila has been made the subject of recent investigation by Baumberger (19I8). The alimentary tract in Drosophila larvæ teems with yeasts. In order to explore a possible relation between the yeast organisms and the nutritional processes of the fly, Baumberger sterilised eggs and pupæ by immersion for a short period in 85 per cent. alcohol. Sterile individuals having been so obtained, both sterile and normal individuals were placed on $(a)$ sterile banana--agar culture media, and $(b)$ a sterile synthetic medium containing mineral salts, sugar, and ammonium tartarate as the sole source of nitrogen. The consequences of this treatment on the two classes of individuals were striking. Normal (i.e. unsterilised) individuals deposited eggs which grew into larvæ that pupated normally on both banana-agar and synthetic media. The larvæ which developed from sterilised eggs and as the offspring of sterilised pupæ failed either to grow or pupate on a sterile medium of either type ; they only survived a few days. When, on the other hand, similar sterilised individuals were placed on media of the same nature which had been previously infected with yeasts, they at once began to thrive, pupating as usual. Thus in the presence of yeasts Drosophila can grow on an artificial medium with ammonium tartarate as its only source of nitrogen.

It may now be asked whether the food requirements are met by any by-products of fermentation. This Baumberger tested by boiling the yeast before adding it to the sterile cultures; fermentation was in this way prevented. The larvæ, however, grew steadily, and the possibility that the fly larva actually ingests the yeasts alone remained. On cultures of compressed yeast-agar with yeast nucleo-proteins as the sole 
nitrogen supply, the sterile larvæ were able to grow and pupate normally. It thus appears that yeasts are the nitrogenous food of Drosophila; the simplest nutrient solution suitable for the yeasts (and certain other micro-organisms) will replace fermenting fruit in the ecology of Drosophila larvæ. These experiments of Baumberger are extremely suggestive in relation to the diet of wood-boring animals, the significance of fungus gardens, the curious habitat of such organisms as the vinegar worm, and a host of other bionomic problems.

Researches have also been carried out on Drosophila larvæ in relation to the accessory food-factors or vitamins. The term "vitamin" is one which at present can hardly be said to convey more than a recognition of our failure to induce mammals to grow healthily on a diet of purified carbohydrate, fat, protein, etc., and our almost complete ignorance of those constituents of natural foods which must be added to such a diet to preserve health and normal development. The necessity for recognising accessory food-factors was first clearly recognised by Hopkins (1906), and the conception became more concrete when Funk (I9II) extracted from Ioo kilograms of yeast $2 \cdot 5$ grms. of a material of which a dose of $2 \mathrm{mg}$. sufficed to cure the polyneuritis induced in pigeons by an exclusive diet of polished rice. There are at least three chemical entities included under the term "vitamin." A is present especially in animal fats, $B$ in yeast, and $C$ in fruit juices; but in fresh animal or vegetable food all three are represented to some extent. The separate identity of these substances is inferred from the different clinical results of eliminating one or the other.

Bacot and Harden (1922) have investigated the extent to which vitamins are essential to the diet of Drosophila. Successful growth of larvæ can apparently proceed in a nutrient medium composed of pure caseinogen, starch, sugar, and salts only if small quantities of yeast extract (as a source of "B ") and traces of butter fat ("A ") are included. " $\mathrm{C}$ " was not found to be essential, though amply available in the normal diet (fermenting fruit-juice).

The behaviour of Drosophila in regard to yeasts more- 
over recalls Keeble's researches on the supposed symbiosis between the turbellarian Convoluta and the Chlamydomonad which infests its subintegumentary tissues and is ultimately destined to be absorbed by intracellular ingestion in the body of its host after degeneration of the alimentary tract in the latter. Reference may be made here to an hypothesis put forward some years ago by Pütter (1907) who maintained that many aquatic organisms absorb dissolved organic matter from the water as a source of food. This view is provocative, because as Dakin rightly points out, though structures resembling the alimentary tract of land animals exist throughout the animal phyla, it is largely on the basis of analogy that these have been regarded as the only avenue through which food passes into the organism. Pütter's hypothesis was based on three lines of reasoning: (i) that there exists in sea-water a comparatively large available quantity of dissolved organic matter; (ii) that the quantity of solid food present in seawater is insufficient to account for the rate of respiration of marine organisms; (iii) that certain animals-e.g. goldfishdo not lose weight if amino-acids, glycerine, etc., are dissolved in the water, but do so if kept without food in water containing no dissolved organic matter. As regards the first, later investigation has not as yet fully confirmed Pütter's analyses, but recent observations of Harvey (1925) and of Atkins (1925) point to the conclusion that appreciable quantities of dissolved organic matter exist in sea-water. The data on which the second conclusion is based are questionable. Experiments of Pütter on absorption of nitrogenous solutes by goldfish and axolotls have recently been repeated by Dakin and Dakin (1925) with negative results. There seems, therefore, insufficient reason for abandoning the view accepted by most students of the plankton, that marine organisms prey on one another, the smaller organisms providing food for larger ones, as in the following series (Johnstone's "Life in the Sea "): Peridinians-Copepoda-Sprats-Whiting-Cod-Man.

Feeding Mechanisms.-Appropriate devices (jaws, beaks, etc.) for the trituration of food in animals which actively select their diet are described in text-books of zoology. A 
few words may be inserted here with reference to the methods adopted by animals of sluggish and sedentary habits for maintaining a supply of food. Most widespread of such feeding mechanisms are those which involve the entanglement of food particles, such as organic debris and micro-organisms of the plankton, in mucous slime through the production of ciliary currents to maintain a constant flow of water over the slime-glands and to propel the entrapped food-particles towards the mouth. In Amphioxus, for example (Orton), water flows from the pharynx into the atrium by the lashing

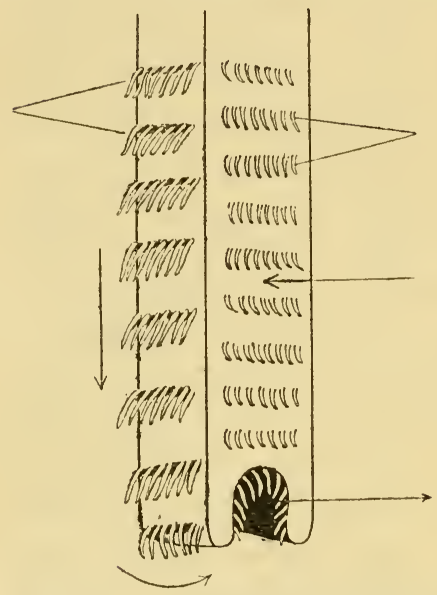

Fig. 23.-Ciliary currents on the Lamellibranch gill. of cilia which line the sides of the pores in two lateral rows; these cilia do not play a direct part in the collection of foodparticles, which are caught in a fine sheet of mucus secreted by the endostylar gland cells and thrown on to the sides of the pharynx by the cilia of the ventral groove. This sheet of slime with its entrapped foodparticles is worked up into cylindrical masses driven towards the dorsal groove by cilia which line the inner wall of the pharynx. The cilia of the hyperpharyngeal groove maintain a current of this slimy suspension in the direction of the intestine where digestion and absorption take place. Essentially similar arrangements exist in Tunicates, Amphioxus, and in at least one Vertebrate, the Ammocote larva of Petromyzon. In the bivalve molluscs it is again the structures which descriptive anatomists have labelled gills which constitute the ciliary net. Water laden with organic debris and microorganisms filters between the filaments of the gills through the action of currents produced by the lateral cilia. A ventrally directed current due to the frontal cilia washes the food-particles entangled in slime downwards towards a 
ciliated groove formed by the distal ends of the filaments. In this food-groove a strong anteriorly directed ciliary current washes the mucous stream on to the labial palps, whence they are propelled-still by ciliary action-into the mouth (Orton, Kellogg, Yonge). There are often special arrangements for excluding coarse particles, sand, etc. In the primitive gastropod Crepidula - and probably other marine prosobranchs - we find analogous phenomena. According to Orton (1913) in Crepidula an ingoing and outgoing current is established along a definite pathway and the single gill acts as a strainer between them. The filaments lie parallel in a horizontal line extending along the left side of the mantle cavity, dividing it into a left ventrolateral inhalent chamber and a right dorsventral exhalent chamber. In feeding, the front end of the shell is raised slightly, water is drawn in along the anterior half of the shell on the left, passed through spaces between the gill-filaments, and expelled along the front half of the right edge of the shell. Upon reaching the tips of the filaments, the food-particles, driven along in a mucous stream by the frontal cilia, are deposited in a food-groove, like that already seen in lamellibranchs, running along the right side of the body. Eventually the food-masses are seized on by the radula. Ciliary feeding occurs in Brachiopods, Polyzoa, and some Polychæta. Entanglement of food-particles in slime is also seen in small crustacea such as Daphnids, where the labial glands exude a stream of mucilaginous secretion which entraps suspended matter in the ventral current produced by the thoracic appendages, to be seized on by the mouth parts.

The History of the Foodstuffs.-We may now turn to consider the changes which the three principal classes of organic food-constituents undergo in the digestive tract, and their subsequent fate in the body. For a detailed treatment of the latter, standard monographs on biochemistry must be consulted; such knowledge as we possess is derived very largely from clinical sources and from the study of mammalian physiology.

As proteins exist in colloidal form, they are incapable of 
passing through the membranes of the digestive tract until broken down into diffusible products by hydrolysis. In the mammal there appear to be three stages in the process. The first takes place through the agency of the gastric enzyme pepsin which exerts its optimum efficiency in an acid medium which is provided for by the presence of free $\mathrm{HCl}$ in the secretion of the gastric mucosa. Prolonged digestion in vitro of proteins in the presence of pepsin does not carry the process to the liberation of amino-acids, which are the end-products of protein hydrolysis in presence of inorganic catalysts. In the body peptic digestion probably promotes only the initial stages of splitting into simpler proteins such as proteoses and peptones.

The enzyme trypsin which is supplied by the pancreatic juice can bring about the complete hydrolysis of proteins in vitro. In the body it seems probable that the reaction is not carried beyond the production of the relatively simple and diffusible condensation-products of amino acids known as polypeptides. The final resolution of these into simple aminoacids is apparently effected with the co-operation of a proteoclastic ferment in the secretion of the intestinal mucosa (erepsin). Proteoclastic enzymes have been detected in extracts of the digestive glands of all groups in the animal kingdom. How far they are identical with those which occur in the mammalian gut is not certain. Using the facility with which a gelatine mixture solidifies when cooled for a fixed period in the ice-bath as a measure of the progress of protein hydrolysis, Bodansky and Rose (1922) extracted from the mesenteric filaments of the jelly-fish Stomolophus and the siphons of Physalia (Siphonophora) a digestive fluid with two $\mathrm{pH}$. optima at $3^{\circ} \circ$ and $7^{\circ} 3$ respectively, roughly corresponding to the $\mathrm{pH}$. optima for mammalian pepsin and trypsin. A rennet-like ferment capable of coagulating the milk protein caseinogen was also found to be present. Yonge (1924) was unable to find a pepsin-like enzyme in the digestive gland of the lobster; but free amino-acids were obtained from an alkaline digest with the extract.

In the tissues, especially in the liver of the Vertebrates, 
amino-acids are partially decomposed with liberation of ammonia. The latter combines with $\mathrm{CO}_{2}$ in the blood to be transformed into urea, which is ultimately excreted; the residual portion of the amino-acid molecule is a keto-acid which forms a common link in the intermediate metabolism of carbohydrates and fats. This process is known as deamination. The importance of this lies in the fact that in some carnivorous animals there is very little carbohydrate present in the food, though, as we have seen, the chemical energy of carbohydrates is the ultimate source of the mechanical energy of molecule contraction. Thus while most animals feed predominantly on nitrogenous food, the nitrogenous part of the protein molecule is of little constructive importance except in growing animals, where new protoplasm is being formed. We have to distinguish between endogenous metabolism which is concerned with growth and tissue waste on the one hand, and exogenous metabolism which is concerned with effector activities and the maintenance of body heat on the other.

Observations have been made concerning the deamination of amino-acids in the blow-fly (Calliphora) by Weinland (1908), who showed that both the larvæ and a pulp made by crushing them had the power, in the absence of oxygen, to split peptones into amino-acids, deaminise them with evolution of ammonia, and produce higher fatty acids with evolution of $\mathrm{CO}_{2}$ - presumably by synthesis from the nitrogenfree remainder of the amino-acids. The particular enzyme reactions which occur on a large scale in the digestive processes are not to be regarded as special properties of the alimentary secretions, but rather as characteristic of what is involved, to a greater or less extent, in the metabolism of all cells in the body. Among the hydrolysis-products of one important class of proteins, the nucleo-proteins, purine bases are found in addition to amino-acids. Purine bases derived from food or tissue waste are excreted in many animals as uric acid. But enzymes are known to exist which oxidise purines with formation of urea; and uric acid is not an invariable excretory product.

The extent to which fats contribute to the diet varies 
greatly with the feeding habits of the organism. In the mammal the bulk of the fat is unchanged in the stomach. In the duodenum, aided by the churning movements of the intestinal wall, bile-salts exert their characteristic effect in lowering surface tension to effect a fine degree of emulsification. The emulsion is acted upon by a lipolytic enzyme of the pancreatic juice, and broken down completely into its hydrolysis products by neutralisation of the fatty acid so formed with production of soaps. The soaps of the higher fatty acids form colloidal solutions, and are not diffusible like aminoacids or sugars. They are absorbed by the cells of the mucous membrane, which are richly gorged with fat-globules after a meal of fat-containing food. The colloidal nature of the higher soaps suggests that the same way of dealing with hydrolysis products of fat should hold in other groups, as the work of Sanford (1918) on digestion in the cockroaches clearly demonstrates. Sanford fed cockroaches on a mixture of sugar and olive oil and showed, by following microscopically the course of digestion, that after a fatty meal the cells lining the wall of the crop teem with fat globules. The contents of the crop exhibited, like the pancreatic juice of the mammal, a powerful lipolytic action. This provides good material for class experiment. The organ is removed from about a dozen cockroaches, ground in a mortar with sand and about ro c.c. of water, a few c.c. of the filtered extract is added to about the same quantity of olive oil and kept for a few days at room temperature, when the amount of free acid liberated is determined by titration and compared with a control tube. For microscopic examination sections of the wall fixed at varying intervals after the meal are treated with osmic acid or the dye known as Sudan III., both of which are specific stains for fat. Sanford also fed cockroaches on a paste of oil and sugar mixed with Nile Blue sulphate, which is absorbed by the fat-globules and gives a red coloration in presence of free fatty acid. On cutting frozen sections a few hours after such a meal, a red mass is seen clinging to the wall of the crop which is itself blue owing to the dye adsorbed by the fat globules in the cells. 
The fats which occur in the animal body are all derived from fatty acids with an even number of carbon atoms. The diabetic animal can form glucose from glycerol; and a stage in the intermediary metabolism of the fatty acids is the formation of keto-acids which further link up the metabolism of fats with that of carbohydrates. Animals fed on carbohydrate or protein diet deposit fat in their tissues, and the study of hibernation indicates that the transformation of fat into carbohydrates also occurs. In hibernating mammals (Pembrey) the respiratory quotient may be as low as $0^{\circ} 3$, showing that there is a conversion of substances with a small quantity of oxygen (fat) into others with a larger amount (carbohydrate).

Of carbohydrates, the polysaccharides starch and cellulose are the principal representatives in animal diet. The rôle of the former alone is understood in relation to the metabolism of the mammal, where the breakdown of starch (and glycogen) occurs in three stages during digestion. An amylase is present in the saliva which is capable of carrying the hydrolysis of starch in vitro through dextrins to the disaccharide malt sugar. Actually the acidity of the gastric juice limits considerably the extent of starch-digestion in its initial phase. The same process is continued in the duodenum by the action of an enzyme present in the pancreatic juice. There are in addition present in the secretion of the duodenal glands enzymes which complete the hydrolysis of maltose and the other disaccharides (lactose and sucrose) into monosaccharide, in which form they diffuse into the body. In the vertebrate the blood, enriched with sugar, after digestion, has to flow through the capillaries of the liver, where conditions occur that permit synthesis of the storage carbohydrate glycogen under the influence of an enzyme (glycogenase). During starvation the reverse reaction predominates-glycogen is transformed into sugar, which can be transported by the blood to the muscle where it is also stored in the form of glycogen. Glycogen is the universal storage form of carbohydrates in animals. And the storage of glycogen is also a function of the so-called liver of crustacea. The amount of glycogen in the crab's liver increases before each moult, and is used 
up during the period when the new shell is being formed and the animal is temporarily deprived of the power to feed.

Amylolytic enzymes have been found in the alimentary tract of all animals investigated with this end in view. In the cœlenterates mentioned, Bodansky and Rose found that an amylase and a maltase were present but lactase was absent. On the other hand, both sucrose and lactose are digested by extracts of the digestive gland of the lobster.

A remarkable phenomenon connected with starch digestion in the invertebrate phyla is presented by the structure known as the crystalline style present in most lamelli-

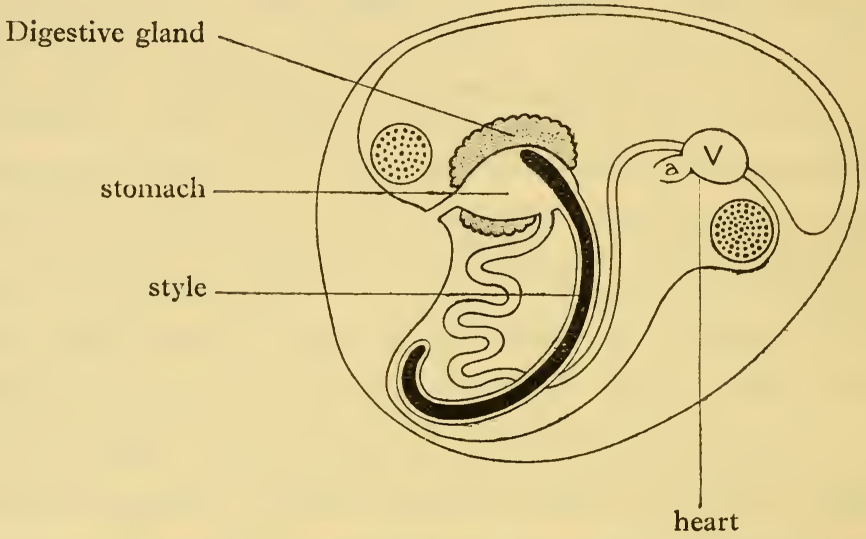

FIG. 24. - The crystalline style of the bivalve mollusc.

branchs and in a few prosobranch gasteropods. The crystalline style is an elongated hyaline rod of proteinous nature to which is absorbed an amylolytic enzyme. It lies freely either in a groove of the intestine or in a separate diverticulum, revolving about its axis in the ciliary current produced by the epithelium of its sac. As it revolves its anterior end, which in many forms projects into the stomach, is worn away against a horny plate (the gastric shield) in the dorsal wall of the latter, entangling in its motion a mucous mass laden with diatoms and inorganic debris. In some forms it is broken down and reformed periodically; in the Eastern oyster (Nelson) it disappears an hour after the fall of tide, and may be reformed in fifteen 
minutes. In other cases, as in Mya (Edmondson), it is permanent and may take months to regenerate if excised. As the hepato-pancreatic secretion which is poured into the stomach contains a proteolytic enzyme which rapidly dissolves the style in vitro, the permanence or otherwise of the style possibly depends (Yonge) simply on whether it is protected by enclosure in a separate diverticulum or lies exposed in an open groove of the intestine. Mitra (I90I) showed that extracts of the style have a strong amylolytic reaction. This is abundantly confirmed in a large number of genera. Style extracts do not digest fats, proteins, inulin, cellulose, or cane sugar. They break down starch and glycogen completely with the production of glucose. The temperature-optimum $\left(32^{\circ} \mathrm{C}\right.$.) is, as would be expected, lower than that of the ptyalin in the saliva ; on the other hand, the amylase found in the digestive gland of the lobster has a very high optimum-about $56^{\circ} \mathrm{C}$., according to Yonge (1924). Temperature optima in enzyme reactions deserve further inquiry as a limiting factor in geographical distribution.

In connection with the digestion of carbohydrates there is one point which will merit further investigation. Cellulose is an important ingredient in the diet of all animals living on plants, yet in vertebrates no cellulose-splitting ferment has been identified with certainty. Biedermann and Moritz (I898) found a cellulose-splitting ferment in the digestive gland of the snail ; and the same authors also detected a cytase in the hepatopancreas of Astacus; but Yonge (1924) was unable to detect any cellulose-splitting action in extracts of the digestive gland of the Norwegian lobster. In herbivorous mammals cellulose splitting appears to be effected by micro-organisms living symbiotically in the alimentary tract.

For a detailed account of intermediate carbohydrate metabolism other sources must be consulted. However, mention must be made of the part played by the pancreas in vertebrates. The mammalian pancreas contains, in addition to the exocrine acini, groups of cells known as "islets of Langerhans." In Teleosts the islet tissue is wholly or partly separate (Rennie) from the acinar elements. In I 889 Mering 
and Minkowski produced glycosuria (increase of sugar in the urine) by the removal of the pancreas in the dog. Later it was shown that ligation of the pancreatic duct produces degeneration of the acini; extraction of the islet tissue then yields a product which, when injected into the diabetic dog was found by Banting and Best (1922) to lower the blood sugar, and raise the respiratory quotient. Macleod and his co-workers have shown that extracts of the islet tissues in fishes relieve the diabetes produced by extirpation of the pancreas in rabbits. The exact stage at which insulin, the internal secretion of the pancreas, influences carbohydrate metabolism is still not fully understood. The lowering of the blood sugar produced by injection of insulin in mammals is accompanied by convulsions, which can also be reproduced according to Huxley and Fulton (1923) in frogs. Macleod finds that injection of insulin reduces the blood sugar content in fishes, and that removal of the islet tissue causes hyperglycœmia.

Absorption and passage of Foodstuffis along the Gut.-The motion of food in the mammalian gut depends upon more than one mode of response on the part of the circular and longitudinal musculature of its wall. There are rhythmical movements which tend to churn the food without moving it predominantly in one direction; these are an intrinsic property of the muscle itself, though subject to inhibitory and excitatory nervous control by the splanchnic and vagus nerves respectively. Further, when mechanically stimulated, intestinal muscle shows a relaxation of tone and inhibition of movement on the aboral side of the point stimulated, accompanied by increased force of movement on the oral side (law of the intestine). This is generally believed to depend on a local nervous mechanism, the myenteric plexus ; its function is to keep the food moving on the whole towards the anal end of the gut.

The food is propelled along the gut by the contraction of its muscular walls in annelids, molluscs, arthropods, and echinoderms as well as in vertebrates. The intrinsic rhythm of the muscular system of the gut is beautifully seen in the excised alimentary tract of many worms, sea-urchins, and 
holothurians. Allen observed that the œsophagus of a species of Syllid pulsates at a rate of 250 per minute. In most cases rhythmical movement can be induced by applying gentle stretching, e.g. by attaching a strip of gut to a light lever. This can be shown in the crop of Helix (Ten Cate), Aplysia (Brucke), the rectum of Astacus (Ten Cate), or in ring preparations of the pharyngeal musculature of Aphrodite (Hogben and Hobson). The property very commonly displayed by plain muscle in responding to gentle stretching by contraction is probably very important in the production of churning movement in the gut. In Lamellibranchs there is very little muscular tissue associated with the alimentary tract, which is ciliated throughout; and ciliary movement is the main factor in propelling the food from the mouth to the anus in these animals. In many Lamellibranchs, however, the rectum pierces the ventricle, and by inserting a cannula in the former, Ten Cate (1924) has shown that the pressure in the rectum of Anodon undergoes rhythmical variation in unison with the heart beat. It seems that the heart may here function as a means of promoting evacuation of rectal contents. The nervous control of defæcation has been studied in the lobster (Homarus) by Miller (I9I2). The radial musculature that controls the closure of the anus (there is no true sphincter) is supplied by fibres from the last abdominal ganglion, and stimulation of these nerves produces rhythmical defæcation movements (incomplete tetanus). It is doubtful whether the mechanism of defæcation is simply a segmental reflex, since such movements can be induced after section of the nerves.

There has been little important work relating to the physico-chemical aspects of absorption based on invertebrate material. However, two points are worth mentioning. The phenomenon of intracellular digestion, familiar enough in the case of cœlenterates, is much more widely prevalent in the invertebrate phyla than is generally recognised. It occurs in animals with very elaborate digestive systems such as Gasteropods and Lamellibranchs. Yonge has photographed ingested diatoms in the cells lining the stomach of the bivalve, Mya. 
The structure of the alimentary canal in Arthropods has prompted several investigations into the localisation of absorption in these animals. The greater part of the tract is lined with chitin. In the case of the cockroach Sanford's observations conclusively prove that absorption can take place in the fore-gut of some insects. On the other hand, the work of Murlin, Cuénot, Jordan, Yonge, and others clearly shows that in crustacea absorption is confined to the mid-gut and the tubules of the digestive gland. Direct experiment shows that the fore and hind gut behave as semipermeable membranes to glucose and salts, which, however, penetrate the wall of the mid-gut.

\section{REFERENCES}

Bacot and Harden (1922). The Vitamin Requirements of Drosophila. Biochem. Journ. 16.

BodANSKY AND Rose (1922). Comparative Studies on Digestion I-II. Am. Journ. Physiol.

Coward and Drummond (1922). On the Significance of Vitamin A in the Nutrition of Fish. Biochem. Journ. 16.

Dakin and Dakin (1925). The Oxygen Requirements of Certain Aquatic Animals and its bearing on the Food Supply. Brit. Journ. Exp. Biol.2.

HUNT (1925). The Food of the Bottom Fauna, etc. Journ. Marine Biol. Ass. 13.

Miller (I9IO). On the Rhythmical Contractibility of the Anal Musculature of the Crayfish and Lobster. Journ. Physiol. 40.

Orton (I912). The Mode of Feeding in Crepidula. Journ. Marine. Biol. Ass. 9.

SANFORD (I918). Experiments on the Physiology of Digestion in the Blattidæ. Journ. Exp. Zool. 25.

Ten Cate (1923-24). Contributions à la physiologie du cœur de l'anodonte. Arch. Neerland. Physiol. 8.

Contributions à la physiologie comparée du canal stomaco-intestinal. I-III. Ibid. 9.

YoNGE (1923-24). Studies on the Comparative Physiology of Digestion. I-II. Brit. Journ. Exp. Biol. I. 


\section{CHAPTER VI}

\section{THE CIRCULATION OF BODY FLUIDS}

INASMUCH as most activities of an organism are intermittent, and the intake of material sources of energy localised, there is usually in Metazoa some arrangement for keeping in motion the body fluids and regulating this motion so as to meet with the constantly changing requirements of the tissues. Thus a consideration of the circulatory system may be conveniently inserted in connexion with the sources of vital energy before turning to the more specialised aspects of co-ordination in the chapters which follow.

The circulatory system subserves two functions : it distributes food to the tissues, and it supplies oxygen to them removing carbon dioxide at the same time. The fact that such intensely active organisms as dragon flies, being provided with a respiratory apparatus which supplies oxygen directly to the tissues, are able to exist with a circulatory system that is practically vestigial, indicates that the primary importance of the latter lies in meeting what Barcroft terms the call of the tissues for oxygen rather than in distributing foodstuffs and products of intermediate metabolism. It is also interesting to note that the smaller representatives of groups the majority of which possess a vascular system are those which are more often found to be without a well-developed circulation. That is to say, the necessity for a circulatory system seems to be greater where the surface for intake of oxygen is relatively less compared with the mass of the organism. The regulation of the oxygen supply to the tissues by the blood is a subject which has been investigated very little except in the higher vertebrates. Most of the work on the circulatory system of 
invertebrates deals with the action of drugs and nervous stimulation on the heart. Molluscs, Arthropods, and Annelids are probably the only invertebrate groups in which the circulatory system plays an important rôle.

Other things being equal, the rate at which a tissue can take up oxygen depends upon the amount of blood which flows through it in unit time. The flow of liquid through a tube depends upon the force propelling it, the viscosity of the fluid, the sectional area of the tube, and the length traversed. The last can be regarded as a constant for present purposes. The second is probably an important but little known factor in the circulation. Attention has mainly been focussed on the propelling force, supplied in vertebrates, arthropods, and mulluscs, by the heart beat, and on the sectional area (constriction or dilatation) of the vessels. As the activity of the heart is an intermittent force, the average force exerted by its action depends upon two variables, the amplitude or force of the individual beat, and the frequency with which the beats occur. The output of the heart in the vertebrate depends partly upon the resistance against which it works, being in so far a selfregulatory mechanism, and is partly determined by a double nervous control-that of the vagus, which is present in all craniates including cyclostomes and is inhibitory, and that of the sympathetic, which is an augmentor factor specially well developed in the warm-blooded vertebrates. Variation in the diameter of the vessels determines the resistance against which the heart works as well as contributing directly to the rate of flow through, and therefore the oxygen supply of any given organ. It is provided for by the fact that the arteries, veins, and capillaries possess contractile elements, plain muscle in the case of arteries and veins and a special type of contractile tissue, the cells of Rouget, in the case of the capillaries. The relaxation and contraction of the contractile elements investing the walls of the vessels is brought about by extrinsic agencies (nerves and hormones) and by the local action of metabolites produced during the activity of an organ, as illustrated by the work of Barcroft upon salivary secretion (see Chapter III). The influence of hormones is 
exemplified by the recent work of Krogh (1922), who has shown in Amphibia that the pituitary is necessary for the maintenance of capillary tone, and that injection of pituitary extract leads to capillary constriction.

Nervous control of the peripheral circulation in vertebrates is complex. The constriction of arterioles is brought about by stimulation of sympathetic fibres which have their cellstations in the chain ganglia. Dilatation is probably produced in the main by a peculiar mechanism which is nervous but not reflex in the strict sense of the term. It is believed that certain sensory fibres have branches with motor terminations in the peripheral vessels, and may thus propagate local disturbances such as arise through mechanical irritation (antidromic action).

The state of constriction of arteries and capillaries has been studied by the three principal methods: manometer measurement of the blood-pressure, volume-changes of individual organs, and rate of flow from vessels artificially perfused. The recognition through the work of Krogh that the capillaries are active agents in determining the resistance to the flow of blood in the peripheral circulation shows that none of these methods is wholly satisfactory ; and our views on the regulation of blood-flow may require considerable revision in the near future. Stimulation of the central ends of most sensory nerves produces reflex rise of blood-pressure in Vertebrates, by exciting the nerve-endings of vaso-constrictor paths which emerge from the vasomotor centre in the bulb. In mammals there is a special afferent nerve from the heart exercising an inhibitory influence on the vasomotor centre (the depressor branch of the vagus).

Our knowledge of the circulatory system of invertebrates is very slight. Practically nothing is known of the peripheral circulation, so that the following account must be confined to the properties of the circulating fluid and the control of cardiac rhythm.

Blood of Invertebrates.-The occurrence of respiratory pigments in the blood of invertebrates has already been treated under that heading. Two further points are of special interest 
from the standpoint of comparative physiology, namely, the osmotic pressure and coagulative power of blood. The osmotic pressure of the blood is important as part of the mechanism of co-ordination. Thus the low blood-pressure of crustacea makes it inconceivable that simple filtration could play any rôle in their excretory processes (as in the glomerular function of vertebrates), because of the high content of proteins whose osmotic force must be overcome in some way in order to effect any separation of water and diffusible salts from the blood. In land vertebrates the osmotic pressure of the blood is a constant quantity for any species. The following figures (cf. Bayliss' "General Physiology") for the freezing-point depression (Bottazzi) bring out a fact of great bionomic interest:

$\begin{array}{llll}\text { Mammal (whale) } & \ldots & \ldots & 0.65^{\circ}-0^{\circ} 7^{\circ} \\ \text { Reptile (turtle) } & \ldots & \ldots & 0.6 \mathrm{r}^{\circ} \\ \text { Teleost } & \ldots & \ldots & \circ .76^{\circ}-\mathrm{I}^{\circ} 04^{\circ} \\ \text { Elasmobranch } & \ldots & \ldots & 2.26^{\circ} \\ \text { Sea water } & \ldots & \ldots & 2.3^{\circ}\end{array}$

The osmotic pressure of the blood of elasmobranchs is the same as that of the sea water in which they live; and the same is true of all marine invertebrates; and, as was first shown by Fredericq (1885), this is not a mere coincidence, for the osmotic pressure of the blood adjusts itself to that of the medium over wide changes of concentration and dilution. We have already mentioned temperature optima of body proteins and loading tension of respiratory pigments as possible physiological factors in geographical distribution. The extent to which an animal can rapidly adjust itself to change in osmotic pressure is doubtless an important aspect of the ecology of estuarine forms. Some modification in response to changed conditions was shown by Dakin in Teleosts, in which we see the beginnings of a fixed osmotic condition of the body fluids. It may be noted in passing that the saline constituents of elasmobranch blood are not much more concentrated than those of the blood of Teleostei ; the difference depends upon the high concentration of urea in selachian blood. Mines found that the presence of urea was necessary to ensure successful perfusion of the elasmobranch heart. The hearts of marine invertebrates in all cases that have been tried will 
beat in sea water. Adjustments of osmotic pressure of body fluids to that of the medium probably takes place through the gills. There is no known advantage in this arrangement ; on the contrary, the extreme sensitivity of colloidal systems to electrolytes implies the advantage of a fixed osmotic pressure for the delicate adjustments of colloidal equilibrium which underlie the physical processes of life in any medium. In this connexion reference may be made to the fact that, while there is a paucity of reliable analyses of the electrolyte content of the blood in invertebrates, such figures as are available indicate a rather higher percentage of magnesium than is present in the blood of the higher vertebrates. It will be remembered that sea water is richer in magnesium than in any other kation with the exception of sodium.

A few words may now be said about coagulation, which also has some bionomic interest ; for while the greatest care should be exercised in interpreting biological phenomena as protective mechanisms, it is difficult to deny any utilitarian significance to the fact that the phenomenon of blood coagulation is exemplified in no more striking manner throughout the animal kingdom than in arthropods, whose segmental structure renders the loss of limbs a common occurrence. The blood of molluscs has little coagulative power. That of crustacea clots with remarkable rapidity ; and the process is often a complex one, taking place in some species in two stages. The first stage in the clotting of crustacean blood corresponds more or less to the coagulation process in that of the Arachnid, Limulus, whose blood also clots rapidly. In Limulus the protein content of the blood is almost exclusively made up by the hæmocyanin and white blood corpuscles. Coagulation is essentially a phenomenon of cytolysis (Alsberg and Clark), and can be prevented by reagents which hinder cell agglutination. For the first stage of coagulation in crustacean blood, which is brought about by the cytolysis of special "explosive" cells, first recognised by Hardy (1892), immediately they come into contact with foreign substance, it has been shown by L. Loeb that calcium ions are not necessary, though they are necessary for the second, which takes place in lobster blood about a 
quarter of an hour later. This consists of a jellying of the plasma, but according to Tait (I9I8) it is accompanied by a further cytolysis of corpuscles, which he designates thigmocytes. Loeb states that lobster tissues yield specific coagulins for the blood of the same species. According to Tait all the corpuscles of crustacean blood are actively phagocytic. The subject has attracted a large number of investigators since attention was focussed upon it by the pioneer labours of Fredericq; but much still remains to be done, especially from the standpoint of a more modern appreciation of colloidal behaviour.

The Ostiate Heart of Limulus and Crustacea.-Investigation into the circulatory system of Arthropods has been chiefly focussed upon the task of elucidating the origin and conduction of the cardiac rhythm. The essential characteristic of the arthropod circulation is the ostiate heart. Generally speaking the heart is composed of striated muscle fibres, and lies in a capacious sinus into which, in those forms which lead an aquatic life, there discharge the lacunar spaces of the gills; in the tracheates the circulatory system is poorly developed, though an ostiate heart is present.

There is no division of the heart into auricular and ventricular portions. It is filled by way of valve-like apertures, the ostia, which communicate directly with the pericardial sinus during diastole, but remained closed during the systolic phase. From the heart proceed the larger arteries. In crustacea, at least in Decapods (Baumann), there are valves at the cardiac end of the larger arteries, so that the pressure in the arterial system does not fall to zero in diastole. A welldeveloped arterial system is found in Limulus, scorpions and decapod crustacea. In those forms in which the arterial system is well developed the heart is a powerful organ, and beats with a frequency comparable to that of the cephalopod heart.

Nevertheless, from such data as we have at our disposal, it would seem that the peripheral resistance is very low, doubtless on account of the fact that the arteries discharge into lacunar spaces and not into a network of capillaries. Brucke 
and Satacke (I9I2) measured the pressure of the blood in the abdominal aorta of the lobster by means of a water manometer, using hirudin as anticoagulant, and found that with the heart beating at a rate of $5^{\mathrm{I}}$ per minute the average pressure-reading was only about $8 \mathrm{~mm}$. of mercury.

The most extensive studies on the circulatory system of any invertebrate are the investigations of Carlson on the heart of the king-crab, Limulus. In this arachnid the heart retains the original segmental character. It attains to a length of about six inches in a full-sized animal, and thus provides excellent experimental material. There are eight pairs of ostia. The major arteries are located towards the anterior end of the heart. Histologically it is a syncytium of striated fibres. On

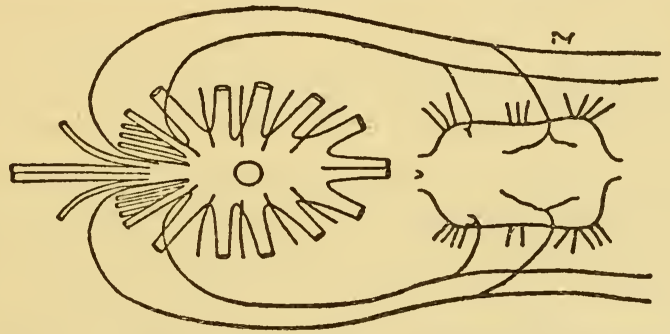

FIG. 25.-Innervation of heart of Palinurus (Carlson).

its dorsal aspect there is an elongated median nerve-ganglion, which can be easily detached. There are also a pair of laterallydisposed nerves connected with the abdominal ganglia and with the cerebrothoracic ganglion of the central nervous system. Electrical stimulation of the extrinsic cardiac nerves from the abdominal ganglia leads to acceleration of the normal rhythm; the same result may be produced by stimulating the ventral nerve-cord or abdominal ganglia themselves after transection of the cord behind the brain. Stimulation of the brain or its nerve-connections with the heart leads to diastolic arrest. There is thus a double augmentor-inhibitor mechanism by which the activity of the heart is subjected to control by the central nervous system, as in vertebrates. The same has been shown to be the case in Maia (Bottazzi, Polimanti) and Palinurus (Carlson) among decapod crustacea. 
However, the origin and conduction of the heart-rhythm, in Limulus at all events, is quite different from what is generally accepted to be the case in vertebrates. In Limulus each contraction starts at the posterior end of the heart, and travels forward to the region from which the main arteries have their origin. When the heart is removed from the body,

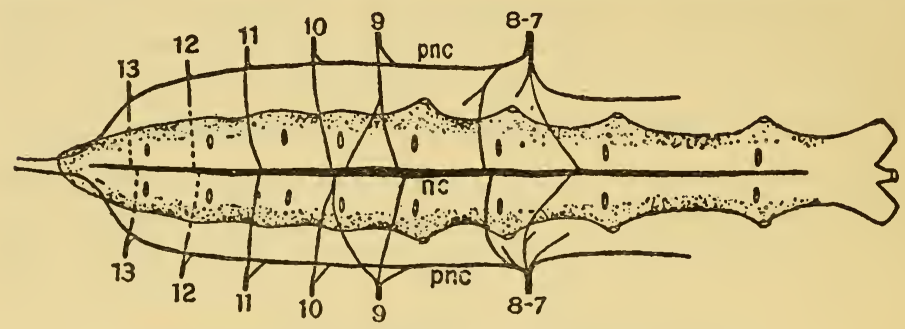

Fig. 26.-Heart and nerves of Limulus (Carlson).

7-8 Cardiac nerve from brain; $9-\mathrm{II}$ cardiac nerve from abdominal ganglia; n.c. cardiac ganglion; p.n.c. lateral nerves.

so that all its connexions with the central nervous system are severed, it still continues to beat with its normal rhythm of about twenty to thirty a minute. From this it might be thought that the heart-rhythm is an inherent property of the cardiac muscle, as in vertebrates. From two lines of experimental evidence, however, Carlson has shown conclusively that this is not the case. He first investigated the effect of stripping off the ganglion referred to above. When the cardiac ganglion

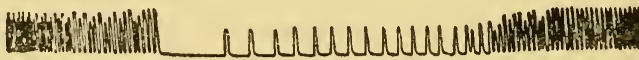

FIG. 27.-Inhibition of heart beat of Limulus by electrical stimulation of brain with weak current (Carlson).

is removed the heart ceases to beat. The normal isolated heart will only beat in plasma or sea water if the ganglion is left intact; after removal of the ganglion the heart may be made to contract rhythmically in isotonic sodium chloride after immersion for half an hour; in this respect it agrees, however, with vertebrate striped muscle, which acquires a regular contractile rhythm in the absence of calcium salts. If, in the isolated heart, the ganglion is divided into four 
portions, alternate segments being then stripped off, the heartbeat continues only in those portions to which the remaining ganglionic tissues adhere, the rhythm of the pulsating regions being now unco-ordinated.

The last-mentioned experiment leads to a consideration of another peculiarity of the cardiac rhythm in Limulus. In vertebrates, not only is it true that the beat arises spontaneously in the muscle-cells of the sinus venosus, or cardinal sinuses (Fishes); but the conduction of the excitation from one part of the heart to another takes place through the muscular tissue. The muscular continuity of the auricles and ventricles in the higher vertebrates is effected through a bundle of modified muscle fibres, the bundle of His. Carlson has shown that section of the heart of Limulus without damage to the median ganglion does not interrupt the synchronism of the two halves ; but section of the median ganglion alone abolishes the coordination of rhythm, each half now beating with a rhythm of its own. It appears fairly certain, therefore, that the origin and co-ordination of the heart beat in Limulus depends upon the rhythmical discharge of nervous stimuli from the cardiac ganglion; there is no precise parallel to such a mechanism in vertebrates outside the central nervous system itself. It is to be noted that stimulation of the heart-muscle or median ganglion itself with an interrupted current produces a tetanus ; the period during which the heart remains refractory to a second stimulus is not protracted to the extent so characteristic of cardiac muscle in the vertebrate.

Some investigators have sought to apply the same interpretation of the origin and conduction of the heart-beat to decapod Crustacea. It is to be noted, however, that the median ganglion of Limulus is an organ sui generis. There may, of course, be ganglion cells in the heart-muscle of crustacea ; but there is no structure comparable to the cardiac ganglion of Limulus in their gross anatomy, Limulus is not very closely related to crustacea in the phyletic scale. Moreover. the embryonic heart of Limulus, which is at first composed of smooth muscle, beats before any nerve-fibres reach it: ontogenetically it is a myogenic heart. And it is quite likely that one would find 
the common ancestor of Limulus and the crustacea in a form which, like Peripatus, possessed only smooth muscle, and therefore, presumably, a heart whose rhythm was myogenic.

In support of the neurogenic interpretation of the crustacean heart beat Hoffmann (I9I2) has emphasised certain peculiarities which are shared by the electrical response of the crustacean and arachnid heart. In both cases each major variation corresponding to a single mechanical contraction displays small superimposed oscillatory deflections. It is, however, to be noted that the exposed heart of the crustacean beating in situ often shows twitching movements superimposed upon the regular beats ; and the same is true of the isolated heart beating in sea water or other suitable media. In connexion with the supposed neurogenic origin of the heart-rhythm in crustacea, it is worthy of note that the frequency of the beats has a temperature coefficient which is fairly high, as may be seen from the following data taken from Brailsford Robertson's paper on Ceriodaphnia :

$$
\begin{array}{lllll}
\mathrm{Q}_{10} \mathrm{II} / 2 \mathrm{I}^{\circ} & \ldots & \ldots & \ldots & \mathrm{I}^{\circ} 92 \\
\mathrm{Q}_{10} \mathrm{I} 3^{\circ} / 23^{\circ} & \ldots & \ldots & \ldots & \mathrm{I}^{\circ} 90 \\
\mathrm{Q}_{10} \mathrm{I} 5^{\circ} / 25^{\circ} & \ldots & \ldots & \ldots & 20
\end{array}
$$

The Circulatory System in Molluscs.-Among the Cephalopod molluscs the circulatory system reaches the highest degree of specialisation met with among the invertebrate phyla. The anatomical relations are briefly as follows. Venous blood is collected by the caval vein which bifurcates to form two branches supplying the gills. These afferent branchial vessels dilate at the base of the gills into rhythmically contractile branchial hearts, which drive the colourless venous blood through the gill-capillaries. Oxygenated blue blood is collected by the efferent vessels directly to the auricles of the systemic heart, the ventricle (which may be divided) pumping the arterial blood into the aortæ. This would seem to be a much more efficient device for supplying oxygenated blood to the tissues at high pressure than the arrangement which exists in fishes, where the force of the heart's heat has to overcome the resistance of the gill-capillaries as well as that of the body 
capillaries. And it is an experimental fact that the bloodpressure in the arterial system of the Cephalopod is much higher than in that of the fish. The aortic pressure of the octopus has been determined by several observers, first by Fuchs, who found that it varied between $25-80 \mathrm{~mm}$. $\mathrm{Hg}$; probably the latter figure is more representative. But the efficiency of the mechanism becomes even more striking when the relation between the rhythm of the branchial hearts, of the systemic hearts, and of the respiratory movements is studied. The pulsation of the branchial hearts precedes that of the systemic hearts, but at the same rate (about 30 beats

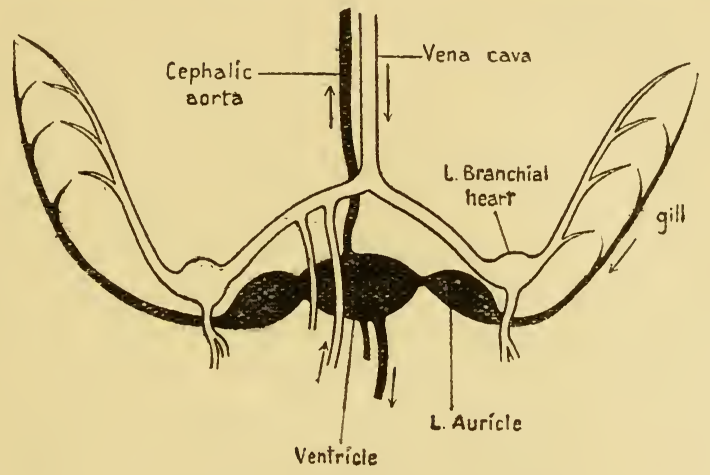

FIG. 28.- Heart of Cephalopod.

per second), and the frequency of the heart-beats is almost identical with that of the respiratory movements. The means by which this synchronism is maintained is a fascinating field; and several investigations have been made into the innervation of the cephalopod heart, notably, with modern methods, by Carlson and by Fry. The later work of $\mathrm{H}$. Fredericq provides the clearest account of the co-ordination of cardiac rhythm in this group. Fredericq's experiments were carried out on the octopus, and deal with the relation of the branchial and systemic hearts. When the ventricle is cut off from the auricles by a ligature, the ventricular beat ceases immediately. This apparently is not due to a severing of the functional continuity of the conducting tissue, if any, as in the case of 
the Stannius experiment on the heart of the frog, where the rhythm originates in the sinus. Several considerations which are borne out by the behaviour of the isolated heart point to the contrary. When the isolated ventricle is perfused with sea water or a suitable saline medium, it ceases to pulsate at once when the pressure falls below about $20 \mathrm{~mm}$. of water, but starts again when the pressure is raised above that level. The increase of pressure beyond this point does not lead to any augmentation of the amplitude; a certain minimum driving force is necessary to initiate the rhythm. The cessation of ventricular movement on ligation of the auriculoventricular junction is due to the fact that the auricles can no longer maintain the requisite critical pressure necessary to set the ventricles in action. If, however, the auricles are separated by a ligature from the efferent branchial vessels they continue to beat synchronously with one another and in unison with the branchial hearts. This co-ordination might reside either in the nature of the contractile tissues, which is unlikely ; or in some reflex mechanism. That a reflex mechanism may co-ordinate the pulsation of one auricle with its fellow is indicated by the fact (Fredericq) that while stimulation of either intact visceral nerve brings the heart to diastolic standstill, stimulation of the peripheral end of the cut nerve produces inhibition of the auricle on the same side only, whereas stimulation of the central end produces inhibition on the opposite side. Here, then, is a mechanism by which one auricle may reflexly inhibit its fellow, by afferent nerve-connexions which recall in one respect the familiar depressor nerve of the mammalian heart. That a reflex mechanism underlies the co-ordination of activity of auricles and branchial hearts is suggested by the effects of direct electrical stimulation, when the beating of the heart has been stopped by the faradisation of the inhibitory nerves. If in this condition one branchial heart is stimulated, it contracts, and its contraction is followed first by that of the branchial heart of the opposite gill, and secondly by that of the two auricles, which is the normal sequence of cardiac rhythm. It is also found that if under similar conditions the renal vein is stimulated, 
contraction of the branchial hearts followed by that of the systemic auricles results. There is thus reason to believe that there exists in cephalopods, as in vertebrates, a complex reflex mechanism co-ordinating the constituent parts of the circulatory system.

The dependence of ventricular rhythm on the stretching force of the auricular beat in Octopus is a phenomenon which is characteristic of the ventricular muscle of other mulluscs, e.g. Anodon, Pecten, Helix, Aplysia, etc. The empty heart of the mollusc does not beat. This fact depends upon a widespread characteristic of plain muscle, studied by Straub, Buddington, and others in denervated preparations of the integumentary muscle of the earthworm. Stretching suffices to induce rhythmical contraction in isolated rings of the segmental muscles of Lumbricus. In the mammalian bladder, distension is the normal stimulus for contraction; and Carey (I92I) has recently found that by introducing fluid into a dog's bladder under considerable pressure, the walls of the latter gradually become thicker, come to simulate microscopically those of the heart and pulsate rhythmically at a rate of two hundred per minute. Carlson (1906) has utilised the fact that the empty heart does not beat in seeking for evidence of cardiac augmentor nerves in his investigations on numerous molluscan genera. Inhibitory cardiac nerves appear to exist in all groups (lamellibranchs, cephalopods, and pulmonates) with the possible exception of marine gasteropods (e.g. Aplysia). There is a well-developed augmentor nerve supply in Aplysia.

Straub (1904) has made a careful study of the effect of pressure on ventricular rhythm in Aplysia. Between the pressures $4-20 \mathrm{~mm}$. of water the pulse volume is almost directly proportional to the pressure applied, and as the auricle supplies a pressure of about $30 \mathrm{~mm}$. (water), the heart normally works under approximately the optimum conditions for ventricular contraction. In gasteropods, however, the peripheral circulation is poorly developed; a few larger vessels empty into ill-defined lacunæ which finally converge upon the gillsinuses. The total resistance of the peripheral circulation is so small that the blood-pressure is not of the same order 
of magnitude as the maximal force which the heart can exert (Straub).

The same is true of Lamellibranchs. Willen and Minne found that the ventricular pressure rises from $10 \mathrm{~mm}$. (water) in diastole to $35 \mathrm{~mm}$. in systole in Anodon. The heart-beat of Anodon is comparatively slow, as may be seen from the following table, for which temperature data are not in all cases available :-

Lamellibranchs:

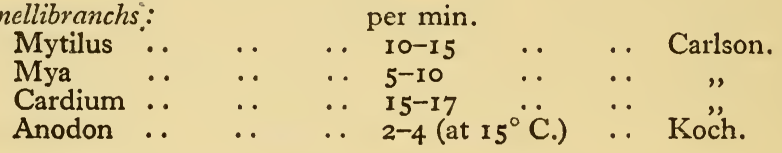

Gasteropods :

Helix

Cephalopods:

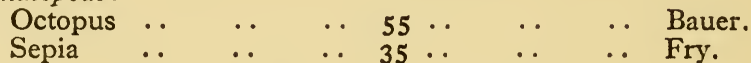

Koch (I9I6) has made a very careful study of the heartbeat in Anodon, which has also been recently investigated by Ten Cate (1923). The former investigator describes a phenomenon which is of great interest from the bionomic standpoint, namely the variation of the pulse-rate with opening and closing of the shell. In the open condition the heart of an animal may beat five times as quickly as when its shell is closed. Saturation of the water with oxygen also increases the frequency of the heart-beat in Anodon.

Periodic Reversal of Rhythm in the Tunicate Heart.-An interesting field for investigation is met with in Tunicates, whose circulatory system displays a peculiarity which has been familiar to zoologists for nearly a century. The heart in the larger ascidians is an elongated cylindrical tube looped round the base of the pharyngeal sac, so that one end lies dorsal to the gut and may extend to the nerve ganglion, the other end being ventral on the opposite side of the pharnyx. The heartrhythm is made up of alternating series of beats progressing respectively from the dorsal (advisceral) and ventral (abvisceral) ends of the heart. In Ascidia mentula, as described by Day (I92I), each pulsation-series lasts from two to four 
minutes and consists of from twenty to forty beats according to the size and condition of the animal. In any individual the number of beats in each advisceral or abvisceral series tends to be approximately constant. Each pulsation series is followed by a pause of from ten to twenty seconds before reversal of the direction of the contraction wave occurs. Acceleration is caused by severing the nerves. Extirpation of the ganglion or incisions in the tunic produce an increase in the number of beats per series, a slight acceleration of the pulsation rate and a diminution of the pause before reversal. After a time varying from an hour to a day the original rhythm returns. In Ascidia atra, which has been investigated by Hecht (I9I8), the heart has a wellmarked nodal constriction about halfway along its length. Most individuals show a marked preponderance of advisceral over

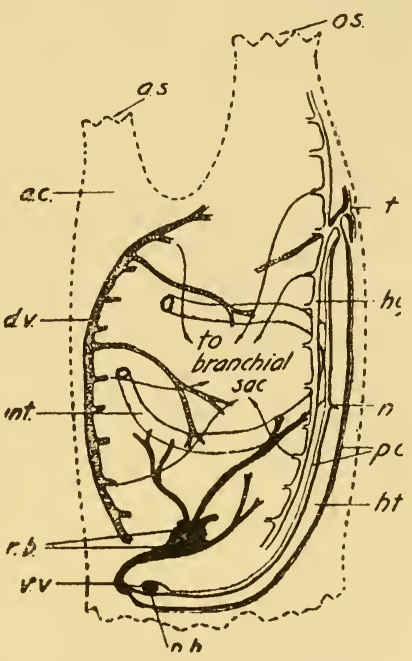

Fig. 29.-Anatomy of Ascidian to show circulatory system (after Hecht). abvisceral beats. Thus in one series of observations the beats succeeded one another as follows :

$\begin{array}{lllllllll}\text { Abvisceral } & & 17 & & 15 & & 36 & & 36 \\ \text { Advisceral } & 20 & & 44 & & 51 & & 65 & \end{array}$ Various hypotheses have been suggested to account for this phenomenon of reversal. In particular one may mention the suggestion that the significant factor is back-pressure from the peripheral circulation. This is dismissed by Hecht on three grounds. First, because it occurs in the isolated heart. Secondly, because it can be abolished by raising the temperature to a certain height (about $35^{\circ} \mathrm{C}$. in Hecht's experiments), when the direction of the contraction wave remains constant. Thirdly, because the peripheral resistance cannot be very 
high on account of the structure of the circulatory system. The blood-spaces are continuous; the cavities in which the blood flows are derived from the primitive blastocoel of the embryo, where the latter is not filled with strands of connective tissue and gelatinous material. Only in the larger ascidians do connective tissue cells lining these lacunæ limit well-defined tubes, such as those formed by evagination into the substance of the test.

In conclusion, some mention is due to the peculiar character of the blood in some Tunicates. In the colourless plasma, there are in addition to amœboid and spherical unpigmented corpuscles, others packed with large granules of green colour and markedly acid reaction. It is curious to note that the green pigment is a compound of Vanadium and a protein. The low oxygen-capacity of the blood makes it practically certain that this is not a respiratory pigment. Clotting as in crustacean blood is brought about by agglutination.

\section{REFERENCES}

Alsberg (1914). The Proteins of the Blood of Limulus. J. Biol. Chem. I9.

Brucke and Satacke (1912). Der Arterielle Blutdruck des Hummers. Zeitschr. Allg. Physiol. 7.

Dakin (1908). The Osmotic Concentration of the Blood of Fishes, etc. Biochem. J. 3.

Carlson (1904-5). Nervous Origin of the Heart Beat in Limulus. Am. Journ. Physiol. 12.

- (I906). Chemical Conditions of Heart Action in Limulus. Ibid. I6.

- (1905). The Comparative Physiology of the Invertebrate Heart. Ibid. I3-14.

- (1922). A Note on the Action of Drugs on the Invertebrate Heart. Journ. Gen. Physiol. 4.

Carlson and Meek (1908). On the Mechanism of the Embryonic Heart Rhythm. Am. Journ. Physiol. 21.

FREDERICQ (1913). Recherches experimentales sur la physiologie cardiaque d'Octopus. Arch. Int. Physiol. I4.

FRY (1909). The Influence of the Visceral Nerves on the Heart of Cephalopods. Journ. Physiol. 39.

Fuchs (1908). Beitrage zur Physiologie des Kreislaufes bei den Cephalopoden Pflugers Archiv. 60.

HART (1924). L'action des ions sur les mouvements rhythmiques du sac muscule cutane du lombric. Arch. Neerland. Physiol. 9.

Hecht (1918). The Physiology of Ascidia atra. Am. Journ. Physiol. 45. 


\section{THE CIRCULATION OF BODY FLUIDS II7}

Hoffmann (I9II). Ueber Elektrokardiogram von Evertebraten. Arch. Anat. u. Physiol. I 9 I I.

Koch (1916). Der Herzschlag von Anodonta. Pflugers Archiv. 156.

LOEB (1903). Ueber die Bedeutung der Blutkorperschen für die Blutgerinnung. Virchow's Archiv. 173.

Polimanti (I9I3). Beitrage zur Physiologie von Maia. Arch. Anat. u. Physiol. I9r 3 .

Straub (1904). Fortgesetzte Studien am Aplysienherz. Pflugers Archiv. 103.

TAIT (I9I8). The Blood of Astacus fluviatilis. Q. J. E. P. I2. 


\section{CHAPTER VII}

\section{ENDOCRINE CO-ORDINATION}

LIFE as understood by the biologist is a term used to denote a certain combination of reactions exhibited by organic systems under the influence of external stimuli. In the opening chapters attention was focussed upon the mechanisms which underlie the characteristic manifestations of vital activity in animals. From these we turned to consider the material exchanges from which the energy of these activities is derived. The activities of an organism are related in a definite manner to external conditions ; and it is this co-ordination or integration of response which gives rise to the conception of the individual as a physiological unit.

The integration of response presents two aspects. In all multicellular animals other than sponges, visible manifestations of activity involve first a receptive surface upon which the stimulus operates; secondly, a structure, the effector organ, specialised for the performance of the appropriate response; and thirdly, intervening between these, a mechanism of co-ordination by which the disturbance is propagated from the seat of stimulation to the region at which the response is carried into effect. Co-ordination of this kind is twofold: all multicellular animals except sponges and a few aberrant organisms (Mesozoa) of uncertain phyletic relationship possess specialised conducting tissue in continuity with both receptor and effector units, which tissue constitutes the nervous system ; in addition stimuli may in some animals give rise to the production of specific chemical entities which make their way through the body fluids to the organs which they are capable of activating. Apart from providing a means for co-ordinating 
metabolic processes the circulatory system acts as a channel through which can diffuse the substances known as hormones. Up to the present no clear evidence of the operation of internal secretion has been demonstrated outside the vertebrate series. Accordingly, to illustrate the nature of endocrine regulation, one cannot select a better instance than the discovery of Bayliss and Starling (1902), who first gave conclusive proof of the functional rôle of hormones in the animal body.

Secretin.-By the end of the nineteenth century it had been established that pancreatic secretion was not entirely prevented by severance of the nervous connections of the gut, though it was well recognised that the secretion of the pancreatic juice followed the signal provided by the entry of the gastric contents into the small intestine. Having found that the introduction of acid alone into the denervated gut was adequate to elicit activity of the secretory cells of the pancreas, Bayliss and Starling injected into the circulation an aqueous acid extract of the mucous lining of the duodenum, thereby activating the pancreas. Subsequent experiments showed that the liberation from the enteric mucosa of a soluble product, called by these authors secretin, provides the immediate stimulus to pancreatic secretion. Carried by the blood-stream to the resting gland, "secretin " possesses the property of producing secretory activity in the pancreatic cells ; the production and translocation of the hormone is a mechanism by which pancreatic activity is co-ordinated with the entry of food into the small intestine.

Nature of Chemical Co-ordination.-With this example before us we may proceed to define what is meant by endocrine or chemical co-ordination and the kind of evidence on which one can rely for proof of its existence. The essential characteristics of a hormone are illustrated by secretin, in that a hormone may be defined as a substance set free in the body by the activity of a localised organ and capable of evoking a specific response in tissues remotely situated from its seat of origin. In one minor respect, however, the production of secretin differs from that of some other well-established cases of internal secretion in that the hormone is not produced from a 
glandular structure (endocrine organ or ductless gland) specifically concerned with its manufacture. In defining the criteria for ascribing to any organ an endocrine function, attention need only be directed for our present purpose to the regulation of specific responses in effector organs. If it is known that an organ contains a substance which evokes a specific local response in some effector unit (e.g. action of adrenaline on the pupil or of pituitary extract on frog melanophores) its endocrine function may be established by one (or both) of two methods. In the first place, it may be shown that when responses which can be specifically evoked in isolated effectors by the presence of its active material occur spontaneously in the intact animal, they are associated with the liberation into the blood-stream of a substance having the same properties as its extract, and in amount significantly greater from that which is normally present in the blood. One may formulate the alternative as follows. Given the fact that an organ contains a specific constituent which evokes response in an isolated effector unit, it is legitimate to conclude that such an organ is of endocrine function, when the consequences of its removal upon the given effector system may be compensated by introducing the active material of its extract into the circulation.

The study of endocrine mechanisms has been prompted to a very large extent by clinical interests which lie outside the scope of the present discussion. Examples of the action of hormones will be found in other chapters dealing with developmental and metabolic processes. The pages which follow will be concerned with the part played by internal secretions in regulating response of a type which is not met with in the mammalia, and to consideration of such evidence as suggests the presence of hormones in the lower animals. Both examples selected for this purpose deal with the regulation of colour-response in cold-blooded vertebrates.

In fishes the controlling mechanism has been shown by Pouchet, v. Frisch, and others to be nervous. The melanophores of fishes are directly supplied with nerve-fibres, and the effects of local section and stimulation of nerve-trunks conclusively 
indicate that the melanophores are subject to direct nervous control. In Amphibia and Reptiles there is as yet no histological proof of innervation of the pigmentary effector system; and, as will be seen, there exists an alternative method of interpreting the regulation of pigmentary changes. We shall first consider the significance of the adrenal glands to the colour responses of reptiles. A word or two may be inserted with reference to the comparative physiology of adrenaline, concerning which there are a few observations which suggest further lines of inquiry. Adrenaline in the Animal Kingdom.-Oliver and Schafer

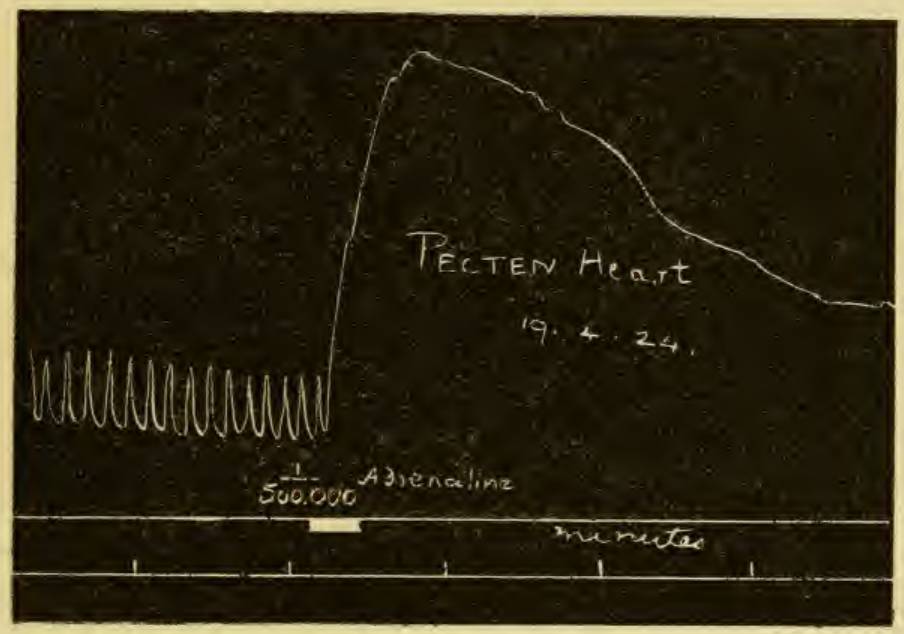

FIG. 30.-Action of adrenaline on the heart of Pecten.

(1895) first discovered that the adrenal medulla of the mammal yields an extract which has a powerful pressor action on the circulation of the mammal. Later the researches of Lewandowsky, Langley, and Elliott showed that in general adrenal medullary extracts, or adrenaline, the active substance isolated by Takamine, produces the same effects upon plain muscle in vertebrate animals as the stimulation of the sympathetic nerves, e.g. inhibition of intestinal tone and rhythm, dilatation of the pupil and constriction of the arterioles in all vertebrates and acceleration of the heart in mammals and birds. It is, however, to be noted that the action of adrenaline is 
not confined to muscles which have a sympathetic innervation ; and the validity of arguing that an effector organ such as a melanophore possesses a sympathetic nerve supply from the fact that it is acted upon by adrenaline, may be questioned. Adrenaline has a powerful action on both the ganglion and heart-muscle in Limulus (Carlson), the heart of the crab Maia (Hogben and Hobson), and the intestine of the crayfish (Ten Cate). It also acts in very great dilution as an excitant to the plain muscle of molluscs and annelids, as illustrated

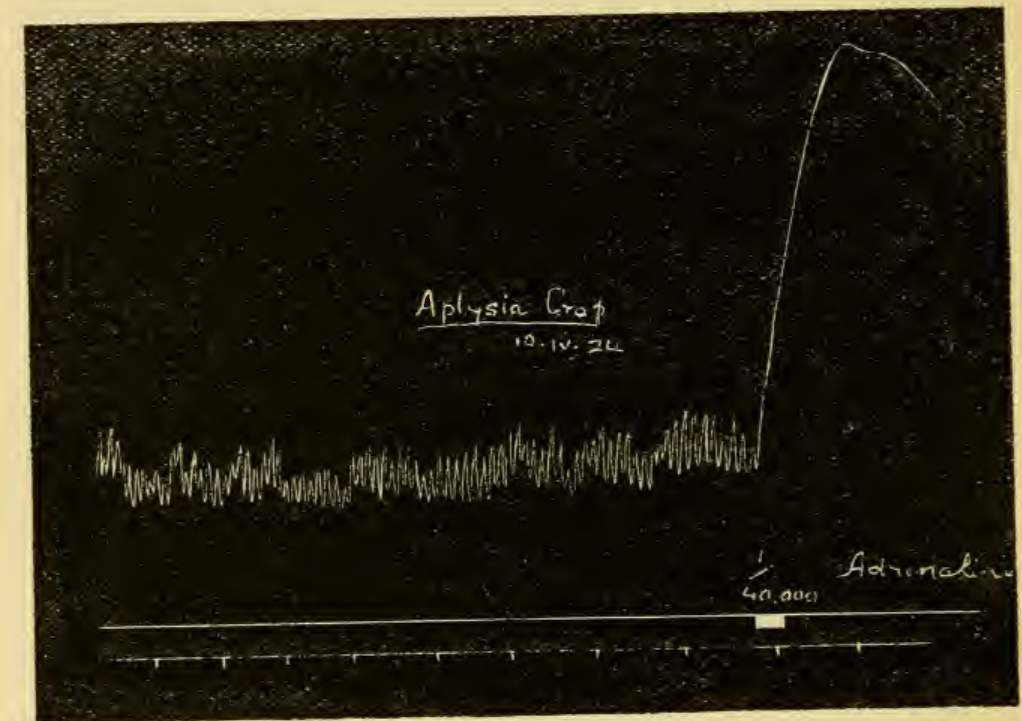

FIG. 31.-Action of adrenaline on the crop of Aplysia.

by the œsophagus of Aphrodite and Aplysia (Hogben and Hobson) and of Helix (Ten Cate), also the heart of Pecten (Hogben and Hobson). The poison with which the cephalopod kills its crustacean prey is a natural base, tyramine $\left(\mathrm{C}_{6} \mathrm{H}_{4} \mathrm{OH}\right.$.$\mathrm{CH}_{2} \mathrm{CH}_{2} \mathrm{NH}_{2}$ ) of closely allied structure to adrenaline $\left(\mathrm{C}_{6} \mathrm{H}_{3}(\mathrm{OH})_{2} \mathrm{CH} . \mathrm{OH} . \mathrm{CH}_{2} \mathrm{NH} . \mathrm{CH}_{3}\right)$ and to certain other phenolic amines for which Barger and Dale have described a similar physiological action on mammalian tissues. In this connexion it is interesting to note the presence of adrenaline in the salivary glands of a toad ( $c f$. Chapter III). 
The adrenaline-secreting cells of the medulla have a close ontogenetic relation to the post-ganglionic nerve cells of the chain ganglia of the sympathetic nervous system; unlike other glands the adrenals are innervated by pre-ganglionic fibres. Owing to the characteristic chrome-staining reaction discovered by Henle their distribution has been studied in a number of groups. In the lower vertebrates chrome-staining cells often occur in the chain ganglia of the sympathetic nervous system, and in elasmobranchs there are paired chromophil bodies associated with each pair of ganglia, the cortex of the mammalian gland being represented by a separate structure, the interrenal body. Gaskell (IgI4) has described chrome-staining cells in the ganglia of Leeches and of those Polychætes which have a well-developed musculature in connexion with the blood-vessels. These chromophil cells are, according to Gaskell, the cell-bodies of those efferent neurones which supply the vascomotor system. Gaskell regards them as the common ancestral representative of both the adrenalin-secreting cell and post-ganglionic neurone. $\mathrm{He}$ obtained from extracts of the sympathetic ganglia of the leech an action like that of adrenaline on the mammalian uterus. Adrenalin-secreting cells have also been described in the mollusc, Purpura, by Roaf. In view of the widespread action of adrenaline in the animal kingdom its distribution and possible function in invertebrates are problems which would well repay investigation.

The Rôle of Adrenaline in Reptilian Colour-response.-Apart from the indications provided by the work of Cannon in favour of the view that excitement phenomena in the mammal are associated with the liberation of adrenaline into the bloodstream, the only evidence for the functional activity of the adrenals so far available is to be drawn from the study of colourresponse in the reptile. The early experimental work on reptilian colour-response centred round the bionomic aspect of the problem, more especially in correcting erroneous teleological descriptions of protective colour-change in the chameleon prevalent at the time and still widely credited. We shall here consider the phenomena of colour-response in the 
so-called horned toad, Phrynosoma, the only reptile which has been made the subject of recent experimental treatment in this field. In the horned toad bodily colour varies between a fuscous shade (associated with the outward migration of pigment granules into the cell processes of the melanophores, which ramify among the yellow interference cells, which lie mmediately below the epidermis) and a pale cinnamon bluff tint (resulting from concentration of the pigment granules in the cell-body of the melanophore). When it is kept upon a neutral background, there is seen to be a daily rhythm of colour-change in Phrynosoma. At night the melanophores are contracted, giving the skin the appearance of pallor. In the early morning the skin becomes uniformly dark through " expansion" of the melanophores. But during the heat of the day-in its warm natural surroundings-the melanophore pigment contracts, and as evening approaches a second expansion supervenes, until night descends. The condition of pallor in natural surroundings is, therefore, seen at night and at midday. In the cooler parts of the day the skin is fuscous.

The exact part which light and temperature respectively play in promoting this sequence of reactions has been made the subject of investigation by Parker (I906) and Redfield (I9I8). From their work it appears that the melanophores of this lizard respond to light and darkness, warmth and cold, in the manner generally characteristic of reptiles, i.e. bright illumination and low temperature promote darkening of the skin, while warmth and darkness bring about pallor. Light and heat interact so that the effect of the latter predominates at extremes of temperature, and it is thus that, in natural conditions, living as these creatures do in a warm climate, pallor intervenes during that part of the day when the temperature rises to a maximum.

But in addition to this response to direct illumination, the horned toad reacts in bodily coloration to the character of the substratum and to mechanical irritation or disturbance. Any nocuous stimulus, such as electrical excitation of the roof of the mouth or the cloaca, evokes pallor in fuscous individuals 
within a few minutes. After being kept for several days on a white background the animals remain fuscous in bright light.

Redfield has recorded the results of careful experiments carried out with a view to locating the receptors involved in these modes of response. He finds that the local exclusion of light from and application of heat to restricted areas of the skin produce a local contraction of the melanophores in the region to which the stimuli are applied, without affecting the colour of the skin in other parts of the body. Furthermore, local illumination produces a local expansion of the melanophores without affecting the pigmentary effectors of other regions, while local reduction of temperature maintains locally a state of melanophore expansion already established, though it apparently cannot initiate. These experiments admit the possibility that melanophore response to heat and to light, in the case of animals kept on a neutral background, is propriogenic in character and results from the direct reactivity of the pigmentary effector organs to incident stimuli. It is not conceivable that these results could be brought about by hormonic regulation through the circulatory system. Redfield states that such local responses can be evoked after the entire nerve-supply of the affected region has been severed. If this is so, there would seem to be no alternative to accepting his conclusion that light and temperature can act directly upon the melanophores, without the intervention of either a freely-circulating hormone or a nicely-adjusted system of reflex arcs.

Nevertheless, Redfield is driven to the conclusion that there is, superimposed on this primary reactivity of the melanophores of the horned toad to light and heat, a coordinating mechanism which will account for the generalised condition of pallor following "excitement," and the peculiar modification of the normal reaction to light in virtue of the background upon which the animal is kept. For the latter response the appropriate receptor is the eye; since blinded individuals no longer display the apparently adaptive response to the brightness or darkness of the substratum. If horned 
toads which have been kept upon a background of dark cinders, are transferred to one of white sand, they become noticeably paler after one day and reach within five days a condition of maximum pallor. But when the eyes are blindfolded, exposure to the same surroundings for several weeks does not result in the disappearance of the dark condition; and the results of carefully controlled experiments showed that this is not due to the mechanical influence of the bandage, but can only be interpreted on the assumption that response to the nature of the background arises through stimuli received in the first place through the organs of vision. In considering the possibilities of pigmentary control through the eyes, it is of interest to contrast the relatively slow and accumulative nature of the response to background with the more rapid primary reaction to incident light. In the case of the horned toad, the intimate nature of the background response was not investigated by Redfield, who devoted his investigation of the co-ordinating mechanism in reptilian colour-response to the peculiarly characteristic phenomenon of excitementpallor, and by an ingenious and painstaking series of experiments has arrived at the conclusion that here too hormonic regulation plays an important part in the process.

The method adopted to induce pallor by nocuous stimulation was the application of a faradic current to excitable areas, such as the cloaca or roof of the mouth, a procedure which, as we have seen, results in general contraction of the melanophores throughout the skin of the whole body. That such treatment results in uniform melanophore contraction in dark animals even after the denervation of definite areas of the skin, such as can be achieved by severing all the nervous connections of a limb, suggests at once that the melanophores are accessible to stimuli received through the circulatory system. Several lines of experimental evidence converge to this conclusion; in particular, the possibility of evoking pallor by transfusion of blood from an excited animal. It has been known for some time that extracts of the suprarenal medulla induce melanophore contraction in fishes and amphibia. In the horned toad destruction of the cord between the eighth and thirteenth 
vertebræ prevents pallor after faradic stimulation of the mouth. In these circumstances the body-cavity may be opened without producing melanophore-contraction; and when the adrenals of such lizards were stimulated, contraction of the melanophores occurred throughout the entire body after the lapse of only a few minutes. It did not occur, however, in the hind limb after ligature of its arterial supply. When the ligature was removed, on the other hand, the skin of the leg rapidly assumed the condition of extreme pallor. Striking collateral evidence in favour of the possibility that adrenal secretion determines excitement-pallor in reptiles was provided by analysis of the blood-sugar content, which is known to rise in Mammals when adrenalin is liberated into the circulation, as during excitement ("emotional glycosuria "). Redfield found that the blood-sugar content was significantly higher in lizards after the production of pallor by nocuous stimulation. To sum up briefly the evidence from these and other experiments bearing on adrenalin, it seems clear : (I) that adrenalin causes the contraction of Reptilian as well as Amphibian melanophores ; (2) that the adrenal glands of Reptiles contain a substance which has the same action as adrenal extracts obtained from Mammalian glands; (3) that there is indirect evidence that adrenal activity is associated with "excitement" in Reptiles as in Mammals ; (4) that removal of the adrenals in Phrynosoma in most cases prevented melanophore contraction in response to nocuous stimulation; and (5) that in addition Reptilian melanophores are capable of direct response.

The Function of the Fituitary Gland.-The part played by secretion of the pituitary gland in determining the normal rhythm of colour-change in amphibia is a further instance of endocrine phenomena of a type which lies outside the province of mammalian physiology. There is reason to believe that adrenalin occurs in the invertebrate phyla. The pituitary gland, on the other hand, is a specifically vertebrate structure from which no active substance has yet been isolated in pure form, so that it is impossible to speculate with profit upon the possible existence of an analogous mechanism in other phyla. In fact, strictly speaking, the pituitary belongs 
only to the Craniata, and the existence of its homologue in Amphioxus and Tunicates is doubtful (de Beer).

The physiological activity of extracts of the posterior lobe of the pituitary was, like that of extracts of suprarenal medulla, first revealed by the classical researches of Oliver and Schafer (I895). Extracts of the pituitary of mammals, birds, reptiles, and fishes (teleostean and elasmobranch) have a powerful excitatory action on the mammalian uterus and upon mammary secretion (Herring, I9I3; Hogben and de Beer, 1925). Extracts of the pituitary of all classes of Amniota, Amphibia, and Teleostei exert a pressor-diuretic action on the mammal. This has not so far been obtained from extracts of the elasmobranch pituitary; such extracts, however, are of a much lower order of activity than equivalent extracts (by weight of gland substance) prepared from the teleost pituitary, when tested on the virgin uterus (Hogben and de Beer). Extracts of the pituitary of fishes, amphibia, and amniota have also a specific depressor action on the circulation of the bird. While Krogh (1922) has given evidence for the conclusion that pituitary secretion contributes to the maintenance of capillary tone in the frog, it is an interesting fact that none of the above responses have any established physiological as opposed to pharmacological significance. In fact, the posterior lobe of the mammal, while a storehouse of probably several substances of prodigious activity and not a little interest to the pharmacologist, has not yet been proved conclusively to have any functional significance. There is, on the other hand, the clearest evidence for regarding pituitary secretion as the main factor in co-ordinating the pigmentary responses of amphibia to the changing conditions of its environment.

The anatomical and bionomic aspects of Amphibian colourresponse may now be summarised briefly as follows. The effector organs concerned with colour-response in Amphibia are the dermal and epidermal melanophores and the dermal xantholeucophores. It seems probable that in Amphibia the activity of the pigmentary effector depends on migration of pigment-granules rather than the movement of the cell as a whole. The rhythm of colour-response in Amphibia depends 
on a balance of natural factors of which humidity, temperature, oxygen supply, and illumination are the most significant. Dryness in the terrestrial species promotes pallor (contraction of the melanophores). Complete melanophore expansion can only occur in natural surroundings in the presence of moisture. Warmth tends to produce pallor. Most commonly bright light has the same effect, at least after continued exposure.

Colour-responses require periods of several hours or even days to reach their maximum intensity. The following citation is taken from Laurens' paper on Amblystoma larvæ :-

"I. Expansion of the melanophores of seeing larvæ in the light one and a half to two hours.

" 2. Expansion of the melanophores of eyeless larvæ in the light two to three hours, and contraction of the melanophores of seeing larvæ in darkness two to three hours.

" 3 . Contraction of the melanophores of eyeless larvæ in darkness four to five hours.

" 4. 'Secondary' contraction of the melanophores of seeing larvæ in the light three to five days, and 'secondary' expansion of the melanophores of seeing larvæ in darkness five days or more."

Laurens does not give the temperature conditions to which such periods are subject.

"Adaptive" response to background colour depends on stimuli for which the retina is the receptor. The characteristic darkening of the skin in the breeding season among Anura is probably independent of the internal conditions incident to reproduction, and results from exposure to optimum conditions for melanophore expansion during the period of coupling and ovulation. The normal pigmentary responses of the frog are summarised in the table on next page.

The synchronous character of the colour responses which occur in Amphibia implies that a regulatory mechanism controls their pigmentary reactions. To earlier workers nothing seemed more natural than the assumption that this mechanism must be the nervous system. Every effort was directed to seek a solution of the problem along this line. The result has been a bewildering conflict of evidence from 
Normal Pigment Responses of the Common Frog

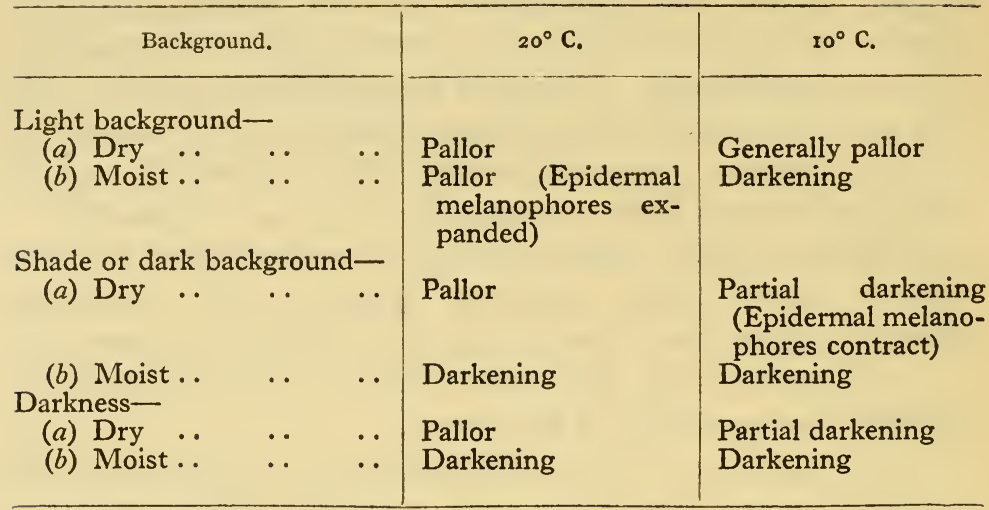

NotE.- "Pallor" implies contraction, "darkening" expansion of both dermal and epidermal melanophores.

equally reliable and competent witnesses on such matters as the effects of nerve section and stimulation, spinal transection and extirpation of sympathetic ganglia. After the researches of Oliver and Schafer (1895) into the physiological effects of adrenalin a new horizon appeared. Three years later Corona and Moroni noticed the effect of adrenalin in producing melanophore contraction in frogs. This observation was extended by Lieben's researches (1906). But though the action of adrenalin in promoting melanophore contraction later suggested to several continental workers, notably Fuchs, the possible alternative that endocrine factors intervene in the control of pigmentary responses, it was only when the action of pituitary extract was tested that it became possible to envisage a second endocrine system capable of inducing melanophore expansion.

This line of attack was suggested by the researches of Adler (I9I4), Allen (I9I7), and Smith (1916), who developed the technique of hypophysectomy in Anuran larvæ and called attention to the condition of extreme pallor which supervenes in consequence of ablation of the pituitary rudiment. They did not, however, appreciate clearly the effector character of the pigmentary change, which was first pointed out by Allen 


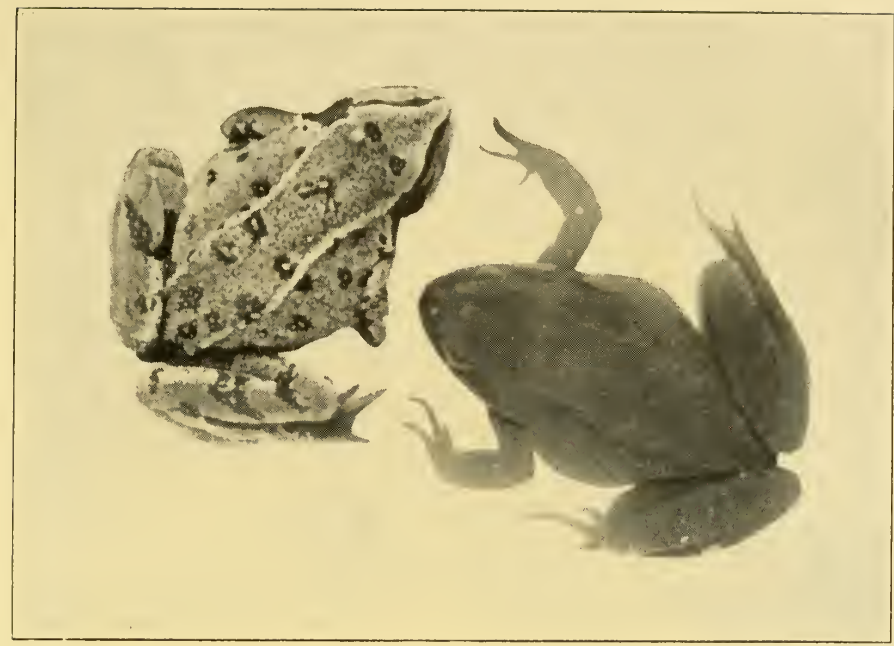

FIG. 32.-Frog on right injected six hours previously with extract of the pituitary of a fœtal ox : 'left, control.

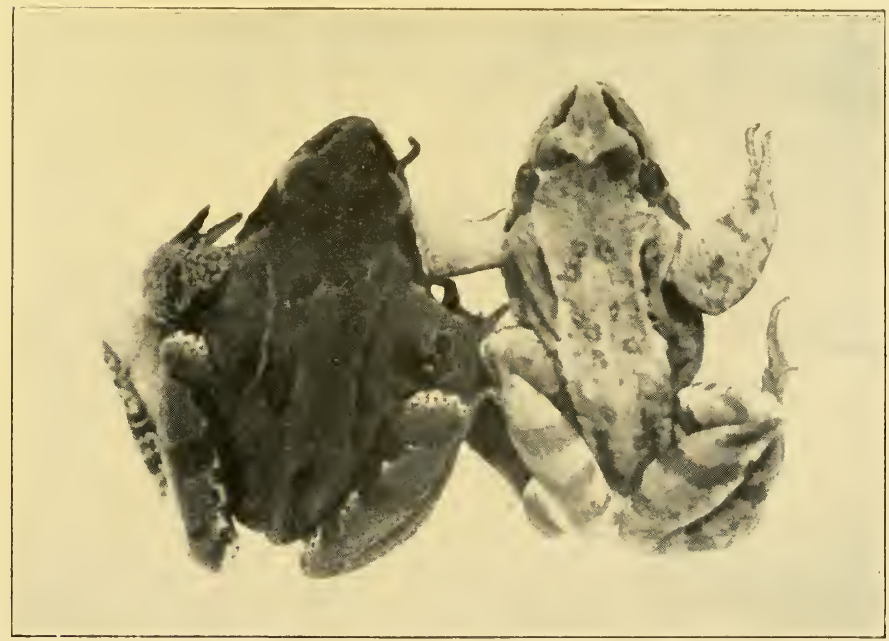

FIG. 33.--Two frogs i9 days after operation: on left anterior lobe only removed; on right posterior and anterior lobe removed. 

(1919). Shortly after it was noticed (Huxley and Hogben, I92I) that Urodele larvæ exhibit darkening of the skin after pituitary administration, and Swingle (I92I) recorded a similar effect after implantation of the pars intermedia in tadpoles. At the same time, the writer initiated a series of experiments on the results of pituitary injection to put to critical test the hypothesis that these effects were due to a freely circulating autocoid of the pituitary gland.

The results of these preliminary experiments (Hogben and Winton, 1922) may be briefly summarised under four headings :-

I. The pituitary ( $p$. intermedia and nervosa) of Mammals, Birds, Amphibia, and Fishes, contains a specific stimulant capable of inducing contracted melanophores of adult and larval Amphibia (Anura and Urodela) to undergo maximum expansion.

2. This property is not shared by such drugs (e.g. histamine) as simulate the physiological action of pituitary extracts in other respects; nor is it shared by other tissue-extracts examined, namely those of spleen, brain, testis, ovary, pancreas, liver, muscle, adrenal, pineal, and salivary gland.

3 . The melanophore response is a very sensitive indicator of pituitary extracts. The gland of a single frog contains sufficient to induce darkening in some fifty or more individuals of the same species.

4. The action of the melanophore stimulant in pituitary extract is direct and local, independent of concomitant vasomotor effects. Taken in conjunction with the phenomena described in Anuran tadpoles by Smith (1920) and Swingle (1921), these data present a strong presumptive case for the view that pituitary secretion forms an important factor in the regulation of Amphibian colour-response.

In a later series of experiments the effects of removal of the whole pituitary, controlled by comparison with effects of exposure of the brain, section of optic nerves, and removal of the anterior lobe alone were investigated in the common frog (Hogben and Winton, 1925) and analogous experiments to those of Smith and Allen on the axolotl larva of the Mexican 
salamander were carried out by the writer (Hogben, 1924). The outstanding results of these researches may be epitomised as follows :-

I. After removal of the whole pituitary in adult frogs, as in Axolotls and Anuran tadpoles (Smith, Allen, and Atwell), the individuals so treated remain permanently pale with the melanophores in maximum contraction, although subjected to conditions which inevitably induce darkening of the skin in normal animals.

2. Melanophore expansion follows pituitary injection in hypophysectomised individuals ; but hypophysectomised individuals so treated regain their characteristic pallor, although subject to conditions which inevitably evoke melanophore expansion in the normal animal.

3. A comparison of the minimal standardised dose of a sample of pituitary extract requisite to induce melanophore expansion in normal and hypophysectomised frogs, under conditions in which the intensity of external factors tending to promote pallor were varied, favours the view that melanophore contraction and expansion in the intact animal is correlated with the amount of pituitary secretion in the circulation.

The regulation of colour-response by fluctuating pituitary secretion is thus adequate to interpret all the accredited phenomena in adult Amphibia, without invoking a direct innervation of melanophores. We may justifiably conclude that in Urodeles as in Anura pituitary secretion is controlled by various (e.g. thermic) receptors in the skin, and is reflexly inhibited by light acting on the retina. This fully explains why in the salamander Diemyctilus (Rogers), within the range of external conditions for which light is the significant factor, section of the optic nerve was found to result in permanent melanophore expansion, although transection of the cord was without effect on the rhythm of colour-response.

It may here be noted that there is no conclusive evidence in favour of the existence of a direct nervous control of the melanophores in amphibia. Contraction of melanophores is brought about in frogs by injection of adrenalin; but 
for reasons stated above this is not a sufficient reason for believing that the melanophores are under nervous control. In tadpoles injection of extract or feeding with substance of pineal gland produces an extreme condition of pallor (McCord and F. Allen). But this reaction does not appear to be shown by urodele larvæ, in which the effects of removal of the pineal (Laurens) on colour response were found to be negligible. It is of interest to note that pituitary extract does not produce expansion in the chromatophores of the chameleon, and in the melanophores of the Atlantic minnow, Fundulus, Spaeth found that it produced contraction. The substance in pituitary extract which produces expansion of amphibian melanophores has recently been shown by Dreyer and Clark to be different from the substances which are responsible for the mammalian pressor and uterine responses.

A group of phenomena of general biological interest that appear to be subject to endocrine control are illustrated by the cyclical activity of the genital ducts (secretory and muscular) in the female of mammalia and their behaviour during the several of gestation. Some advance has recently been made by the discovery of Allen and his co-workers (1924) that definite changes follow the injection of liquor folliculi into ovariotomised rodents. In young rodents removal of the ovary inhibits the growth of the genital ducts, and in older animals produces degenerative changes in the latter with cessation of cyclical œstrous changes. When fluid contained in the ovarian follicle of the normal individual is repeatedly injected into a spayed female accelerated growth and secretion characteristic of the œstrous cycle are induced.

\section{FURTHER REFERENCES}

Schafer. The Endocrine Organs. Longmans, Green.

Hogben. The Pigmentary Effector System. Oliver and Boyd. Swale Vincent. Internal Secretion of the Ductless Glands. Arnold. 


\section{CHAPTER VIII}

THE MECHANISM OF NERVOUS CONDUCTION AND EXCITATION

BEFORE attempting to describe the part played by the nervous system as an arrangement for integrating the response which an organism exhibits in everyday life, it is desirable to acquaint ourselves with what is known of the properties of nervous tissue as a conducting system. It is assumed that the reader is already familiar with the elements of nervous histology and the distinction drawn between afferent or sensory and efferent or motor nerves. The recognition of the excited state in nerve depends on the response which it calls forth in an effector organ, either directly in the case of efferent nerves, or indirectly through the C.N.S. in the case of sensory fibres. The stimulation of efferent nerves leads either to initiating or augmenting activity in an effector organ (excitatory action) or to diminishing or abolishing response (inhibitory action).

Reference has already been made to the phenomenon of inhibition, as illustrated by the effects of stimulating the cardiac branch of the vagus in the vertebrate, or certain nervefibres connected with the heart in crustacea and molluscs. Little is known of peripheral inhibition: the phenomena of excitation, conduction, etc., in nerve have been chiefly elucidated through the study of excitatory motor nerves supplying limb-muscles (nerve-muscles preparation): that the phenomena are essentially similar in other types of nerve is inferred by certain similarities such as the electrical conditions which accompany the propagation of the excited state in all irritable tissues.

The excitation of a muscle through its nerve involves three 
distinct events : (I) the initiation of some local change at the point of application of the stimulus constituting nervous excitation in the restricted sense employed below ; (2) the propagation of a disturbance of some kind along the nerve-fibre, or as it is commonly called the conduction of the nervous impulse; (3) the production of some change at the junction between nerve and muscle. We shall consider each aspect of the process separately.

(a) Excitation.-Nerve, like muscle, may be stimulated to activity by means of thermal, electrical, mechanical, and chemical stimuli. Of these only electrical stimuli are appropriate for the manipulative requirements of quantitative experiment. In both cases electrical stimulation may be brought about either by induced or direct currents. The latter on the whole yield more instructive results. Up to the present excitation phenomena have been studied pre-eminently in amphibian motor nerve.

For the purpose of investigating the nature of excitation, the excitability of nerve is usually defined in terms of the minimal intensity of stimulus required to evoke an impulse, other conditions (duration, etc.) being constant. The first thing to note is that the local change which constitutes excitation is a reversible one. When two induced electrical stimuli are sent into a nerve successively, it is found that the effect of the second depends on the time which elapses between it and its predecessor. The receipt of the first stimulus is followed at first by a brief interval during which the nerve is incapable of being excited by any strength of stimulus; this interval, the absolute refractory period, is followed under certain conditions by a restoration of excitability which increases beyond its original value, so that for a further brief interval, the supernormal phase, the nerve is capable of being excited by a stimulus appreciably less than that necessary to evoke response when presented singly. Thus when two stimuli which exceed the threshold intensity for a single shock are applied successively with the lapse of an interval less than the absolute refractory period, the second is completely ineffective ; when, on the other hand, two stimuli are applied successively, 
the first, if adequate to set up a nervous impulse, for a measurable interval after the refractory phase leaves the point of excitation in a more excitable state, so that with an appropriate period intervening between the two stimuli a second one of subminimal intensity may become an effective agent of excitation. The time-relations in the case of the frog's sciatic gastrocnemius preparation are represented by Adrian and Keith Lucas, as in Fig. 34. Their possible bearing on the phenomena of inhibition and summation in the central nervous system will be dealt with later. We must first consider the

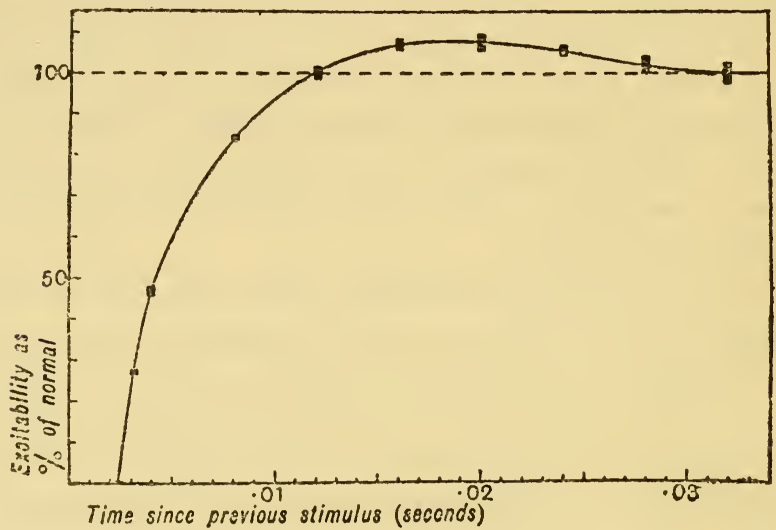

FIG. 34.-Excitability to second stimulus in the sciatic gastrocnemius preparation of the frog (Adrian and Keith Lucas).

light they throw on the nature of the local change which precedes the propagated disturbance in nerve. To account for both the refractory period and the supernormal phase we may picture this change as a phenomenon of disintegration; if excitation involves dissolution of some constituent in the neighbourhood of the electrode, we should expect no further stimulus to have any effect so long as the latter state persists ; and if the disintegrative process is reversible, it is possible to conceive why this period should be followed by one in which, restoration being incomplete, a less potent stimulus is required to reverse the process.

Further light is shed on the problem by taking into account 
the direction, duration, and intensity of constant currents in relation to excitation. The effect of direction was early recognised through the work of Pfluger and his contemporaries. The action of the constant current is characteristically polar, that is definitely orientated with reference to the surface at which the stimulus is applied. By placing a commutator for reversing the current in the circuit for exciting a nerve (nonpolarisable electrodes being, of course, used), it is easily demonstrated that excitation takes place at the cathode, i.e. the point to which positive ions move through the tissue, while simultaneously excitability is diminished at the anode, i.e. at the surface from which kations move away, when the current is made. When conversely the current is broken, stimulation again results ; but the polar relations are reversed, excitation occurring at what was the anode, i.e. at the point to which the kations now tend to revert. The relation of duration and intensity of stimulus to the excitation process has been elucidated chiefly through the work of Lapicque and Keith Lucas. There exists both a time limit and a limit of intensity for effective stimulation. If the stimulus is of an intensity less than a certain amount, it cannot excite, however prolonged its duration may be; on the other hand, however great the intensity of the stimulus may be, it cannot excite, if the duration of the current falls below a certain value. Alternating currents of very high frequency may thus be quite ineffective in provoking physiological responses. This critical duration during which a minimal stimulus must operate to produce a manifest effect varies with different nerves in the same individual and with corresponding nerves in different species of animals. As a measure of the time-factor Lapicque has introduced the constant chronaxie, which is defined as the minimal duration required for excitation with a current whose intensity is twice the threshold necessary for excitation when the duration of the stimulus is indefinitely prolonged. The significant fact emerging from this line of inquiry is that the length of the refractory period and the interval which must elapse for production of summation effects in different tissues is greater or less according as the chronaxie has a high or low value. 
These peculiarities of the excitation process and other considerations based on the study of currents of varying intensity point in one direction. Stimulation results in a local change which is associated with the migration of ions to or from a surface in the neighbourhood of the point of application of the stimulus. The conditions of duration and intensity suggest that a certain minimal concentration of ions at this surface is an essential feature of the process. In order that such a minimal concentration of ions may be reached there must naturally be a minimal quantity of electrical energy imparted, and there must also be a minimal time during which the directive force of the electrical current may influence the migration of ions to and from the surface concerned. The consequences of such a hypothesis are susceptible to mathematical treatment, as was first suggested by Nernst, later elaborated on the theoretical side by Hill and subsequently put to experimental test by Keith Lucas. We are thus in a position to construct a working hypothesis of the excitation process. If, through a solution enclosed between two membranes impermeable to ions of a particular kind, a galvanic current is for a while allowed to pass continuously in one direction, there will be a local concentration of such ions at one of the membranes, reaching a limit conditioned by their diffusion constant. A finite time must be allowed to elapse before any appreciable increase of concentration can take place at the membrane, the duration depending upon the intensity of the current. If the current is reversed before the requisite time has elapsed the flow of ions will be correspondingly reversed. From this consideration Nernst was led to seek an explanation of the inefficacy of alternating currents of very high frequency as agents of excitation. If the membranes are indefinitely separated, the relations which must exist between minimal intensity of current $(i)$, duration $(t)$, or frequency $(n)$ in order that an arbitrary critical concentration may be reached are expressed by the equations :

$$
\begin{aligned}
& k=i \sqrt{t} \text { (for constant current) } \\
& i=k^{\prime} \sqrt{n} \text { (for alternating currents) }
\end{aligned}
$$


The formulæ of Nernst account for the experimental data relating minimal frequency, duration, and current strength necessary to set up an excitation within a restricted range. By taking into consideration the conditions arising when the membranes at which ions of opposite sign collect are close together, A. V. Hill deduced a modified expression relating the duration of an exciting current to its least strength with greater accuracy than the formulæ of Nernst. Hill's expression is :

$$
\imath=\frac{\lambda}{\mathrm{I}-\mu \theta^{t}}
$$

In this equation $\lambda, \mu$, and $\theta$ are constants depending upon the distance apart of the membranes $(a)$, and the distance from the membrane excited at which concentration changes are considered $(b)$, the number of ions $(\nu)$ by which a given quantity of electricity is carried, the diffusion constant of the ions involved $(k)$ and an arbitrary factor (C). Thus :

$$
\lambda=\frac{c \cdot \frac{k}{v}}{\frac{a}{2}-b}, \mu=4 a \cos \frac{\pi b}{2 a}, \theta=e^{-k \cdot \frac{\pi^{2}}{a^{2}}}
$$

whence it is seen that $\log \theta$ is directly proportional to the diffusion constant of the ions concerned.

Keith Lucas has evaluated the constants of Hill's equation and shown not only a remarkable correspondence between observed and calculated values, but that a number of interesting phenomena are illuminated by the results so obtained. The evaluation is straightforward, if the equation is written :

$$
i \mu \theta^{t}=i-\lambda
$$

Thus in an experiment of Lapicque the corresponding threshold-values for current strength and duration (in $0.00 \mathrm{I}$ sec.) were :

$\begin{array}{rrrrrrrr}t & I / 3 & 2 / 3 & I & I \cdot 5 & 2 & 3 & \infty \\ i & 175 & 115 & 9 I & 76 & 68 & 6 I & 60\end{array}$


To satisfy the above equation the factor $\mu \theta^{t}$ on the left must vanish for $t=\infty$, so that $\lambda$ is the smallest current which will excite at all, i.e. $\lambda=60$ in this experiment. Substituting $i, t$, and $\lambda$ for any two pairs, $\mu$ may be eliminated by dividing one equation by the other : $\theta$ then becomes 0.375 and $\mu$, by substitution, $0^{\circ} 909$. The recalculation of $i$ for corresponding values of $t$ by means of the formula gives the following :-

$\begin{array}{lllllllll}i \text { (observed) } & \text { 175 } & \text { 115 } & 9 \text { 1 } & 76 & 68 & 64 & 61 & 60 \\ i \text { (calculated) } & \text { 178 } & \text { II5 } & 91^{\circ} 2 & 75^{\circ} 9 & 68 \cdot 9 & 65^{\circ} \times & 62 \cdot 4 & 60\end{array}$

For instances of specific phenomena on which further light is shed by Hill's analysis, the paper by Keith Lucas may be consulted. It is of considerable interest to note that the equation holds equally for direct excitation of muscle, so that we may infer that the event which initiates the changes described in an earlier chapter is of the same type in both tissues. This is a fact which it is most important to bear in mind when discussing the origin of the electrical variation in muscle ; and in any attempt to unravel the anomalies which beset the study of the relation of electrolytes to muscular activity ( $c f$. pp. 21, 22).

Minimal Duration of Stimulus for Excitation in Muscle (Lapicque).

Gastrocnemius of Rana temporaria .. $\quad \ldots \quad \ldots \quad \ldots 0^{\circ} 003 \mathrm{sec}$.

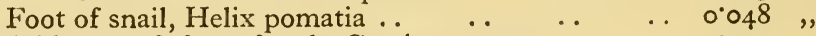

Adductor of claw of crab, Carcinus mænas . $0^{\circ} 300$,

Mantle of sea-slug, Aplysia punctata $\quad$. . . $0.8 \circ \quad$ ",

Ventricle of tortoise, Testudo græca $\quad \ldots \quad \ldots \quad 0.82 \quad$,

(b) Conduction.-When a nerve is stimulated the disturbance set up at the seat of stimulation is propagated along each neurone at a measurable rate. The rate of conduction can be determined directly by observing the difference in the latent period of muscular contraction, when a nerve-muscle preparation is stimulated at points along the nerve separated by a measured distance apart: the difference in the latent period of contraction then represents the interval taken for the nervous impulse to traverse this distance. This now familiar class experiment was first performed by Helmholtz (1852), before whose time it has been supposed that the nervous impulse travelled at a rate comparable with the velocity of 
light; and the train of thought which prompted Helmholtz to experiment is instructive. "As long as physiologists thought it necessary," he argued, " to refer nerve-actions to the movements of an imponderable or psychical principle, it must have appeared incredible that the velocity of the movement could be measured within the short distances of the body. At present we know from the researches of du Bois Raymond upon the electromotive properties of nerve that those activities by means of which the conduction of an excitation is accomplished are in reality actually conditioned by or at least closely connected with an altered arrangement of their material particles. Therefore conduction in nerves must belong to the series of self-propagating reactions of ponderable bodies. ..." Only six years before Helmholtz' experiment Johannes Müller had denied the possibility of ever attaining the means of measuring the velocity of nervous transmission; the history of mechanistic thought is paved with such denials.

The rate of propagation of the excited disturbance varies greatly in different animals. In the following tables some examples are given :-

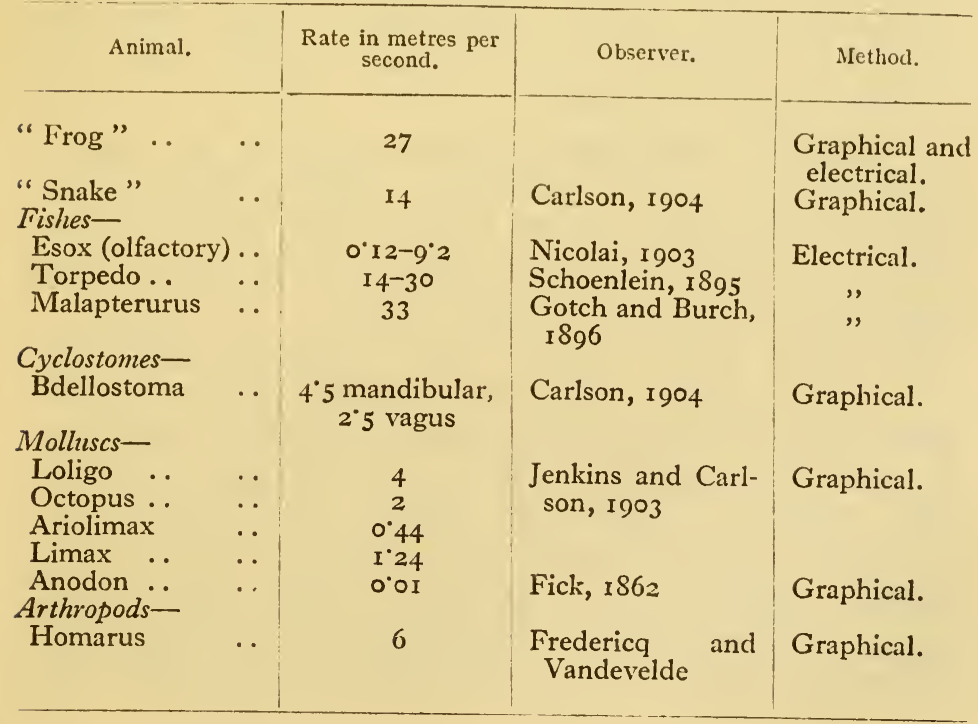


In addition to observations on those animals in which it is possible to isolate suitable lengths of nerve-axons, the observations of Jenkins and Carlson (1903) on conduction through the nerve-cord of various worms are interesting, though the values given are not necessarily comparable with the above, since they involve conduction across synapses in the C.N.S. All these data are derived from direct (graphical) observation.

\begin{tabular}{|c|c|c|c|c|}
\hline \multirow{2}{*}{$\begin{array}{l}\text { Nemertinea : } \\
\text { Cerebratulus }\end{array}$} & \multicolumn{4}{|c|}{$\mathrm{Cm}$. per s } \\
\hline & . & .. & $\cdots$ & $5^{\circ} 4$ \\
\hline $\begin{array}{l}\text { Hirudinea : } \\
\text { Aulastomum }\end{array}$ & & & & \\
\hline Aulastomum & .. & $\ldots$ & .. & 56 \\
\hline Polychæta : & & & & \\
\hline Cirratulus .. & $\ldots$ & . & . & 90 \\
\hline Arenicola .. & .. & .. & .. & 126 \\
\hline Bispira $\quad$. & . & .. & .. & 606 \\
\hline Aphrodite .. & $\ldots$ & .. & . & 56 \\
\hline Polynoe .. & .. & .. & . & 230 \\
\hline Sthenelais .. & .. & .. & .. & 205 \\
\hline Eunice $\quad$.. & . & .. & .. & 475 \\
\hline Nereis $\quad \ldots$ & .. & . & .. & I 33 \\
\hline Lumbriconereis & $\ldots$ & .. & .. & 262 \\
\hline Glycera $\quad$.. & $\ldots$ & .. & $\ldots$ & $44 \mathrm{I}$ \\
\hline
\end{tabular}

From these data it would appear that the rate of conduction in annelids may be higher than in the lower vertebrates as exemplified by the hagfish, Bdellostoma. Parker found that the rate of transmission in the nerve-net of the sea-anemone was about $\mathrm{I} 3 \mathrm{~cm}$. per second.

Propagation takes place on either side of the point of stimulation in opposite directions. This is shown by the effects of stimulating the cut ends of fibres which bifurcate, and by study of the electrical response which is an invariable accompaniment of the nervous impulse. In seeking for further light on the nature of the propagated disturbance, certain facts clearly emerge from experimental investigation upon the nerve-muscle preparation. These are : first, that the disturbance depends upon a supply of energy distributed along the whole course of the neurone, so that if an impulse is once set up, its intensity is independent of that of the stimulus which initiates it so long as other factors remain constant; second, that the transmission of the excited state is associated with an electrical variation which travels along 
the nerve at the same rate as the propagated disturbance itself.

The first proposition implies that a means of treating the intensity of the nervous impulse by quantitative methods is available. Adrian (1912) has sought to establish this on the assumption that the nervous impulse suffers decrement in passing through a region of narcosis. If a nerve is narcotised in a gas chamber, a stimulus applied within the region subject to narcosis (inside the gas chamber) will evoke a response in its attached muscle after response to stimulation on the far side of the gas chamber has been abolished; the depth of narcosis, as measured by the time of exposure, required to abolish response becomes continuously less as the length of nerve exposed is increased. Thus the ability of the nervous impulse to traverse a region of narcosis can be employed as a measure of the strength of the impulse. By arranging electrodes at intervals along the course of a nerve, enclosed at intervals along its course by gas chambers in which measurable lengths are subjected to narcosis, it can be shown that, when a length of nerve is narcotised until its power of conduction is almost abolished, it retains its ability to transmit an impulse through a second region of narcosis of length just sufficient to abolish response to a stimulus applied immediately outside the latter. If the impulse is not completely extinguished in passing through a region of decrement, it recovers its full capacity to face exposure to the same degree of narcosis; on re-entering a normal region it regains its original intensity. Nervous conduction is thus an all-ornone phenomenon, i.e. its energy of propagation is independent of the strength of the stimulus which initiates it, being distributed along the whole course of the neurone.

To avoid undue abstraction an experiment of Adrian (1912) may be described in detail. Four gas chambers as in Fig. 35 are arranged. A and B have a diameter of $4.5 \mathrm{~mm}$. The diameter of $\mathrm{C}$ is $9^{\circ} \mathrm{mm}$. Nerves are arranged for the experiment as indicated. In all chambers the depth of narcosis for the length of nerve traversed is identical. The narcotic used by Adrian was alcohol vapour. In each experiment the 
depth of narcosis (measured by the time of exposure) which was just sufficient to prevent the transmission of a stimulus

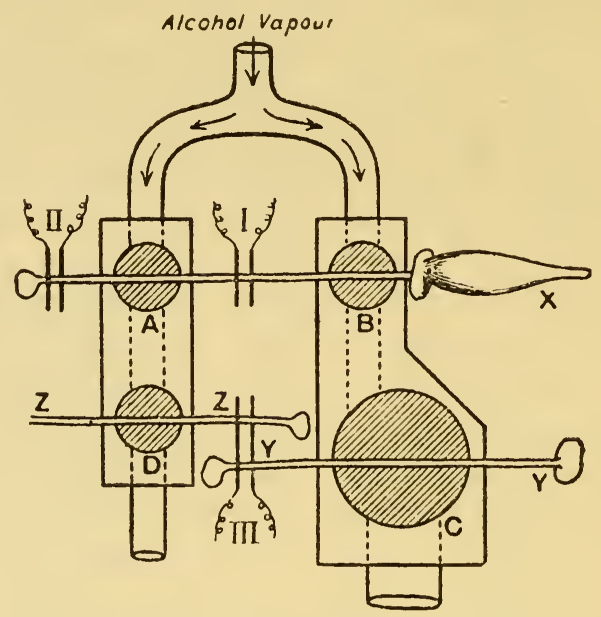

FIG. 35.-(After Adrian-see text.)

through $\mathrm{A}$ or $\mathrm{B}$ alone, through $\mathrm{C}$ alone, or through $\mathrm{A}$ and $\mathrm{B}$ successively.

Time to NARCosis.

\begin{tabular}{|c|c|c|c|}
\hline Expt. No. & $\begin{array}{c}\text { Through B only, } \\
4{ }^{\circ} 5 \mathrm{~mm} \text {. }\end{array}$ & $\begin{array}{l}\text { Through A and B } \\
\text { successively, } 9 \mathrm{~mm} \text {. }\end{array}$ & $\begin{array}{c}\text { Through } \mathrm{C} \text { alone, } \\
9 \mathrm{~mm} .\end{array}$ \\
\hline I. & $10 \mathrm{~min}$. & Io $\mathrm{min}$. & $6 \mathrm{~min}$. \\
\hline 2. & $10^{\circ} 5$, & 10 ," & 6.5, \\
\hline 3. & I $3 \quad$, & I3 ," & \\
\hline 4. & I $2^{\circ} 5$, & I2, , & 8 \\
\hline 5. & I6 ", & I6 & $8 \cdot 5$ \\
\hline 6. & I $8 \cdot 5$, & I7 , & 10 \\
\hline 7. & 24 & $24 \quad$, & I 6 \\
\hline
\end{tabular}

Inspection of these figures shows (I) that the degree of narcosis which extinguishes a nervous impulse transmitted through a region of narcosis $9 \mathrm{~mm}$. long is quite inadequate to extinguish it if the section is divided into two halves separated by unaffected nerve, i.e. recovery of intensity occurs on emergence from the region of narcosis; (ii) that the depth of narcosis which suffices to extinguish an impulse is practically 
identical whether the impulse traverses a given distance of narcotised nerve $(A)$, or double the distance $(A+B)$ when there is an intervening region of unaffected nerve between $\mathrm{A}$ and $\mathrm{B}$. This indicates that the impulse emerges from the region of decrement with fully recovered intensity.

The second point can be demonstrated by observing the interval between the galvanometer deflections obtained by the use of non-polarisable electrodes, separated by a measured distance of nerve. The electrical variation recalls what has already been observed in muscle; the excited part at a given instant is electronegative to a non-excited region. The electrical variation is an invariable accompaniment of the transmission of the nervous impulse; and its existence may be taken as indicative that reversible movements of ions occur along the track of the nervous impulse. This suspicion is strongly reinforced by the fact that the propagation of a nervous impulse is completely blocked by a region through which an ascending (but not a descending) constant current is passed (Bernstein's experiment).

Taking into consideration the fact that the energy of the impulse is distributed along the whole length of the fibre, we might picture the propagation of the nervous impulse in one of two ways : either by comparing it to the ignition of a train of gunpowder, regarding it as a process which is in the thermodynamic sense irreversible, or interpreting it as a succession of local reversible changes of colloidal equilibrium along the course of the neurone. In the first case, it would be predicted that the nerve would be fatiguable, since it could not have inexhaustible supplies of the material sources of its energy of transmission. Conduction would be accompanied by increased metabolism. In the second case, the bioelectric currents propagated along the course of the nervous impulse would be the only physically measurable accompaniments of its passage. The facts that nerves are not fatiguable; and that nervous conduction is not, according to the extremely delicate determinations of Hill, associated with any measurable increase of heat-production, favour the second alternative. At the same time certain observers, Tashiro among others, have 
claimed to demonstrate increased respiratory activity of nerve during the propagation of the impulse. It remains to be seen whether these claims will be sustained by further research.

In its most recent form the theory of excitation propounded by Nernst and extended by Hill and Keith Lucas is amplified by Lillie as follows. The surface-membrane of a resting neurone is supposed to be impermeable to certain anions which are present in greater concentration inside the fibre than outside it. The kations are free to pass through the membrane, but the electro attraction of the anions forces the kations to remain close to the membrane, forming an electrical double layer. The change in ionic concentration at the membrane during excitation implies the removal of anions
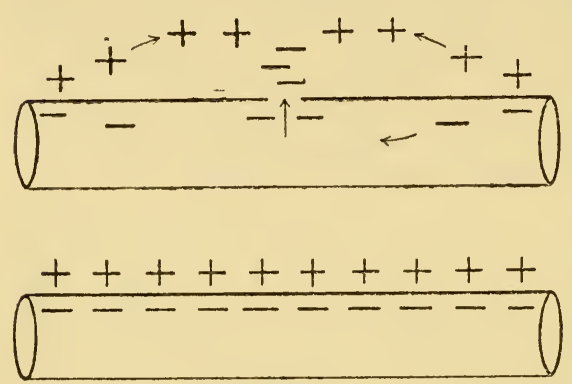

FIG. 36 . and therefore the removal of the double layer (Fig. 36). This depolarisation is accompanied by an increase of permeability at the kathode, and escape of anions at the permeable area initiates an action current. The local bioelectric current leads to a depolarisation of adjacent parts of the membrane which in their turn become permeable and the seat of a bioelectric current. Thus the change is propagated along the nerve-fibre, the action current in one section becoming the stimulus for the setting up of a similar condition in the next. According to this view all stimulation is electrical. It is of interest therefore to note that incident light produces an electrical variation (Piper) in the denervated eye both of Vertebrates and Cephalopods.

The balance of evidence is at present in favour of the view that in the phenomenon of nervous conduction we have to deal with a process which is essentially of the same nature as the excitation process itself. It might therefore be expected that the capacity of the nerve to conduct a second impulse 
following immediately after a preceding one would be characterised by phenomena analogous to the refractory and supernormal phases described above. Such has been shown to be the case by Keith Lucas and Adrian. The method for measuring the conductivity of a nerve after the passage of a previous impulse was the same as that employed for demonstrating the all-or-nothing law. The passage of a nervous impulse is followed first by a refractory period in which the impulse is more easily extinguished by narcosis, and then by a supernormal phase in which it is able to traverse a longer distance through a region of decrement than in the resting state. These facts are of great interest in connexion with the phenomena of summation in the central nervous system and in peripheral tissues.

Summation in Peripheral Tissues.-So far we have dealt exclusively with excitation and conduction in nerve-trunks. The phenomena of propagation of nervous impulses in reflex arcs show two outstanding peculiarities differing-one in kind, the other only in degree-from the phenomena of nervous transmission hitherto described. When a synapse intervenes in the path of the nervous impulse, conduction can take place only in one direction-from the afferent to the efferent side. Furthermore, a single stimulus of any strength whatever usually proves inadequate to induce a response, although sufficient to set up a disturbance (measured by the electrical variation) in the afferent nerve. Thus Sherrington, to whose labours we owe so much of our knowledge of reflex mechanisms, records cases in which the scratch reflex (alternate responses of the flexors and extensors of the hind-limb on stimulating an area of the back in the spinal dog) did not appear till the fortieth shock had been administered. The significance of this phenomenon receives some light from a consideration of the phenomena of summation in peripheral tissues. We have already considered a condition in the sciatic gastrocnemius preparation of the frog in which the minimal intensity for a second stimulus is lower than for the initial one. This depends upon the mechanism of excitation at the seat of application of the stimulus: a probable explanation is that summation 
of this type occurs when the first stimulus sets up a concentration of ions at the point of excitation which does not subside till the second comes into operation. Summation of this kind can obviously take place only when the nerve is stimulated in both cases at precisely the same point. But the phenomena of the refractory and supernormal states in muscle and nerve allow for at least two other types of summation. These summations can occur when the electrodes for the successive stimuli are not at the same point : that is, when the first stimulus initiates a disturbance in the nerve itself but does not lead to response in the peripheral organ. This may occur, either because the second stimulus fell in the supernormal phase of excitability of the peripheral tissue; or because the second impulse falls in the period in which the nerve itself conducts with supernormal intensity, so that if the intensity of the first impulse were just insufficient to penetrate the junction of nerve and muscle the second may succeed.

An example of the latter is provided by the work of Richet, Lapicque, and Keith Lucas upon the crayfish claw. The phenomena in this case are complicated, it may be remarked, by the existence of a double neuromuscular mechanism; one concerned with sustained contraction, and the other with rapid closing of the pincers. This is shown by the fact that a different type of response is given by strong currents of short duration (twitch-like movement) from that elicited by weak currents of long duration (protracted closure). A similar state of affairs was shown by Keith Lucas to exist in the lobster, Homarus, where the curve relating duration of condenser discharge to the minimum potential requisite to produce contraction of the adductor showed a discontinuity on one side, of which the response was a rapid twitch and on the other a sustained movement. Lapicque showed a somewhat similar phenomenon in the claw of Carcinus. Richet showed that when the abductor nerve of the claw in Astacus is initially stimulated a small twitch results. If this is followed by two shocks delivered in rapid succession a more powerful contraction results. If the preparation is stimulated every halfminute alternately by a single shock and by two successive 
shocks at an interval of 0.0036 second, the response to the single shock soon vanishes, while the response to the successive shocks persists (Fig. 37). At this stage we have therefore a summation of stimuli individually inadequate to elicit a response, and that this summation does not depend upon polarisation at the seat of stimulation is shown by several facts ; in particular, first, that it is obtained by alternating make and break shocks, in which case the effect of the second stimulus must be to prevent the persistence and extent of the polarisation due to the first; and second, that it is equally well seen when the successive stimuli are applied at different points along the course of the nerve. The interval which must elapse between successive stimuli if

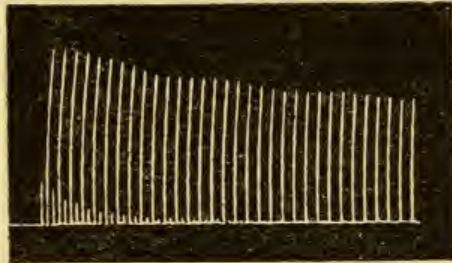

FIG. 37.--(After Keith Lucas.) summation is to occur was found by Keith Lucas to have about the same range as the supernormal phase for conduction in the nerve itself.

Integrative Action of the Central Nervous System.-Considerations of the kind which have been advanced already open to us, in the words of Keith Lucas, " a whole range of possibilities in the regulation of nervous activity. According as we time impulses in the nervous system to follow one another at a shorter or a longer interval, we can make them less or more capable of being conducted through any regions of decrement which the system may contain. If there is a region of decrement such that normal impulse just cannot pass, then impulses of moderate frequency may pass it successfully, while impulses of high frequency may not only fail to pass it, but may by their frequency prevent other impulses finding their way through." The last sentence offers a possible interpretation of a very important phenomenon on which Sherrington lays emphasis in discussing the integrative action of the central nervous system. The normal organism is subject to an infinite variety of stimuli : at any moment it is under the influence of not one but many stimuli, each adequate under 
appropriate conditions to elicit a characteristic response. Yet in fact its responses are at any minute definite and restricted.

\section{FURTHER READING}

Keith LucAs. The Conduction of the Nervous Impulse. Longmans, Green.

Lrillie. Protoplasmic Action and Nervous Action. Univ. Chicago Press. Hill (192I). The Energy Involved in the Electrical Discharge in Muscle and Nerve. Proc. Roy. Soc., B. 92. 


\section{CHAPTER IX}

THE ANALYSIS OF BEHAVIOUR IN ANIMALS

IN the last chapter the attempt has been made to indicate some of the evidence available for an understanding of the nature of the processes involved in the transmission of the excited state. It will now be necessary to inquire into what is known regarding the way in which stimuli normally present in the surroundings operate to produce the characteristic and more or less appropriate sequence of responses which constitutes an animal's behaviour. It will coincide best with our present treatment to consider the question from a phyletic standpoint.

The simplest form of response is the direct reaction of an effector organ to external stimuli. This has been already met with in the pigmentary effector organs of the shrimp and lizard. The reaction of the iris to light in vertebrates and cephalopods is another instance. But in both cases we find a co-ordinating mechanism superimposed upon the local form of reaction. In the osculum of the sponge with its collar of primitive muscular elements we have an apparently purely local mechanism. No co-ordinating arrangement is shown by the behaviour of other oscula when a neighbouring one is stimulated. Their normal function is to react to running water by relaxation and to still water by closure, response occurring after an interval of several minutes.

Neuroid Transmission.-Undifferentiated protoplasm possesses the property of propagating the excited state. This is best seen in the co-ordination of ciliary movement, so important an aspect of behaviour in large numbers of marine animals. Ciliary motion is metachronial; the cilia do not 
beat simultaneously but in regular succession one after the other with reference to the axis along which the ciliary current is maintained. It is this that gives the active ciliary epithelium an appearance like a field of corn blown by the wind. The metachronial rhythm of cilia does not depend upon mechanical stimulation of one cell by the ciliary activity of its neighbour. There is abundant evidence for this statement, but perhaps the most convincing is provided by experiments of Kraft, who showed that by cooling a zone of ciliated epithelium till mechanical activity subsided, effects of mechanical and thermal stimulation on one side of the quiescent zone were transmitted to the other. There is no clear evidence of nervous agencies at work in connection with ciliary mechanisms; and it seems fairly certain that in general the disturbance which underlies the metachronial rhythm is propagated through the undifferentiated protoplasm of the cells. Chambers has shown experimentally that in cells with intercellular protoplasmic bridges the effects of an injurious stimulus are transmitted from one cell to another. Where there are no demonstrable protoplasmic connexions this is not the case. Such transmission is usually called neuroid, although there is as yet no evidence of its depending upon the same type of mechanism as true nervous conduction.

The Elementary Nervous System.-The simplest possible form of neuromuscular system is met with in the tentacles of some sea-anemones (e.g. Cerianthus). Here the entire complex consists of a sensory cell ending in a process which arborises round the underlying muscle fibres. The single cell combines all the functions of receptor, afferent, and efferent neurone. The internal processes tend to run towards the base of the tentacle, and with this, according to Parker, is correlated a polarity in the response to stimulating the tentacle at its distal and basal extremities respectively. To quote from Parker, "when the tip of a tentacle is vigorously stimulated the whole tentacle is likely to respond, but when a part lower down in the side of the tentacle is stimulated, the reaction is chiefly from this point proximally."

Howvever, in the trunk region of Actinozoa and in general 
among Colenterates, a more specialised arrangement exists. Nucleated cell-bodies intercalated in a reticulum of fibrils connecting the sensory cells and muscular elements are continuous with one another; there is between the sensory and motor apparatus an uninterrupted network.

Ingenious experiments on the physiological properties of the nerve-net were performed by Romanes more than half a century ago. Romanes worked on Aurelia, the common jelly-fish of our coast. From the sensory tentaculocysts the nerve-net extends inwards over the circular sheet of muscular tissue round the mouth by whose contraction the rhythmical pulsation of the swimming bell is brought about. Excision of all the tentaculocysts brings about a cessation of the pulsations. If, however, one marginal sense-organ is left behind it induces a double wave of contraction-one to the right and one to the left-and the rhythmical movements are preserved. To ascertain whether special paths of conduction exist in the nerve-net, Romanes made a series of incisions in the bell. Spiral, circular, and interdigitating incisions in the under surface of the body did not prevent pulsation so long as at any point the nerve-net of the parts separated was left in continuity, although the muscular coat might be completely severed. Thus one part of the nerve net is as good as any other for the transmission of nervous impulses. The same, according to Parker, is true of transmission in the trunk region of the sea-anemone. But here definite paths of conduction seem to exist in the nerve-net in virtue of the fact that the fibrils run pre-eminently in an oral-aboral direction. Hence if the tip of a tongue of tissue cut from the wall of the body in a longitudinal direction is stimulated, generalised muscular contraction ensues, while if the tip of a tongue of tissue cut in the equatorial plane is stimulated, no general response is evoked. Such polarisation suggests how the separation of a C.N.S. may in the first place have been brought about. But the central nervous system of cœlomate animals is fundamentally different in that the nervous elements are not structurally continuous. The experiments of Romanes, which were independent of and contemporaneous with others 
by Eimer, have been amplified and extended by those of Mayer (1905), Loeb (1906), Bethe (1909), Harvey (1912), and others. These workers have conclusively shown in various ways that conduction takes place through the nerve-net and not through the muscle. This is quite easy to show in the jelly-fish Rhizostoma (Bethe), where the muscle of the bell and nervenet are not coextensive, inasmuch as the "sphincter" is composed not of a continuous band of muscle as in Aurelia, the form with which Romanes worked, but of sixteen separate areas with intervening non-muscular tissue across which the nerve-net extends.

The Synaptic Nervous System.-In contrast with the nervenet of the cœlenterate and the generalised modes of response associated therewith, we now turn to the synaptic nervous system of echinoderms, annelids, molluscs, arthropods, and vertebrates. The unit of response in these animals is essentially localised; the stimulation of any group of receptors calls forth response in a strictly limited number of effectors. To illustrate more concretely the conception of the reflex the following observations of Bethe (1897) on the behaviour of the shore crab (Carcinus) will serve.

I. When the eye is blackened to exclude photic stimuli, gentle mechanical stimulation causes the eye which is touched to be drawn under the carapace; both of the antennules are simultaneously withdrawn. When the same eye is subjected to a more powerful mechanical stimulus, in addition to the withdrawal of the antennules and the eye itself the second antenna of the same side is withdrawn. The opposite eye and corresponding second antenna are not affected.

2. When the covered eye is subjected to electrical stimulation, the walking legs of that side are brought into such a position that the body tends to be tilted forwards from the ground at an angle of $45^{\circ}$. If both eyes are stimulated the body tilts upward symmetrically, both chelæ being extended. Only one chela is involved as a result of unilateral stimulation of the eye.

3. Weak mechanical stimulation of the second antenna provokes first the withdrawal of the antennule of the same 
side and then the stimulated organ itself. Stronger stimuli lead first to the withdrawal of both antennules, then the antennæ, and finally the eyes of both sides.

The unit of structure in the synaptic system is the reflex arc. But it should be remembered that the barrier between one reflex arc and another is physiological rather than structural; the injection of strychnine results in a condition in which stimulation of any receptive area will elicit convulsive movements of all the muscles of the body. The simplest reflex

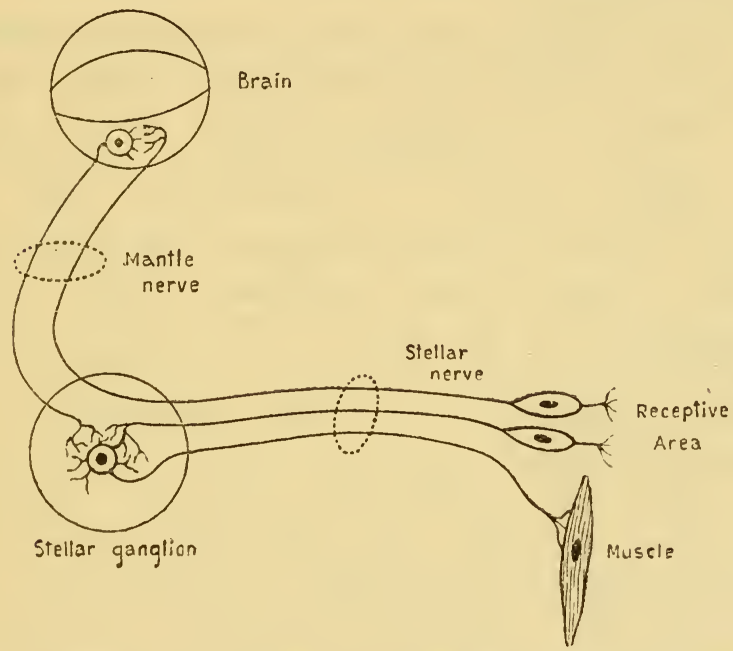

Fig. 38.-Diagram of simple reflex arc (stellate ganglion of Cephalopod).

path is one in which the receptor is represented by the peripheral arborisations of an afferent neurone whose dendrites terminate distally in connexion with the cell-body of a motor neurone. Such an ideally simple reflex arc is probably realised in the reflex paths which have their synapses in the stellate ganglion of the Cephalopod (Fig. 38). The stellate ganglion is connected by the pallial commissures with the brain and by the stellar nerves with the musculature of the mantle. Fröhlich (I9ro) showed that local stimulation of its surface evokes generalised contraction of the musculature of the mantle so long as the stellar nerves are intact. If the 
latter are cut a purely local response is evoked. The generalised response which occurs when the stellar nerves are intact is obtained equally well after section of the pallial commissures so that the stellate ganglion is completely isolated from the rest of the C.N.S. It follows that the stellate ganglion is a centre of reflex activity. Generally, however, reflexes make use of paths in which at least one intermediate (internuncial or proprio-spinal in the vertebrate) neurone between the afferent and efferent elements is involved. This condition is also seen in Fig. 38.

The more specialised forms of perception concerned with phototropic, geotropic, and chemotropic reflexes discussed below involve, in practically all cases, separate terminal organs, receptors, in connexion with the peripheral ends of the afferent neurones. A great deal has been written about the anatomy of chemoreceptors, and photoreceptors. So little is known of the mechanism of these structures in vertebrates that the scope of the present work does not permit of more than a reference to Winterstein's "Vergleichende Physiologie" for further information. A brief reference is, however, due to the receptors for space orientation, which are essentially alike throughout multi-cellular animals (and one might almost add plants where, however, they are unicellular in structure). The statocyst is essentially in all cases a sac lined with cells in connexion with nervous elements, enclosing a solid body with sufficient space to move freely under the influence of gravity, which brings it to rest in such a position as to stimulate one or another group of nerve-endings according to the position of the body in space. Kreidl's (I893) ingenious experiments in replacing the statoliths of crustacea by iron or nickel filings during ecdysis, showed that when the normal mechanical effects of gravity are replaced by those of the magnet the individual behaves with reference to the field of magnetic attraction precisely as it should on the hypothesis that equilibration depends on the group of receptors on which the statolith impinges.

The central nervous system usually consists of more or 
less distinct commissural portions composed of internuncial axons and ganglionic regions in which the cell-bodies and cellconnections are located. In Vertebrates the commissural part (white matter) encloses the ganglionic (gray) matter in the greater part of the C.N.S.; while among invertebrates the C.N.S. is built up of discrete ganglionic and commissural parts. A peculiarity of the Vertebrate C.N.S. lies in the fact that all secreting cells and smooth muscle fibres are innervated by motor neurones whose cell-bodies are located in subsidiary (autonomic) ganglia receiving efferent impulses from the cord but not themselves the centre of reflex activity. 'They

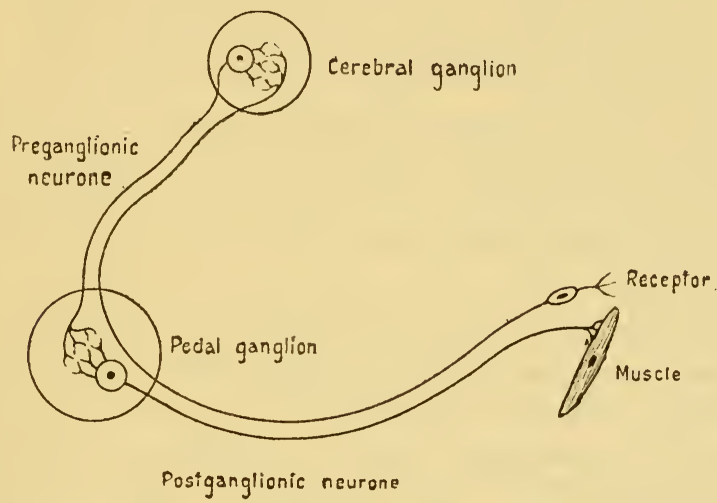

Fig. 39.-Diagram of pedal ganglion ot Razor-shell.

are thus distributive centres for multiplying impulses to be relayed to a large number of similar effectors of which simultaneous and identical action is required. According to experiments by Drew (1908) on the nervous system of the Razorshell clam an analogous state of affairs is seen in the pedal ganglion of the Lamellibranch (Fig. 39). Drew's experiments indicate that the pedal ganglion of the Lamellibranch only serves as a distributive centre for impulses from the cerebro-pleural ganglia. But in the gasteropod Aplysia, the pedal ganglion is, according to Frohlich (1910), a reflex as well as a distributive centre. The cardiac ganglion of Limulus is a structure which has probably no close analogy in Vertebrates, unless to the 
myenteric plexus of the gut; which is probably in essentials similar to a nerve-net.

It is possible that many segmental reflexes in Crustacea may employ a simple afferent-efferent reflex arc. In Vertebrates this is rarely the case ; the same internuncial neurones are involved in a multiplicity of reflex arcs. In the adjustment of response an important result of Sherrington's analysis of the properties of reflex action is the recognition of the principle of the final common path. If two receptive areas when stimulated evoke response of one kind or another in the same set of muscles, the effect of simultaneous stimulation is in general either one of reinforcement, or the complete exclusion of one reflex response in favour of the other. When it is remembered that in normal life the organism is subject to a large variety of stimuli simultaneously impinging upon reflex systems the majority of which may make use of a common path in some part of the C.N.S., the general importance of this fact in defining the behaviour of the animal at any moment is obvious.

For the scientific analysis of behaviour in animals possessing a nervous system the term "tropism" is a convenient label for grouping reflexes concerned with bodily orientation in response to a particular type of stimulus. According to established usage the term is extended also to modes of behaviour in metazoa which do not possess a central nervous system, as well as to protista and plants. Thus we speak of phototropisms, geotropisms, thigmotropisms, chemotropisms to classify reflexes concerned with orientation with reference to light, gravity, contact, or chemical stimuli. The analysis of behaviour has progressed chiefly bystudying: (i) the isolation of tropisms or other reflex systems by experimental procedure involving the exclusion of particular receptors or parts of the C.N.S. itself; (ii) tropistic reactions or other reflexes which normally predominate over other modes of behaviour in the intact animal; (iii) the modification of normal modes of response by physico-chemical means.

The study of tropisms in animals has been advanced especially through the labours of Loeb, whose most valuable 
contributions concern the behaviour of animals under the influence of light. That in many animals response to light predominates over other modes of response is proverbial. The behaviour of moths, and many other nocturnal insects is very widely known. When the organism moves towards the light it is said to be positively phototropic. The opposite type of reaction, negative phototropism, is well shown by blowfly maggots. Loeb was first attracted by the bending of sedentary organisms like Tubularia or tubicolous worms towards the source of illumination, a phenomenon which superficially resembles the effect of light on the growth of plants. He observed that in doing so the animal tends to take up such a position that its photo-sensitive surfaces are symmetrically illuminated; and advanced the hypothesis that orientation depends upon reflex muscular tone maintained through the photo-receptors. When the animal bends towards the light it does so because the tone of the muscles on the side exposed to light is increased by stimulation of the photosensitive surface on which the incident rays fall. The consequent flexion of the body eventually brings it into a position when the photo-sensitive surfaces are equally illuminated, so that the muscular tension on either side of the body is balanced. Anthropomorphic bias ascribes the movement of the moth towards the candle to the preference of the animal for the light. This view does not permit us to make verifiable predictions which can be inferred from a more objective attitude to the problem. It follows that if the insect's movements are mainly concerned with the direction of the rays, it will move from a strongly to a weakly illuminated situation, when conditions are so arranged that by doing so it continues to move along the path of the incident beam with both eyes equally illuminated. These conditions are easy to arrange by projecting on to a tube containing some positively phototropic organism such as caterpillars of Porthesia a slanting beam of parallel rays, the intensity of one half of the beam being artificially reduced, and in this way the animal is induced to move from the light into the shade, which is contrary to what the anthropomorphic view would lead us to anticipate. If 
unequal muscle tension reflexly excited by unequal illumination of the eyes leads an animal to turn into the position in which (moving towards or away from the source of light) the two eyes are equally illuminated, it follows also that blackening of the eye should lead to circus movements. Such circus movements have been shown by Loeb and many other workers-Parker, Holmes, Lyon, among others-in various insects, and are well illustrated by Garrey's (I919) experiments on the Robber fly (Protacanthus). These experiments support Loeb's hypothesis and researches on the unilateral removal of the

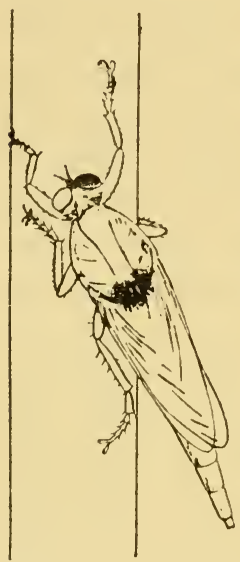

FIG. 40.-Effect of unequal illumination on climbing insect. cerebral ganglia in insects (cf. Matula, I9I I), and others confirm the view that the nervous mechanism of muscle tonus is predominantly unilateral. However, crossed reflexes are also involved in the forced movements of insects, since Mast (1924) has shown that when the posterolateral border of one eye is illuminated the limbs of one side move forward and those of the opposite side backwards, the front feet towards the light and the hinder ones away from it, thus showing that the location as well as the intensity of the stimulus in the photoreceptors of either side is involved in the reflexes which underlie orientation. This does not invalidate the fundamental conception underlying Loeb's contribution to the problem, though it shows that a complete analysis of the phenomenon is a rather more intricate task than he himself supposed.

Flies with normal eyes ascend either a plane or cylindrical surface vertically. When one eye is blackened they ascend a plane surface obliquely, veering towards the unblackened eye (Fig. 40). If made to ascend a cylindrical surface equally illuminated on all sides, the insect with one eye blackened ascends with a spiral motion towards the seeing eye, the number of spirals depending upon the intensity of illumination. If the cylinder is obliquely placed so that one side is 
in the shade, insects with one eye blackened move in very different paths on the two sides: "On the shaded side the spirals are parallel and the pitch is acute, but in the light of the other side the fly's path is more nearly horizontal, as would be expected from the different conditions of muscle tonus resulting from light of different intensities "(Garrey). Loeb (1890) first showed that if rotated on a turn-table flies describe circus movements in the opposite direction to the movement of the table. These, as later shown by Lyon (1900), do not occur when both eyes are blackened. In Garrey's experiments flies were rotated on a revolving cylinder illuminated from above. The normal fly circles towards the opposite direction, in its ascent thus describing a spiral path, If the speed is sufficiently increased a horizontal path may be induced. When one eye is blackened, the forced motion is intensified if the cylinder is rotated towards the same side and the vertical component is nullified with a much slower motion. When rotated with the blackened eye in the opposite direction to the motion the circus movements are diminished and at a certain speed the fly ascends vertically.

The conclusion that different regions of the eye in insects are, as implied in Mast's observations, related to different reflexes involved in orientation is of special interest in connexion with a phenomenon studied by Parker (I922) in young turtles. Newly hatched loggerhead turtles find their way from their nests to the sea in consequence of at least three factors, one depending on gravity as shown in their tendency to move down slopes, one which is a response to localised retinal images in that they move towards regions of the horizon which are open and clear rather than interrupted, and finally a response to colour, since they move towards blue areas. The first of these may be described as geotropism, but the last two are types of reaction rather more complex than those to which the term " phototropism" is customarily applied.

In most animals it is but rarely that one set of stimuli predominates over all others to the extent that light does in many insects. More frequently the normal orientation and 
movement of organisms is dependent on such a finely balanced interplay of phototropic, geotropic, chemotropic, and thigmotropic reflexes that only careful analysis can evaluate their respective influences. Thus the normal swimming movements of Mysids are in ordinary circumstances unaffected by removal of either the eyes alone or the statocysts alone. If, however, both statocysts are extirpated the mysid swims on its back when illuminated from below. Deprived of both eyes and statocysts, the animals can effect efficient orientation only when in contact with a surface (through touchreceptors in the appendages). Other factors which underlie seemingly inconsequent modes of behaviour are seen in the effect of physico-chemical conditions on the sign of a tropism. It was shown many years ago by Loeb that the larvæ of Polygordius, and various small crustacea, which are in normal life negatively phototropic, can be made either indifferent to light or definitely positive in their phototropic response when certain salts and acids are added to the medium. Similar phenomena have been described by Minkiewicz, Moore, Ewald, and others, who have also succeeded in producing a reversal of sign in the normal tropism of various animals by chemical means. An interesting example is recorded by Kanda (I914), who studied the effect of electrolytes on the behaviour of Arenicola larvæ with reference to gravity and light. In normal circumstances the larvæ of Arenicola are positively phototropic, swimming towards the light by ciliary and muscular movements. When placed in darkness they swim upwards, i.e. they are negatively geotropic. When excess of $\mathrm{K}$ or $\mathrm{Na}$ ions is present (i.e. on addition of a certain amount of isotonic potassium or sodium chloride solution to the sea water) the larvæ cease to swim towards the source of illumination when placed in the light ; they tend to swim in the opposite direction, becoming negatively phototropic, though feebly so. The geotropic response of the larvæ in darkness is not affected by such treatment. When, however, there is an excess of $\mathrm{Ca}$, or $\mathrm{Mg}$ ions the larvæ swim downwards in darkness; their behaviour towards gravitational attraction is reversed, they have become positively geotropic. The reaction 
to light is not influenced to the same extent by excess of $\mathrm{Ca}$ and $\mathrm{Mg}$. As a bionomic illustration of these phenomena the following suggestion by Loeb is based on the fact that larvæ of Porthesia, which as already observed are strongly phototropic, become indifferent to light after a meal. Porthesia lays its eggs on a shrub. The larvæ hatch out in autumn and hibernate on the ground. Provided that the temperature is raised sufficiently they can be induced to leave the nest at any time. When they emerge of their own accord they crawl directly up the shrubs on whose leaves they feed, always moving upwards, i.e. in the direction of the rays reflected from the sky. At the top of the shoot they encounter young buds, where they feed, and becoming phototropically indifferent in consequence, are free to move downwards and thus ultimately find another source of food.

Conditioned or Associative Behaviour.-The phenomena of reflex action as studied in a mammal from which the cortex has been removed are predictable, and there is reason to hope that they will fall into line with the phenomena of peripheral conduction, summation, and inhibition as suggested in the last chapter. We have seen that considerable progress towards a knowledge which will enable us to predict the behaviour of intact animals has been made by (I) analysing the interaction of reflex systems brought into play by different classes of stimuli normally present in the surroundings, (2) determining the way in which reflex responses may be modified by physicochemical factors in the external medium. There is, however, a further aspect of response which has to be taken into account in discussing the behaviour of animals. It can be illustrated well enough by the feeding of minnows. If food in the form of pieces of meat is presented to it the animal behaves in a predictable way; it snaps at the food. If paper coloured to resemble pieces of meat is presented, for the first few times the fish behaves in a predictable way by snapping. After a number of trials which can be predicted within limits by experiment, the fish no longer snaps at the paper. To the mechanism which conserves the effects of previous stimulation psychologists still employ the subjective term " memory." 
It is the essence of scientific method that it deals only with relations that are the result of external observation, that it aims at expressing these relations in quantitative terms, and that it employs no assumptions that could be eliminated without affecting the verifiability of its conclusions. We have then to ask whether it is possible by objective analysis to obtain any further light on the mechanism by which the simultaneous application of two classes of stimuli may enter into the result of the simple operation of one of them on a subsequent occasion. Associative phenomena probably play comparatively little part in the lives of any animals outside the vertebrate series. This special development is characteristic of mammals in general; and is the chief glory of man. Though we are here concerned primarily with the lower organisms, some account must be given of those properties which pre-eminently distinguish mammals from those animals which we elect to regard as "lower" than them, creatures which in any case appear to have less complex and less flexible possibilities of behaviour.

In the objective analysis of associative phenomena an immense advance has been made during the past two decades through the work of Pavlov and his associates. Pavlov studied salivary secretion in dogs. In the absence of the cortex, the entry of food in the mouth is an efficient stimulus for reflex salivary secretion. With the cortex intact, sight or smell of food also evokes secretion. Further analysis led to a fundamental distinction being drawn between a type of reflex which is only known in the animal with its higher cortex intact and the reflexes which exist in both normal and decerebrate preparations. In the intact animal a previously indifferent stimulus applied at suitable intervals simultaneously with the application of a stimulus which unconditionally evokes a particular response, eventually acquires the capacity to evoke the response unaccompanied by the "unconditioned" stimulus. A new non-inherited reflex has been brought into being, known as a conditioned reflex; its previously ineffective agent is known as the "conditioned" stimulus. This appears to hold good for a large number of reflexes; the salivary reflex 
is usually chosen because quantitative measurement of the amount of secretion can be made by using a cannula.

As Pavlov's work is still somewhat inaccessible to the English reader, the main points will be outlined. We will begin with the formation of conditioned reflexes, as follows :-

I. Any event in the external world which affects a sense organ may in the intact mammal become a conditioned stimulus, provided that its occurrence coincides with the unconditioned stimulus a sufficient number of times. Even nocuous stimuli such as intense electrical stimulation or burning of the skin may, if systematically accompanied by feeding, cease to evoke their normal consequences and become a signal for salivary secretion. Nocuous skin stimulation may thus be formed into a conditioned stimulus for the unconditioned feeding-reflex, but not for the unconditioned reflex salivary secretion produced by application of acid to the tongue. Nocuous stimulation of the skin over the bones, however, cannot be made a conditioned stimulus for either. The response of a conditioned reflex is essentially similar to the unconditioned reflex from which it is derived. If a lighted lamp be made a conditioned signal for food, the dog not only secretes saliva when the stimulus is presented, but makes groping movements appropriate to food itself.

2. It is necessary that the indifferent stimulus with which it is desired to form a conditioned reflex should be rigidly isolated; an unnoticed accompaniment such as an extraneous smell, sound, sight or movement of the experimentalist may otherwise become a new conditioned stimulus and vitiate the interpretation of the phenomena observed.

3. The indifferent stimulus should operate while the animal is in a quiescent condition with reference to the unconditioned system into which it is to be incorporated, i.e. it should precede by a short interval the unconditioned stimulus.

From what has been said, it follows that, since the animal is normally subject to an immense variety of stimuli, formation of new conditioned reflexes could only have chaotic consequences unless there exist definable factors which tend to inhibit the formation or check the operation of conditioned 
reflexes. The possibility of isolating a conditioned reflex for study implies that some inhibitory agency preserves the normal surroundings of the laboratory from exerting very much influence. Inhibition in conditioned phenomena presents four distinct aspects depending upon inherent properties of the central nervous system ; these are :-

I. Inhibition by extinction. When an indifferent stimulus has become a conditioned stimulus for salivary secretion, and is allowed to act alone on several occasions without the conditioned stimulus, it gradually loses its potency, but recovers it after a period.

2. Conditional inhibition. If the conditioned stimulus in a conditioned reflex is accompanied by another indifferent stimulus the extinction referred to under (I) takes place more rapidly than it would if allowed to operate alone.

3. Differential inhibition. Stimuli which resemble a conditioned stimulus fairly closely may at first evoke response when applied alone, but lose this efficacy more readily than the original conditioned stimulus.

4. Retardation. If in the formation of a conditioned reflex, the new stimulus precedes by a definite interval (from a half to three minutes) the unconditioned stimulus, the response to the conditioned stimulus when the new reflex is established is delayed by a corresponding interval of time.

In addition to the above may be mentioned the generalised form of inhibition of the activity of the cortex known as sleep. This can be regularly evoked in dogs by application of warmth or cold to an area of the skin. A further complication is introduced by the fact that external agencies not only give rise to inhibition but to release from inhibition. The phenomenon of "inhibition of inhibition" may be illustrated thus. By repeated synchronous action of the sound and presentation of food, an organ note of rooo vibrations per second becomes a conditioned stimulus evoking salivary secretion in absence of the food itself. If repeated too often alone it suffers inhibition by extinction, but recovers its efficacy with a sufficient period of rest. If during the indifferent period, there is superimposed on the now ineffective sound stimulus a second 
indifferent stimulus such as lighting a lamp before the dog's eyes, the sound immediately regains its efficacy. The sound and the light were each indifferent stimuli ; their combined effect depends on the fact that the former had previously been a conditioned stimulus, i.e. that the latter breaks down the inhibition to which the former was temporarily subject. The possible bearing of this phenomenon on the phenomenon of "attention" is evident. How unexpected fields may be illuminated by study of the conditioned reflex is well seen in the phenomenon of experimental neurasthenia. When a new internal inhibition is in process of formation a preformed inhibition is weakened. Suppose a spheroidal object is established as a conditioned stimulus for salivary secretion. When an ellipsoid differing only in the length of one axis is presented, it is at first an effective stimulus and ceases to be so by differential inhibition as already described. Now suppose that we successively present ellipsoids approaching more nearly the spheroidal form, pushing the process to the limit of discrimination, marked changes in the dog's behaviour occur, firmly established inhibitions disappear, its excitability is greatly increased. After two months' rest the previous state is regained and old conditioned reflexes reappear.

Finally, the study of conditioned reflexes as implied in the last type of experiment opens up a new horizon for the objective and quantitative treatment of sensation, aside from the consideration of the sense-organs as physical apparatus. This may be illustrated by employing the conditioned reflex to define the limits of discrimination. The sound of a tuningfork of 256 vibrations (middle $\mathrm{C}$ ) is accompanied by electrical stimulation of the paw until it is established as a conditioned stimulus. A tuning-fork of 264 vibrations presented as a signal for withdrawal of the paw evokes response which subsides on successive presentation before the effect of the original conditioned stimulus is extinguished by internal inhibition, as may be tested by applying it. A series of pairs of forks with diminishing differences in tone are now tried out till no differential inhibition can be established for a given pair. The limit of discrimination for sound in dogs is 
represented by a fraction of a tone. Similarly a fine degree of discrimination of time, doubtless connected with the mechanism of inhibition by retardation mentioned above, is shown by the fact that differential response to a metronome beating 104 and 100 per minute can be established and maintained for periods of over twenty-four hours. The application of this method of analysis shows, on the other hand, that dogs and cats are completely colour-blind, their world being defined usually by differences of light-intensity like an ordinary photograph.

\section{Further Reading}

HerTER. Mechanische Sinnesorgane U. S. W. Leipzig.

LoEB. Forced Movements, Tropisms and Animal Conduct. Lippincott. PARKer. The Elementary Nervous System. Lippincott.

SherRington. The Integrative Action of the Nervous System. Yale University Press. 


\section{CHAPTER X}

\section{THE FERTILISATION OF THE EGG}

IN the foregoing summary we have taken the existence of an animate unit or individual for granted, considering its characteristic properties, their sources of energy and the way in which they are brought into working relationship with one another and with the external world. It is one of the characteristic properties of animate systems that they are self-propagating. The quantitative analysis of this property is therefore an important branch of physiology. In spite of the immense volume of careful quantitative work in this field, the important fact that living organisms reproduce their kind-and that the power to do so is one of the most remarkable features which characterise living beings-is customarily neglected in physiological text-books or summarily treated from a teleological standpoint which betrays little sympathy with the advances which have been made in the last two decades through the work of Loeb on fertilisation and the rediscovery of Mendel's method in the opening years of the twentieth century. The explanation of this omission is to be sought chiefly in the fact that, while exact knowledge of metabolism, muscle, nerve, and respiration has been advanced chiefly by studies on the higher animals, practically every important discovery in the field we are now about to consider is based on material of too humble origin to interest the medical man. Nevertheless conclusions derived from these studies are, as will be seen, of wide applicability. For this reason a very brief outline of existing knowledge of the mechanics of reproduction will now be given. The subject is full of interest on the bionomic side in connection with the possibility that living organisms are 
related by common ancestry, and with the attempt to trace out the significant factors which have directed their past history on the earth in the light of the evolutionary hypothesis. As the treatment of the evolutionary problem forms the subject matter of a separate volume in this series, we must here confine ourselves solely to those questions which are amenable to quantitative analysis, leaving out of account issues which bear specifically on evolutionary biology. One may in passing legitimately comment upon the importance still attached by many physiologists to Darwinian concepts, a fact which is surprising when it is remembered that the exact study of these problems does not begin till the dawn of the present century; that it was not till more than ten years after the issue of the "Origin of Species" that the fertilisation of the egg by a single sperm was clearly established; and that the material available for the study of inheritance by Darwin's contemporaries was largely derived from popular tradition current among stockbreeders.

The natural starting-point for a study of the physiology of reproduction is the fertilisation of the egg. The important fact that the normal process of fertilisation involves the union of only one gamete of either sex was first clearly established by Hertwig and Fol (1875). The recognition of this fact raises two problems. The entry of the sperm into the egg normally implies (I) the initiation in the egg of active celldivision culminating in the formation of a new individual ; (2) the transference to the zygote of something in virtue of which the new individual so formed resembles the male as much as it does the female parent. Kupelwieser (I9I2) found that with sufficiently long exposure of the egg and high concentration of the sperm, it was possible to bring about the development of a sea-urchin egg with the sperm of the common mussel. The offspring reared resembled the former parent only. Though the sperm was able to penetrate the egg, its nucleus was eliminated during the subsequent cell-divisions, and it therefore made no contribution to the hereditary constitution of the fertilisation product. Hence, though it is not the rule in nature that a sperm can supply the stimulus that 
initiates development without materially contributing to the structural characteristics of the individual so formed, it is legitimate to treat these two issues quite independently. The nature of the hereditary process will be considered later.

The immediate problem of fertilisation has another aspect besides the elucidation of the mechanism by which the cleavage process is brought into operation, namely what factors operate to bring about contact between the sperm and the egg. Logically perhaps it would be better to consider, first of all, the attraction (if any) of the egg for the sperm; but since our knowledge of the fertilisation process is largely derived from elimination of the sperm by the use of physico-chemical reagents, it is just as convenient to begin with the mechanism which initiates cleavage.

Parthenogenesis exists as a normal occurrence in nature in many groups of the animal kingdom, though authentic cases in Vertebrates (observed with experimental safeguards) are not known. In some species of stick-insects and gall-flies the male has been eliminated. The existence of natural parthenogenesis has prompted many biologists to imitate the operations by which the agency of the sperm can be dispensed with in nature. The first fruitful work in this field was done by Loeb (1899), whose labours have enriched so many and diverse branches of general physiology. Loeb, who contemporaneously with Ringer was a pioneer in studying the relation of contractile tissues to electrolytes, was impressed with the fact that stale eggs of marine animals sometimes show signs of cleavage in process of dissolution, and began his researches in the endeavour to explore the possibility of producing artificial fertilisation by an increase in the hydrogen-ion concentration of the sea water. This was not in the first place successful. The action of other ions was then investigated, and successful rearing of swimming pluteus larvæ (a stage which is taken as indicating completely successful development, since the pluteus is self-supporting) from uncontaminated eggs of the sea-urchin Arbacia was obtained by exposing the eggs for a certain period to a mixture formed by adding a hypertonic solution of magnesium chloride to 
sea water. Further experiment showed that this was not a specific effect of the magnesium ion at all, but could be reproduced by increasing the osmotic pressure of the solution with a number of different reagents. Exposure for two hours to any one of the following mixtures suffices to induce development up to the pluteus stage in eggs of Arbacia when transferred back into normal sea water :-

$$
\begin{aligned}
& 50 \text { c.c. sea water, } 50 \text { c.c. }{ }^{\circ} 25 \mathrm{M}, \mathrm{MgCl}_{2} ; \\
& 90 \text { c.c. sea water, } 10 \text { c.c. } 2^{\circ}{ }^{\circ} \mathrm{M}, \mathrm{NaCl} \text { or } \mathrm{KCl} \text {; } \\
& 100 \text { c.c. sea water, } 25 \text { c.c. } 2^{\circ} 0^{\circ} \mathrm{M} \text {, cane sugar ; } \\
& 80 \text { c.c. sea water, } 17^{\circ} 5 \text { c.c. } 2^{\circ} 5 \mathrm{M} \text {, urea. }
\end{aligned}
$$

The freezing point of sea water is about of the order $\frac{M}{2}$ to $\frac{5 \mathrm{M}}{8} \mathrm{NaCl}$. From inspection of the above it is clear that one salient feature is common to all these mixtures-they have an osmotic pressure higher than that of sea water; and since the cell is in osmotic equilibrium with its environment, they must tend to withdraw water from the egg. The following table, taken from experiments of Loeb on another sea-urchin, Strongylocentrotus purpuratus, indicates the optimum concentration and osmotic pressure of sea-water mixtures for different reagents :

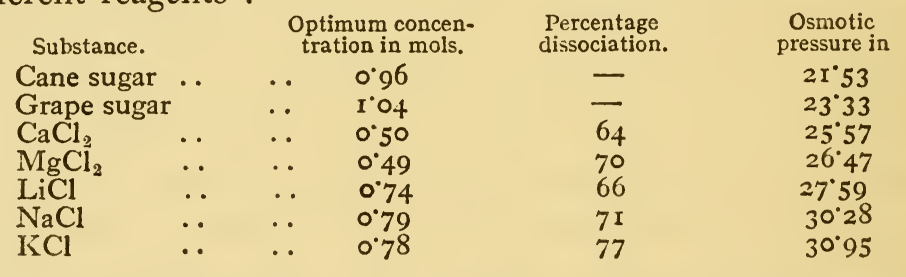

Less reliable results were obtained in subsequent experiments on Strongylocentrotus than with Arbacia. And osmotic activation alone did not produce a hundred per cent. yield in either case. The plutei were in some respects abnormal in that they did not swim near the surface ; there was a fairly high mortality; and-most significant of all-the eggs did not form the characteristic investment, known as the fertilisation membrane which is an invariable consequence of normal fertilisation by the agency of the sperm. This last fact 
suggested the possibility of a more perfect imitation of the natural process. Inquiry was next directed by Loeb to artificial membrane formation. In earlier experiments on the action of the hydrogen-ion, mineral acids were used. It was now found that exposure to ethyl acetate induced the production of a typical fertilisation membrane ; and further study showed that this action was due to the acid hydrolysis product. This suggested that the fatty acids might be successful agents of membrane formation. By leaving the unfertilised eggs of Strongylocentrotus in a mixture of 50 c.c. sea water and 2.8 c.c. $\frac{\mathrm{N}}{\mathrm{IO}}$ butyric acid at $15^{\circ} \mathrm{C}$. for about two minutes, all the eggs are induced to form membranes, when replaced in normal sea water. Eggs of Strongylocentrotus subjected to this treatment passed through the early developmental stages.

The combination of both methods was next employed. Exposure to the action of the fatty acid after treatment with hypertonic sea water gave better results. When, however, the reverse procedure was adopted, the eggs being treated with hypertonic sea water (for a shorter period) after artificial membrane-formation, success was complete. A hundred per cent. yield of swimming larvæ was obtained; the larvæ were normal in their behaviour; and the cleavage process precisely resembled that of the normally-fertilised egg. Loeb (1904-5) thus made what must be regarded as one of the most audacious contributions to mechanistic thought in replacing that mysterious complex the living sperm by familiar physicochemical agencies in its rôle of activating the developmental process.

Before pursuing the problem further, it will be as well to form a more concrete picture of the ground so far traversed. MacLendon (I912) has shown that fertilised eggs readily shrink in isotonic sugar solutions; but that the unfertilised eggs do not do so with equal readiness. From this and other experiments by MacLendon and by Gray on the conductivity of the egg before and after fertilisation there seems good reason to believe that an essential feature of normal fertilisation is increased permeability of the cell-membrane. A variety 
of considerations converge to reinforce this conclusion. Lyon and Schackell have shown that eggs become more permeable to dyes as the result of fertilisation. Harvey (I9I0) has not only confirmed this, but shown by intravitam staining with neutral red a temporary increase at fertilisation of the permeability of the egg to alkalies. Again, Lyon (I909) found that fertilised eggs of sea-urchins, three minutes after insemination, liberate about double as much oxygen from hydrogen peroxide as do unfertilised eggs, a fact most readily explicable on the assumption that the intracellular catalases are more accessible to the peroxide in the former case. Thus normal fertilisation may be regarded as a phenomenon of which one result is that water tends to be withdrawn from the cell; we can imitate this process either by withdrawing water from the cell (osmotic activation), or by changing the surface properties of the cell-surface so as to increase its permeability, as appears to be the effect of butyric acid and of cytolytic reagents. According to Carter (I924) the formation of a fertilisationmembrane is not an essential feature of this change.

The surface change which accompanies fertilisation can be induced in quite a number of ways. The eggs of the polychæte Nereis (which provides more accessible material for workers in this country than sea-urchins, as it spawns all through the summer) can be made to segment (I) by osmotic activation (Fischer), (2) by exposure for a suitable period to a temperature of $35^{\circ}-36^{\circ} \mathrm{C}$; (3) by standing them for ten minutes in the sea-water exudate of Echinoderm eggs or Echinarachnus lipolysin. Potassium cyanide, radium emanations, fat-solvents, alcohol, distilled water, saponins, bilesalts, sera, mechanical injury-the method which can be used for fertilisation of frog's eggs-have all been employed successfully as substitutes for the fertilising action of the sperm. It is not profitable in the limited space at our disposal to select further instances from an extensive literature dealing with artificial parthenogenesis in representatives of Echinoderms, Polychætes, Molluscs, Arthropods, Fishes, and Amphibia. In general we may say that all these agencies have in common the property of producing cytolysis at the surface of the egg. 
Favourable material is naturally provided by animals which spawn into the water eggs which contain relatively little yolk; and the eggs of marine animals are best for this purpose, the physico-chemical equilibrium being in such cases of a more mobile character. From the rapid advances made of late years in the technique of tissue-culture it would not seem unlikely that the initiation of developmental stages without contact with sperm will be accomplished in our own time in mammalian ova.

In the Echinoid egg, which up till now has yielded the most satisfactory material for experimental manipulation, an important aspect of the union of the sperm and egg is the immediate increase in oxygen consumption which occurs after entry of the sperm. At an early stage in the study of this problem, Loeb suggested that the immediate effect of the penetration of the sperm might be to promote a series of oxidative processes. Warburg's (1908) determinations of the oxygen-consumption of fertilised and unfertilised eggs of Arbacia confirmed Loeb's prediction. Warburg found that a quantity of eggs (about four million) in sea water, equivalent to $28 \mathrm{mg}$. total nitrogen by the Kjeldahl estimation, took up 4-5 c.c. of oxygen during the first hour after insemination, while only about $0.5^{-0} 7 \mathrm{c}$.mm. were consumed by the unfertilised egg in the same time. Warburg's original experiments were carried out by a titration method (Winkler); in later ones the manometer was used for the gas analyses; and readings of the rise in oxygen consumption were not taken till ten minutes after fertilisation occurred. From the recent observations of Cresswell Shearer (1922), using the Barcroft differential manometer, there emerges the remarkable conclusion that the mere contact of the spermatozoon with the external surface of the egg is capable of increasing the oxidation rate of the latter by rather more than 8000 per cent. in the space of one minute. The eggs were fertilised in the chamber of the manometer, so that there was no interruption of the readings before and after fertilisation. Within a minute of the liberation of the sperm the increase in oxygen-consumption starts, but it takes more than two minutes for the sperm to penetrate 
the egg-membrane. That is to say, the increase begins when the sperm is still only in contact with the outside of the egg ; and the curve for rate of oxygen consumption (and $\mathrm{CO}_{2}$ production) is steepest during the phase of surface contact.

That the sperm brings about profound changes while still in surface contact with the egg is shown by Lillie's experiments on eggs of Nereis, in which the sperm does not penetrate the cytoplasm till thirty minutes after the initial phase of fertilisation. Meiosis is initiated by the surface contact of the sperm; but if the jelly surrounding the egg is separated from the latter, taking with it the sperm itself, meiosis is not followed as in the ordinary course of events by cleavage. The chromosomes break down without the formation of the first cleavage-spindle derived from the nuclear apparatus of the egg.

Turning now to another side of the problem of fertilisation, there is no need to emphasise the fact that the spermatozoa of practically all animals (and many plants) are flagellate units. We have, therefore, to inquire how the motility of the sperm is so regulated that it is brought into contact with the egg of the same species. In introducing this question it is necessary to refer to the normal behaviour of spermatozoa. Spermatozoa are almost without exception immobile while they remain in the gonad or generative duct of the male. They usually become active in the medium in which fertilisation occurs. Generally in marine animals this is the sea; but in some starfishes the sperms do not become very active in sea water, unless its hydroxyl-ion concentration is raised, or egg secretions are added. In mammals the sperm becomes motile in the secretion of the accessory glands (prostate, etc.); but sperm taken from the epididymis becomes active in Ringer's solution. The sperm appears to possess no means of taking in nourishment-at least in marine forms, though it may be able to do so in animals such as bees and bats, in which insemination may take place months or even years before fertilisation; and it therefore has a strictly limited term of life. Cohn (I9I8) has shown that the total carbon dioxide output of the sperm is the same whether its life is artificially prolonged or curtailed 
by influencing its motility. Spermatozoa swim with a spiral motion, adhering to surfaces with which they come in contact, a fact which may be of some significance to the present question. There are really two problems that arise in this connection, for we have not only to account for the fact that a sperm may eventually make contact with an egg, but also to explain how it is that in general eggs are only fertilisable by sperm of the same species. It is not necessary to suppose that the same agencies are responsible for both phenomena.

Considering first the influence of the egg upon sperm motility, one has to face the possibility that the contact of sperm and egg is a matter of pure chance, or more strictly, that the only provision made to ensure fertilisation is the synchronous ripening of the gonads in the two sexes, and the prodigious fecundity of the species in animals where coitus does not occur. Where there is congress of the sexes there is nothing unlikely in this. What evidence is available has been chiefly derived from studying the effect of egg "secretions" on the sperm. In practice this amounts to observing the effect exercised upon the latter when brought into contact with sea water decanted from an egg-suspension, and for brevity called egg-water.

In the case of starfishes the influence of egg-secretion is conclusive. Since it is highly improbable that immotile spermatozoa can bring about fertilisation, and since in any case activity must increase the chance that a sperm will make contact with an egg enormously, the fact that immobile sperms of Asterias are raised to intense activity by addition of eggwater points strongly to the belief that, in these creatures at any rate, the egg exercises some directive influence on the sperm. In the absence of quantitative methods for studying the rapidity of motion in spermatozoa, it is impossible to be certain that egg-secretions have any action upon the spermatozoa of forms like Arbacia and Nereis in which the sperms are normally active in sea water. Some support is given to the affirmative belief by observations of Loeb who found that the spermatozoa of sea-urchins, which are immobile but live for days in isotonic sodium chloride, may be made 
intensely active by addition of egg-water. There is some indication - though the evidence is inconclusive-of specificity in this reaction, as can be seen from the following table, which summarises the effect of egg-water on sperm of different genera of starfishes and sea-urchins :-

Egg-water.

Sperm.

\begin{tabular}{|c|c|c|c|c|c|}
\hline & & Asterias & Asterina & Arbacia & $\begin{array}{l}\text { Strongylo- } \\
\text { centrotus }\end{array}$ \\
\hline Asterias & . & Very motile & No effect & $\begin{array}{l}\text { Moderate } \\
\text { activity }\end{array}$ & $\begin{array}{l}\text { Very slight } \\
\text { effect }\end{array}$ \\
\hline Asterina & . & No effect & Very motile & Very motile & $\begin{array}{l}\text { Very slight } \\
\text { effect }\end{array}$ \\
\hline $\begin{array}{l}\text { Arbacia } \\
\text { Strongylo- } \\
\text { centrotus }\end{array}$ & & $\begin{array}{l}\text { Slight effect } \\
\text { Slight } \\
\text { effect }\end{array}$ & $\begin{array}{l}\text { No effect } \\
\text { Slight } \\
\text { efiect }\end{array}$ & $\begin{array}{l}\text { Activity } \\
\text { Activity }\end{array}$ & $\begin{array}{l}\text { Activity } \\
\text { Activity }\end{array}$ \\
\hline
\end{tabular}

However, it would not be justifiable to conclude from this line of argument that the sperm is directed to the egg by the excretion of substances from the latter whose diffusion sets up a gradient in favour of greater motility in propinquity to the egg itself. The question has been further attacked by two forms of procedure known respectively as the drop and tube methods. The latter was introduced by Pfeffer, and consists of filling capillary tubes with egg-water or other fluid and observing the reaction of the sperm when the tubes are placed in a sperm-suspension. The data so obtained are difficult to interpret. It is true, for example, that capillary tubes containing sea water which has been in contact with ripe eggs of Echinus esculentus soon become plugged with sperm when introduced into a sperm-suspension of the same species. And Dakin and Fordham (1924) have endeavoured to establish the chemotactic orientation of the sperm towards the egg by comparing the accumulation of sperm in the eggwater tubes with accumulation of sperm in tubes containing other immobilising agents (e.g. acid) which would act as a trap collecting the quiescent sperm. With this particular species the control tubes were always found to contain less sperm than the egg-water tubes, and it is pointed out by the authors mentioned that the sperm travelled a greater length in the egg-water tubes. However, using the same method for the study of other material, both Buller and Loeb obtained 
results which do not support the conclusion that in general the eggs of marine animals give off substances which actually direct the movement of the sperm. Dakin and Fordham themselves were unable to demonstrate chemotaxis in the sperm of the mollusc Teredo. The drop method employed by Lillie and his pupils yields results which are interesting but somewhat difficult to bring into relation with those obtained by Dakin and Fordham, though Lillie himself advocates the existence of chemotaxis. When a drop of the egg-water of Arbacia is introduced under a cover slip into a spermsuspension of the same species three effects are manifest on microscopic examination. There is momentarily an intensification of the normal motility of the sperm. This is followed by an effect which has the appearance of a precipitation and takes place in two stages: $(a)$ aggregation, the loose association of spermatozoa in groups which can be imitated by passing $\mathrm{CO}_{2}$ into a sperm-suspension, and also occurs spontaneously in dense sperm-suspensions presumably through the accumulation of their own respiratory products; (b) agglutination, in which masses of sperm firmly adhere together. This latter phenomenon is reversible, when the egg-water is prepared from the same species as that from which the open suspension is derived. That is to say, after a few seconds or minutes, the sperm-masses separate, but individually the sperms remain immobile. Similar phenomena have been described in Nereis, Asterias, and Echinarachnius.

It is possible to study the agglutinating reaction quantitatively by determining the greatest dilution at which an indisputable reaction occurs for given samples of egg-water. The properties of the agglutinating substance have been worked out by Lillie and others, and it has been shown that the substance is not excreted by the fertilised but only by the unfertilised egg. It appears to be of colloidal nature. The egg-waters prepared from Arbacia and from Nereis both contain substances capable of agglutinating the sperm of the same species. The egg-water of Nereis produces no effect on the sperm of Arbacia. On the other hand, sperm-suspensions of Nereis undergo agglutination in presence of egg-water of 
Arbacia, and this reaction is an irreversible and toxic effect, unlike the reversible reaction of the sperm to egg-secretion of the same species. According to Lillie's experiments the "iso"-and " hetero"-agglutinating reagents are different substances. He infers this from two lines of evidence : (I) that egg-water of Arbacia, which originally acted on the sperm of both genera, on keeping lost its action upon the eggs of Nereis while retaining its activity with reference to sperm of the same species ; and (2) after removal of all the agglutinating substance which affects Nereis sperm by addition of the Arbacia egg-water to a sperm-suspension of Nereis, the agglutinating action of the egg-secretion on Arbacia or Arbacia sperm was unimpaired. It was also found that the sperm of a Teleost would neutralise the hetero-active substance. While these phenomena provide new materials for the serologist, it is perhaps premature to emphasise very strongly the conclusion stated by Lillie that " egg substances that thus activate and direct specific spermatozoa and render them adhesive are well suited to favour the fertilisation reaction."

Such information as is available with reference to the specificity of the fertilisation act does not lead to very definite conclusions. The sperm of one species will not in general fertilise the eggs of another species. But this specificity is not by any means absolute, and as illustrated by the rather extreme example of Kupelwieser's experiment, it can be overcome to some extent by experimental manipulation. When this can be done it is possible to search for some factor which specially distinguishes the normal process from the experimental procedure. The problem still remains to be solved. Baltzer, Tennent, Shearer, de Morgan and Fox, Fischel, and others have successfully hybridised different species and genera of Echinoderms ; similar experiments have been made on Teleosts by Newman and Moenkhaus, and on Amphibia by Bataillon.

Careful investigations into this phenomenon by Fox (1916) on Ciona failed to throw very much light on the question. Ciona exhibits an interesting form of specificity, one that may be common among hermaphrodite organisms and does not 
reinforce the teleological view that hemaphroditism, so widely spread among parasitic and sedentary organisms, is an adaptation to overcome the impediments to sexual intercourse in these forms. In the Tunicate the eggs are much more readily fertilised by sperm of another individual than by sperm derived from the same individual. When a certain number of eggs of an individual A of Ciona in a given volume of seawater are fertilised by the addition of a certain quantity B of a sperm-suspension of another individual, the number of eggs which segment is smaller than when an approximately equivalent suspension $\mathrm{A}$ is fertilised by an equivalent amount of $B$ in the presence of an extract made from the ovary on the one hand, or from grinding up the eggs either of the individual from which the eggs were obtained, the individual from which the sperm was obtained, or a third individual. In the same way the eggs of Arbacia and Strongylocentrotus contain substances which increase the fertilising power of the sperm of the same species. One may say in conclusion that there are a large number of data available which suggest that eggs secrete substances which influence the sperm; that there are indications that these substances are of the same general character as "antibodies"; and that possibly the action of some such substances may facilitate fertilisation by a sperm of the same species, while other substances tend to prevent union with sperm of another species. But the last proposition remains to be proved.

\section{Further REAding}

LILlIE. Problems of Fertilisation. Chicago University Press.

LOEB. Artificial Parthenogenesis and Fertilisation. Idem.

For later work consult :

CARTER (1924). On the Early Development of the Echinoderm Egg. Proc. Camb. Phil. Soc. (Biol.) I.

Shearer (I922). On the Oxidation Processes of the Echinoderm Egg during Fertilisation. Proc. Roy. Soc. B. 93. 


\section{CHAPTER XI}

\section{INHERITANCE}

BEFORE proceeding to a consideration of the subsequent history of the fertilised egg it is necessary to take into account an aspect of fertilisation which is significant to the final result of the process. The entry of the sperm into the egg not only provides the stimulus for further development, but influences the development so that the new individual bears resemblance to the male as well as to the female parent. The study of reflex phenomena has provided an instance of a field of physiological inquiry which has been made susceptible to quantitative treatment by the work of Sherrington, Pavlov, and others, though the physicochemical basis of the phenomena themselves is but little understood. The ultimate mechanics of hereditary transmission is perhaps even more obscure; but there is hardly any branch of biological research which has attained a higher degree of precision in the quantitative treatment of those relations with which it is concerned. The excellent presentation of the existing state of knowledge in such recent works as that of Crew is sufficient excuse for omitting a large mass of experimental detail. To such the reader may turn for confirmation of statements which, owing to lack of space for detailed treatment, may appear to be dogmatic. One can, however, hardly omit all reference in an account of this nature to properties common to all organisms, and properties concerning which, moreover, the bulk of our knowledge is derived from the study of the lower organisms.

The Factorial Hypothesis.-The exact study of inheritance begins in the opening years of the present century with the rediscovery by Tschermak, Correns and de Vries of certain principles originally formulated by a contemporary of Darwin, 
the Abbot Mendel. In their original form Mendel's laws were based on the study of plant types, but they were at an early stage extended to animals by Bateson (1902), whose brilliant critique of the speculations of nineteenth-century naturalists in his "Materials for the Study of Variation" (1895) had done so much to prepare the way for the development of genetic physiology.

In Mendel's original experiments inheritance was studied in the common pea, which possesses a number of true-breeding strains distinguished by well-defined characteristics such as colour (yellow or green) of the seed coat, or size of shoot (tall or dwarf). Mendel's method, which is the basis of all truly quantitative treatment of inheritance on experimental lines, differed from that of his predecessors in three particulars : he confined his attention exclusively to the transmission of single well-defined characteristics; he recorded separately the progeny of the individuals employed; and he used in his crosses only individuals from stocks proved to breed true for such characteristics. Experiments not safeguarded by this precaution have no value for purposes of scientific reasoning * in relation to our present problem, namely, the extent to which the sperm and egg respectively contribute in maintaining the continuity of resemblance between parent and offspring.

As an introduction to the problem let us consider the results of mating an individual from a pure wild stock of the fruit-fly Drosophila, in which the wings extend beyond the tip of the abdomen, with an individual from a pure stock of the well-established mutant (sport) in which the wings are vestigial. We shall attempt to build up the argument at each stage in the experiment. The offspring of the first generation, commonly referred to as the F.I (first filial), are all of the normal (long-winged) type. Bodily they are indistinguishable from the long-winged parent of the cross ; but when mated among themselves they behave in a different manner, in that a definite proportion of their progeny have vestigial wings. The long-

* The pure line experiments of Johannsen are not so much to be regarded as having constructive significance, but rather as a means of clearing up confused habits of thought resulting from the neglect of this precaution in earlier work.-AUTHOR. 
winged (referred to henceforth as "longs" for the sake of brevity) flies of the F.I thus differ from the parental longs in producing gametes some of which are characterised by the possession of a material something-let us call it a gene, without discussing its nature-which leads to the production of the vestigial condition of the wings. If we denote the gene which determines the long-winged condition by the symbol $\mathrm{V}$ and the gene which determines the vestigial condition by the symbol $v$, we may refer to the F.I longs as Vv, to denote that they form gametes bearing both $\mathrm{V}$ and $v$. By analogy the parental long and vestigial types, which since they breed true may be regarded as forming one type of gamete only, may be denoted by the symbols VV and vv. Let us proceed to examine the progeny (F.2) of the F.I longs mated inter se. One quarter are vestigial indistinguishable from the original vestigial, breeding true to type when mated with their like or with the original vestigial type. They may therefore be denoted by the symbol $v v$ as before. The remaining three-quarters are longs. They do not all behave in the same way on crossing. If they are individually crossed back to the original vestigial stock, one-third of the F.2 longs produce, like the original longs, only long-winged offspring; and individuals which behave in the back-cross in this way, when mated inter se breed true to type; they may therefore be denoted by the symbol VV. The remainder when back-crossed to vestigial give offspring half of which are longs and half vestigials. These impure F.2 longs when mated inter se behave like the F.I longs, giving a $3: 1$ ratio of long to vestigial. Thus they may again be denoted by the symbol Vv. The constitution of the F.2 is therefore $I V V: 2 \mathrm{Vv}: \mathrm{I}$ vv. Now if we make a very simple assumption about the distribution of the genes $\mathrm{V}$ and $v$ in the formation of the gametes the quantitative relations of all these crosses fall into line. Let us suppose that on the average the gametes produced by an individual consist of equal numbers containing the gene derived from one or the other parent. The F.I long receives from its vestigial parent the gene $v$, and from its long parent the gene $\mathrm{V}$ : one-half of the gametes it produces carry $\mathrm{V}$ and the other half $v$. V may fertilise V or $v$. Similarly 
$v$ may fertilise $\mathrm{V}$ or $v$. Since the probability of two events happening together is the product of their separate probabilities, the resulting probabilities of all possible combinations are $\left(\frac{1}{2}\right)^{2} \mathrm{VV}:\left(\frac{1}{2}\right)^{2} \mathrm{Vv}:\left(\frac{1}{2}\right)^{2} v \mathrm{~V}:\left(\frac{1}{2}\right)^{2}$ vv. This gives the proportions $I: 2:$ I for pure longs, impure longs, and vestigials, or a $3:$ I ratio of longs and vestigials.

In general characters distinguishing different hereditary

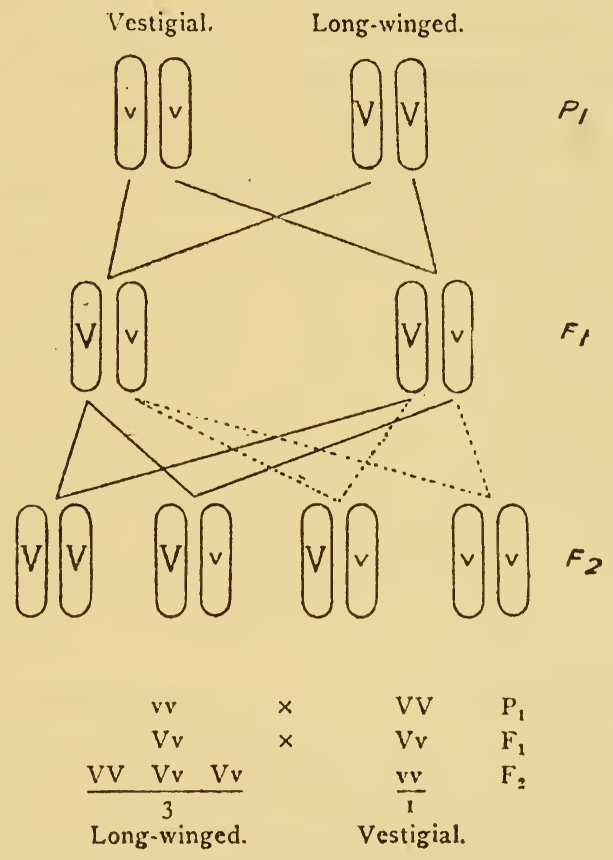

FIG. 4I.-Genetic segregation.

strains are distributed in hereditary transmission according to the assumption that they depend upon genes derived from both parents which segregate in the formation of the gametes, so that a gamete either contains the paternal or the maternal gene. The individual bearing dissimilar paternal and maternal genes (heterozygous condition) is not always predominantly like one or the other parent; it may be quite intermediate, or unlike either. When the character of one 
parent predominates in the heterozygous condition, it is called the dominant character (long in this case) in contradistinction to the recessive (vestigial in this example).

An immense variety of characters both in plants and animals have been found to follow the rule of segregation. To mention but a few, colour of the hair in mammals, duration of life in Drosophila, fecundity and absence of feathers on the neck in fowls, brachydactyly in man, absence of eyes and wings in flies. These suffice to show what diverse types of hereditable characteristics, anatomical and physiological, depend on segregating hereditary factors or genes.

However, factorial analysis, as this method of investigation is sometimes called, is not often as simple as in the case cited. And those who have criticised the universal applicability of the gene hypothesis usually do so in the expectation of a textbook simplicity in every instance. When we cross two strains, it may, and often does, happen that the difference which distinguishes them depends on more than one gene. The applicability of the factorial hypothesis can here be substantiated by the possibility of recovering types identical with both parents in the F.2 generation. Of course, as the number of genes involved increases, the number of possible combinations in the F.2 increases, and the likelihood of reclaiming the parental types diminishes.

There is another criterion of segregation which has been successfully applied to the analysis of a phenomenon which has been held up as a stumblingblock to the general validity of the gene hypothesis, namely the inheritance of size. In a good many cases clear-cut size differences depending on single genes have been found out. Very often, however, the F.2 form a continuous unimodal series. If segregation took place in a cross involving a large number of factors, it follows from quite elementary statistical principles that the coefficient of variation in the F.I should not be greater than that of either parent ; but that the coefficient of variation of the F.2 should be greater than that of the F.I ; and that the coefficient of variation of every subsequent generation would be on the whole less and never greater than that of the F.2. Furthermore, 
the range of variability in F.2 should extend to or beyond the limits of the two parental ranges. This has been shown to be true in cases worked out by East and Jones.

We have next to inquire how the transmission of one gene reacts upon that of ancther; and what results occur when two or more pairs of genes are involved in a cross.

Independent Assortment.-In the wild form of the banana fly, Drosophila, which has been the material of a considerablevolume of research by Morgan and his school, the body is gray and the wings extend beyond the tip of the abdomen. Two truebreeding mutants have appeared in Morgan's cultures respectively distinguished by the shade of body colour known as ebony and by a vestigial condition of the wings. Both are recessives to the wild condition. On crossing an ebony fly with longwings with a gray fly with vestigial wings, all the F.I are of the gray-long type; and the F.2 the four combinations: graylong, ebony-long, gray-vestigial, and ebony-vestigial in the proportions $9: 3: 3: \mathrm{I}$. On the assumption that the pair of genes responsible for the ebony and gray characters, on the one hand, and the long and vestigial characters on the other are transmitted quite independently, there is a $3: \mathrm{I}$ chance of any individual having either dominant character in the F.2. The probability of an individual having both dominant characters is $\left(\frac{3}{4}\right)^{2}$, that of it having one dominant but not the other and vice versâ is $\frac{3}{4} \times \frac{1}{4}$, and that of having neither dominant character $\left(\frac{1}{4}\right)^{2}$. This gives the $9: 3: 3:$ I ratio and proves that the assumption is correct. This is further borne out by the fact that identical results follow the mating of an individual of ebony colour and vestigial wings (double recessive) with the wild type.

Linkage.-This independent assortment of separate pairs of genes is very common in all organisms investigated. If, however, separate pairs of genes always segregated in this way, we should be compelled to postulate an indefinite number of structural units to provide for the material basis of inheritance. As a matter of fact, independent assortment is not a universal rule. Association of genes belonging to different allelomorphic (i.e. segregating) pairs in the process of transmission in contradistinction to the independent assortment illustrated 
by the experiment just described is known as linkage. Linkage may be partial or complete.

Both types of linkage are illustrated by the cross between the recessive mutants of the fruit fly known respectively as black (already mentioned) and vestigial. When a black fly with long wings is crossed with a gray fly with vestigial wings all the offspring as in the foregoing experiment are gray with long wings; and the same is true if a black fly with vestigial wings is crossed with a fly that is homozygous for the gray body colour and long-winged condition. But whereas, when the F.I male from the cross between gray-vestigial and blacklong is mated to the double recessive (black-vestigial) female, one-half of the offspring are gray-vestigial and the other half black-long; when the F.I male of the cross between blackvestigial and gray-long are mated to the double recessive female one-half of the progeny are black-vestigial and the other half gray-long. The genes re-emerge in the same combinations as those in which they were present in the original parent. Here linkage is complete.

Partial linkage is seen when the F.I females are crossed to the double recessive males. The offspring of the mating between the double recessive male and F.I female from the cross between black-vestigial and gray-long are not fifty per cent. black-vestigial and fifty per cent. gray-long but $4 \mathrm{I}^{\circ} 5$ per cent. black-vestigial, $4^{\circ} 5$ per cent. gray-long, 8.5 per cent. black-long and 8.5 per cent. gray-vestigial. Similarly the offspring of the mating between the double recessive male and the F.I females from the cross between black-long and grayvestigial are $4 \mathrm{I}^{\circ} 5$ per cent. black long, $4 \mathrm{I}^{\circ} 5$ per cent. grayvestigial, 8.5 per cent. black-vestigial and 8.5 per cent. graylong. In seventeen per cent. of the offspring there has been "crossing over"; the genes for black-gray and long-vestigial have become detached, though not to such an extent as to segregate with complete independence.

Linkage has been studied in several hundred mutants of Drosophila, and two important general results emerge from these researches of Morgan's school: (I) if a gene $a$ is linked with a gene $b$ which is also linked with a gene $c$, then $a$ and $c$ 
are also linked, and the percentage of crossing-over between $a$ and $c$ is in linear relation to the percentage crossingover between $a$ and $b$ on the one hand, and $b$ and $c$ on the other ; similar phenomena appear to hold in the sweet pea, where linkage was first discovered by Bateson and Punnett (1906); (2) if the gene $a$ segregates independently of $d$, then $b$ and $c$ which are linked with $a$ also segregate independently of $d$. Thus in the fruit fly all the mutant genes can be classified in four groups such that members of a given group show linkage inter se and independent segregation with respect to members of other groups. The genes of Drosophila thus appear to be associated in four pairs of material units.

Sex-linked Inheritance.-One group of linked characters in Drosophila is of special importance to a consideration of the general applicability of the gene hypothesis, and is equally important because of the light which it sheds on the problem of sex-determination. A single instance will suffice to make clear the characteristic feature of this group. In the wild fruit-fly the eye is red; there is a mutant form with white eyes. A red-eyed female crossed with a white-eyed male yields an F.I composed exclusively of red-eyed individuals; but in the F.2, which consists of three reds to one white, all the females are red-eyed, and all the whites are male. Now when a pure red-eyed male is crossed with a white-eyed female the result is quite different; all the females in the F.I as before have the dominant red eye ; but the males are whiteeyed. When the F.I are mated inter se, equal numbers of white-eyed and red-eyed females and males are produced. The inability of the male to transmit red to his offspring of the same sex is readily explained on the asumption that the red gene is linked to something which, if present in the zygote in duplicate, leads to the production of a female, and if present in the zygote unpaired (diagram) leads to the production of a male; the red-eyed male produces sperm of two kinds, one bearing the "red" gene destined to fertilise an egg which must become a female, and one which cannot bear the red gene and which is destined to lead to the production of another male (Fig, 42 ). This implies that sex itself is predetermined 
by genetical factors for which one sex is heterozygous, so that a I : I sex ratio is maintained by the normal consequences of a homozygous-heterozygous mating. Since in this case maleness is the state associated with the single condition and femaleness with the duplex state as regards the sex-linked genes, the male may be represented symbolically as $\mathrm{F} f$ and the female as $\mathrm{FF}$, using the symbol $\mathrm{F}$ for that which determines femaleness. This type of sex-linked inheritance occurs in most insects

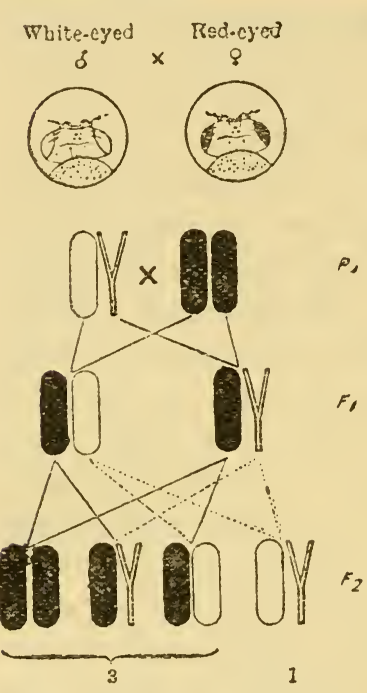

FIG. 42.- Sex-linked inheritance in Drosophila. and in mammals; and for reasons given later may be anticipated to occur in practically all higher bisexual animals except birds and lepidoptera (moths and butterflies). The phenomenon of sex-linked in-

ค, heritance was first discovered in the latter group by Doncaster (I906). A variety of the currant moth Abraxas grossulariata is distinguished by the pale colour of the wings as lacticolor. If a lacticolor female (wings of a pale cream tint) is crossed with the normal darkwinged (grossulariata) male, all the offspring of both sexes are of the grossulariata type : in the F.2 there is a $3:$ I ratio of grossulariata to lacticolor, but all the males are of the grossulariata type. In the reciprocal mating the grossulariata female can only transmit the grossulariata pattern to her sons; all the female offspring are of the lacticolor type. When the F.I are mated inter se, equal numbers of lacticolor and grossulariata males and females are produced (diagram). Here the female moth is constitutionally simplex with respect to the sex-linked genes. This is the exact reverse of the state of affairs in sex-linked characters in Drosophila. Femaleness is associated with the simplex condition of genes which in the duplex condition give rise to maleness.

The predetermination of sex by genetic factors does not 
mean that sex is irrevocably fixed at fertilisation; like all other genes those which ordinarily determine sex require appropriate external and internal conditions in which to operate; and we shall return to this question in considering sex-differentiation as part of the physiology of development.

It is interesting to note how nicely balanced the genetic factors influencing sex-differentiation may be. This is well seen in experiments of Goldschmidt on the gypsy moth, Lymantria. Individuals from the same local races of this widely distributed form when bred among themselves produce a normal sex ratio ; when individuals of different local races are crossed the relations of the sexes among the offspring may be abnormal. If females from a European race are crossed with males from a Japanese race, the offspring are normal males together with females showing a number of modifications in the direction of maleness; the would-be females are intersexual. Reciprocally, when a Japanese female is mated to a European male the F.I generation is normal but a definite proportion of the males in the F.2 are intersexual, i.e. show modifications in the direction of femaleness. Varying grades of intersexuality characterise the results of crossing individuals from different local races; the grade from the cross between any two given races is always the same. In the extreme case all the individuals of such a cross may be of one sex, but half of these on being bred back to a parent stock can be shown to have the genetic constitution of the alternate sex. By making two assumptions Goldschmidt has brought into line the results of a very large number of such racial crosses: (I) in addition to the genes for maleness for which the female has the constitution $\mathrm{Mm}$ and the male MM (as in Abraxas where the same type of sex-linked inheritance occurs) there is something dependent on the constitution of the egg, transmitted therefore through the female parent only, that modifies the degree of maleness, and is denoted by the symbol $\mathrm{F}$. Thus a female $\mathrm{MmF}$ forms gametes $\mathrm{MF}$ and $m \mathrm{~F}$ while the male $\mathrm{MMF}$ forms gametes $\mathrm{M}$ only; (2) it is further assumed that in different local races the efficiency of $\mathrm{M}$ and $\mathrm{F}$ respectively to influence differentiation in the direction of maleness or femaleness are quantitatively 
different. By denoting $\mathrm{M}$ and $\mathrm{F}$ in terms of an arbitrary system of numerical symbols Goldschmidt has elaborated a system by which the appearance and degree of intersexuality of his crosses between local races can be faithfully predicted.

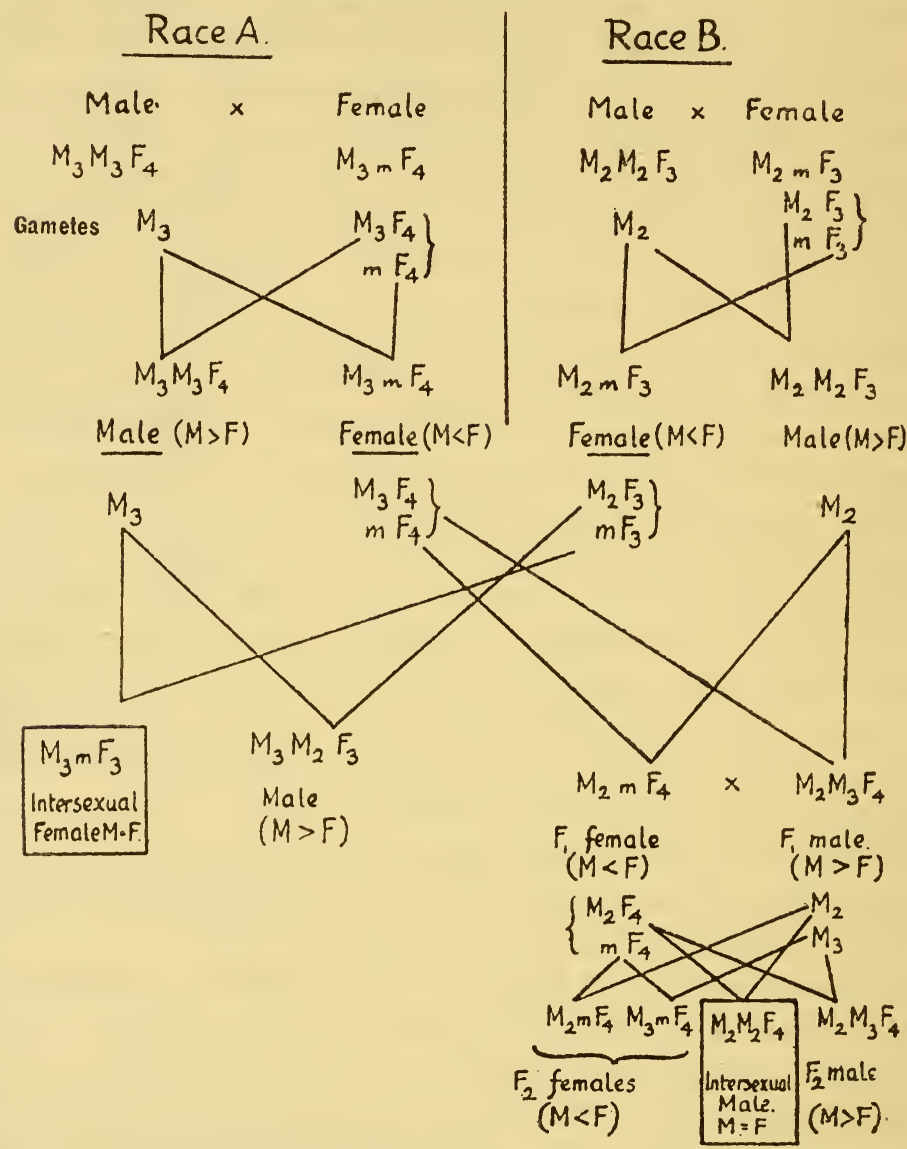

FIG. 43. - Simplified representation of the results of Goldschmidt's investigation of crossing in the gypsy moth Lymantria. The suffixes to $\mathrm{M}$ and $\mathrm{F}$ denote the "strengths" of the male and female factors. When the sum of $M$ is $>F$, the animal is male; when $<F$, a female; when $=$ $\mathrm{F}$, intersexual.

Many thousands of individuals have been employed in these crosses. The accompanying scheme is a simplified representation by the author of Goldschmidt's essential ideas (Fig. 43). 
Structural Basis of Inheritance.-Just as it is possible to identify in the reflex arc the structural basis of neuro-muscular co-ordination in the higher animals, so it is possible for the genetic physiologist to identify in the chromosomes the structural basis of hereditary transmission in animals and plants. It is probable that prevailing ignorance of the cellular morphology of inheritance accounts in no small measure for the neglect of Mendel's work by his contemporaries. By the middle of the latter half of the nineteenth century the work of Hertwig, Fleming, Strasburger, Boveri, Van Beneden, and others had led to the recognition of the union of the nuclei of the male and female gametes as the essential fact of sexual reproduction; of the constancy in number for every species of the chromosomes or nuclear components in cell-division; and the maintenance of this constancy by the reduction of the chromosomes to half the species-number in the production of the gametes. By the beginning of the twentieth century the studies of Strasburger and Sutton on the sizes and shapes of chromosomes, the detailed study of the reduction division and its antecedents by von Winiwarter, and the study of sexual differences in the chromosome complex by McClung, whose work was extended and elaborated by Stevens, Wilson, and others, had accumulated sufficient evidence to locate in the chromosomes the anatomical basis of Mendelian segregation, and encourage the belief that the principles revealed by factorial analysis were of widespread applicability.

Let us now consider separately the conclusions derived from experimental study in the light of microscopic knowledge available to-day.

r. Factorial analysis leads to the conception of material units present in the fertilised egg in duplicate, and segregating before the formation of the gametes into maternal and paternal components, one member of each pair and one only being present in each gamete. As is well known, the chromosomes in all animals and plants are present in the fertilised egg in twice the number found to be present in the gametes. Furthermore, in many animals (and plants) from the most diverse phyla, the chromosome complex of a species is characterised 
not only by a definite number but a definite configuration. It is possible to distinguish among the chromosomes pairs of different sizes and shapes (this is true of man, and many mammals) ; and the maintenance of this constant configuration implies that when reduction takes place one member of each pair passes into each gamete. In other words, the chromosomes are present in the fertilised egg in pairs, segregating in the formation of the gametes into maternal and paternal components, one member of each pair and one only being represented in each gamete.

2. The material units on which hereditary transmission depends are associated in groups, the members of which are independently segregated with reference to members of other groups. There are four such groups in Drosophila; and in Drosophila there are exactly four pairs of chromosomes. No organism is known in which the number of linkage groups is numerically greater than the number of pairs of chromosomes.

3. Lastly, we have seen that with respect to one group of linked characters the sexes are differently constituted. Sexlinked inheritance has been described in several groups of the animal kingdom, including mammals; there are several well-established cases in man, where, as in Drosophila and the cat, it is the male that produces two types of gametes. In several hundreds of animal species from the most widely divergent groups it is now established that one pair of chromosomes which is equally paired in one sex is represented in the other sex by a single member, or a pair of unequal elements. For instance, in the cockroach the male has thirty-three chromosomes (Morse) and the female has thirty-four chromosomes (Hogben). The female produces eggs which contain seventeen chromosomes, while the male produces sperms half of which possess sixteen and half seventeen chromosomes. Clearly, if a sperm of the former type fertilises an egg the resulting zygote will have the chromosome number (33) characteristic of the male, while if the latter type fertilise an egg the resulting zygote will have the female constitution (34). Drosophila, on the other hand, is a case where one pair of chromosomes $(\mathrm{XX})$ similar in the female is represented by 
two unequal elements (XY) in the male. The same is true of man and numerous genera of mammals. In the vast majority of cases the male is the heterogametic sex. We have seen, however, that in moths and birds the female is the heterogametic sex. In birds the chromosomes are too small and numerous to provide satisfactory material for investigation, though recent work of Hance shows that the female is heterogametic. In some moths (Seiler) there is a pair of dissimilar elements in the female which are equally paired in the male.

The coincidence between the genetic and microscopic data has been illustrated still further by the phenomenon of "non-disjunction" described by Bridges in connection with several sex-linked nutant characters of which our original instance of white eye-colour will serve as an example. There appeared among the white-eyed mutant stock of Drosophila certain strains of which the females when crossed to normal red-eyed males gave a certain proportion of red-eyed males and white-eyed females in addition to the usual red-eyed females and white-eyed males alone. When the white-eyed female offspring of such abnormal crossings were mated back to red-eyed males, they in their turn gave all four classesred-eyed males and females, white-eyed males and females. The white-eyed females behaved like their mothers, giving abnormal results in all cases. Half of the red-eyed females gave normal and half abnormal results in crossing. Of the male progeny the red-eyed individuals were normal, whereas only half the white-eyed individuals were normal, the remainder begetting daughters whose progeny was exceptional. Bridges found that in the F.I abnormal white females the chromosome complex of the dividing cells showed a $\mathrm{Y}$ element in addition to the XX pair. This is explicable on the understanding that at reduction of the egg in a certain proportion of cases the $\mathrm{X}$ elements failed to disjoin, so that the ripe egg contained either two X elements or none at all. If we represent the sperms of a red male as $\mathrm{X}^{\prime}$ or $\mathrm{Y}$, two additional types of individuals will result from fertilisation by a $\mathrm{Y}$ or $\mathrm{X}^{\prime}$ sperm respectively : an $\mathrm{XXY}$ or white female, and $\mathrm{X}^{\prime} \mathrm{O}$ or red male. This accounts for the exceptional individuals in the F.I, and accords with 
the facts elicited. Next consider the results of back-crossing these XXY abnormal F.I white females to a normal $\mathrm{X}^{\prime} \mathrm{Y}$ male. According to whether the $\mathrm{X}$ elements segregate with respect to one another or the $\mathrm{Y}$ chromosome, the F.I white females will lay four types of eggs: $\mathrm{XX}, \mathrm{Y}, \mathrm{XY}, \mathrm{X}$. If these are fertilised by a $\mathrm{Y}$ sperm (which cannot bring in the red factor), we get four types : (a) XXY white females which will obviously behave in the same way, thus agreeing with breeding experience; (b) YY-individuals with such constitution cannot exist; (c) XYY-white males which should produce $\mathrm{XY}$ sperms so that in crossing with normal white females daughters of the XXY type producing exceptional progeny would result; (d) XY-normal white males. When, on the other hand, the same four classes of eggs are fertilised by an $\mathrm{X}^{\prime}$ sperm carrying the red factor, four red types of offspring would result, as follows : (a) $\mathrm{X}^{\prime} \mathrm{XX}$ - a triploid female which usually dies; (b) $\mathrm{X}^{\prime} \mathrm{Y}$-normal red males; (c) $\mathrm{X}^{\prime} \mathrm{YX}$ red females with abnormal offspring ; $(d) \mathrm{X}^{\prime} \mathrm{X}$ normal red females. Thus the non-disjunction of the $\mathrm{X}$ chromosome in the formaion of the eggs of some of the females of the parental whiteeyed stock accounts for the entire series of exceptional genetic phenomena which occur in these strains.

Recently Bridges has shed further light on the genetical aspect of sex-determination by the discovery of non-disjunction in chromosomes other than the sex-chromosomes, sometimes referred to in contrast to the latter as autosomes. In an experiment in which a brown mutant of Drosophila was crossed back to a parental stock, a culture was obtained in which the individuals were almost exclusively females or sex intermediates. These "intersexes" displayed intermediate sex-characters throughout, notably in the abdomen and in the sex-combs of the tarsal joint of the forelegs, and also genitalia. On the whole they fell into two groups, one tending more to the female, the other to the male condition. Genetical evidence led Bridges to conclude that for one group of genes at least the female individuals of these cultures were triploid, i.e. inherited a double instead of a single set of genes from their fathers. Microscopic examination of the germ cells 
revealed the fact that the second and third chromosomes were present in triplicate, while an additional fourth chromosome was present in some but lacking in others, there being thus two degrees of the triploid condition, that with three fourth chromosomes being more female (Morgan, Bridges and Sturtevant, 1925). The X chromosome was present in duplicate in the intersexes but the females possessed three $\mathrm{X}$ elements. Thus using the symbol A for autosome and $\mathrm{X}$ for the sex-chromosomes, the genetical constitution of these intersexes and abnormal females were respectively $3 \mathrm{~A}+2 \mathrm{X}$ and $3 \mathrm{~A}+3 \mathrm{X}$, as contrasted with the normal female constitution $2 \mathrm{~A}+2 \mathrm{X}$. Abnormal males were also found with the constitution $3 \mathrm{~A}+\mathrm{X}$, as contrasted with the normal male constitution $2 \mathrm{~A}+\mathrm{X}$. Therefore if $\mathrm{X}: \mathrm{A}=\mathrm{I}$ or $>\mathrm{I}$ the individual is a female, if $\mathrm{X}: \mathrm{A} \frac{1}{2}$ or $<\frac{1}{2}$ it is a male, but when $\mathrm{X}: \mathrm{A}$ lies between the $I$ and $\frac{1}{2}$ the intersexual condition is manifested.

Ratio of sex chromosomes

to autosomes.

Sex.

I or $>$ I

F

$\frac{1}{2}$ or $<\frac{1}{2}$

$>\frac{1}{2}$ but $<$ I

$\mathrm{M}$

Intersexual.

General Validity of the Factorial Hypothesis.-The factorial hypothesis has aroused a good deal of hostility, not unnaturally, for it conflicts with many accepted speculations as to the evolution of living organisms and throws doubt on not a few beliefs still current in the medical profession. The remarkable diversity of inherited characteristics, anatomical and physiological, with which it deals; the truly amazing correspondence between the conclusions derived from experimental and microscopic studies; and finally, the established fact that the nucleus is the only recognisable cell-element which is universally contributed by the sperm to the development of a new individual can leave little room for doubt in the minds of impartial students of the subject that, in broad general outline, it will be found to apply to all the essential phenomena of biparental inheritance. If this is so its importance for the study of animal function does not lie merely in the account it gives of the contribution which the male and 
female respectively make to the constitution of a new animate unit.

Bearing on Other Branches of Physiology.-For example, many kinds of physiological experiment involve comparisons for which controlled observations can only be carried out on different individuals, e.g. effect of diet or endocrine substances on growth. It is clearly established that growth-phenomena and size-differences in a number of cases depend upon factorial inheritance. Experiments of this kind, therefore, unless based on large numbers of animals (which is often impossible) and subjected to statistical analysis, are of doubtful value, when the material is not known to be genetically homogeneous.

To achieve this end it is not necessary to set about breeding pure strains with reference to every characteristic it is desired to study. With the aid of the conventional symbols the reader can easily satisfy himself that in a cross involving one pair of factors, the proportion of heterozygotes diminishes generation by generation in a continuously convergent series, if any system of close inbreeding is employed. After about twenty generations of brother and sister mating, for instance, or ten of self-fertilization, the proportion of heterozygotes is indefinitely small. If a stock that is not undergoing mutation is bred from generation to generation by close inbreeding, it must eventually become for all practical purposes homozygous for any characteristic. Such stocks of white rats have been reared by the Wistar Institute, and are employed in physiological experimentation increasingly by American workers (see East and Jones).

Again, the following citation, from an important physiological memoir, illustrates how easily genetical bias enters into physiological reasoning :-

"Now the history of the surfaces in the hearts of rays on the one hand and of the dogfish and angel-fish on the other, differs in this significant respect. They have been laved for years, or one might properly say for generations before the experiment, with solutions of different hydrogen ion concentration."

It is here implied that the action of a stimulus upon the 
body of the parent can affect the reaction of the offspring to the same stimulus. This belief, at one time universally held, still awaits confirmation by properly controlled experiment. If we attempt to analyse in exact terms the belief that " acquired characters " are inherited, it appears to involve two separable issues : $(a)$ whether the inhibition or destruction of a character is accompanied wholly or partially by the destruction of its material antecedent in the germ cells ; $(b)$ whether, if a stimulus of a given magnitude is required to call forth a given response, the application of that stimulus to the parent carries with it the possibility of evoking the corresponding respense in the offspring with a stimulus of smaller intensity. Without committing oneself to a dogmatic negative, it can be stated as a matter of fact that in a good many cases the answer is certainly in the negative (within the limitations of experiment on these lines), and that in no single instance where a positive answer has been given has independent and rigorous reinvestigation confirmed the observations recorded. The principle of economy of hypothesis is therefore best preserved if the Lamarckian principle is eliminated from consideration, when the bearing of hereditary transmission on other branches of experimental biology is under discussion.

\section{FURTHER READING}

GoLDSCHMIDT. Mechanism and Physiology of Sex Determination. Methuen.

Morgan. The Physical Basis of Heredity. Lippincott.

Crew. Introduction to the Science of Animal Breeding. Oliver and Boyd.

EAST AND JoNes. Inbreeding and Outbreeding. Lippincott.

Morgan, Bridges and Sturtevant (1925). The Genetics of Drosophila. Bibliographica Genetica (the Hague), vol. 2. 


\section{CHAPTER XII}

\section{THE PHYSIOLOGY OF DEVELOPMENT}

INHERITANCE, which was discussed in the last chapter, is a rhythmical repetition in each species of a definite and (on the whole) similarly repeated series of events in which the production of one individual leads up to the formation of gametes whose union initiates a new being. The fertilised egg bears within it the power to develop into an individual resembling the parents from which the sperm and egg were derived. Fertilisation starts in the egg a period of active cell-division. In the initial stages of cleavage all the cells may be, and often are, for a considerable period very much alike. As they go on dividing they differentiate individually and regionally to build up the structural architecture of the new individual. In the early stages there is no increase in size ; at some point, however, the developing organism begins to augment in weight and volume. This process usually goes on long after the final morphological order characteristic of the individual is completely established. Developmental phenomena may thus be considered under two headings : differentiation, individuation and growth.

Individuation, or the differentiation of structural pattern in cellular animals, raises perhaps the most recondite issues in the whole field of biological inquiry. It is convenient to consider it separately in its spatial and chronological aspects, that is to say (I) the agencies which determine whether a particular region is to differentiate into one type of structure rather than another; and (2) the agencies which determine the orderly sequence in which the differentiation of one structure follows another. In this chapter no attempt will 
be made to deal with that large body of inquiry in the field of " experimental embryology" which is not as yet susceptible to quantitative treatment *; we shall merely attempt to indicate directions in which what are ordinarily called physiological methods have been brought to bear upon developmental phenomena. As the subject is a difficult one a certain amount of latitude in defining concepts which may assist to clarify the issues may be permitted.

The normal end-product of development-the individual as we know it-is only one of a large number of ways in which the hereditary constitution can be realised spatially. By the methods of regeneration and implantation of organs, and by varying the physicochemical constituents of the external medium other structural patterns can be induced. Modification by physicochemical agencies alone falls within the scope of this treatment. As in dealing with the problems of fertilisation, if the experimentalist can modify the course of events by physicochemical means, some progress will have been made towards an understanding of the mechanical basis of the natural process. A measure of success has already attended the efforts of experimentalists in modifying the course of individuation by physicochemical agencies. One may recall the well-known experiments of Stockard (1906), who found that by placing eggs of the Atlantic minnow in a mixture of sea water and magnesium chloride (19/6o M) about half the individuals developed into one-eyed forms. These Cyclopean monsters were of two varieties; in one kind the two optic rudiments approximated at an early stage in the middorsal line and coalesced ; in the other only one eye developed, shifting into a median dorsal situation. Many of these embryos hatched out, and were able to swim like the normal individual. Again, there is the well-known method, due to Herlitzka, of producing Siamese twins in newts by mechanical means. If the two cells of the first cleavage in the newt's egg are separated by a fine noose of hair in the plane of the first furrow each half may segment as a whole, developing

* On this, readers should consult Jenkinson (1909), Dürken (1919), and Wilson (1925). 
into a complete larva; but if the constriction is incomplete double-headed forms result. Double-headed monsters can be produced from frog's eggs by inverting them in the two cell stage, or (Bellamy) by the action of cyanides in appropriate concentration at a later stage in development. Lastly may be mentioned the production from sea urchins by Herbst (1893) of plutei without arms or spicules by exposing the egg to the action of potassium salts.

Pioneer work of this kind provided a wealth of spectacular instances of ways in which differentiation and individuation can be partially controlled in a predictable manner by experimental procedure. But in many cases the characteristic abnormalities were on subsequent examination found to be procurable by such a variety of methods as to defy analysis. Thus Stockard's cyclopean embryos, thought at first to be due to the specific action of the magnesium ion, can be obtained with alcohol and other very different reagents. McLendon (I9I2) produced cyclopia in fish embryos with isotonic solutions of lithium chloride, sodium hydrate, and a number of other equally dissimilar substances.

During the past few years a new impulse has been given to experiment on these lines by a hypothesis which has been elaborated by Child. The evidence brought forward by Child and his co-workers in favour of his hypothesis can hardly as yet be said to be crucial. But its effect has been to introduce new concepts which, whether the main body of this work stands or falls, are bound to simplify the nature of the problems of individuation and prove the starting-point of new lines of investigation. Of these concepts, it is not least important that Child, by emphasising the idea of polarity and describing the architecture of the organism with reference to axial symmetries, has provided us with the very useful term, axiate pattern. The arrangement of structural parts in the higher organisms is so immensely complex that one must limit the field in order to make the search thorough. One way of doing this is to confine attention to the arrangement of parts with reference to some axis of symmetry, e.g. the oral-aboral axis of the body. 
The first postulate of Child's hypothesis which need here concern us may be stated thus :--the morphological differentiation of parts (axiate pattern) with reference to a given axis is preceded by the appearance of a gradient of physiological activity (axial gradient) along this axis. This proposition may be shown to be true in a number of ways; and is quite independent of the particular interpretation of the axial gradient which may be stated later. The existence of a physiological gradient is here taken to imply that there exist between the properties of the cells quantitative differences following a definite orientation with reference to the future axiate pattern. A very clear instance of this is provided by experiments on asexual reproduction in Planaria dorotocephala. If a large number of individuals of this species are cut up into strips, it is found that the frequency with which corresponding strips taken from different regions regenerate a head and develop into complete new individuals varies in a perfectly definite way. If we plot the statistical results of such an experiment with frequency of head-formation as ordinates and regional position of the strip along the abscissa (taking the head extremity as zero), the ordinates gradually diminish as we pass along the $x$-axis up to a certain point, then increase abruptly to a new maximum and then diminish (Child, 1915). Thus before there exists any outward structural appearance of the formation of a new head, there exists a physiological difference in the tissue at the point where the new head is to be formed.

The second proposition brings us on to more debateable ground. To do justice to the author, it may be stated, in his own words: "Axial gradients have often been called metabolic gradients, because differences in metabolism, or more specifically of oxidative metabolism as indicated by various experimental methods, appear to be characteristic and conspicuous features of them." In this sentence for the first time an attempt is made to put the problem of individuation on a basis which is accessible to quantitative methods of physiological inquiry.

Various methods have been employed by Child and his co-workers in the attempt to demonstrate regional differences 
in metabolic activity in small organisms and embryos. 'Two of these, neither of which are wholly satisfactory, may be mentioned. One is the use of potassium permanganate as a colorimetric indicator of oxidative processes. Potassium permanganate is readily, reduced by protoplasm with the production of a brown coloration, the intensity of which may be taken as a measure of oxidation in a particular region, but depends on other things besides. Child and Hyman (19r9) studied the effect of placing small organisms and embryos in very dilute solutions (M/10,000), and described in all cases a gradient along the oral-aboral axis with maximum activity at the anterior end.

The other method is the so-called susceptibility method. The results obtained with this, though more striking still, provide evidence of a somewhat indirect nature. In this method Child has concentrated on defining the effects of reagents like the cyanides which are known to reduce oxidative activity. The method of interpretation is elaborate and requires further investigation before it can be applied indiscriminately, and one would feel more assured if Child had confined his observations to the action of the cyanides alone. Child and his co-workers have carried out experiments on tissues at different temperatures and in different states of activity which point to a quantitative relation between susceptibility to the toxic action of cyanides on the one hand and to metabolic rate, or, at least, to some form of physiological activity, on the other. This relation is according to these observations a complex one; in lethal doses which are not sufficiently concentrated to produce death within a short period of exposure, the regions of higher activity are always affected first, so that above a critical concentration susceptibility varies directly as the physiological activity, while below this concentration the reverse relation is seen, in that regions of higher activity recover and adjust themselves to the reagent more successfully than regions of lower activity. In applying the susceptibility method to embryonic development, lethal concentrations may be used but not allowed to act long enough to produce death in the embryo, and in such cases 
they will, according to Child's interpretation, inhibit regions of higher activity to a more marked degree than regions of lower activity; while, on the other hand, in very low concentrations of the reagent such as to permit acclimation and recovery, the region of higher activity will be inhibited, according to Child's interpretation, less than regions of lower activity.

Two instances of the use of the susceptibility method must suffice to indicate some positive results of the application of Child's hypothesis. Eggs of Polychætes were placed in lethal concentrations of $\mathrm{KCN}$. Initially dissolution begins at the anterior end. As development proceeds the region of maximum susceptibility shifts to the posterior region (where growth is most active) so that when the larva is ready to undergo metamorphosis the posterior extremity is the region which succumbs most readily to lethal and recovers most easily from sublethal concentrations. Child (19I7) finds that embryos submitted to short exposure of lethal concentration in the earliest developmental stages develop into individuals with abnormally small heads. Embryos which are similarly exposed at the later stage develop into individuals with abnormally large heads.

In a similar study by Child of development in sea-urchins, long exposure to sublethal concentration as well as the short exposure to lethal concentration was investigated. Two resultant types of plutei are figured, that produced by " differential acclimation" (long exposure) with abnormally enlarged oral lobe and widely divergent arms and that produced by " differential inhibition" (short exposure) with diminished oral lobe and angle of divergence between the arms. It is impossible in the short space at our disposal to do justice to Child's voluminous publications, which must be consulted for further information. The susceptibility method may well prove a useful instrument of research, when its theoretical assumptions are independently substantiated by accurate gas analysis. Shearer (1924) in a recent publication records results of an investigation based on direct measurement of oxygen consumption with a technique that for the purpose is 
above criticism; the new data are decidedly confirmatory of the main contentions of Child's work.*

Shearer first studied $(a)$ portions of the living chick embryo from the anterior and posterior ends of the blastodisc during the first ten days of incubation; $(b)$ pigments from the anterior and posterior extremities of the earthworm. In the first case the oxygen consumption was measured by Barcroft's differential manometer. In the second case Haldane's apparatus was

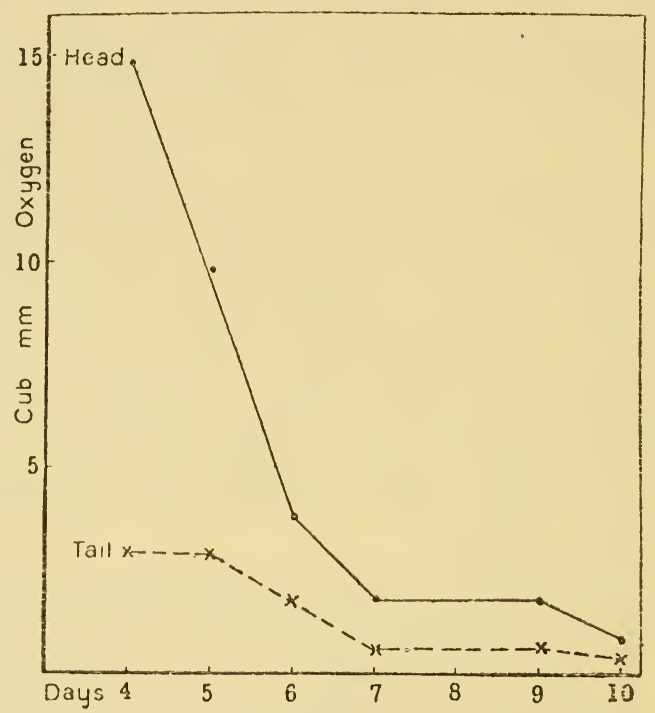

FIG. 44--Oxygen consumption of chick embryos (Shearer).

employed. In both sets of experiments the tissue used was incinerated and estimated for protein content by Kjeldahl's method. Thus all values of oxygen were expressed in absolute units by reference to an equivalent amount of $\mathrm{NH}_{3}$ liberated in the Kjeldahl determination at the end of the experiment. The results of the experiments on chick embryos are represented graphically on Fig. 44. Here the point to notice is that the gradient of the oxygen consumption curve for the head and tail portions become identical at the seventh day, when

* [Note by the Editor, Sept., 1925.] Later, as yet unpublished, work has somewhat modified these conclusions, Dr. Shearer informs me. 
the axial pattern is established and further development is mainly concerned with increase in size. The existence of an antero-posterior metabolic gradient in the earthworm is seen from the following data :-

EARTHWORM EXPERIMENTs (Haldane's Method).

Temperature $12^{\circ} 5^{\circ} \mathrm{C}$. $760 \mathrm{~mm}$. $\mathrm{Hg}$. All values reduced to 5 c.c. $\mathrm{NH}_{3}$ Kjeldahl.

(I) In 3 hours worm consumed head $\mathrm{I}_{3} 3$ cub. mm. oxygen.

$"$,

$"$,

$\begin{array}{lll}\text { tail } 0.3 & , & , \\ \text { head } 0.85 & , & , \\ \text { tail } 0.27 & , & , \\ \text { head } 0.75 & , & \text { ", } \\ \text { tail } 0.25 & , & \text { ", }\end{array}$

In a second series of experiments Shearer investigated the action of acetone powders instead of living tissues, the former being prepared after the manner of acetone yeast preparations by dehydrating the fresh tissue in acetone and subsequently desiccating it. Such powders on being made into a thin emulsion in distilled water take up oxygen. If the powder prepared from the head region has a greater oxygen capacity than powder prepared from the tail region, it is impossible to escape the conclusion that the head region has an intrinsic power to consume oxygen more rapidly, independently of its structural organisation. This is indeed the case. The results were again reduced to a fixed amount of protein, i.e. in terms of roo c.c. $\mathrm{NH}_{3}$ (Kjeldahl). The duration of each experiment was one hour twenty minutes at a temperature of $40 \mathrm{C}$. and standard pressure. The oxygen consumption in three experiments with acetone powders from 6-7 embryos estimated by Barcroft's method is given in cubic millimetres as follows :-
(I) Head 0.62 Tail 0.23
(2) Head 0.52
Tail 0.29
(3) Head $0^{\circ} 47$
Tail 0.27

The axial gradient hypothesis has naturally aroused considerable hostility ; it is subversive of the underlying assumptions of the germ layer theory. For this reason the independent 
experiments of Shearer have been cited in some detail. It opens up the possibility of substituting for architectural mnemonics quantitative experiment along two lines: (I) how external agencies acting on the egg or embryo set up spatially orientated differences in cellular oxidative or other processes; in this connection important work on electrical gradients in organisms has been done by Lund $(192 \mathrm{I}-22)$ and Hyman and Bellamy (1922). (2) How the structural features of isolated tissues are affected by artificially induced differences in oxygen consumption. In relation to the last issue papers by Huxley on de-differentiation may be mentioned for suggestive indications.

Let us now turn from the spatial aspect of individuation to the mechanism which determines the orderly succession of developmental stages. The nature of the issue is clearly presented by reference to experiments of Uhlenhuth (I912-I7) who has studied the effects of grafting eyes and skin of larval salamanders into individuals of different ages. His observations show conclusively that when such organs are transplanted they assume the adult characteristics not at the time when their original possessor attains maturity, but always when the animals into which they have been grafted attain metamorphosis. Hence for the development of, say, the adult skin characteristics (e.g. yellow pigment areas) there must be present something which is normally produced at the time of metamorphosis and is produced by the body as a whole or by some special organ or organs. The nature of this factor is now clearly established as regards the case selected.

Animals which like Amphibia undergo a metamorphosis are peculiarly suitable for the study of the time factor in development. Up to a certain point individuation proceeds actively. It is then checked; growth continues for a period without much structural rearrangement. Then a second phase of active structural differentiation is intercalated. In the Anura this involves (I) closure of the gill clefts ; (2) resorption of the tail ; (3) full development of the limb rudiments. In Urodeles the events are (I) resorption of the external gills ; (2) resorption of the dorsal fin and shedding of the larval skin; (3) closure of the gill clefts. The Urodele larva has fully- 
developed limbs and the tail persists into the adult stage. The nature of the physiological change which initiates this series of events is the same in either case.

The first experiment which threw any light on this was the discovery of Babak (I9II) that the axolotl larva of the Mexican salamander (Amblystoma tigrinum) which is normally neotenous, can be induced to undergo transformation into the adult form by thyroid administration. Gudernatsch (1912-14) showed that this was true of frog tadpoles. If tadpoles are fed on diets of various tissues, ovary, liver, thymus, brain, pancreas, spleen, pituitary, and thyroid-those fed on thyroid gland develop limbs and lose their tails long before the others. Thus in Rana catesbana (Swingle), a species which normally requires three seasons to attain to the stage at which metamorphosis occurs in nature, the six-weeks-old tadpole will transform into a pigmy frog if fed on ox thyroid. These observations received abundant confirmation both as regards urodele larvæ and anuran tadpoles (Morse,Barthelemez, Jensen, Huxley and Hogben, Uhlenhuth).

Bennet Allen (1916-18) succeeded in overcoming the manipulative difficulties of extirpating the thyroid gland in tadpoles of the toad. The thyroidectomised tadpoles behave in a perfectly normal manner until the limb-buds develop, when transformation should occur. Instead of undergoing metamorphosis at this stage they remain permanently in the larval state, attaining as age advances dimensions far exceeding those of a normal tadpole. They can, however, be induced, as Swingle (1918) showed, to develop into normal frogs if fed on thyroid tissue. Later E. R. and M. M. Hoskins confirmed the work of Allen by similar experiments on frogs and others on urodele larvæ.

Thus both in Anura and Urodeles it is certain (I) that the removal of the thryoid normally prevents metamorphosis; (2) the administration of thyroid substance (or implantation of thyroid tissue) accelerates normal metamorphosis and initiates metamorphosis in thyroidless individuals. It has long been known that the thyroid gland is essential to normal growth in mammals, that it contains a high percentage of 
iodine, and that administration of the gland substance compensates for the clinical disturbances resulting from its removal or disorder-notably a reduction in basal metabolism. Recently Kendall has isolated a substance having the properties of thyroid extracts and the constitution of a tri-iodo derivative of tryptophane. Helff (1923) and Huxley (1925) have shown that thyroid extract increases respiratory exchange in the tadpole ; but this does not appear to be the case in the adult ; and Champy (1919) claims that the thyroid hormone acts selectively on larval tissues. The significance of the thyroid has been further explored by Swingle (1919) and by Uhlenhuth (I92 I and 1922). Swingle's observations concern the relation of the organism to its iodine supply: the iodine content of water and food is the limiting factor in thyroid development and consequently in metamorphosis. This observation throws a flood of light upon a phenomenon of no little bionomic interest-neoteny in Anura. Neoteny in urodeles, however, is a different matter. Two different grades are illustrated in Amblystoma tigrinum by the European strain of the Mexican species and the species from Colorado. The former never undergoes metamorphosis in aquaria; the latter is easily induced to transform into the terrestrial salamander form by external disturbances of one kind or another. Inorganic iodine administered to urodele larvæ does not induce metamorphosis as was shown by Swingle to be the case in frog tadpoles. The experiments of Uhlenhuth and of Swingle (1922) show that the axolotl thyroid, while containing the thyroid hormone, requires some special stimulus to bring about its discharge into the blood stream. Neoteny may be due then to lack of sufficient iodine in the environment or inadequacy of the mechanism which controls the discharge of the thyroid hormone. It may finally be asked whether either of these explanations extend to the true perennibranchiate genera (Proteus, Necturus, Typhlomolge, and Siren). The first three (Jensen, Huxley and Hogben, Uhlenhuth, Swingle) have not been found to respond to the action of the thyroid hormone at all. But since it is almost certain (I) that thyroid does not increase basal metabolism in adult frogs; (2) that the action 
of thyroxin on the frog tadpole is correlated with an increased respiratory exchange; and since all the perenibranchiates used for these experiments were of fairly advanced age, it cannot be stated with certainty that these forms are not representatives of the persistent larval stage of species whose " adult" form has been eliminated through decreased sensitivity to the action of the thyroid hormone.

These considerations lead us to go back a step and inquire what it is that controls the development and activity of the thyroid in Anura. Light has been shed on this by the work of several investigators of the American school. In Anuran tadpoles the hypophysial rudiment lies above the mouth in a very accessible situation; by pricking the surface of the head in the embryo at a certain stage the ablation of the pituitary anlage can be accomplished. This was first done by Adler (19I4). Smith (I9I7) and Bennet Allen (I9I7) simultaneously and independently discovered that hypophysectomized tadpoles in addition to showing the pigmentary disturbances already mentioned, fail to undergo metamorphosis, this failure being associated with arrested development of the thyroid gland. Later it was shown by Bennet Allen (1919) that such individuals can be made to complete their development by thyroid administration, and by Swingle (1922) that the same result can be brought about by implantation of the pars anterior. Metamorphosis of the Axolotl by injection of fresh extracts of ox anterior lobe was recorded by Hogben (1922), and metamorphosis of hypophysectomised frog tadpoles by Smith (1922) (see Spaul, 1925). Smith found that thyroidless tadpoles will not respond to this treatment. On the whole the evidence points to the following sequence : development of the pituitary ; development of the thyroid under the influence of a substance secreted by the pars anterior ; closure of gillclefts accompanied in Anura by development of limbs and resorption of tail and in urodeles by shedding of the larval skin and resorption of external gills under the influence of the thyroid hormone, with the discharge of which in Urodeles special-at present unknown-agencies are involved.

Another set of problems connected with the chronological 
aspect of individuation is presented by the appearance of sexual differences. In some animals, e.g. mammals and birds, there is a sex metamorphosis (puberty). The effect of castration in the male of mammals is too well known to call for elaborate comment, and the work of Steinach, Lipschütz, Sand, Moore, and others definitely establishes between sexual metamorphosis and the glandular constituents (the " interstitial cells ") of the gonads, a relation analogous to that seen in the phenomena just described. But there is no complete proof that the interstitial tissue exerts its influence on metabolism by discharging a hormone into the blood. The same remark applies to birds, where spaying of the female leads to assumption of male characteristics of comb, plumage and spurs ; and to Amphibia. All the established phenomena are equally well explained by the hypothesis suggested by Geoffrey Smith : that is, the gonads quantitatively affect the metabolism of one or other blood constituents by their own activity in situ.

Some reference is due to a conception introduced by Goldschmidt because of its suggestive bearing on the general consideration of time relations in development, and because it at once disposes of any difficulty we might find in harmonising the established rôle of genetic factors in sex-determination with the undoubted facts of sex-reversal in the animal kingdom. The production of intersexes in the gypsy moth, Lymantria, by crossing local races has already been mentioned (p. 19I). In moths the sexual and somatic metamorphoses are synchronous. The sex differences are very marked in the copulatory devices, colour, wing pattern, feathering of the antennæ, shape of abdomen, etc. And intersexuality in Lymantria is not an intermediate condition of sex differentiation affecting all parts alike. The intersexual individual is a sex mosaic. Females with a low grade of intersexuality may display modification in the antennæ alone, these being of the feathered, i.e. completely male type. A higher grade of intersexuality is seen when the wing-colour as well as the antennæ are characteristically male, all other organs being of the female type. The most advanced stage of recognisable intersexuality is that in which the individual is externally a perfect male but internally 
possesses ovaries instead of testes. "If we now," states Goldschmidt, " try to formulate a rule which governs this strange seriation .... we find the most important fact that this series is the inverse order of differentiation of the organs in development. The last organs to differentiate in the pupa and the first to be intersexual are the branching of the antennæ and coloration of the wings. The first imaginal organ differentiated is the sex gland, and if we apply this law even to the parts of a single organ like the copulatory organ we find it also holds good.

From these facts Goldschmidt elaborates a hypothesis which may be stated in the following three propositions : (I) that the relative potencies of one or other type of sexdetermining reaction-system are not the same throughout the whole course of development ; (2) that genetic factors normally ensure that one or other system predominates at the time when sex-differentiation normally occurs; (3) that if sexdifferentiation can be induced at an earlier or later stage, it may be made to synchronise with the predominance of the system alternative to that which controls differentiation in the normal course of events. To put it in another way, if we represent the potency of the male- and female-determining reactions by ordinates and the time of development along the abscissa, there is usually some stage in the life cycle of either sex where the two curves intersect; this point generally lies either well before or well after the stage at which sex-differentiation actually occurs. Such being the case we should anticipate the possibility of sex-reversal by influencing the growth-rate in forms where the two systems are, as in Lymantria, fairly delicately balanced; and Goldschmidt has produced female intersexes in pure strains of Lymantria through rearing the embryos at a very low temperature.

In concluding the foregoing sketch of developmental physiology, one may frankly admit that we are only at the beginning of a scientific treatment of the problem, and no useful purpose is served by understating the difficulties inherent in the subject and the distance which must still be traversed before we can begin to envisage a purely physico- 
chemical treatment of individuation. However, when in the light of such recent inquiries as have been touched on in this chapter, one considers the fact that little more than a decade has passed since entelechy was the centre of discussion in developmental physiology, there is no justification for a pessimistic attitude to the possibility of arriving at predictable conclusions in this field of knowledge.

\section{Further ReAding}

CHILd, C. M. (1915). Individuality in Organisms. Chicago. - (1924). Physiological Foundations of Behaviour. New York.

Di'RKEN, B. (1919). Einführung in die Experimentalzoologie. Berlin.

Goldschmidt, R. (1923). The Mechanism and Physiology of Sex Determination. London.

Jenkinson, J. W. (1909). Experimental Embryology. Oxford.

Wilson, E. B. (1925). The Cell in Development and Heredity (3rd ed.). New York.

\section{Recent Papers}

Champy (1919). Arch. Morphol. Exp. et Gen., 1919.

HelfF, O. M. (1924). The Oxygen Consumption of Thyroid and Düodotyrosine-fed Tadpoles. Proc. Soc. Exp. Biol. Med., 21, 34.

Huxley, J. S. AND DE BEER, G. R. (I923). Studies in Dedifferentiation, IV. Quart. Journ. Micr. Sci., 67, 473.

HuxLey, J. S. (1925). Studies in Amphibian Metamorphosis, II. Proc. Roy. Soc., (B) 98, I1 3 .

Hyman, L. H. and Bellamy, A. W. (1922). Studies on the Correlation between Metabolic Gradients, Electrical Gradients and Galvanotoxis. Biol. Bull. 43.

Lund, E. J. (1921-22). Experimental Control of Polarity by the Electric Current, I and II. Journ. Exp. Zool., 34 and 36.

Shearer, C. (1924). On the Oxygen Consumption Rate of Parts of the Chick Embryo, etc. Proc. Roy. Soc., (B) 96, 146.

Spaul, E. A. (1925). Experiments on the Localization of the Substances in Pituitary Extracts, etc. Brit. Journ. Exp. Biol., 2, 427.

Stockard (1907). Artificial Production of a Single Median Eye, etc. Arch. Entro. Mech., 23, 249.

Swingle, W. W. (1919). Studies on the Relation of Iodin to the Thyroid, I and II. Journ. Exp. Zool., 27, 397.

- (1922). Experiments on the Metamorphosis of Neotenous Amphibians. Journ. Exp. Zool., 36, 397.

Uhlenhuth, E. (1921). The Internal Secretions in Growth and Development of Amphibia. Amer. Nat., 55, 193.

(1922). The Effect of Iodine and Iodothyrin on the Larvæ of Salamanders, III. Biol. Eull., 42, 143. 


\section{INDEX}

Abraxas, 190

Absorption spectra, $70,73,76,78$

Acids, secretion of, 62

Adler, 130

Adrenaline, 39, 122

Adrian, 14, 136, 143

Agglutination, I79

Aggregation, I79

Allen, I30, 209 et seq.

All or nothing law, 143

Alsberg and Clark, 75, 105

Amino acids, 92, 93

Amphibian metamorphoses, 208 et seq.

Amphioxus, 90

Amœboid movement, 30

Amylolytic enzymes, 96

Anaphylaxis, 59

Anodon, 15, I 14

Anson and Mirsky, 79

Antidromic action, $\mathrm{IO} 3$

Aphrodite, 99, 122

Aplysia, 81, 99, I 13, I 22, 157

Arbacia, $7 \mathrm{I}$

Arenicola, 73, I62

Ascidia, II 4

Associative behaviour, $\mathrm{I}_{3}$

Astacus, I6, 77, 97

Atlantic minnow, 20, 38, 201

Atwell, I32

Aurelia, I 53

Autonomic ganglia, 157

Axial gradients, 203

Axolotl, 209 et seq.

Babak, 69

Bacot and Harden, 88

Baglioni, 52

Banting and Best, 98

Barcroft, 28, 49, 50, 73, 101, 102, 175

Barium, 39

Bateson, 183
Baumberger, 87

Bayliss, 33, I I 9

Bernstein, 13, 58, 63, I45

Bert, 64

Bethe, 32, I 54

Biedermann and Moritz, 97

Bioluminescence, 52 et seq.

Blood pressure, 103,107, I I I

Bridges, 195

Brücke, 99, 106

Bodansky and Rose, 92, 96

Bodo, 66

Botazzi, 82, 104

Bounhiol, 66

Robert Boyle, 53

Buchner, 55

Buddenbrock and Rohr, 67 et seq.

Calcium ions, $16-22,27,35,163$

Calliphora, 93

Cancer, 77

Capillaries, 102

Carbon dioxide, tension of, 68,80

Carbon monoxide, 74

Carcinus, I6, I 54

Carlson, I07 et seq., I I I

Carter, 174

Catch muscle, 15

Cellulose, 97

Cephalopods, eye of, 146

Cerianthus, 152 nervous system, 155

Ceriodaphnia, I 10

Chaetopterus, 52

Chambers, 35,152

Chemotaxis of sperm, $178-9$

Child, 201 et seq.

Chironomus, 65

Chlamydomonad, 89

Chlorhæmidæ, 77

Chlorocruorin, 77 et seq.

Chromatophores of crustacea, 39

Chromosomes, 193 et seq. 
Chronaxie, 137

Ciliary feeding, $89-9 \mathrm{r}$

Ciona, $\mathrm{r} 80$ motion, 23 et seq., I $5 \mathrm{I}$

Clark, 19

Clowes, $\mathrm{I} 2 \mathrm{I}$

Coagulation of crustacean blood, 105

Coelenterates, 52

Cockroach, 94

Cohn, 176

Collip, $8 \mathrm{r}$

Conditioned reflexes, ${ }^{6} 64$ et seq.

Conduction of nervous impulse, 140

Convoluta, 89

Crew, 182

Crepidula, 91

Crystalline style, 96

Ctenophores, 52

Cushny, 50

Cutaneous respiration, 65

Cyanides, 20

Cyclopea, 201

Cypridina, 52 et seq.

Dakin, 89, 104, 178

Dale, 60

Darwin, 170

Day, II 4

Demarcation current, 12

Denis, $5 \mathrm{I}$

Depressor nerve, I03

Dhéré, 75-7

Diemyctilus, 132

Dioxinia, 15

Dissociation of oxyhæmocyanin, 76 of oxyhæmoglobin, $7 \mathrm{I}-4$

Dixipus, 67

Dolium, 62

Dominant, 186

Doncasier, 190

Dreve, 157

Drosophila, 7,183 et seq.

Dubois, 56

\section{Edmondson, 97}

Edwards, Milne, 77

Eimer, I 54

Elasmobranch, blood of, 104

Electric organs, $57-8$

Electrocardiogram, 12, 110

Electrolytes, I6 et seq., 35-6, 39

Elementary nervous system, 152

Elliott, $12 \mathrm{I}$

Endogenous metabolism, 93

Enzymes, 54 et seq.
Ergotoxine, 39

Esculin, 56

Lovatt Evans, 16

Excitation in nerve, $135 \mathrm{et} \mathrm{seq.}$

Exogenous metabolism, 93

Explosive cells, 105

Fat digestion, 94

Fienga, 17

Final common path, ${ }_{5} S$

Fletcher, 7

Fox, 65, 77, 180

Fredericq, I04, I I I

Frog's heart, 19

Frohlich, 155, 157

Fry, II I

Fuchs, I II

Fulton, 13,98

Fundulus, 20, 38

Gamble, 40 ei seq.

Garrey, 160-I

Gaskell, 123

Gas, secretion of, 62

Glomerulus, 48

Glycogen, 95

Goldschmidt, 191, 212

Grasshopper, 66, 69

Gray, 23 et seq., 173

Gunn, 60

Gymnotus, 58

Hæm, 79

Hæmatin, 7r, 79

Hæmatoporphyrin, 71

Hæmochromogen, 7 I, 79

Hæmocyanin, 75-7

Hæmoglobin, $7 x$ et seq., 79

Hardy, 105

Hartree, 10

Hartridge, 12

Harvey, 32, 54, 154, 174

Heat production in muscle, 9-10

Hecht, I 15

Helicocrubin, 179

Helix, 17, 77, 97, 122

Helmholtz, $14 \mathrm{I}$

Henle, 123

Henry, I

Henze, 60

Herring, 128

Hertwig and Fol, 170

Heterozygote, 185

Hibernation, 95 
Hill, 4 et seq., I39, I 45

Croft Hill, 55

Hippolyte, 40 et scq.

Hirudin, 6I

His, bundle of, Io9

Hogben, 17, 122, I 28

Holothurian, 66

Homarus, 14, 77

Hopkins, 7, 88

Hormones, I 19

Hydrogen concentration, 8, 14, 25-7, 33

Imbibition 28

Immunity, 59

Inhibitory nerves, 107 , I 3

Insulin, 98

Intersexuality, I91 , I 96, 212

Intestinal movements, 98

Intracellular digestion, 99

Islets of Langerhaus, 97

Isometric contraction, 6

Isotonic contraction, 2

Fohnstone, 89

Foule, 86

Keeble, 40 et seq., 89

Koch, I 14

Krcidl, 156

Krogh, 65, 66, 72, 103, 128

Kulne, 55

Kupclweiser, 170

Lactic acid, 8-I I

Lampyris, 52

Langley, 121

Lankester, Ray, 77

Lapicque, $16,137,148$

Laplace, 85

Laurens, 129, 133

Lavoisier, 85

Law of Intestine, 98

Lee, 69

Leeches, 123

Lewandowsky, I 2 I

Lieben, 130

Lillie, 20, 176 et seq.

Limulus hæmocyanin, 75 blood, 105 heart, 107

Linkage, I87

Loeb, 20, 105, 154, 158 et seq., 17 I et seq.
Loggerhead turtles, I6I

Lophius, 5 I

Lucas, Keith, II , I36-9, I47-9

Luciferase, 56-7

Luciferm, 56-7

Lumbricus, $\mathrm{II}_{3}$

Lymantria, I 91,212

Lyon, 161, 174

Lysins, 59

Macromyses, 40 et seq.

Macleod, 98

Magnesium ions, $17-20,27,35,163$

Maia, 81, 107, 122

Malapterurus, $57-8$

Maltase, 55

Mast, 160

Matula, 160

Mayer, 86, 154

Melanophores, 38, 123-32

Membranipora, 52

Memory, 163

Mendel's Law, 183 et seq.

Mering and Minkorwski, 97

Methæmoglobin, 71

Mexican salamander, 64, 209 et seq .

Microdissection, 35

Mines, I4, I6 et seq., 52

Mitra, 97

Monochromatic light, 45

Mustelus, $5 \mathrm{I}$

Mya, 99

Myenteric plexus, 98

Mysids, 162

Mytilus, 23 et seq.

Negative variation, 2

Nelson, 96

Nereis, $174-6$

Nernst, I 38

Neurogenic heart beat of Limulus, I08-10

Neuroid transmission, $15 \mathrm{I}$

Neutral red, 33

Nitrogenous excretion, 5 I

Non-disjunction, 195

Nucleoproteins, 93

Octopus, $65,75,77,8 \mathrm{I}, \mathrm{II}$ I

Osmotic pressure, of blood, 104 and fertilisation, 172

Ostiate heart, 106

Oval, 62

Overton, 16 
Oxygen consumption of cilia, 28-9 of eggs, 175 embryos, 206 muscle, 8-1 I

Oxyhæmoglobin, 70

Palæmon, 42

Palinurus, 81, 107

Pancreas, 97, II 9

Pantin, 32 et seq.

Parker, I 24, I 52, I6I

Parnas, I 5

Parsons, 8I

Pasteur, 55

Pathenogenesis, 17 I et seq.

Pawlow, 164 et seq.

Pecten, I 5

Pedicellariæ, 59

Pepsin, 92

Peters, I2, 7I

Pfluger's Law, I 37

Phallusia, 8I

Pholas, 53

Phototropism, I 59 et seq.

Phrynosoma, 124

Phyllirhœ, 53

Physalia, 92

Physoclisti, 62

Pigmentary effect on system, 37 et seq.

Pineal, 133

Piper, 146

Pituitary gland, $103,127,2$ I I

Pollack, 63

Porthesia, 159,163

Pouchet, 120

Protacanthus, 160

Purpura, 123

Pütter's hypothesis, 89

Pyrosoma, 53

Pyrophorus, 53

Quagliariello, 75, 83

Raia, 17

Recessive, 186

Redfield, 124

Refractory period, 135

Renal secretion, 47 et seq. tubules, 48

Rennet, 54

Rennie, 9I

Respiratory movements, 67,69 quotient, 30, 49, 95
Reversal of rhythm in tunicate Rhumbler, 33 heart, II 5

Ritchie, 8

Roaf, 123

Robber fly, 160

Robertson, Brailsford, I10

Rogers, 132

Romanes, 153

Ronget, cells of, 102

Sabelliformia, 77

Sanford, 94

Schafer, I 2 I

Schulz, 6r

Scyllium, 77

Secretion, I 99

Self-sterility, I 80

Sepia, 53

Sergester, 53

Sex determination, $189-92$ differentiation, 2 I I

Shearer, 175, 206

Sherrington, $147,149,158$

Simulium, 66

Smith, $P$. E., 1 20, 130

Snail, I 7, 77, 97

Spreth, 38 et seq.

Spallanzani, 53

Sperographis, 77

Sponges, I 5 I

Stannius experiment, II 2

Starling, 49

Statoliths, I 56

Stedman, 76

Stick insect, 67

Stigmata, 67

Stockard, 201

Straub, I 3

Stretching, effect of, on muscle, I I 3

Strongylocentrotus, $\mathbf{I 7 2}$

Strong acids and bases, 25-6

Suprarenals, 127

Susceptibility method, 204

Syllid, 99

Synoptic nervous system, 154

Swingle, 131, 209

Takamine, $12 \mathrm{I}$

Teleosts, 97, blood of, 104

Temperature, 28-9, I 10

Ten Cate, 99, I 14,122

Tentaculocysts, 153

Tetanus, 3 
Thyroid gland, 209 et seq.

Tonus, 15

Torpedo, 58

Tracheal respiration, 66 et seq.

Trivalentious, 18

Tropisms, I 58

Tunicate heart, 114

Tyramine, 60, 122

Uexkull, 15

Uhlenhuth, 208 et seq.

Urea in blood and urine, $5 \mathrm{I}$

in selachian blood, 104
Uric acid, 93

Urine, $5 \mathrm{I}$ in blood and urine, $5 \mathrm{I}$

Vanadium, 1 10
Van 't Hoff solution, 25

$V$. der Heyde, $5 \mathrm{I}$

Venoms, 60

Vitamins, 88

Vlés, 74

Voit, 85

v. Frisch, 120

Warburg, 175

Weak bases and weak acids, 25-6

Weinland, 93

Winterstein, $65^{-6}$

Wöhler, I

Woodland, 13

Yeasts, 87-9

Yonge, 92, 97 




